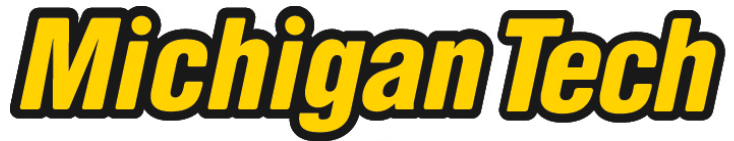 \\ Michigan Technological University Create the Future Digital Commons @ Michigan Tech
}

Dissertations, Master's Theses and Master's Reports - Open

Dissertations, Master's Theses and Master's

Reports

2013

Spatial and Temporal Evolution of the Volcanics and Sediments of the Kenya Rift

Alexandria L. Guth

Michigan Technological University

Follow this and additional works at: https://digitalcommons.mtu.edu/etds

Part of the Geology Commons

Copyright 2013 Alexandria L. Guth

\section{Recommended Citation}

Guth, Alexandria L., "Spatial and Temporal Evolution of the Volcanics and Sediments of the Kenya Rift", Dissertation, Michigan Technological University, 2013.

https://doi.org/10.37099/mtu.dc.etds/484

Follow this and additional works at: https://digitalcommons.mtu.edu/etds

Part of the Geology Commons 


\title{
SPATIAL AND TEMPORAL EVOLUTION OF THE VOLCANICS AND SEDIMENTS OF THE KENYA RIFT
}

\author{
By \\ Alexandria L. Guth \\ A DISSERTATION \\ Submitted in partial fulfillment of the requirements for the degree of \\ DOCTOR OF PHILOSOPHY \\ In Geology
}

MICHIGAN TECHNOLOGICAL UNIVERSITY

2013

(C) 2013 Alexandria L. Guth 
This dissertation has been approved in partial fulfillment of the requirements for the Degree of DOCTOR OF PHILOSOPHY in Geology.

Department of Geological and Mining Engineering and Sciences

Dissertation Advisor: James Wood

Committee Member: Jacqueline Huntoon

Committee Member: $\quad$ Aleksey Smirnov

Committee Member: Carol MacLennan

Department Chair: Wayne Pennington 


\section{Dedication}

This work could not have happened without the field geologists who came before me and spent years working on the ground, collecting rocks, and doing analyses. My first and foremost dedication is to these scientists, whose hard work has allowed this synthesis to occur.

On a personal level I would like to thank my advisor, Jim Wood who took me to Africa, my parents Sharon Alley (1981) \& Lawrence Guth (1991) who raised me in a science-filled home, and my partner in science \& life: Bryan Franklin (2009).

In case anyone ever reads this: as all who have written likely know, it is difficult and time consuming to distill your thoughts into a single page, and I am sure most academic writers do not do so unless compelled by page limitations. Thus, to paraphrase Blaise Pascal (1656): I apologize that this work is so long, I lacked the time to make it short. 


\section{Table of Contents}

List of Figures ....................................................................vii

List of Tables.......................................................................

List of Files ...........................................................................

Acknowledgments ................................................................

Definitions .........................................................................xii

List of Abbreviations ............................................................xiii

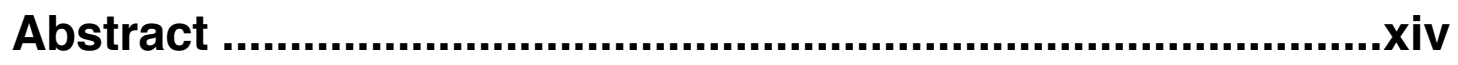

Introduction and Summary .....................................................

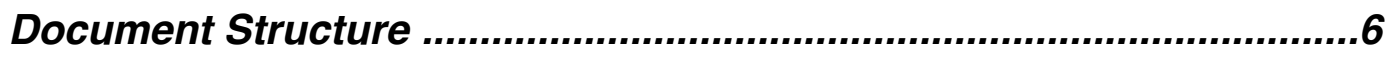

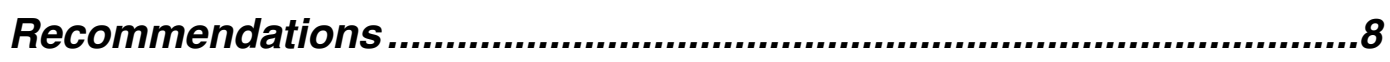

1. Geological mapping in the Kenya Rift ...............................

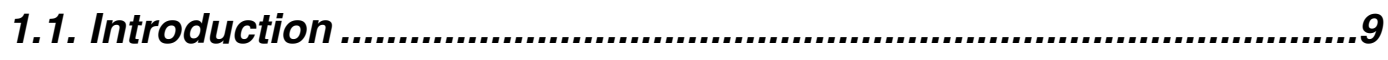

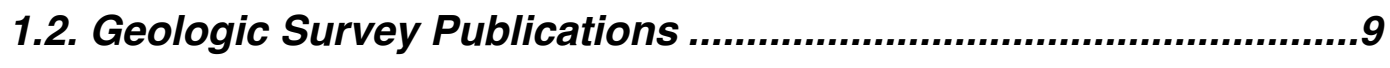

1.3. Non-Survey Maps and Reports...............................................11

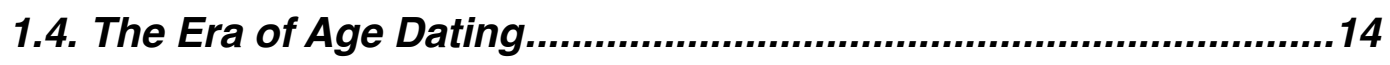

1.5. A Digital Map of the Kenya Rift Geology ..................................17

1.5.1 Digital Mapping Techniques \& Sources of Map Error .................17

2. Rift characterization \& current state of research ...............20

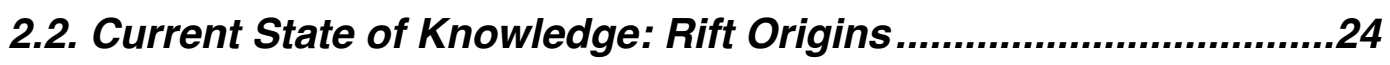

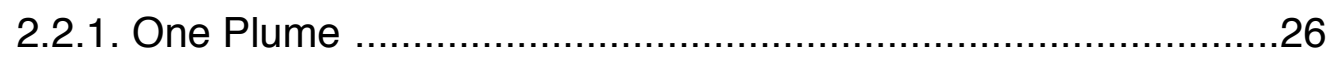

2.2.2. Several Small Plumes .........................................................26

2.2.3. Superplumes, Piles, and LLSVPs........................................29 
2.2.4. Modified Single Plume

2.2.5. The Plate Model...................................................................33

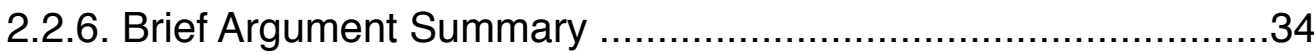

2.3. Current State of Knowledge: Timing of rift development ............36

2.4. Current State of Knowledge: Crustal Structure ............................37

2.5. Current State of Knowledge: Plate Motions ..................................41

3. Geologic development of the Kenya Rift: trends and patterns ....................................................................................44

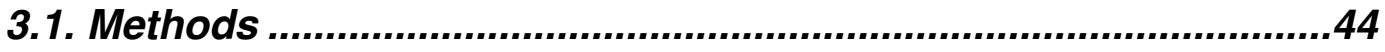

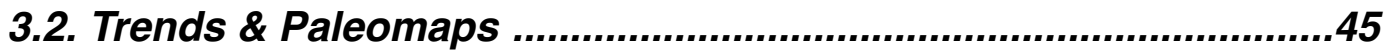

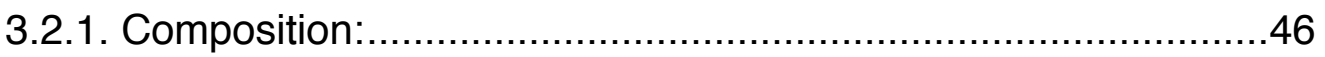

3.2.2. Spatial and Temporal Trends: ................................................49

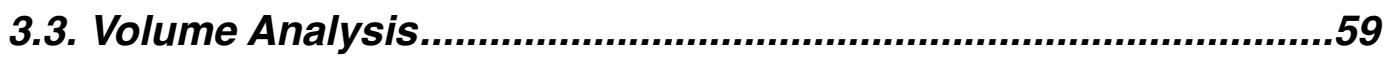

3.3.1. Seismically derived thickness estimates ................................66

3.3.2. A note on volume estimates; sediments and dense-rock

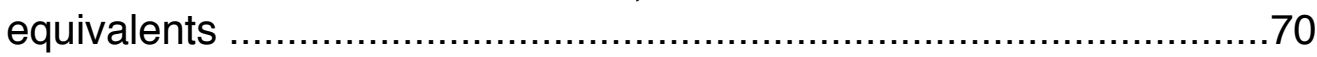

3.3.3. Volume estimate comparisons ..............................................

3.3.4. Reconciling seismic and map-derived volume estimates ..........71

3.4. Volcanic pulses and eruptive rate comparisons ..........................74

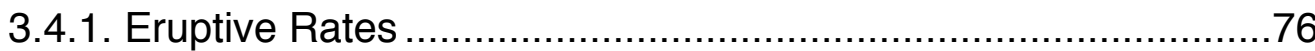

3.4.2. Comparisons with other large eruptive events - LIPs and SLIPs

3.4.3. Volcanic mass flux \& comparisons with other systems..............83

3.5. Chapter Conclusions: spatial, temporal \& volumetric trends .....86

4. Lake and hominin site distributions from Miocene to present in the Kenya Rift 88 
4.1. History of Lake Sedimentation in the Kenya Rift. 88

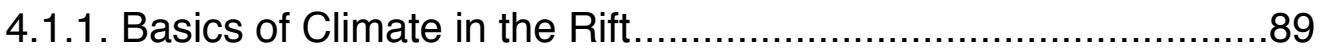

4.1.2. Lacustrine deposits: volcanic and hominin synergies..............91

4.1.3. Volcanic and Lake Sedimentation trends in the Kenya Rift .....100

4.1.4. Lake Deposition History ............................................ 104

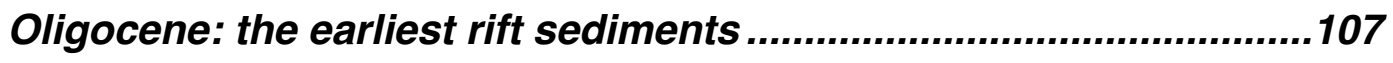

Early Miocene: 15-18 Ma..............................................................107

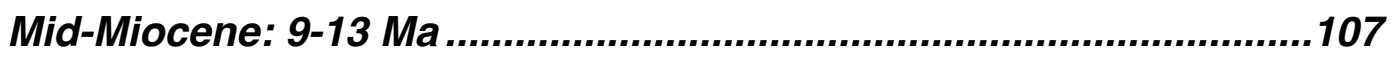

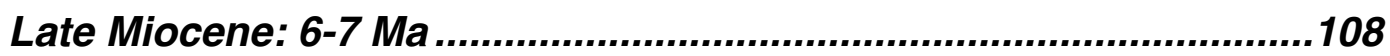

Pliocene: 3-4 Ma ...........................................................................110

Late Pliocene - Early Pleistocene: 1.7-3 Ma..................................110

Discussion of Pliocene - Pleistocene Climate ..............................111

Middle Pleistocene: 0.5-1.5 Ma ....................................................112

Late Pleistocene: 100-200 ka ......................................................114

Holocene: the last 10 ka ..............................................................115

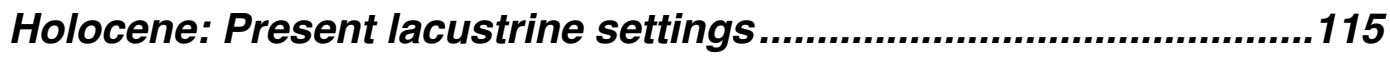

4.2. Hominin developments in reference to rift and lake basin development ...................................................................................117

4.2.1. Background to hominin research .................................117

4.2.2. Hominin trends in the Rift .......................................121

4.3. Conclusions: rift-related lacustrine \& hominin trends ...............126

4.3.1. Open questions and future research needs:....................127

5. Discussion \& Conclusions ................................................132

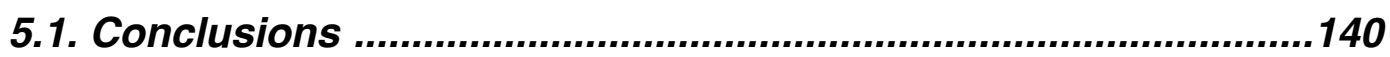

References ................................................................................143 


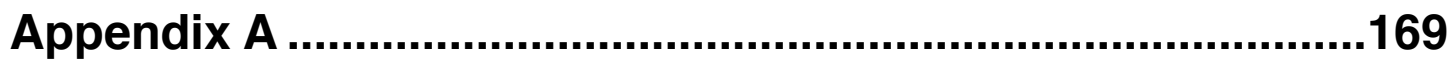

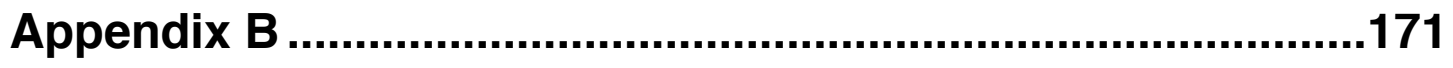

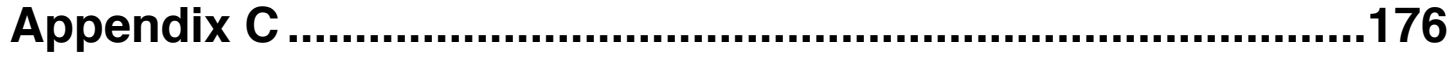

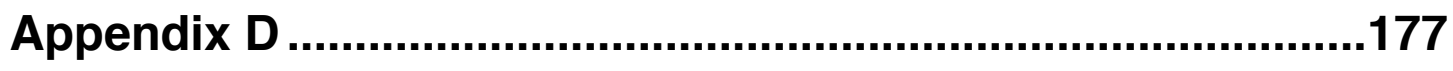

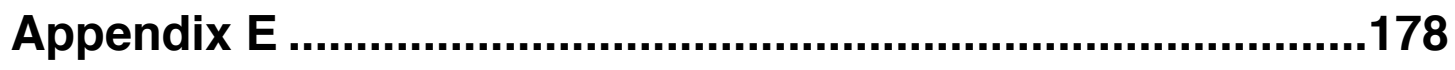




\section{List of Figures}

Figure 1.1. Outline of Kenya showing location of the available maps produced by the Kenya Geologic Survey. 9

Figure 1.2. Geologic maps for regions affected by rift volcanism. The number in each box is the report number or degree sheet. 13

Figure 1.3. Map of Kenya showing smaller, newer, more detailed maps used to update geologic information found in the maps published by the Kenya Geologic Survey. 14

Figure 2.1. Established, and developing, plate boundaries and the named rift segments. 20

Figure 2.2. Shaded DEM and elevation profiles (50x vertical exaggeration) showing the anomalously high topography associated with the EARS, and the naming scheme used in this work. 23

Figure 2.3. Two different plume models that rely on differing plate motions. 28

Figure 2.4. Illustration of the different plume hypotheses. 31

Figure 3.1. Geologic maps representing the cumulative eruptive products related to the Kenya Rift since the Eocene. 50

Figure 3.2. Pie charts showing the relative volume of different erupted lithologies for individual geologic stages. 51

Figure 3.3. Volumes of different lithologies by Latitude and Longitude. 52-53

Figure 3.4. Simplified lithology plotted at the centroid for each volcanic units of the Kenya Rift. 57

Figure 3.5. Plot of centroid-lithology in a Longitude vs Age dimension. 58

Figure 3.6. Charts showing the relative normalized eruptive rates in km3/Ma. 60

Figure 3.7. Erupted volume over time in the Kenya Rift. 63

Figure 3.8. Cumulative erupted volume since the late Eocene. 63

Figure 3.9. Plot showing contribution to cumulative volume over time for each unit's centroid. 65 
Figure 3.10. Map showing the centroid of each eruptive unit colored by Group, as defined in the previous figure. 66

Figure 3.11. Erupted volume of a formation versus age on a semi-log scale. 72

Figure 3.12. Map showing geologic units that lack absolute age information, or are loosely constrained. 75

Figure 3.13. Plot showing estimated eruptive rates in cubic kilometers per year over time in millions of years. 78

Figure 4.1. Map of main lake basins associated with the Kenya Rift. 93

Figure 4.2. Plot showing location of lake deposits, plotted by time and Latitude, colored by associated modern basin. 101

Figure 4.3. Plot showing location of lake deposits, plotted by time and Longitude, colored by associated modern basin. 102

Figure 4.4. Maps showing the general size and distribution of known lakes during different stages. 106

Figure 4.5. Plot showing the distribution of hominid fossil localities within the Kenya Rift by latitude and time. 122

Figure 4.6. hominid sites for the Kenya rift with geologic and lake data. 123

Figure 4.7. Hominid sites in the Kenya rift, plotted with volcanic, as longitude versus age. 124

Figure D.1. diagram showing how volumes were calculated based on simplified geometry. 177 


\section{List of Tables}

Table 1.1. Publications providing age dates for the Kenya Rift. 16

Table 2.1. General physical properties of the different segments of the EARS. 22

Table 2.2. Timing of rift initiation and estimated crustal extension for basins in the EARS. 39

Table 2.3. General crustal structure for the Kenya Rift from North to South. 40

Table 3.1. Seismic derived thicknesses of volcanic fill in the rift valley. 69

Table 3.2. Comparison of erupted volume estimates from different sources for the Kenya Rift. 71

Table 3.3. Estimate volume of various continental flood basalts in comparison to the Kenya Rift. 80

Table 3.4. Calculations of mass flux for the Kenya Rift. 84

Table 3.5. Calculations of normalize mass flux for the Kenya Rift and comparison sites. 84

Table 4.1. A list of significant lacustrine deposits within the Kenya rift, including age ranges and pertinent references. 96-98

Table 4.2. Significant survey publications providing lacustrine histories for wide areas of the Kenya Rift. 99

Table 4.3. Publications with paleogeographic reconstructions within the Kenya Rift, sorted by basin. 105

Table A.1. Headings and descriptions of fields in the attribute table for for the Kenya-volcanics shapefile. 169-170

Table C.1. List of file name, size, and type, of maps showing paleogeography provided on accompanying CD. 176

Table D.1. Values used to calculate seismic-based volumes for subsections of the Kenya Rift. 177

Table E.1. Locations, ages, and notes regarding hominid-bearing deposits in the Kenya Rift. 178-180 


\section{List of Files}

\begin{tabular}{|c|c|c|c|}
\hline File Name & File Type & File Size & Description \\
\hline Guth2013 & PDF & $9.9 \mathrm{MB}$ & Full dissertation \\
\hline GuthKenyaMap & ZIP (SHP, SHX, DBF) & $3 \mathrm{MB}$ & $\begin{array}{l}\text { Shapefile and associated files } \\
\text { for geologic map of Kenya }\end{array}$ \\
\hline GuthKenyaMapGE & ZIP (KMZ, KML) & 2.9 & $\begin{array}{l}\text { Geologic map data in Google } \\
\text { Earth format }\end{array}$ \\
\hline MapRefs & PDF & $67 \mathrm{kB}$ & $\begin{array}{l}\text { Full references for citations } \\
\text { used in attribute table }\end{array}$ \\
\hline PaleoMaps & ZIP (PDF) & $5.3 \mathrm{MB}$ & $\begin{array}{l}\text { contains a compressed folder } \\
\text { containing PDF maps of } \\
\text { geology by age (see } \\
\text { Appendix C for list) }\end{array}$ \\
\hline
\end{tabular}

file type descriptions:

DBF$^{\star}$ : database file that contains shapefile attribute information in dBase IV format.

KMZ: Keyhole Markup Language (compressed), derived from XML. Developed for use with Google Earth.

PDF: Portable Document Format developed by Adobe.

PRJ: Projection format as plain text. Optional file to accompany shapefile data.

SHP*: Esri shapefile that contains the vector feaures.

SHX $^{*}$ : Esri shapefile index, file contains the position index of the vector features.

${ }^{*}$ These files are all required for using the shapefile 


\section{Acknowledgments}

I would like to thank the Michigan Space Grant for financial support used to investigate desert varnish, the Institute of Rock Magnetism for access to a wonderful set of machines \& people, and the Geology Department of Michigan Technological University for the mutually symbiotic relationship over the years.

I would also like to acknowledge and thank my committee members who provided both valuable insight and feedback on this dissertation. 


\section{Definitions}

African Superswell. region of anomalous topography in eastern Africa

African Superplume. region of low seismic velocity near the core-mantle boundary, located under southern Africa.

East African Rift System. series of rift valleys starting at the Afar and including the Ethiopian Rift and the Western and Eastern Rift branches.

hominid. great apes, hominins and humans

hominin. humans and their direct, or indirect, ancestors after the split from the great apes.

human. members of the genus Homo

Mohorovičić discontinuity. boundary between the Earth's crust and mantle based on seismic velocity changes resulting from a change in composition/density. 


\section{List of Abbreviations}

CMB. Core-Mantle Boundary

EAGLE. Ethiopia-Afar Geoscientific Lithospheric Experiment

EAR or EARS. East African Rift System

KGS. Kenya Geologic Survey

KRISP. Kenya Rift International Seismic Project

LLSVP. Large Low-Shear Velocity Provinces; e.g. the African Superplume

MER. Main Ethiopian Rift

Moho. Mohorovičić discontinuity 


\section{Abstract}

New volumetric and mass flux estimates have been calculated for the Kenya Rift. Spatial and temporal histories for volcanic eruptions, lacustrine deposition, and hominin fossil sites are presented, aided by the compilation of a new digital geologic map. Distribution of volcanism over time indicates several periods of southward expansion followed by relative positional stasis. Volcanism occurs throughout the activated rift length, with no obvious abandonment as the rift system migrated. The main exception is a period of volcanic concentration around $10 \mathrm{Ma}$, when activity was constrained within $2^{\circ}$ of the equator.

Volumes derived from seismic data indicate a total volume of c. $310,000 \mathrm{~km}^{3}$ $\left(2.47 \times 10^{10} \mathrm{~kg} / \mathrm{yr}\right)$, which is significantly more than the map-derived volumes found here or published previously. Map-based estimates are likely affected by a bias against recognizing small volume events in the older record. Such events are, however, the main driver of erupted volume over the last $5 \mathrm{Ma}$. A technique developed here to counter this bias results in convergence of the two volume estimation techniques.

Relative erupted composition over time is variable. Overall, the erupted material has a mafic to silicic ratio of $0.9: 1$. Basalts are distinctly more common in the Turkana region, which previously experienced Mesozoic rifting. Despite the near equal ratio of mafic to silicic products, the Kenya Rift otherwise fits the definition of a SLIP. It is proposed that the compositions would better fit the published definition if the Turkana region was not twice-rifted.

Lacustrine sedimentation post-dates initial volcanism by about 5 million years, and follows the same volcanic trends, showing south and eastward migration over time. This sedimentation delay is likely related to timing of fault displacements.

Evidence of hominin habitation is distinctly abundant in the northern and southern sections of the Kenya Rift, but there is an observed gap in the equatorial rift between 4 and 0.5 million years ago. After $0.5 \mathrm{Ma}$, sites appear to progress towards the equator. The pattern and timing of hominid site distributions suggests that the equatorial gap in habitation may be the result of active volcanic avoidance. 


\section{Introduction and Summary}

The East African Rift System (EARS) offers a unique opportunity to study a modern continental rift representing several stages of rift development as well as distinct modes of rifting. Overall, this region provides an exceptional laboratory to pursue answers to numerous basic questions regarding rifting development and processes. Some questions as they pertain to the Kenya Rift, which is a subset of the EARS, are enumerated below. Each driving hypothesis, which guided the research presented in this dissertation, is followed by its own background, methods, results, and discussion.

Hypothesis 1: The eruptive rate for the Kenya Rift can be determined by quantifying mass of erupted rock as a function of time, volume, and location.

- The data required to determine erupted mass are easily obtained from combining surface areas, formation thicknesses, and density. Previous volume estimates have been made using paper maps for the region (Williams 1972, Baker, Mohr \& Williams 1972, Baker 1987), which had then been converted to volumetric rate based on total eruptive duration (Baker 1987). New age data published since these estimates were made have pushed back the oldest volcanism in Kenya to the Eocene (McDougall \& Watkins 2006), whereas Williams (1972) starts his volumetric analysis in the Miocene. Volume estimates have not been attempted using a digital dataset before, and previous estimates have never been independently tested. The availability of seismic data (e.g. Simiyu \& Keller 2001) provides a promising data set that is independent of surface mapping, with which to test these volumes.

- A digital map for the Kenya Rift was created in order to calculate surface areas and volumes of the rift volcanics. To test the validity of these mapbased volumes, seismic data available for the Kenya Rift were used as an independent method of determining volcanic volume. 
- Volumes derived from seismic data indicate a total volume of c. 310,000 $\mathrm{km}^{3}$, which is significantly more than the map-derived volumes found here or previously. Using the seismic volume, the volcanic flux erupted from the Kenya Rift has been calculated to be 0.0088 km³/yr. Map-based volume estimates are likely affected by a bias against recognizing small volume events in the older record. A technique developed here to counter this bias results in convergence of the two estimates when applied to the map-based volumes.

- The seismic data indicate that using mapped surface geology to estimate volume will significantly underestimate the true volume associated with a well established rift. The mass of erupted rock can be quantified, however, calculations based solely on surface geology should be treated as a minimum estimate. With a sufficiently large dataset of eruptive event ages and volumes, it is possible to recognize the influence of observational/ preservational biases, and map-based estimates can then be corrected. This correction technique should be tested in other locations where geologic maps and seismic data are readily available.

Hypothesis 2: Composition and volume trends through space and time will highlight developmental progression of the rift. The Kenya Rift should be classifiable based on these metrics, and should be comparable to similar rift systems.

- Previous attempts to examine the propagation of the Kenya Rift have used only the spatial pattern of the oldest eruptive formations (Macdonald et al. 2001; Macdonald 2003). Analysis of temporal and spatial trends have also been attempted through plots of age date frequencies (Morley 1999) and complex, hand-drawn, diagrams (e.g. Baker et al. 1971; Baker 1987). The spatial distribution of the oldest volcanism can be useful for tracing the overall propagation of the rift, but details of rift development would be lost compared to examining the position and timing of all volcanic formations. 
The age-date frequency technique was utilized only for the Turkana region, and was not scaled by eruptive volume. While covering a larger region, the mentioned hand-drawn diagrams also did not incorporate volume, and would be difficult to recreate with updated information. For comparing the Kenya Rift to other systems, two main classification schemes were considered. Merle (2011) presents a simple classification scheme based on causative tectonic environment, in which the Kenya Rift is a plume-related rift. The Rio Grande Rift is approximately the same age as the Kenya Rift, and they are known to share many similarities (e.g. Keller et al. 1991), but the Rio Grande Rift is a subduction-related rift in Merle's scheme, as it is the subducted Farallon slab that is creating mantle upwelling (Moucha et al. 2008). Merle (2011) uses mid-ocean ridges as the point in the presented classification scheme to which continental rifts should converge regardless of the tectonic environment in which the rift initially formed. As such, comparisons are considered justified against ancient plume-driven rifts (same tectonic setting), the similarly aged Rio Grande Rift (different tectonic setting), and mid-ocean ridges (idealized end point). The second classification metric is presented by Bryan et al. (2002), who distinguish a new class of igneous province which is dominated by silicic volcanism and significant ignimbrite activity. These provinces tend to be lower volume and longer duration than mafic-dominated large igneous provinces (LIPS). While the Kenya Rift meets the stated requirements of the new class (termed a SLIP) based on results from hypothesis 1, it was not considered in Bryan et al.'s (2002) analysis.

- A detailed attribute table was created to accompany the digital map of the Kenya Rift volcanics, and includes age and compositional information for each formation. Due to the geometric complexity of a mapped geologic formation, a centroid dataset was created from the digital geologic map to aid in visualizing trends. Volumes were calculated for each formation, and plots were created to indicate spatial and temporal trends of volume and 
lithology. Ratios of mafic to silicic eruptive products for the Kenya Rift calculated from the map data, and were used in conjunction with eruptive rates to determine where the Kenya Rift fits into the above classification schemes.

- The Kenya Rift propagated southward in fits and starts. Activity is maintained along the entire length of the activated rift, except during a period in the mid-Miocene when eruptive activity was concentrated around the equator. Relative erupted composition over time is variable. Overall, the erupted material has a mafic to silicic ratio of $0.9: 1$, which is more silicic than previously recognized (Williams 1972). Based on the location of carbonatite products through time, these may be a "trail blazing" volcanic product in this region which are buried by later volcanism. Basalts are most common through time in the Turkana region, large phonolite eruptions occurred in the mid-Miocene around the equator, and more recent eruptions around the equator and south have been dominated by trachytes.

- The Kenya Rift is not easily classified or comparable, based on volume, composition, or eruptive rate. An igneous province with nearly equal proportions of mafic to silicic products has not been previously described, and Bryan et al. (2002) suggest that no such large volcanic provinces exist. Given the data presented here, this is obviously not the case, and using LIPs and SLIPs as binary end-members should be reconsidered. While rifts are generally noted as having bimodal composition, the other systems used for comparison were dominated by mafic material, indicating that tectonic setting is not enough to dictate compositional similarity. In terms of midocean ridges, all but the "ultra-slow" Gakkel ridge in the Arctic Ocean had eruptive rates significantly higher than the Kenya Rift. The dominance of basalt in the Turkana region may be related to the "twice rifted" history of that region, while the rest of the rift has predominantly erupted intermediate and silicic material. Were it not for the earlier Mesozoic rifting, Kenya may have been a more typical SLIP. 
Hypothesis 3: Volcanic activity associated with the rifting should exert some control over the spatial and temporal distribution of hominins in the rift.

- Recent studies have indicated that hominins show a distinct spatial correlation with tectonically active landscapes (Bailey, Reynolds, and King 2011; Reynolds, Bailey, and King 2011). The East Africa Rift has long been recognized for its unique fossil assemblage of hominins (e.g. Tattersall and Schwartz 2009; White et al. 2009), which is likely due tectonic forces that create hominin-friendly landscapes, enhance preservation of remains by creating sedimentary basins, and expose sediments in later faulting events. While studies have previously looked for correlations between hominin distributions and climate changes (e.g. Ashlet et al. 2009; Basell 2008; Blome et al. 2012), there have not been any attempts to examine what effects, if any, volcanism has had on the distribution of species in the rift. Unlike the Western Branch, the rift in Kenya has been very volcanically active, and eruptions can have a pronounced effect on local environments (e.g. Harris and Van Couvering 1995). The age and exposure of sediments in the rift has allowed for the extensive study of hominin and mammal remains, which provides an intriguing opportunity to examine the interaction between biologic communities and a magmatically active rift. Such information would not be available for ancient rifts like the Midcontinent Rift System in North America (too old at 1.1 billion years), and would likely be obscured at rifted continental margins or failed rifts that have been filled with sediment.

- To differentiate between hominin patterns associated with lacustrine settings and those potentially caused by volcanic activity, both hominin and lacustrine datasets were created from the literature. These data were then plotted against the volcanic data from hypothesis 2, to examine temporal and spatial correlations. Sites hosting only tools were also included, and distinctions made by tool technology (mode) and clade (hominid, hominin, or human). 
- Lacustrine sedimentation post-dates initial volcanism by about 5 million years, and follows the same trends as the volcanics with both south and eastward migration over time. Evidence of hominin habitation is distinctly abundant in the northern and southern sections of the Kenya Rift, but there is an observed gap in the equatorial rift between 4 and 0.5 million years ago. After $0.5 \mathrm{Ma}$, sites appear to progress from the southern concentration of activity towards the equator.

- The gap between volcanism and lacustrine deposition is proposed here to represent a delay between initial volcanic eruption and major fault displacement, and may be a useful proxy for temporally constraining initial faulting. The observed gap in hominin habitation occurs despite the presence of lacustrine environments, and corresponds with a period of active volcanism north and south of the equator. It is thus suggested, that the observed habitation gap is due to active volcanic avoidance by hominin species. The proposal of volcanic avoidance could be further tested by examining spatial and temporal trends of other animal populations during the same time span. It is suggested that large migratory mammals would also vacate a volcanically active area as conditions change, and repopulation of the region may be later hampered by volcanic barriers. In the later case the environment of the area previously vacated may be hospitable, but would lack animal populations that are incapable of crossing the volcanically modulated terrain.

\section{Document Structure}

This dissertation is divided into four main chapters as outlined here, followed by a fifth, and final, chapter that presents overall discussion and conclusions.

Chapter One focuses on the historical framework of the Kenya Rift in terms of geologic studies. In particular, the history of geologic mapping and age dating initiatives are highlighted, as it is the combined outcomes 
of these previous field campaigns that allow for the interpretation of satellite imagery and the production of the digital geologic map created for this research. Figures showing the locations of the primary and supplemental maps utilized as source material are provided as visual references. Additionally, publications that provide significant collections of geologic age data are called out specifically to highlight important contributions.

Chapter Two provides an overview of the physical characteristics (e.g. topography, climate, overall structure) of the rift, and presents a synopsis of the current understanding of the evolution of the East African Rift System. The purpose of this chapter is to synthesize the most up-to-date information regarding the general causes and timing of rifting, crustal and sub-crustal structure, and plate motions.

Chapter Three presents the data derived from the digital mapping effort to address hypotheses 1 and 2. Examples of derived datasets include eruptive volumes obtained from the mapped surface geology, eruptive composition, and formations that lack age-dates. Time-series maps along with graphs representing the spatial and temporal distributions of volume and composition are used to interpret rift development. Volume estimates based on the mapped geology and calculated from previously published seismic models are presented. A significant discrepancy between these two techniques for determining volume is discussed and reconciled.

Chapter Four seeks to examine the relationship between volcanic and hominin activity within the Kenya Rift, to address hypothesis 3 . As hominin remains are often associated with lacustrine systems, a synopsis of the paleolake history from Oligocene to present is also given, and lacustrine depositional patterns are compared against the volcanic data. The 
lacustrine-hominin relationship is then examined, followed by patterns seen in hominin and volcanic distributions. A background to hominid/ hominin research is presented to facilitate discussion for those not already familiar with that field.

\section{Recommendations}

The understanding of the formation of the Kenya Rift, and the connections between rifting, volcanism, climate signals and human evolution could be greatly furthered by the following:

- acquisition of new age dates to refine the timing of eruptive sequences, and to provide dates on units that are currently undated.

- creation of a maintained, online, database of geologic age data for the rift would be of general scientific benefit (e.g. Swedish radiometric age data base).

- detailed field studies to determine volcano-tectonic histories of the basins associated with the rift.

- detailed seismic surveys of the rift basins, ideally tied to core data or run up to outcrops to provide a more precise view into the hidden volcanic and sedimentary records of the rift.

- examination of large mammal trends in correlation to the volcanic record would further test the validity of volcanic avoidance. 


\section{Geological mapping in the Kenya Rift}

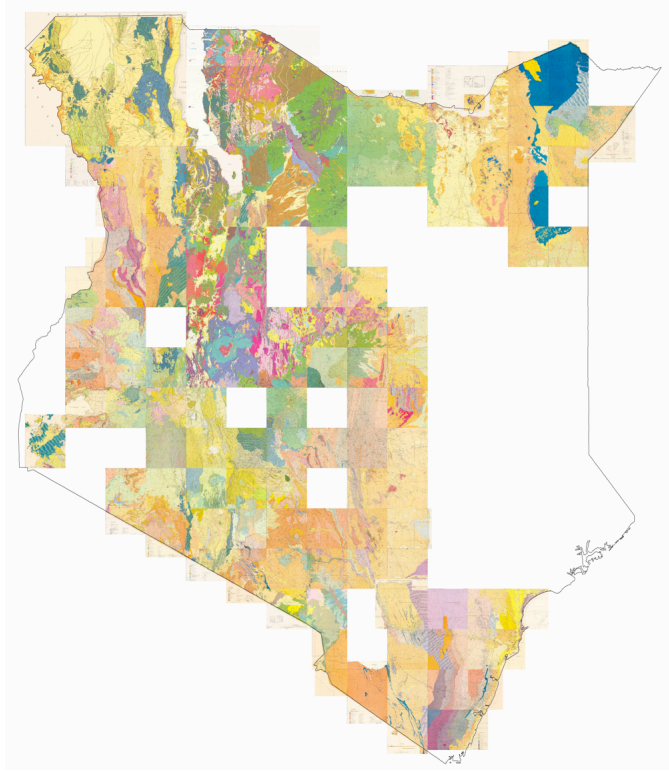

Figure 1.1 Outline of Kenya showing location of the available maps produced by the Kenya Geologic Survey.

\subsection{Introduction}

In order to better understand the evolution and development of the Kenya Rift, a digital geologic map was created by utilizing a combination of published geologic maps and satellite data. There is a vast amount of information available from previous geologic studies in the rift, however this data has not been previously combined to produce a comprehensive geologic map for the entire length of the Kenya Rift. The mapping techniques used for creating the digital map are relatively straightforward and involve comparing published maps, digital elevation models and Landsat 7 imagery to guide the creation of digital polygons (Guth 2007). A detailed attribute table was created to accompany the digital geology, and descriptions of the fields can be found in Appendix A. The following sections present a generalized history of geologic mapping in the Kenya Rift starting with the Kenya Geologic Survey maps. It is the combined effort of numerous geologists over the last several decades that allowed for the digital map presented here to be created. Maps used as main visual references for the creation of the digital map are discussed below.

\subsection{Geologic Survey Publications}

The Kenya Department of Mines and Geology was officially formed in 1933, with the bulk of the geologic maps and reports covering the country being released between 1945 and 1973. This systematic mapping produced quarter degree 
sheets and corresponding reports, for much of Kenya (Figure 1.1). A few maps and reports were published for areas in northern Kenya during the 1980's and early 1990's at the 1:250,000 scale; these generally cover areas of a square degree or larger (e.g. Allia Bay, Isiolo, Baringo-Laikipia). While many of these later publications reflect newer field work, some regions were surveyed and mapped in the 1960's, but the reports were not published until decades later (e.g. Nairobi and Suswa). Such reports were published mostly as they were originally written, with the occasional addition of footnotes by the editors to point out pertinent new understandings.

Obvious gaps exist in the coverage as can be seen in Figure 1.1, however, much of the rift zone is represented in the published geologic maps. Unfortunately, these maps cannot simply be digitized in order to create a comprehensive digital geologic map for the rift. Due to the publication dates of these maps spanning a large number of years, there are several issues with direct digitization. One of the main issues, discussed also in Guth (2007), is the non-continuity of geologic units across some maps, where boundaries do not match up, or do not continue, between maps. This is generally due to the evolution of geologic knowledge, with new units having been recognized over time. The areas lacking survey map coverage also present difficulties for creating a comprehensive map, as the situation essentially represents a large region without ground control. A similar issue is that the survey-published maps stop at the country's border, and thus publications from the adjacent country, or assumptions of lateral continuity, are needed in order to completely map some geologic units.

Regardless of these limitations, the survey produced maps are an invaluable resource and were utilized as a primary source of "ground truth" information. Fortunately maps from the Tanzania Geologic Survey were acquired and could be used for the southern border-spanning areas, however, Ethiopian survey maps for the northern Kenya-Ethiopia border were not obtained for this work. 
The geologic maps from the Kenya and Tanzania Geologic Surveys used as sources for digital mapping are shown in Figure 1.2. As this work is only concerned with the Kenya Rift, the shown maps represent the areas in Kenya affected by rift-related volcanism. Due to extensive eruptions prior to rift valley formation, and the recent development of large, off-axis, volcanic centers (e.g. Mt Kenya, Kilimanjaro), the area covered by rift-related volcanics extends well beyond the bounding rift escarpments. Outside of the area covered by these rift related volcanics, Kenya mainly has exposed metamorphic rocks or Mesozoic sediments exposed at the surface.

\subsection{Non-Survey Maps and Reports}

In addition to the maps published directly by the geologic surveys, specialized reports can serve as important sources of updated geologic information. Clarke et al. (1990), as part of a report on geothermal phenomena, provide a map of the Naivasha region which provides enhanced distinction between geologic units than seen on the original survey map for the same region. Dunkley et al. (1993), again as part of a report investigating the geothermal activity of the rift, provides five maps at a 1:50,000 scale for several volcanoes in Northern Kenya. It is worth noting that Woolley (2001) provides a great accumulation of pertinent references, age dates and petrology information, even though the included generalized maps were not directly used for mapping.

Other important sources of updated geologic maps are graduate students (e.g. Guest, 1953; Leat, 1983; Skilling, 1988), and journal publications. Such maps are crucial sources of geologic information that cannot be obtained by simply digitizing the original survey maps. Age information, plus the more tightly constrained stratigraphic relationships found in these sources, are especially important for understanding the development of the region. 
The non-survey sources utilized for creating the digital map presented as part of this work are shown in Figure 1.3. In addition to the important role of providing updated ground truth information, these smaller maps aid in the correlation of older mapped units across map boundaries and with recently acquired age data. Some of the original survey maps did not assign the mapped geologic units to formal lithostratigraphic formations. Rather, all olivine basalts in a region were assumed to be the same if no clear stratigraphic relationships were present. It often became clear later, however, that this lithologic grouping really represented several distinct eruptive events separated by significant time. Recent maps such as those shown in Figure 1.3, can aid in the separation of these older lithologic units into ones that more accurately represent eruption history. Some papers such as McDougall and Brown (2009) do not present updated maps directly, but are still extremely useful, as the authors provide new detail and age information to units from an older mapped area (Walsh and Dodson,1969); see the "Digital Mapping Techniques \& Sources of Map Error" section below for a more detailed discussion of this case.

Obtaining maps found scattered amongst different journals can be tedious, but acquiring older theses and dissertations from other countries can be downright difficult and expensive if they pre-date digital publication. Fortunately, this may become easier, as some organizations like the British Library are making efforts to digitize these works and to make them available at low, or no, cost. While the boon of electronic publishing allows for the quick dissemination of more recently completed graduate works, access to earlier theses and dissertations is important for the ability to obtain original maps and data, some of which do not appear to be published elsewhere. 


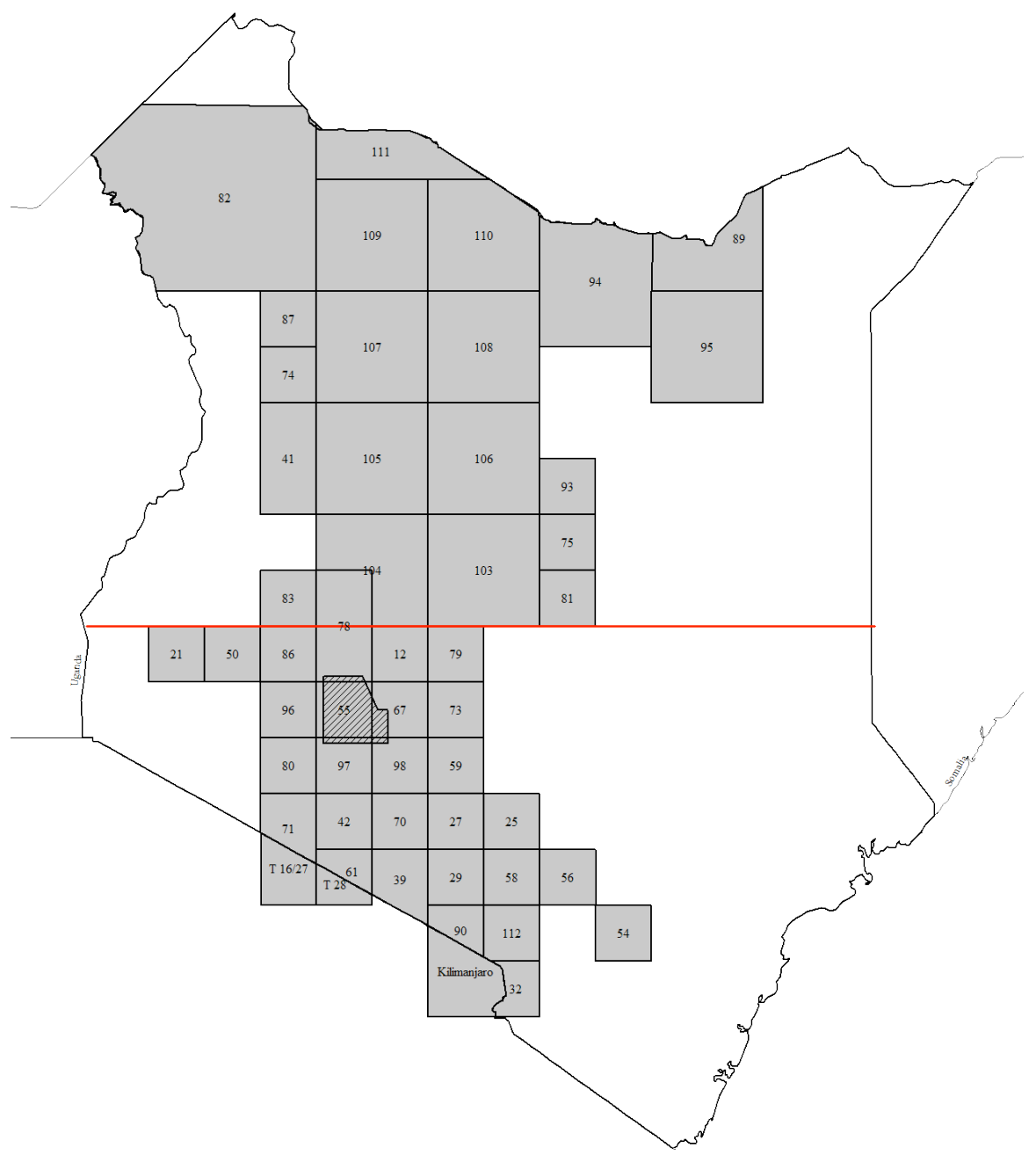

Figure 1.2. Geologic survey maps for regions affected by rift volcanism. Numbers represent the report number or degree sheet number used by the Geologic Survey.

12: Shackleton, 1945

21: Saggerson, 1952

25: Dodson, 1953

27: Baker, 1954

29: Searle, 1954

32: Bear, 1955

39: Joubert, 1957

41: Mason \& Gibson, 1957

42: Baker, 1958

50: Binge, 1962
54: Sanders, 1963

55: Thompson, Dodson, 1963

56: Walsh, 1963

58: Saggerson, 1963

59: Fairburn, 1963

61: Baker, 1963

64: Sanders, 1963

67: Thompson, 1964

70: Matheson, 1966

71: Saggerson, 1966

73: Fairburn, 1966

74: Joubert, 1966

75:Williams, 1966

78: McCall, 1967

79: Baker, 1967

80: Wright, 1967

81: Rix, 1967

82: Walsh \& Dodson, 1969
83: Walsh, 1969

86: Jennings, 1971

87: Dodson, 1971

89: Walsh, 1972

90: Williams, 1972

93: Dodson, 1991

94: Dodson, 1991

95: Williams, 1991

96: Williams, 1991

97: Randel \& Johnson, 1991

98: Saggerson, 1991 103: Hackman et al. 1989

104: Hackman, 1988

105: Key \& Ridgway, 1987

106: Charsley, 1987

107: Ochieng et al., 1988
108: Key, 1987

109: Wilkinson, 1988

110: Charsley, 1987

111: Key \& Watkins, 1988

112: Omenge \& Okelo, 1992

hashed: Clarke et al.

T 16/27: Dundas \&

Awadalla 1999

T 28: Guest \&

Pickering, 1966

Kilimanjaro: Wilkinson

\& Downie 1965 


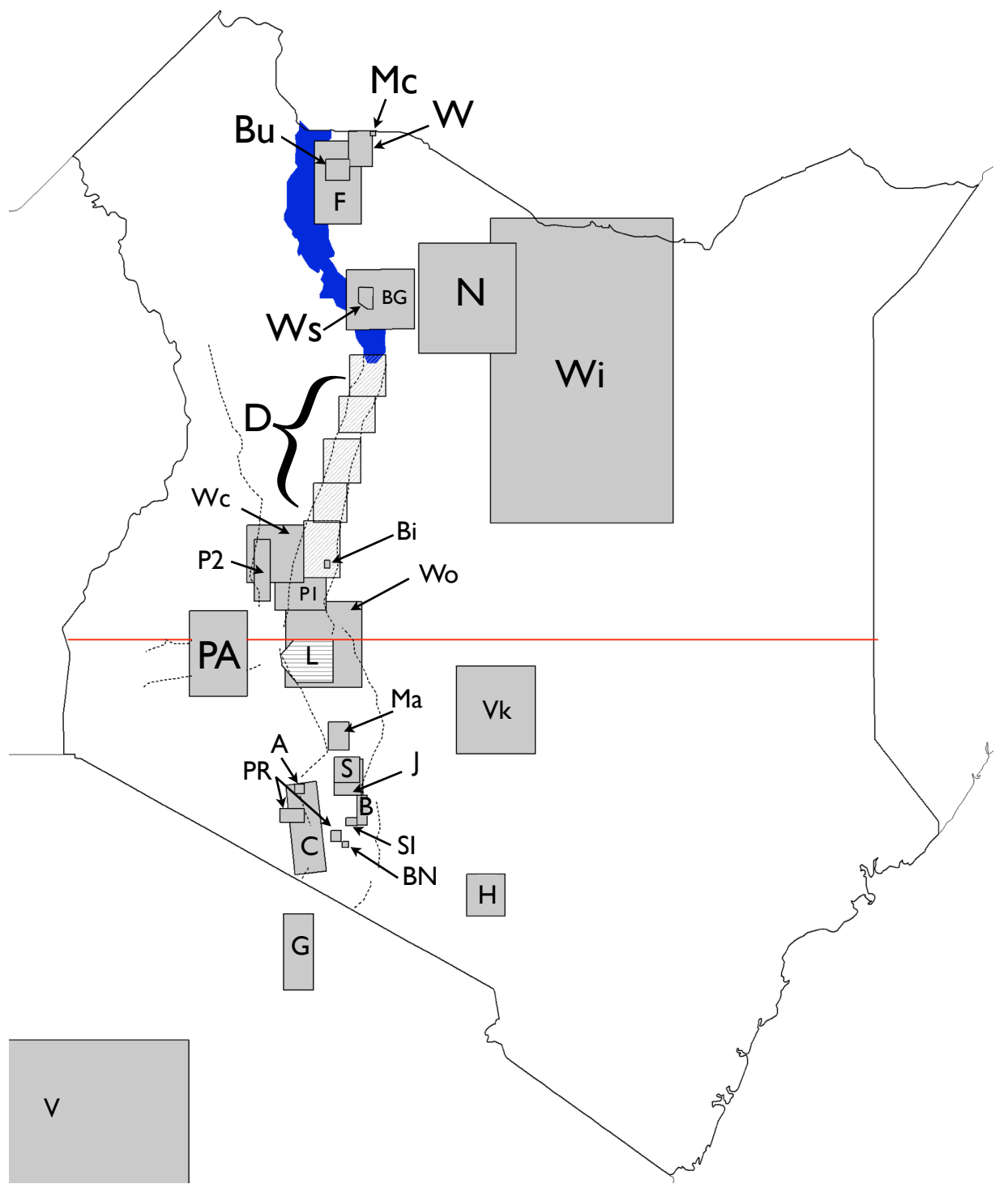

Figure 1.3: Map of Kenya showing smaller, newer, more detailed maps used to update geologic information found in the maps published by the Kenya Geologic Survey. Letters map to the author and publication year as follows:

A: Ambrose, 2007

B: Baker \& Mitchell, 1976

Bi: Bishop, Hill \& Pickford, 1978

BG: Bruhn et al. 2011 \& Gathogo et al. 2008

BN: Baker, 1975

Bu: Buchanan, 2010

C: Crossley \& Knight
D: Dunkley, 1993

F: Findlater, 1978

G: Guest, 1953

H: Haug \& Strecker 1995

J: Johnson, 1969

L: Leat, 1983

Ma: Marshall et al., 2009

Mc: McDougall \& Watkins 2006

N: Nyamweru, 1986

P1/P2: Pickford, 1978

PA: Pickford \& Andrews, 1981

PR: Patel \& Raja, 1979

S: Skilling, 1988

SI: Shakleton 1978, Isaac 1978

V: Verniers, 1997
Vk: Veldkamp et al. 2012

W: Watkins, 1986

Wc: Williams \& Chapman, 1986

Wi: Williams, 1978

Wo: Wohlenberg \& Bratt, 1972

Ws: Williamson \& Savage, 1986 


\subsection{The Era of Age Dating}

Many of the original geologic reports predate the common use of radiometric age dating, which is why newer publications have better constrained stratigraphic relationships and a greater number of recognized geologic units. Often, what had been mapped as a single unit based strictly on lithology, is later recognized as being two, or more, distinct units based on clusters in age data. Since the 1970's, a number of survey papers have been published in an effort to provide age-dates for a variety of geologic formations associated with the rift. Table 1.1 lists some of the main publications that provide age dates for a number of units over a wide area. Age data for specific formations, or reports covering only small research areas, are not explicitly listed here due to the shear number of them. Data from such publications were, however, utilized as part of the digital mapping initiative and are recorded within the attribute table for specific geologic units.

The more recent synthesis papers, such as Brown and McDougall (2011) listed in Table 1.1 make for excellent sources as they have often applied recommended corrections to earlier published K-Ar and $\mathrm{Ar}-\mathrm{Ar}$ ages, and filtered out age dates deemed to be too uncontrolled (i.e. those with significant reported error). Such age date collections and syntheses provide a solid backbone for interpreting the overall geologic evolution of the rift.

The proliferation of age dates, and the refinement of age dating techniques, provide vital information that was largely missing from the original survey publications. These newer reports and maps also provide important geologic detail though enhanced distinction of units that were not previously recognized on the earlier maps. It is these contributions that justify the effort to combine information from such sources with the original survey maps, rather than simply attempting to digitize the survey works. 
Table 1.1: Main survey publications providing age dates for a wide assortment rocks associated with the Kenya Rift. See references section for full citations.

\begin{tabular}{|c|c|c|}
\hline Year & Authors & Title \\
\hline 1971 & $\begin{array}{l}\text { Baker, Williams, Miller, \& } \\
\text { Fitch }\end{array}$ & $\begin{array}{l}\text { Sequence and Geochronology of the Kenya Rift } \\
\text { Volcanics }\end{array}$ \\
\hline 1972 & $\begin{array}{l}\text { Fairhead, Mitchell, \& } \\
\text { Williams }\end{array}$ & $\begin{array}{l}\text { New K/Ar determinations on rift volcanics of } \mathrm{S} \text {. Kenya } \\
\text { and their bearing on age of rift faulting }\end{array}$ \\
\hline 1976 & Baker \& Mitchell & $\begin{array}{l}\text { Volcanic stratigraphy and geochronology of the } \\
\text { Kedong-Olorgesailie area and the evolution of the } \\
\text { South Kenya rift valley }\end{array}$ \\
\hline 1978 & Chapman \& Brook & $\begin{array}{l}\text { Chronostratigraphy of the Baringo Basin, Kenya Rift } \\
\text { Valley }\end{array}$ \\
\hline 1979 & Crossley & $\begin{array}{l}\text { The Cenozoic stratigraphy and structure of the } \\
\text { western part of the rift valley in southern Kenya }\end{array}$ \\
\hline 1979 & Jones \& Lippard & $\begin{array}{l}\text { New age determinations and the geology of the Kenya } \\
\text { Rift-Kavirondo Rift junction, W Kenya }\end{array}$ \\
\hline 1981 & Crossley \& Knight & $\begin{array}{l}\text { Volcanism in the western part of the rift valley in } \\
\text { southern Kenya }\end{array}$ \\
\hline 1984 & Brotzu et al. & $\begin{array}{l}\text { Miocene to Quaternary volcanism in eastern Kenya: } \\
\text { sequence and geochronology }\end{array}$ \\
\hline 1988 & $\begin{array}{l}\text { Baker, Mitchell, \& } \\
\text { Williams }\end{array}$ & $\begin{array}{l}\text { Stratigraphy, geochronology and volcano-tectonic } \\
\text { evolution of the Kedong-Naivasha-Kinangop region, } \\
\text { Gregory Rift Valley, Kenya }\end{array}$ \\
\hline 1999 & Morley et al. & $\begin{array}{l}\text { Geology and Geophysics of the Western Turkana } \\
\text { Basins, Kenya }\end{array}$ \\
\hline 2003 & Clément et al. & $\begin{array}{l}\text { Pleistocene magmatism in a lithospheric transition } \\
\text { area: petrogenesis of alkaline and peralkaline lavas } \\
\text { from the Baringo-Bogoria Basin, central Kenya Rift }\end{array}$ \\
\hline 2009 & McDougall \& Brown & $\begin{array}{l}\text { Timing of volcanism and evolution of the northern } \\
\text { Kenya Rift }\end{array}$ \\
\hline 2011 & Brown \& McDougall & $\begin{array}{l}\text { Geochronology of the Turkana Depression of Northern } \\
\text { Kenya and Southern Ethiopia }\end{array}$ \\
\hline
\end{tabular}




\subsection{A Digital Map of the Kenya Rift Geology}

The maps shown in Figures $\underline{1.2}$ and $\underline{1.3}$ were combined with data from papers such as those in Table 1.1, to aid in the interpretation of Landsat 7 data and the creation of an attribute table which supports the created geologic polygons. A description of the information contained in the attribute table can be found in Appendix A. The geologic map data is presented in both shapefile and kmz formats, as both are widely used formats at the time of writing. For a full listing of associated files, please refer to the "List of Files" section in the front matter. The digital map data have also been prepared as a modern bedrock map which is presented in a PDF format. Other map products derived from this data are introduced and described in Chapters 3 and 4.

\subsubsection{Digital Mapping Techniques \& Sources of Map Error}

As the original maps were not simply traced, but rather used to interpret the satellite imagery, the digital geology will deviate from the georeferrenced source maps. In particular, some of the more recent maps shown in Figure 1.3 were created with detail finer than what can be resolved easily on Landsat data, which has a 30 meter pixel size (nominally $15 \mathrm{~m}$ when pan-sharpened). Thus the digital data will have lower resolution in some areas compared to available source material. Other sources of error can occur due to the ambiguity of what happens with geologic contacts across the borders of maps with different authorship. For example, the map by Clarke et al. (1990), identifies the tuffs and ash fall deposits on the rift shoulder as the "Maiella Pumice", but across the southern map boundary in the Suswa area, the same are designated at the "Mau Ashes". Without a directly stated correlation between them, and the lack of visible contacts in the satellite imagery, the mapped boundary becomes somewhat arbitrary. 
Another set of difficulties comes from the older survey maps, such as Walsh \& Dodson's map of the Norther Turkana region, where geologic units were mapped by lithology rather than strict age relations. For example, all "augite basalts" were mapped as "Tvb1" and are implied to be consistently older than the "olivine basalts" mapped as "Tvb2". Realistically, these authors covered a huge area in only 3 months, and the work, which was conducted in 1963, preceded the common use of age dating. McDougall and Brown (2009) discuss these issues, returned to re-examine the area and report that age dating results indicate that units mapped as "Tvb1" represented ages from $36 \mathrm{Ma}$ to $27 \mathrm{Ma}$, and the "Tvb2" units encompassed basalts from $30 \mathrm{Ma}$ to $16 \mathrm{Ma}$.

Importantly, while the rhyolites were initially mapped as all being "Tvr", the ages found by McDougall and Brown (2009) indicate that the rhyolites are coeval with the basalts of all major ages, from 36-16 Ma. It is quite clear from their work, and they note succinctly, that the "correlation of basalt sequences by mineralogy.... is a poor guide to age". However, unlike the similar issues with earlier maps for the Lake Magadi region (Baker 1963; Baker 1958) which have been updated and remapped several times to distinguish units and clarify age relations (e.g. Baker and Mitchell 1976; Crossley 1979; Crossley and Knight 1981), the northwestern region of Kenya has not been remapped in this manner. While age dates are extremely useful for dividing the originally mapped units, translating what is essentially point-data (the age dated samples) into areas for remapping purposes, is both qualitative and subjective.

Errors in age dating can also cause issues with mapping, such as inappropriate unit correlations. Bruhn et al. (2011) note that some formations near Turkana previously mapped as pre-Pliocene, were actually Pliocene in age, which had significant ramifications for the area's paleogeographic reconstructions. For the digital map, some units were grouped based on shared lithology and similar age. It was assumed that the formations had been given local names within different 
map boundaries, and that similar age and lithology justified correlation. However, if the age dates, or assumed ages, are wrong, such correlations may be in error.

Despite these potential sources of error, one of the goals of the mapping effort was to produce a data set that could be easily updated and modified as new studies are done, higher resolution satellite imagery is obtained, or new techniques are developed. Publishing digital data in an open format allows for others to more easily build upon the work, which will hopefully reduce duplicated efforts, as well as expedite the sharing of up to date information among the community interested in the rift geology. 


\section{Rift characterization \& current state of research}
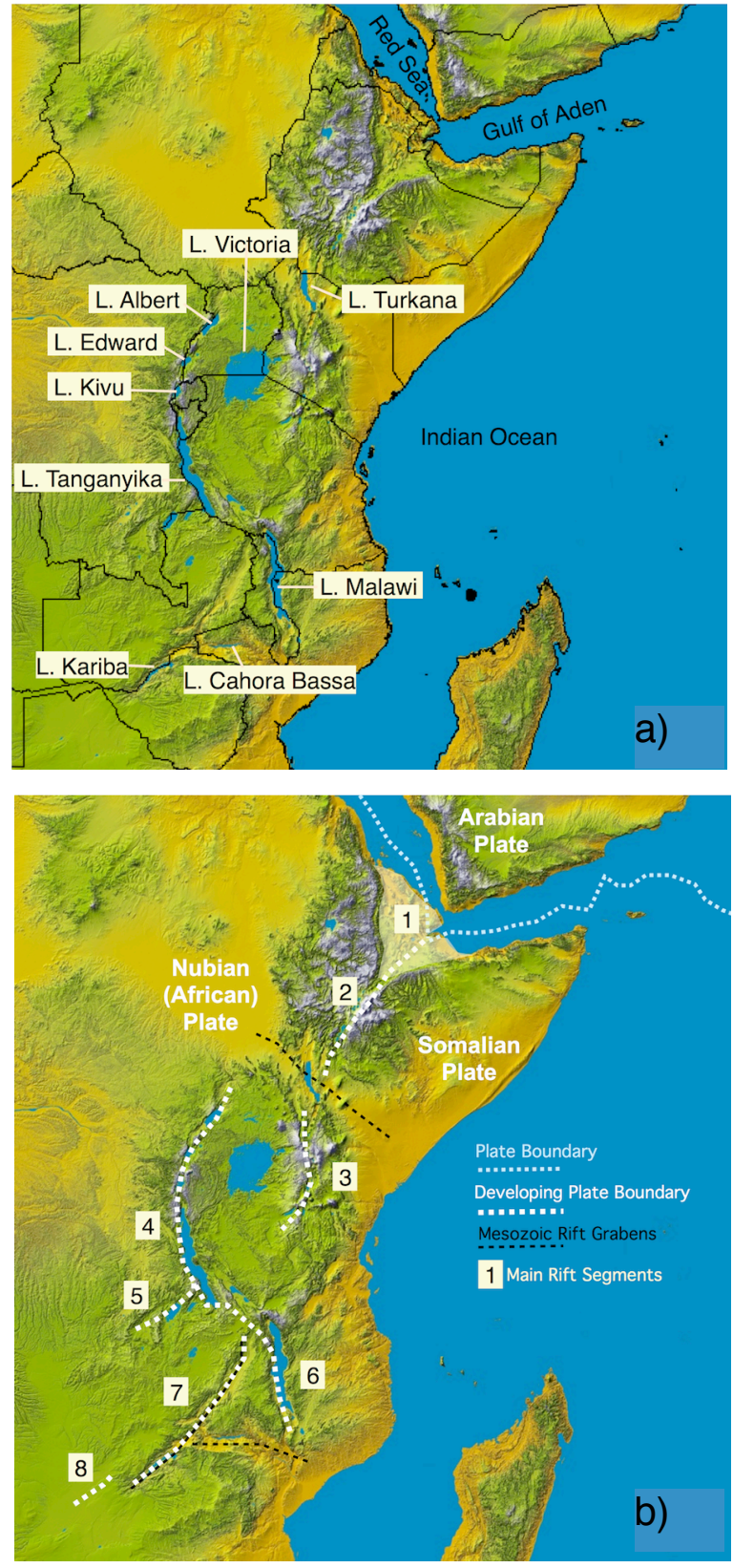

Figure 2.1. Topographic maps of East Africa showing a) political borders, rift lakes, and marine bodies, and $b$ ) the rift segments and main plates discussed herein. Named rift segments; 1 (shaded region): Afar Depression/ Triangle, 2: Main Ethiopian Rift, 3: Eastern Branch, 4: Western Branch, 5: Lake MweruLuapula Graben, 6: Malawi Rift, 7: Luangwa Rift, 8: Okavango Rift Zone. Base image courtesy of NASA/JPL-Caltech/NIMA.

\subsection{Rift Subdivisions}

This work is concerned with the section of the East African Rift System (EARS) that runs through the country of Kenya (Figure 2.1). This is merely one section of a much larger structure, as the main system (Afar to Malawi) runs for a north-south length of around $4100 \mathrm{~km}$, in addition to several side branches. This rift system can be divided into several distinct segments as shown in Figure 2.1b. The active rifts of the modern EARS cut across, and sometimes follow, older rift structures from Mesozoic rift systems associated with the break up of Pangea (e.g. Catuneanu et al. 2005; Feibel 2011).

It should be noted that the exact division of the EARS into subsections varies by author. The naming scheme that reserves the term "eastern branch" to describe the Kenyan/ Gregory Rift is used here, as the "branches" can be thought of as diverging from the Main Ethiopian Rift 
around the Lake Victoria region. This naming scheme has been used in several publications (e.g. Ebinger 2005; Stamps et al. 2008), however, other authors include both the Ethiopian and Kenyan segments in the "Eastern Branch" (e.g. Chorowicz 2005; Frostick 1997; Baker, Mohr, and Williams 1972; Kampunzu and Mohr 1991). The previous use is preferred here, as the diffuse rift zone of the Turkana basin forms a natural gap that divides the more defined Ethiopian and Kenyan sections which encourages their independent naming in the opinion of this author. The Turkana depression also serves as a clear topographic divider that separates the Ethiopian and East African domes. This low spot is partially occupied by the modern Lake Turkana, and the overall depression itself is thought to be caused by the Mesozoic Anza Rift, which is an older rift structure related to the separation of Madagascar (e.g. Morley, Bosworth, et al. 1999; Chorowicz 2005); thus there also seems to be a distinct geologic divider between these rift sections.

The naming of the elevated domes also seems to vary by author, with the large topographic high bounded by the Western and Eastern Rifts being referred to as the East African Dome/Plateau (e.g. Furman 2006) or the Kenyan Dome/Plateau (e.g. Pik et al. 2008; Chorowicz 2005; George, Rogers, and Kelley 1998). If the larger structure is termed the East Africa Dome, then the high structure localized around the Eastern Rift is termed the Kenya Dome (e.g. Dawson 2008; Simiyu and Keller 2001). This later scheme is preferred here and is used in Figure 2.2.

The basic physical characteristics of the different rift segment are presented in Table 2.1 below. It can be seen that the domes are relatively similar in size; the slightly smaller area of the Ethiopian dome can be explained by the separation of Arabia, which technically contains the northern section of this topographic high (see Fig. 2.2). While the mean elevations can be seen to be nearly identical, the minimum and maximum elevations (derived from a digital elevation model, DEM) are noticeably different. These differences can be explained by the segments 
representing different stages in rift development; the Red Sea and Gulf of Aden are submerged rifts, the Afar Triangle is at the most advanced continental-stage with some subregions below sea level (e.g. the Danakil Depression), and the Eastern and Western branches are in the "birth" to "adolescent" stages of development (Ebinger 2005). In terms of the overall Wilson Cycle, which describes the ocean basin lifecycle, the rifts and seas of East Africa are the embryonic to young stages of the cycle (e.g. Burke 2011).

Table 2.1. General physical properties of the different segments of the EARS. Segment numbers are shown in Figure 2.1. Elevations were rounded to the nearest $20 \mathrm{~m}$ based on the stated vertical accuracy from the SRTM specifications of $\pm 16 \mathrm{~m}$.

\begin{tabular}{|l|l|c|c|c|c|c|c|}
\hline $\begin{array}{c}\text { Rift } \\
\text { Section }\end{array}$ & $\begin{array}{c}\text { Common } \\
\text { Name }\end{array}$ & $\begin{array}{c}\text { Length } \\
(\mathrm{km})\end{array}$ & $\begin{array}{c}\text { Mean } \\
\text { Width } \\
(\mathrm{km})\end{array}$ & $\begin{array}{c}\text { Min } \\
\text { Elevation * } \\
(\mathrm{m})\end{array}$ & $\begin{array}{c}\text { Max } \\
\text { Elevation } \\
(\mathrm{m})\end{array}$ & $\begin{array}{c}\text { Mean } \\
\text { Elevation } \\
(\mathrm{m})\end{array}$ & $\begin{array}{c}\text { Mean relief } \\
(\mathrm{m}) \\
\left(\begin{array}{c}\text { shoulder - } \\
\text { rift floor })\end{array}\right.\end{array}$ \\
\hline 1 & Afar & 500 & 400 & -160 & 1780 & 400 & 2200 \\
\hline 2 & Ethiopian & 650 & 50 & 490 & 2640 & 1380 & 1400 \\
\hline Ethiopian Dome** & $1,380,000 \mathrm{~km}^{2}$ & -160 & 4240 & 1200 & $+720 \mathrm{~m}$ \\
\hline 3 & $\begin{array}{l}\text { Eastern } \\
\text { Branch }\end{array}$ & 1300 & 65 & 255 & 3380 & 880 & 1000 \\
\hline 4 & $\begin{array}{l}\text { Western } \\
\text { Branch }\end{array}$ & 2300 & 65 & $400^{*}$ & 4400 & 860 & 1000 \\
\hline
\end{tabular}

* see discussion below regarding the minimum rift floor elevation

${ }^{* *}$ not including the section on the Arabian plate shown in Fig 2.2

The Eastern and Western Branches have similar rift width and general relief between the rift rim and floor. This is misleading however, as the reported elevation of the rift floor in the Western Branch represents the surface of the African "great lakes", rather than the absolute floor of those basins. For example, Lake Tanganyika has a maximum depth of 1470m (Tiercelin et al. 1994), meaning the actual minimum elevation of the Western Rift should be reported as 700 meters below sea level. Given that much of the length of the Western Branch is occupied by such lakes, the influence of the adjusted depth on the calculated 
average elevation would be significant. With that in mind, the Western Branch should be recognized as having a lower average rift floor elevation, and a higher mean relief, than the Eastern Branch.

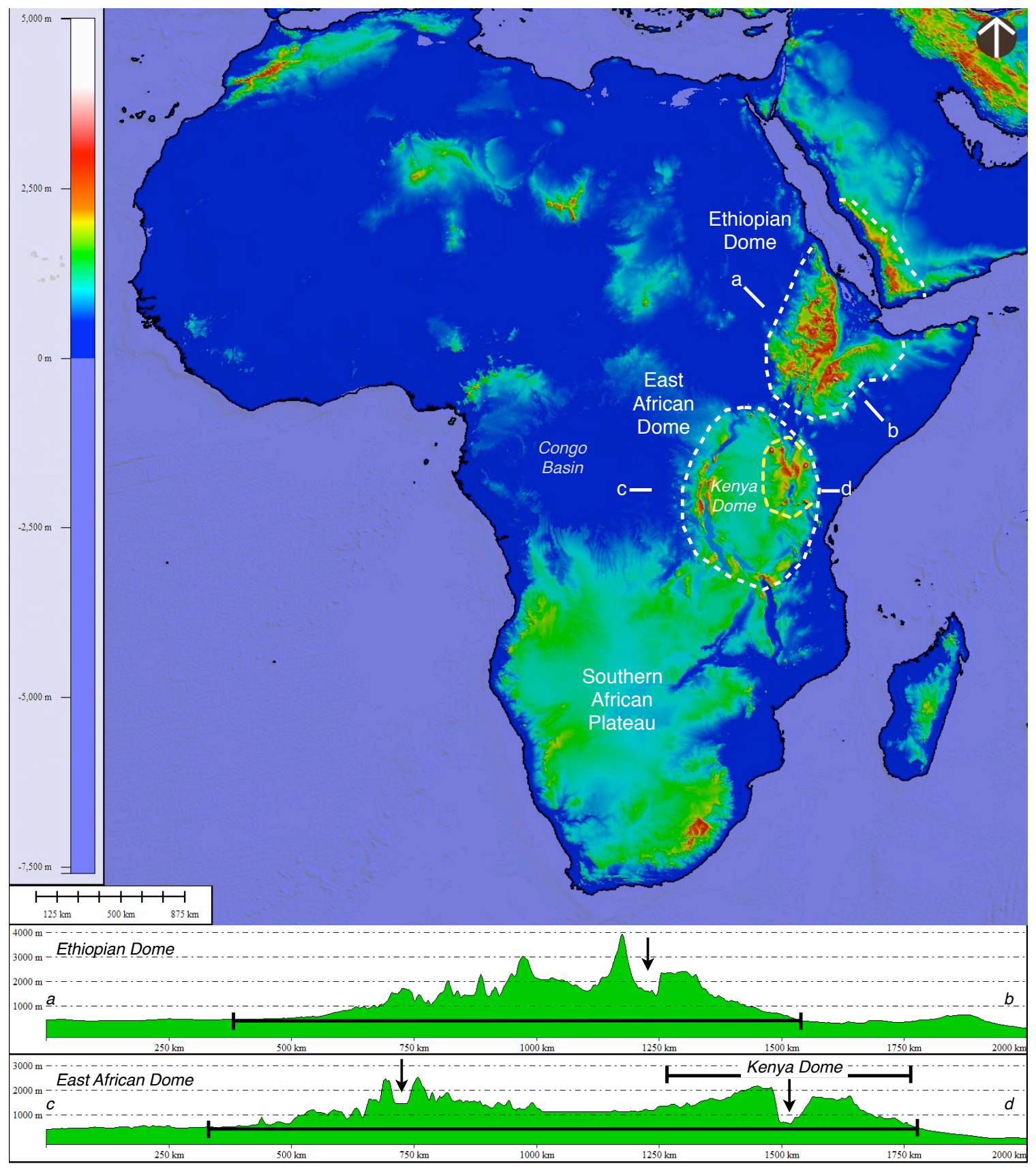

Figure 2.2. Shaded DEM and elevation profiles (50x vertical exaggeration) showing the anomalously high topography associated with the EARS, and the naming scheme used in this work. On the profiles the rifts are denoted by arrows, and the domes are highlighted by horizontal brackets. Elevation is from the CleanTopo2 dataset, and coastline data are from Natural Earth. 
In addition to the two well defined domes, the entire region from Ethiopia to the South Africa is generally defined by a positive topographic anomaly termed the African Superswell (Nyblade and Robinson 1994), which can be easily seen in Figure 2.2. The East African and Ethiopian domes average about $700 \mathrm{~m}$ above the surrounding coastal and inland plains while the overall Superswell has an average elevation anomaly of c. $500 \mathrm{~m}$. This broad elevation anomaly may share a causative force with the rifting events as discussed in the section on superplumes below.

\subsection{Current State of Knowledge: Rift Origins} one plume, two plumes, no plumes, superplume?

As is generally stated when recounting the known history of the EARS, the incursion of one or more plumes occurred before the initiation of rifting in East Africa. A mantle plume is generally described as a localized site of upwelling, where hot buoyant material from the lower mantle rises to the base of the lithosphere. Plumes are often visualized as having a wide, bulbous "head" that is fed by a narrow conduit, or "tail". The plume head is generally modeled to spread and thin as it impacts the lithosphere, and changes in volcanism over time are often attributed to the different effects of the head vs tail of a plume.

While variations of the above description are often encountered and diagramed in textbooks, it is important to note that the very existence of mantle plumes is a currently debated topic. The main alternative hypothesis is referred to as the "plate model", which seeks to explain lithospheric extension and intra-plate volcanism (hotspots) through plate tectonic and shallow mantle processes rather than by anomalous upwelling from the lower mantle. Fortunately these academic arguments have yet to devolve into Tycho Brahe-inspired duels, but rather, discourse related to the debate has taken the form of several very large volumes, two of which have been published by the Geological Society of America (Foulger and Jurdy 2007; Foulger et al. 2005). 
Current technology and available data are seemingly insufficient to determine which mechanism is more correct, and as of this writing, neither model can explain all observations at all "hotspots" (locations of intra-plate volcanism typically explained by mantle plumes). Unfortunately, while one would hope that seismic data could sort this problem out, seismic-based tomography of the mantle can smear anomalies, which can lead to contentious image interpretation (Walker et al. 2005). Nolet, Allen, and Zhao (2007) provide a "FAQ" (frequently asked questions) as part of their paper which is an excellent reference for understanding some of the present issues and limitations of mantle tomography.

Since this dissertation is focused on the timing of the surface eruptive products and the evolution of the surface features, it is considered beyond the scope of this work to provide a comprehensive critical review of these two mechanisms (and the internal variations thereof) to determine which is a better model for East Africa. Good synthesis papers on this debate include Foulger (2007), Sleep (2007), Anderson (2005), and Anderson and Natland (2005), while a relatively brief review of the proposed rifting mechanisms is presented below.

The majority of authors publishing specifically on the EARS seem to ascribe to variants of the plume model, so these will be described first. There is still plenty of contention amongst these authors regarding the timing, shape, depth, and number of mantle sources feeding volcanism in the EARS. Chang and Lee (2011) note that a major divide regarding the number of plumes under East Africa seems to exist between the geochemical and geophysical communities. The geochemical evidence seems to support the existence of two separate plumes, while a larger, single, plume is more favored in the geophysical circles. For further review of plume models associated with the EARS, see the introduction in Macdonald et al. (2001). An additional complication in determining the "truth" of the matter is that, as mentioned in Furman et al. (2006), it is not even known how 
much the African continent has moved over the last $30 \mathrm{Ma}$, and thus different plate motions are used in the various plume hypotheses to explain the timing and distribution of volcanism (Fig. 2.3).

\subsubsection{One Plume}

Ebinger and Sleep (1998) proposed a model in which one large plume $(750 \mathrm{~km}$ diameter head) under Ethiopia could account for volcanism in multiple locations in East Africa. This single plume is thought to have impinged on the sublithosphere of East Africa and was then channeled by the topography of the craton roots and old rift structures, with localized mantle differences accounting for the different compositions of eruptive material. A sub-radial distribution of volcanism around Ethiopia is presented evidence for the presence of a single plume. As summarized by Davies (1998), the channeling aspect of the Ebinger and Sleep (1998) model is a novel way to explain apparently disparate volcanism by a single source. In this model, the separation of Arabia from Africa, and the formation of the Red Sea and Gulf of Aden are explained by far-field stresses related to the collision of Africa with Eurasia, and a stationary African continent is assumed. As Furman et al. (2006) point out however, while the simplicity of this model is appealing, it does not seem to fit the available geophysical data, and rather, these authors argue for a modified single-plume as discussed in its own section below.

\subsubsection{Several Small Plumes}

The main alternative plume-model encountered in the literature explains the volcanism and doming in East Africa by the arrival of two (or more) distinct plumes in addition to the northward motion of the African continent. The initial volcanism in southern Ethiopia and Northern Kenya was caused by the "Kenyan plume", as plate motion now places that thermal anomaly under Kenya. Later volcanism in Ethiopia is envisioned to be the result of Africa moving northward 
over the "Afar plume". Ar-Ar ages from Southern Ethiopia suggest an initial phase of magmatism at 45-35 Ma, which is used by George, Rogers, and Kelley (1998) to argue for the initial impingement of a plume under what is now Southern Ethiopia. Motion of the African plate since then would place that plume under the Lake Victoria region. This model is used to explain the decrease in age of initial volcanism from Southern Ethiopia to Tanzania, as well as the different isotopic signatures between the older Ethiopian lavas and the more recent eruptive material which are ascribed to the Afar plume (George, Rogers, and Kelley 1998). Differential flow of the plume head around the Tanzania craton to under the eastern rift branch may explain the enhanced volcanicity in that region compared to the Western Branch (Nyblade et al. 2000).

Pik, Marty, and Hilton (2006) use helium isotope data to argue that the Oligocene flood basalts in Ethiopia represent a deep mantle source, and that geochemical evidence is not consistent with the model by Ebinger and Sleep (1998) where all the volcanism is explained by a single large plume. The authors suggest the presence of two types of plumes under East Africa: a deep seated mantle plume that caused the continental flood volcanism in Ethiopia c. $30 \mathrm{Ma}$, followed by shallow mantle upwelling involving only the upper $500 \mathrm{~km}$ of the mantle that is separate from the plume.

On the other hand, Furman (2007) argues in their study that geochemistry alone cannot distinguish between various plume models, but argue, for simplicity's sake, that the geochemical signatures could be caused by distinct shallow 'plumelets' originating from a single deep mantle source (the African Superplume; see below). It was noted that the volcanics south of Lake Turkana have a geochemical signature associated with recycled oceanic lithosphere, which makes sense given that the metamorphic rocks in Kenya record the closure of the Mozambique ocean (e.g. Stern 1994; Nyamai et al. 2003). In the view of Furman (2007), these different eruptive compositions between the Ethiopian and 
Kenyan/Western Rifts do not necessarily indicate shallow vs. deep mantle sources, but rather the differential effects of lithospheric mantle composition combined with a heterogenous deep mantle source.

Tomographic data presented by Chang and Lee (2011) indicates three mantle anomalies in the East Africa and Arabian area: one under the Afar, one under Jordan \& Syria, and one under Lake Turkana (this study did not go farther south than Lake Turkana, so the Kenyan anomaly is not well constrained). Each plume is considered to be sourced at different locations. The authors suggest that the Kenyan activity may be fed by the deep seated African Superplume (see below) but consider the Afar plume to have a different source.

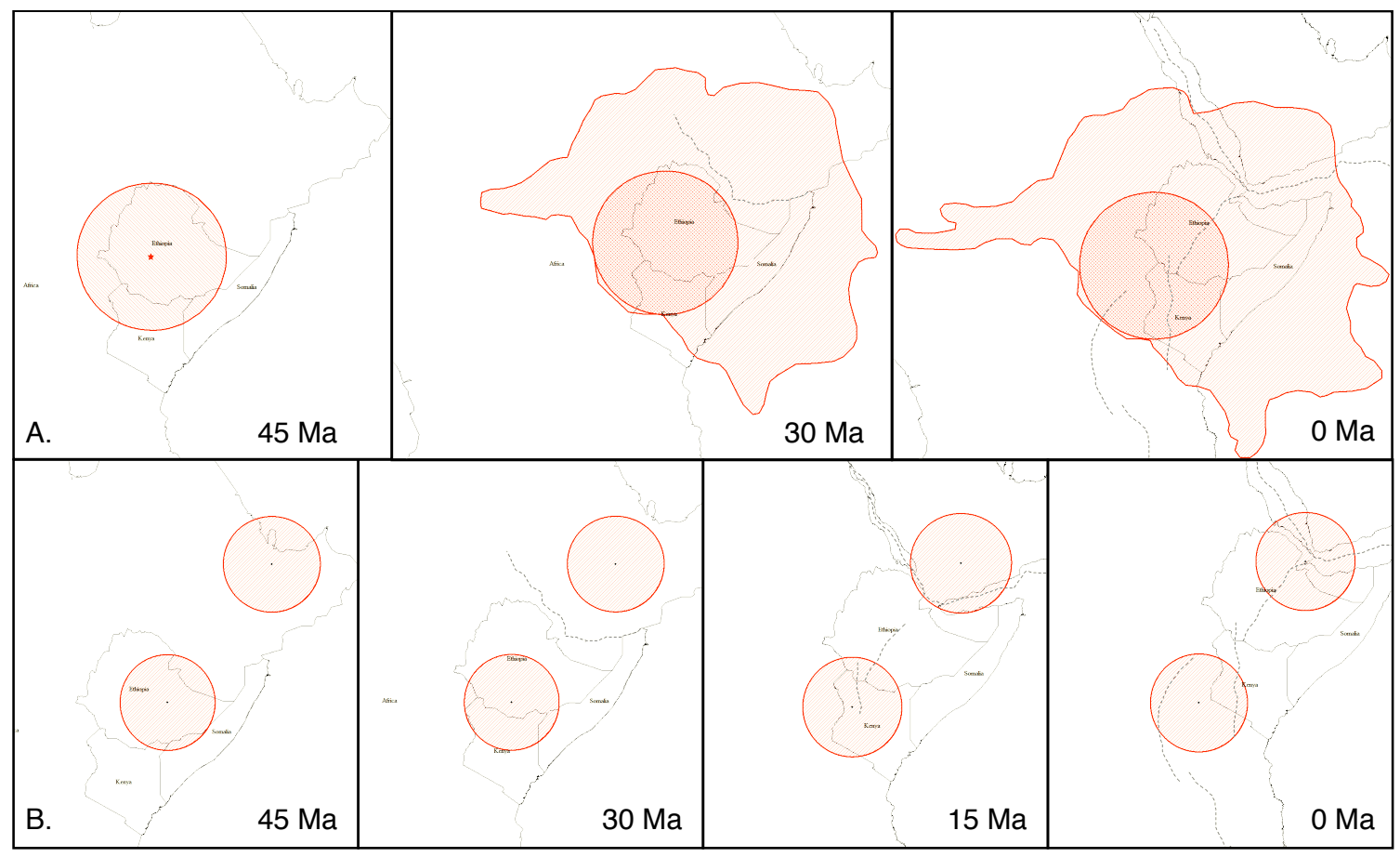

Figure 2.3. Two different plume models that rely on differing plate motions $A$ ) the one-plume scenario as proposed in Ebinger and Sleep (1998) where a single large plume with a head radius of $750 \mathrm{~km}$ impinges beneath Ethiopia. Spread of plume material and melting is directed by crustal root topography. Also indicated in this diagram is a slow $(1.0 \mathrm{~cm} / \mathrm{yr})$ continental movement to the $\mathrm{NE}$. B) the two-plume model where the African continent drifts over 2 stationary plumes (with a $500 \mathrm{~km}$ radius) with a faster plate velocity to explain the progression of oldest volcanism from $S$. Ethiopia to S. Kenya. A rate of $3.2 \mathrm{~cm} / \mathrm{yr}$ along a bearing of $50^{\circ}$ was used based on the NNRMORVEL56 plate model (DeMets, Gordon, and Argus 2010). 


\subsubsection{Superplumes, Piles, and LLSVPS}

The terminology used in this discussion can become confused due to the varied usage of certain terms in the literature. For example, "superswell" is generally used to indicate the "African Superswell" which is a region of elevated topography in East and South Africa. In Figure 2.2, this African Superswell would encompass the Ethiopian, East African, and South African Plateaus, in addition to a region of elevated bathymetry off the southwest coast of Africa (Nyblade and Robinson 1994; Pik 2011). However, the term "superswell" has sometimes be used to indicated the lower mantle anomaly that is invoked as a cause for the elevated topography (Furman et al. 2004). Even more confusingly, Pik, Marty, and Hilton (2006) uses the term to refer to the topographic region, but cites Kieffer et al. (2004), who uses the term to refer to the deep mantle structure, so within Pik, Marty, and Hilton (2006), "superswell" has two distinct meanings. In keeping with the initial usage presented in Nyblade and Robinson (1994), "superswell" will be used herein to refer only to the topographic manifestation of mantle processes.

In the literature, the "African Superplume" refers to a thermal and/or chemical anomaly (detected due to the low seismic velocity of the body) in the mid to lower mantle beneath South Africa, that may give rise to the volcanism and elevated topography in East Africa (e.g. Gurnis et al. 2000; Furman 2007; Moucha and Forte 2011; Nyblade 2011). However, confusion can arise between the "superplume" concept and the single-large plume model suggested by Ebinger and Sleep (1998) depending on how these concepts are introduced. For example, Chang and Lee (2011), start by discussing the single-plume model by Ebinger and Sleep (1998), argue it is supported by geophysical studies, and then start discussing the African Superplume, with the implication that these two concepts are synonymous. This is not the case, as a more proper linkage between these concepts would be the "modified single plume" hypothesis presented by Furman et al. (2004); see the next section. 
The African Superplume is more technically a large low-shear velocity province (LLSVP) as described by Garnero, Lay, and McNamara (2007). These structures are supposed to represent long-lived and stable piles of material near the core mantle boundary. They are envisioned as being passively swept aside in areas where mantle material downwells, while simultaneously bulging up in other regions; however, the exact dynamics depend on if these piles are more or less dense than the surrounding mantle. The apex of the ridges of these deep mantle structures may then be initiation sites for buoyant thermal plumes.

Sun, Helmberger, and Gurnis (2010) use tomographic techniques to provide evidence for a narrow (<150 km diameter) pipe-like structure emanating from the LLSVP below South Africa. As this data was recorded by the Kaapvaal array, it does not image the region that directly underlays the EARS, however, it does indicate that narrow, plume-like structures originating from the African LLSVP are a physical reality (even if not much is known about them).

In essence, the African Superplume (sometimes referred to as a "pile") concept can potentially link the surface volcanism in East Africa to a single, deep, source that may also be invoked as a dynamic force to produce the anomalous topography in south and east Africa. Mantle tomography identifies one of these velocity anomalies under South Africa near the core-mantle boundary (CMB), which then rises towards East Africa (e.g. Gurnis et al. 2000; Garnero, Lay, and McNamara 2007). Moucha and Forte (2011) use a time-reversed mantle convection model and simulate East African dynamic topography over the last 30 million years. They argue that the southern propagation of elevated topography through time represents the northward motion of the African plate over the superplume structure. The elevation of eastern Africa was coeval with subsidence in the Congo basin, which Moucha and Forte (2011) ascribes to associated mantle drawdown. 
Based on calculations by Garnero, Lay, and McNamara (2007), a ridge of the African Superplume rises underneath the elevated and rifted areas of East Africa. Based on seismic imaging presented by Lay and Garnero (2011), in a best fit model of the LLSVP below Africa, the pile rises to a peak height of $\sim 1200 \mathrm{~km}$ above the CMB below Kaapvaal (South Africa), and slopes off to a height of 500 $\mathrm{km}$ to the northeast where the anomaly abruptly ends between Tanzania and Kenya. Much recent work has been devoted to understanding these LLSVPs as described in Lay and Garnero (2011). While there is evidence that these structures are non-uniform compositionally, it is considered unknown if they are composed of abnormally dense material or if they represent buoyant material. In either case, there seems to be a connection between the location of LLSVPS (and other lower mantle abnormalities), hot spot volcanism at the surface, and mantle velocity patterns as seen in tomography data; however the role LLSVPs might play in any of these things is, again, uncertain. These might be geologically long lived features, as there seems to be some correlation between the locations of observed LLSVPs and the emplacement of large igneous provinces (LIPS) in plate reconstructions (Lay and Garnero 2011). Thus, these features may be fixed in the way that mantle plumes were the traditionally conceived, and may be long standing drivers of surface volcanism.

\subsubsection{Modified Single Plume}

Furman et al. (2004) claim that the tomographic data argues against the Ebinger and Sleep model (as presented), and instead propose a "single discontinuous plume model" where the LLSVP located under southern Africa is focused by mantle currents into a conduit towards the surface under the East African Rift. This discontinuous plume model allows for similar ratios of incompatible elements between places like Turkana, the Red Sea and the Gulf of Aden, while local differences, sometimes ascribed to multiple separate plumes, can be explained by mixing with the local asthenosphere. Here, the deep seated African Superplume is envisioned as generating separate shallow mantle plumes. Given 
the idea of LLSVPs, the Afar plume, which was argued by Chang and Lee (2011) to be separate from the East African plume based on observed separation of the anomalies above $1400 \mathrm{~km}$ depth, could be linked to the East African plume at greater depth.

In a mathematical sense, multi-scale plumes have been modeled by Matyska and Yuen (2007) who simulated a complex mantle (e.g. including viscosity changes due to temperature and pressure, mineral transitions) that resulted in multi-scale thermal plumes. These arose from the $\mathrm{CMB}$, ponded within the mantle at the $670 \mathrm{~km}$ density boundary, and gave rise to several smaller plumes above that boundary. This could be a hypothesis that harmoniously merges single-plume, CMB superplume, and multi-plume hypotheses. This is postulated as the favored model by Huerta, Nyblade, and Reusch (2009) and is similar to the modified single-plume of Furman et al. (2004) described above. A simple illustration of some of the various plume-based hypotheses is presented as Figure 2.4. Upper mantle "plumelets" can be formed by any ponding of material below a density boundary, and thus can be worked into a hypothesis involving a large standard plume or a LLSVP like the African Superplume.

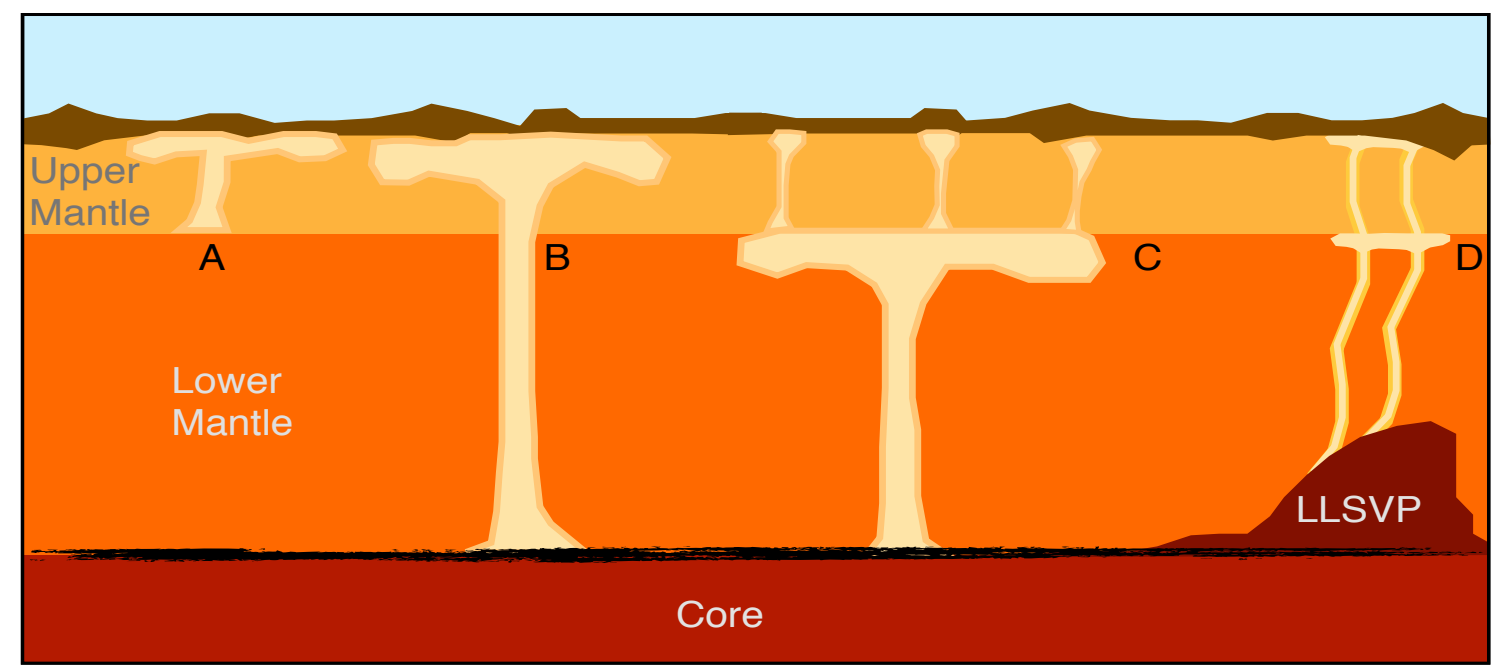

Figure 2.4. Illustration of the different plume hypotheses. A) shallow plume that only involves the upper mantle, B) deep seated 'traditional' plume arising from the CMB, C) A plume that arises from the CMB but doesn't itself cross the boundary into the upper mantle but instead generates shallower 'plumelets', D) thin conduits generated from the edges of an LLSVP, with possible ponding. 


\subsubsection{The Plate Model}

Proponents of the plate model suggest that the doming, volcanism, and rifting of East Africa can be explained through tectonic forces, rather than on deeplyrooted mantle plumes. There has been some intriguing connections postulated between the formation of the EARS and other world geologic events. Bailey and Woolley (2005) discuss an hypothesis proposed by Vogt (Vogt 1975), that notes the start of volcanism in East Africa occurred at the same time as the bend in the Emperor-Hawaiian seamount chain, a change in the magnetic reversal frequency, and the collision between Indian and Asia. It is thus suggested that the volcanism and rifting in East Africa is caused by larger global forces that are somehow coupled to the core dynamo. Further, the East African Dome may be the result of ponding magmas from shallow mantle sources $(<660 \mathrm{~km})$, rather than an impinging plume head (McHone et al. 2005).

As described in Foulger (2007), the "plate model" invokes the Earth's upper thermal boundary (heat transfer at the surface) rather than the core-mantle boundary, to explain observations traditionally associated with hotspots. Melting anomalies are considered to reflect shallow mantle processes that are related to plate tectonics. Erupted volume is associated with the fertility of the underlying mantle plus extension rates. The relative fertility of the upper mantle is thought to be related to past subduction, a process which introduces surface materials into the upper mantle. Extension over an infertile section of the mantle will result in little extrusive magmatism, while extension over fertile mantle will result in abundant magmatism. Because the fertility depends on the tectonic history at any given location, the mantle is considered to be considerably heterogenous, leading to varying melting characteristics that can change substantially over a relatively small lateral space. The temperature of the mantle and thickness of the lithosphere will also influence the amount of melt generated. Temperature 
variations in the upper mantle are thought to be driven by plate tectonics rather than the presence of focused heat sources from the lower mantle.

\subsubsection{Brief Argument Summary}

Anderson (2005) argues that the mere presence of a large-volume low-velocity zone in the mantle is not enough to prove the presence of a plume; it must also behave like an upwelling body of buoyant material. They should "start in a thermal boundary layer, spread out at barriers, elevate the $650 \mathrm{~km}$ phase change boundary, and culminate in a large BF [buoyancy flux] hotspot or swell at the surface". In scoring various "hotspots", Anderson (2005) gives the Afar a score of 6 out of 12 to denote its plume characteristics. Of the plumes ranked, only Iceland was determined to be more "plume-like". Thus, mantle signatures below East Africa do not allow for straightforward interpretation at the time of writing.

In argument for a plume, a synthesis of available seismic studies by Nyblade (2011) indicates a depression of spinel transition zone ( $a$-spinel to $\beta$-spinel phase transition) by 20-40 km under the southern Kenya Rift, which could reflect increased temperature (by $\sim 350 \mathrm{~K}$ ). Additionally evidence presented for upwelling material comes from shear splitting analysis by Chang and Lee (2011) that indicates the existence of three fast axes which converge at the expected location of the Afar Plume. These fast axes run along the Gulf of Aden, northwards under the Arabian Shield, and following the Ethiopian Rift. Since these point back to the Afar region, this trend is used as evidence to suggest that the fast axes represent flow of material away from a central upwelling source.

Modeling of the deviatoric stresses (due to lateral variations in gravitational potential caused by topographic differences) over the African continent by Stamps, Flesch, and Calais (2010), indicates that while these stresses are generally tensional over the EARS, the calculated maximum stress is not 
sufficient to overcome crustal strength. This was true even at Bogoria, which was determined to have the weakest crust in the EARS based on work by Albaric et al. (2009). Thus, the stresses induced by the abnormal topography in East Africa cannot induce rifting by itself.

More generally, Nolet, Allen, and Zhao (2007) argue that, despite the lack of agreement in detail between different models, and the blurry nature of the tomographic images, "there is no doubt that plumes exist in the lower mantle." It may be possible that mantle tomography will evolve to the point of providing unambiguous imagery in the future. Projects like EarthScope, where hundreds of seismometers are being deployed across the United States in a systematic grid, are aimed at understanding the Earth's interior. While no large seismic network such as EarthScope has been deployed across the East African Rift System, hopefully the data collected from North America will provide a clearer image of the mantle underlying the similarly aged Rio Grande Rift.

However, one thing that needs to be considered in this discussion is that, as noted by Pik, Marty, and Hilton (2006), that the definition of a "plume" is a shifting target. The plumes as initially envisioned in the 1970s, and the hypothesized fixed nature of hotspots, has generally fallen out of favor. As quoted in Ananthaswamy (2012), Dr. Shun-ichiro Karato from Yale states that "at the time plate tectonics was formed, the deep interior was unknown, so people drew cartoons...this is beyond cartoons." LLSVPs might be the new version of longlived deep mantle anomalies, but data suggest that they do not look like the traditionally depicted ascending "mushroom" of material as seen in countless papers and textbooks (and Fig. 2.4). As called for by Burke (2011), what is needed is deeper understanding that encompasses "plate tectonics, deeply subducted slabs, and stable LLSVPs". 


\subsection{Current State of Knowledge: Timing of rift development}

Despite debates over how the rifting was initiated, understanding the subsequent development of the rift valleys is comparatively straightforward, as they can be traced using direct observations and age dating. Tiercelin and Lezzar (2004) presents a nice overview of the evolution of the EARS on a large scale, both temporally and spatially. Below is a general summary of rift development as a whole, but with focus on the Eastern Branch, since the initiation of the most recent rifting event.

Overall the geologic history of the rift in Kenya is relatively recent, with the bulk of the associated rock record spanning Miocene to present. The geologic record consists primarily of large volumes of volcanic material, starting as early as the Paleogene in northern Kenya (McDougall and Watkins 2006), erupted onto Precambrian metamorphic rocks. From the Turkana region in northern Kenya, Wolfenden et al. (2004) present evidence that the main Ethiopia Rift (MER) propagated northward after $25 \mathrm{Ma}$, and linked with the Gulf of Aden and Red Sea rifts around $11 \mathrm{Ma}$. This indicates that the MER is unrelated to the $30 \mathrm{Ma}$ basaltic provence in N. Ethiopia, as rift development postdates the eruptions by c. $18 \mathrm{Ma}$. While voluminous phonolite eruptions occurred in Kenya prior to rift faulting, the gap between the two events is generally less than $3 \mathrm{Ma}$. Due to this, Wolfenden et al. (2004) consider the formation of the MER to be more related to the incipient boundary between Nubia and Somalia, rather than caused directly by the separation of Africa and Arabia.

Table 2.2 below provides the age of initiation of different sections within the EARS, grouped by main rift segment (see Fig. 2.1). The table is focused on the origination of the lake basins, however, it should be noted that the present-day lakes did not form at the same time the basin did. Extension values are reported as either stretching factors $(\beta)$ or as length. Unfortunately reporting is inconsistent in the literature and it is difficult to convert between the two reported 
extension values without additional information. Both values are reported if available.

Dates given in Table 2.2 are associated with modern lake names for convenient geographic purposes, but should not be construed to equate with the initiation of the lake itself (see Chapter 4 for more on the lakes). By examining the initiation of the various basins, it can be seen that during the same time that the MER was propagating northward, the Kenya Rift was propagating southward. Around the time the MER had linked with the Gulf of Aden and Red Sea rifts at the modern triple junction, the Kenya Rift had reached the equatorial region. Thus, over the course of $14 \mathrm{Ma}$ (from $25 \mathrm{Ma}$ to $11 \mathrm{Ma}$ ), the MER had propagated $1000 \mathrm{~km}$, while the Kenya Rift only progressed around $400 \mathrm{~km}$ during the same time. One major difference between these two rifts is the presence of the Tanzania craton under the Lake Victoria region, which may have resisted the southward propagating rift. It is suspected that the presence of the cold, thick, craton may have caused the the shifting of stress to the Western Branch (Nyblade and Brazier 2002). Propagation rates reported in Chorowicz (2005) for the East African Rift overall range from 2.5 to $5 \mathrm{~cm} / \mathrm{yr}$, and calculations using the above approximations yield roughly consistent propagation rates between 3 and $7 \mathrm{~cm} / \mathrm{yr}$.

\subsection{Current State of Knowledge: Crustal Structure}

The Eastern and Western rift branches run through ancient mobile belts associated with the formation of the African continent. In particular, in East Africa, these belts surround the Tanzania craton. The Mozambique Belt runs through Kenya (e.g. Bauernhofer et al. 2008; Baker, Mohr, and Williams 1972), while the Western Branch follows the Ruwenzori, Kibaran and Ubendian belts (e.g. Aanyu 2010). The Mozambique Belt was created by the closure of the Mozambique ocean, such that the exposed basement rocks on the rift flanks represent ancient near-shore sediments and ophiolites (e.g. Stern 1994; Bauernhofer et al. 2008). 
What is known about the overall crustal structure comes from several large seismic arrays. Broadband seismic arrays were deployed in Tanzania, Kenya and Ethiopia between 1994-2002, and the KRISP (Kenya Rift International Seismic Project) and EAGLE (Ethiopia-Afar Geoscientific Lithospheric Experiment) projects recorded earthquakes between 1985-2003.

Numerous publications have come out of these projects, which have helped elucidate the crustal and sub-crustal structure of the rift zones (e.g Prodehl et al. 1997; Khan et al. 1999; Keranen and Klemperer 2008; Bastow, Keir, and Daly 2011), with several volumes of Tectonophysics being devoted to the structure of the crust and upper mantle below the EARS (v. 236, 1994; v. 278; 1997).

The average thickness of the crystalline basement outside the rift in southern Kenya was $37.5 \mathrm{~km}$, while the average thickness within the rift was only $31 \mathrm{~km}$ (Mechie et al. 1997). It should be noted that these thickness measurements may under-represent the extension due to some amount of intrusion and underplating of mafic material adding to the measured thickness of the crust. When calculating the stretching factor, Mechie et al. (1997) use what they consider to be a conservative estimate of $3.5 \mathrm{~km}$ to represent the additional mafic material. Results from the EAGLE indicates that extension in the Main Ethiopian Rift (MER) is in fact accomplished by the magma-assisted rifting model (Bastow, Keir, and Daly 2011), where extension occurs via dike and vein intrusion which does not lead to observed crustal thinning.

In Kenya, the KRISP 94 results initially suggested only minor thinning of the crust in southern Kenya, however more detailed studies subsequently suggested that there had been significant underplating of the crust, which would likely obscure the true extent of crustal thinning (Simiyu and Keller 2001; Thybo et al. 2000). Between lakes Baringo and Magadi, Simiyu and Keller (2001) mention that a significant amount of underplating has occurred near the Moho. 
Table 2.2. Timing of rift initiation (initial faulting associated with rift or basin development) and estimated crustal extension for basins in the EARS. $\beta$ is the stretching factor, and is the ratio of initial crustal thickness to final crustal thickness.

\begin{tabular}{|c|c|c|c|c|c|}
\hline Rift Segment & Basin & $\begin{array}{l}\text { Initiation } \\
\quad(\mathrm{Ma})\end{array}$ & Extension & $\begin{array}{c}\text { boundary } \\
\text { fault throw } \\
(\mathbf{k m})\end{array}$ & Sources \\
\hline \multirow{6}{*}{ Western } & Lake Albert & 8 & $<1.15 \beta$ & $4-5$ & $\begin{array}{l}\text { Brachert et al. } 2010 \\
\text { Roller et al. } 2010 \\
\text { Laerdal \& Talbot } 2002\end{array}$ \\
\hline & $\begin{array}{l}\text { Lake Edward- } \\
\text { George }\end{array}$ & & $<1.15 \beta$ & 7 & Laerdal \& Talbot 2002 \\
\hline & Lake Kivu & 10 & $<1.15 \beta$ & $\sim 2$ & $\begin{array}{l}\text { Ebinger } 1989 \\
\text { Laerdal \& Talbot } 2002 \\
\text { Wong \& Von Herzen } 1974\end{array}$ \\
\hline & $\begin{array}{l}\text { Lake } \\
\text { Tanganyika }\end{array}$ & $9-12$ & $\begin{array}{l}1.2-1.3 \\
\sim 13 \mathrm{~km}\end{array}$ & 10 & $\begin{array}{l}\text { Cohen et al. } 1993 \\
\text { Chorowicz } 2005\end{array}$ \\
\hline & Lake Malawi & $6-8$ & & 7 & Chorowicz 2005 \\
\hline & Lake Rukwa & 7 & $\begin{array}{l}10-2 \mathrm{~km} \\
\text { (SE-NE) }\end{array}$ & 7.5 & $\begin{array}{l}\text { Wescott et al. } 1996 \\
\text { Morley, Wescott et al. } 1999\end{array}$ \\
\hline $\begin{array}{l}\text { Gulf of Aden \& } \\
\text { Red Sea }\end{array}$ & $\begin{array}{l}\text { Rift } \\
\text { development }\end{array}$ & 30 & & - & Wolfenden et al. 2004 \\
\hline \multirow{2}{*}{ Ethiopian } & $\begin{array}{l}\text { North } \\
\text { Ethiopian Rift }\end{array}$ & 11 & $1.3 \beta, 28 \mathrm{~km}$ & - & Wolfenden et al. 2004 \\
\hline & $\begin{array}{l}\text { South } \\
\text { Ethiopian Rift }\end{array}$ & $11-19$ & $1.2 \beta$ & - & George et al. 1998 \\
\hline \multirow{5}{*}{ Eastern } & Turkana & $30-15$ & $\begin{array}{c}1.3-1.6 \beta \\
35-40 \mathrm{~km} \\
10 \mathrm{~km} \text { over } \\
\text { last } 5 \mathrm{Ma}\end{array}$ & 7 & $\begin{array}{l}\text { Nyblade \& Brazier } 2002 \\
\text { McDougall \& Brown } 2009 \\
\text { Mechie et al. } 1997 \\
\text { Furman et al. } 2004 \\
\text { Haileab et al. } 2004 \\
\text { Morley, Karanja et al. } 1999\end{array}$ \\
\hline & $\begin{array}{l}\text { Lokichar } \\
\text { (SW Turkana) }\end{array}$ & $30 ?$ & $12 \mathrm{~km}$ & 7 & $\begin{array}{l}\text { Morley, Karanja, et al. } 1999 \\
\text { Wescott et al. } 1996\end{array}$ \\
\hline & Baringo/Kerio & 11 & $5-10 \mathrm{~km}$ & 6 & $\begin{array}{l}\text { Simiyu \& Keller } 2001 \\
\text { Mechie et al. } 1997 \\
\text { Mugisha et al. } 1997\end{array}$ \\
\hline & Naivasha & & $5-10 \mathrm{~km}$ & 6 & $\begin{array}{l}\text { Simiyu \& Keller } 2001 \\
\text { Mechie et al. } 1994\end{array}$ \\
\hline & $\begin{array}{l}\text { Magadi- } \\
\text { Natron }\end{array}$ & 7 & $5-10 \mathrm{~km}$ & 3.6 & $\begin{array}{l}\text { Macdonald } 2003 \\
\text { Simiyu \& Keller } 2001 \\
\text { Birt et al. } 1997\end{array}$ \\
\hline
\end{tabular}


Simiyu and Keller (2001) note also that the thickened crust extends outside of the rift by over $200 \mathrm{~km}$ in the Magadi region, however they assume this is partially due to a zone of legitimately thicker crust caused by the geologic history of the Mozambique belt, rather than accounting for all thickening via underplating. $\mathrm{A}$ more recent study by Albaric et al. (2009) however, which focused on the strength of the crust, found that the entire lower crust (between 20-40 km depth) is predominantly mafic (diabase) material, except for the Bogoria region which had the weakest crustal strength modeled (dominant diorite composition). They note that numerous magmatic events have affected the region over the last 2.5 billion years. Thus the extensive underplating may be the consequence of several events, not just the recent rifting.

Basic crustal structure information along the Kenya rift is presented in Table 2.3 below. Note that the depth to the Moho increases to the south, from Turkana to Lake Eyasi in northern Tanzania. In particular, the thickness of the basement above the Moho increases to the south. This pattern is to be expected given Table 2.2, which indicates that the Turkana region has been undergoing extension longer (and repeatedly if one considers the Anza Graben), with rift propagation to the south over time.

Table 2.3. General crustal structure for the Kenya Rift from North to South

\begin{tabular}{|l|c|c|c|l|}
\hline Location & $\begin{array}{c}\text { Depth to } \\
\text { basement } \\
\mathbf{( k m )}\end{array}$ & $\begin{array}{c}\text { Depth to } \\
\text { Moho }(\mathbf{k m})\end{array}$ & $\begin{array}{c}\text { Basement to } \\
\text { Moho (km) }\end{array}$ & \multicolumn{1}{|c|}{ Sources } \\
\hline Turkana & $5-6$ & 20 & 15 & Mechie et al. 1994 \& 1997 \\
\hline $\begin{array}{l}\text { Baringo/ } \\
\text { Kerio }\end{array}$ & 6 & 30 & 24 & $\begin{array}{l}\text { Mugisha et al. 1997, } \\
\text { Albaric et al. 2009 }\end{array}$ \\
\hline Naivasha & $5-6$ & 35 & 30 & Mechie et al. 1994; Omenda, 1998 \\
\hline Magadi & 3.5 & 35 & 31.5 & $\begin{array}{l}\text { Simiyu and Keller, 2001, } \\
\text { Albaric et al., 2009 }\end{array}$ \\
\hline W. Eyasi & 3.5 & 37 & 33.5 & Dawson, 2008; Albaric et al., 2009 \\
\hline
\end{tabular}


Gravity measurements are another geophysical technique that has been used to understand the crustal structure under the rift. A main feature in gravity study data from southern Kenya is an along-axis gravity high, often interpreted as being due to large-scale crustal intrusions. Simiyu and Keller (2001) argue instead, that the along-axis highs reflect the presence of large volcanic centers, buried horsts, and only small-scale magmatic intrusions that alter the density of the upper crust by $1-2 \%$. The crustal underplating noted above would cause long-wavelength anomalies in the gravity data, and thus would not be contribute to the sharply defined high that seems to trace the rift valley. The simple image of a persistent gravity high following the rift is argued by Simiyu and Keller (2001) to be the consequence of widely spaced data and closely spaced volcanic piles.

\subsection{Current State of Knowledge: Plate Motions}

Oddly, as pointed out in the section above regarding plumes, Furman et al. (2006) claim that despite all the various research regarding the EARS, the absolute plate motion of Africa during the course of the rifting event is not clearly known. It seems that paleomagnetic studies could potentially resolve this issue, given the length and duration of volcanic activity in the region, however relatively few such studies have been conducted in the rift.

There are some detailed magnetic studies spaced along the Eastern Rift Branch from Turkana near $4^{\circ}$ North (Opdyke et al. 2010), past Mount Kenya (Tauxe et al. 1985; Opdyke et al. 2010) and Lake Magadi (Patel and Raja 1979), to Ngorongoro crater at $3.5^{\circ}$ South (Grommé et al. 1970). While representing rocks spanning the last 15 million years, the data density is not sufficient to discriminate between the different plate motion used in various plume hypotheses. A shift of $5^{\circ}$ latitude near the equator should alter the expected magnetic field inclination resulting from a geocentric axial dipole by around $10^{\circ}$. However, as the actual magnetic pole does not align with the rotation axis at 
every given time (hence needing to adjust for magnetic declination on a compass based on location), a number of closely spaced samples would be needed to remove the effects of geomagnetic secular variation. Even in the data collected by Grommé et al. (1970), collected at Ngorongoro crater and representing a relatively narrow window of time around $2.4 \mathrm{Ma}$, the magnetic inclinations range from $-53.3^{\circ}$ (upward) to $+24.7^{\circ}$ (downward). Without specific, targeted collecting, it is doubtful such a small motion near the equator would be detectable by analyzing the published data.

Modern technologies can help shed light on present-day plate motions, as recent motion calculations have utilized Global Positioning System (GPS) networks to constrain plate direction vectors (e.g. McClusky et al. 2003; Stamps et al. 2008; DeMets, Gordon, and Argus 2010). In addition to the availability of GPS data, recent models such as the one presented by DeMets, Gordon, and Argus (2010), now distinguish between the Nubian and Somalian sub-plates rather than treating the African continent as a single unit. A plate motion calculator based on the model presented by DeMets, Gordon, and Argus (2010) and Argus, Gordon, and DeMets (2011), indicates the rate of motion for the equatorial Kenya Rift located on the Somalian plate in the no-net rotation frame is $35.5 \mathrm{~mm} / \mathrm{yr}$ along a northeast bearing. If this motion was constant over the last 45 million years, the total motion since the earliest hypothesized arrive of a mantle plume is nearly $1600 \mathrm{~km}$ (see Figure 2.3b). It should be considered that the assumption of constant plate motion over this time is somewhat unlikely given the complex nature of the plate boundaries to the north.

Regarding extension related to the rifting, the model used by Stamps et al. (2008) predicts opening rates of $4 \mathrm{~mm} / \mathrm{yr}$ in the Turkana region, decreasing to 1 $\mathrm{mm} / \mathrm{yr}$ in central Tanzania. Baker, Mitchell, and Williams (1988) provide several fault-based extension estimates that range from 3 to $5.5 \mathrm{~mm} / \mathrm{yr}$ for the central Kenya Rift, which seems to be in reasonable agreement with the more recent 
estimate by Stamps et al. (2008). Extension rates continue to increase northwards from Turkana, as Stamps, Flesch, and Calais (2010) note that the extension rate in the Main Ethiopian Rift is closer to 6-7 mm/yr, and spreading rates in the Red Sea vary from $10-16 \mathrm{~mm} / \mathrm{yr}$ based on location, with the fastest spreading around $18^{\circ}$ North (Chu and Gordon 1998). 


\section{Geologic development of the Kenya Rift: trends and patterns}

\subsection{Methods}

Mapping current surface geology was considered to be the most important first step in visualizing and quantifying the development of the Kenya Rift. A digital map was created using methods described in Guth (2007). False-color Landsat imagery utilizing bands 7, 4 and 2 (mid-infrared, near-infrared and green, respectively), was used in combination with digital elevation models (DEMs) derived from the Shuttle Radar Topography Mission (SRTM). Previously published geologic maps (see Figures 1.2 and 1.3) were used to represent ground truth, and to interpret the Landsat and topography data. Digital polygons representing the different geologic units were created in Global Mapper, which is a commercial geographic information system software. A supporting attribute table was created to include information such as age, lithology and references for each unit. A full list and description of the attribute table fields can be found in Appendix A.

Mapping was conducted at a variety of scales. To assess the maximum potential error in the surface area calculations due to digitizing, a road was traced at the scale of 1:200,000, which was the smallest scale (most zoomed out view) used for polygon creation. The error was taken to be the average number of meters from the digitized road to the visible center of the road on the Landsat imagery. A total of thirty-five (35) measurements were recorded, with an average error of $52.9 \mathrm{~m}$, which is approximately 1 screen pixel. The maximum error in placement due to digitizing is thus taken to be $+/-53$ meters. When this "excess perimeter" is applied to polygons within two standard deviations of the mean perimeter to surface area ratio, the resulting change in surface area and volume can be calculated. Using a perimeter to surface area ratio allows easy exclusion of the polygons with extreme perimeter to surface area ratios, which would 
disproportionately affect an average. This was considered valid as the very small polygons, which suffer the most extreme ratios, were digitized at very different scales than that assumed above. Ideally, errors would be calculated for polygons of various sizes based on different mapping scales used, however, only the smallest scale was noted at the time of digitizing as to take care to not be overly zoomed out. Using the above procedure indicates the expected average error on values derived from mapped surface area is then $6 \%$ for calculated areas, and $8 \%$ for calculated volume.

\subsection{Trends \& Paleomaps}

The construction of a digital dataset with accompanying age information allows the creation of maps representing different time periods. A time series representing cumulative emplacement of eruptive material since the Eocene can be seen in Figures 3.1a-l. Baker and Wohlenberg (1971) also presented time series maps, but presented only four, from Miocene to Quaternary. The digital geologic dataset allows for the easy creation of maps for each geologic stage with full preservation of formation and compositional complexity. Note that small images are presented here to aid discussion, while full page versions can be found on the accompanying compact disc (see Appendix $C$ for file paths and names). Due to the narrow time range represented by the rift-related geology, colors are used to represent lithology instead of time, similar to Guth (2007). The United States Geological Survey does suggest that related sequences of volcanic rocks may be colored based on time, composition, or volcanic style (United States Geological Survey 2005). To increase the color-space available, patterns are used to group formations of a particular time. This also allows for the re-use of colors and distinction of units when the entire dataset is plotted.

The most basic of eruptive trends visible from Figure 3.1 is the southward progression of volcanic units over time. The oldest materials have been 
recognized to be representative of the Eocene's Priabonian stage (McDougall and Watkins 2006; McDougall and Brown 2009; F. H. Brown and McDougall 2011), and are exposed in the northernmost section of the Kenya Rift. The volcanic activity expands southward though mid-Miocene. It is important to note however, that during, and after, this expansion, volcanic activity is found throughout the length of the Kenya Rift rather than the activity being strictly concentrated at the propagating edge. With the building of the Chyulu Hills, and the recent activity at Kilimanjaro, both located on the eastern rift shoulder, it can be seen that recent activity is not exclusively contained within the rift valley either.

While it is tempting to use the volcanic activity as a proxy for the propagation of the rift, this is not strictly the case. It is generally considered that some volcanic activity, especially the plateau phonolite series, predated initial faulting and halfgraben formation in a given area (Crossley 1979; Williams and Truckle 1980; Smith 1994; Macdonald 2003). Thus, the southward progression of the phonolites likely predates faulting in some areas of the rift by 1-3 million years. However, some faults seem to have been present prior to volcanism (e.g. the Kerio fault west of Lake Baringo), and may have been due to Paleogene activity (Mugisha et al. 1997). Thus, while faulting and volcanism are obviously related in this rift, they do not necessarily occur in a strict progression.

\subsubsection{Composition:}

Detailed composition information is lacking for the vast majority of the geologic units, however general lithology is readily available. Instead of plotting specific total alkali versus silica (TAS) values for available units to represent rock types erupted over time, the available lithologic information was simplified and presented as pie charts, plotted by geologic stage (Fig 3.2 a-o). Plotting specific chemical analyses would obviously be more explicit, and such plots could be use 
to examine petrology trends, however, the trade-off in giving up detail is the abundance of general rock type information. A number of chemical analyses are available in the literature, and many of these can be obtained from the GEOROC database (Sarbas 2008). However, for this work, it was considered sufficient to show the general, simplified, trends in erupted rock type over time, as the origination or petrologic evolution of the various magma sources is not a focus of this research. Such simplifications are used in published works that are similar to the effort presented here (e.g. Williams 1972).

It should be noted that the volcanic rocks that typify the Kenya Rift are more alkaline than the traditional basalt-andesite-dacite-rhyolite trend. For example, phonolites are a relatively common eruptive product for the rift, and have a silica amount similar to andesite but are significantly enriched in alkalies $\left(\mathrm{Na}_{2} \mathrm{O}\right.$ and $\mathrm{K}_{2} \mathrm{O}$ ). Trachytes, again a common product in the rift, are similar to dacite in terms of silica content but are again more alkaline. Nephelinite and melanephelinte both have a large nepheline component and are more alkaline and less silica-rich than basalt.

Simplified categories of volcanic rocks utilized are shown in the legend accompanying Figure 3.2. While many rock types are interesting for understanding the petrogenesis of the area (e.g. carbonatites, benmoreites, mugearites), the volumes of these are proportionally low, and the increased number of varieties reduced readability of the charts. Lithologic details are recorded as part of the attribute table that accompanies the digital geologic data; while the information presented in Figure 3.2 is simplified, the data in the attribute table is not. While more detailed analyses could be attempted with specific chemical analyses, there are a significant number of publications devoted to understanding the petrogenesis of the lavas in East Africa (e.g Chakrabarti et al. 2009; Beccaluva et al. 2009; Furman 2007), so it is unclear if any further understandings would be gained here. 
Volumes directly associated with complex volcanic cones are listed as "mixed" in Figure 3.2. Williams (1972), who published the first volumetric accounting for the rift, noted that the central volcanoes associated with the Kenya Rift are often composed of a great variety of different rock chemistries, which complicates volume determinations of individual lithologies. This is particularly notable when examining maps of recent volcanoes (e.g. Dunkley et al. 1993) where many varieties of erupted lavas are clearly distinguished at the surface of some vents. Due to the varied eruptive products, it becomes subjective whether or not to count the entire cone volume as one lithology or another, as the basal layers are often not exposed for study. As such, the volcanic centers were treated independently in the volumetric study by Williams (1972), and it was determined to be the best way to approach many of the volcanoes in this work as well (e.g. Suswa, Lenderut, Silali). Some volcanoes like Mt. Elgon, Asie Shield, and Chyulu Hills, are only described in terms of singly lithologies, so such centers were counted as a single composition in those cases.

Examining only the relative percentages of different lithologies over time in Figure 3.2 does not indicate any clear compositional trends (e.g. mafic to more silicic or vice versa). Rather, different periods of time are dominated by different lithologies, with the dominant lithology switching between mafic (basalt, nephelinite \& melanephelinite), intermediate (phonolite) and silicic (trachyte and rhyolite) products. The main exception is that intermediate products are only dominant during the mid-Miocene, whereas the other periods are either dominantly mafic, silicic, or bi-modal. This bi-modal character has been noted as being a common characteristic of other intra-continent rift systems and large igneous provinces (Bryan et al. 2002), however, the older Mid-Continent Rift System in North America only seem to approach 25\% silicic material (Vervoort et al. 2007). 


\subsubsection{Spatial and Temporal Trends:}

The visual complexity and variable area of the mapped units in Figure 3.1 can hinder visual inspection of compositional trends in space and time even though the maps are useful for visualizing eruptive events as a whole. Figure 3.2 gives a sense of the bulk eruptive compositions during different times, but there could be spatial and temporal information not seen in these diagrams. To help address these issues, the rough centroid of each mapped unit was marked as a point feature via visual inspection in the GIS software. This allows for the composition information to be plotted at a single point, which can create visually simplified geographic and temporal plots.

Volumes of the different lithologic groups were plotted by latitude and longitude utilizing the centroid coordinates for each unit (Figure 3.3) to highlight spatial trends not represented in previous pie charts. Unlike in Figure 3.2, volcanoes that have erupted carbonatites have been separated from the general mixed volcanoes, even though these carbonate-rich lavas may only be a small portion of the total erupted volume. This was done due to the geologic rarity of carbonatites as well as the potential enhanced contribution to "mock aridity" signals in the paleoclimate record compared to normal volcanic products (Harris and van Couvering 1995). It was also considered possible that there may be visible trends in space and time if attention were called to these peculiar rocks. Such rocks are of enough interest, that an entire book series has been published on their occurrence worldwide, with an entire volume dedicated to Africa (Woolley 2001). 

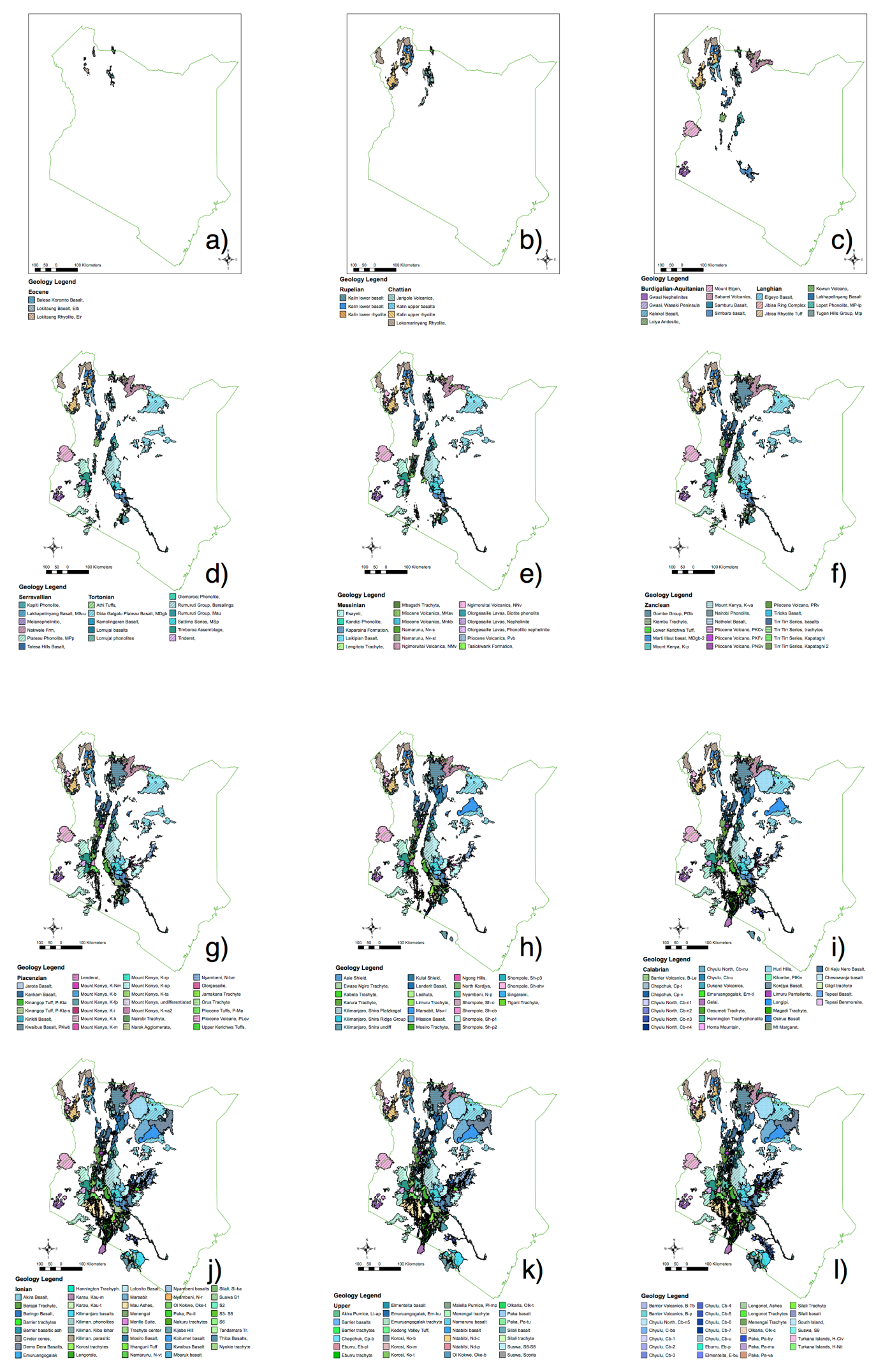
Figure 3.1. (Previous page): Geologic maps representing the cumulative eruptive products related to the Kenya Rift since the Eocene. Please see full-sized figures included on the accompanying $\mathrm{CD}$ for full detail and readable legends. (a) Eocene; $(b)$ Oligocene; Miocene: $(c)$ Burdigalian \& Aquitanian, (d) Serravalian \& Tortonian, (e) Messinian; Pliocene: $(f)$ Zanclean, $(g)$ Piacenzian; Pleistocene: (h) Gelasian, (i) Calabrian, (J) Ionian, (k) "Upper"; (I) Holocene
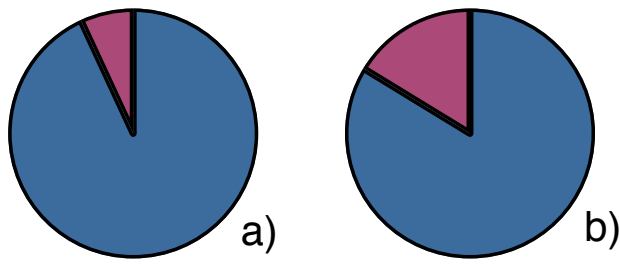

b)

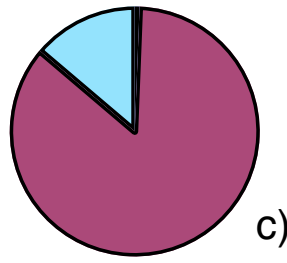

c)
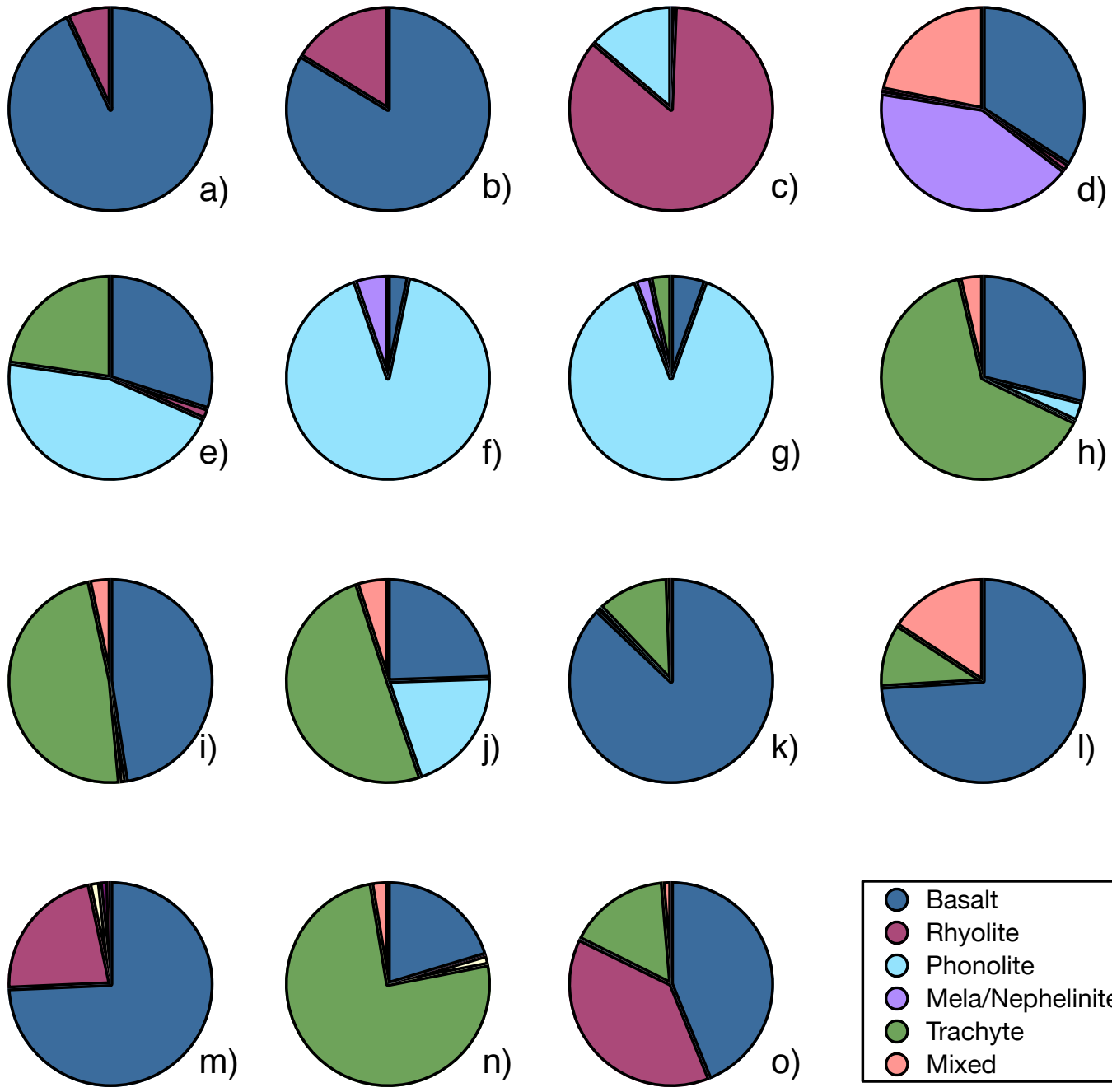

Basalt

Rhyolite

Phonolite

Mela/Nephelinites

Trachyte

0)

Figure 3.2. Pie charts showing the relative volume of different erupted lithologies for individual geologic stages. Eocene: (a) Priabonian; Oligocene: (b) Rupelian, (c) Chattian; Miocene: (d) Aquatanian \& Burdigalian, $(e)$ Langhian, $(f)$ Serravallian, $(g)$ Tortonian, $(h)$ Messinian; Pliocene $(l)$ Zanclean, (J) Piacenzian; Pleistocene ( $k$ ) Gelasian, () Calabrian, $(m)$ Ionian, ( $n$ ) “Upper”; (o) Holocene. 

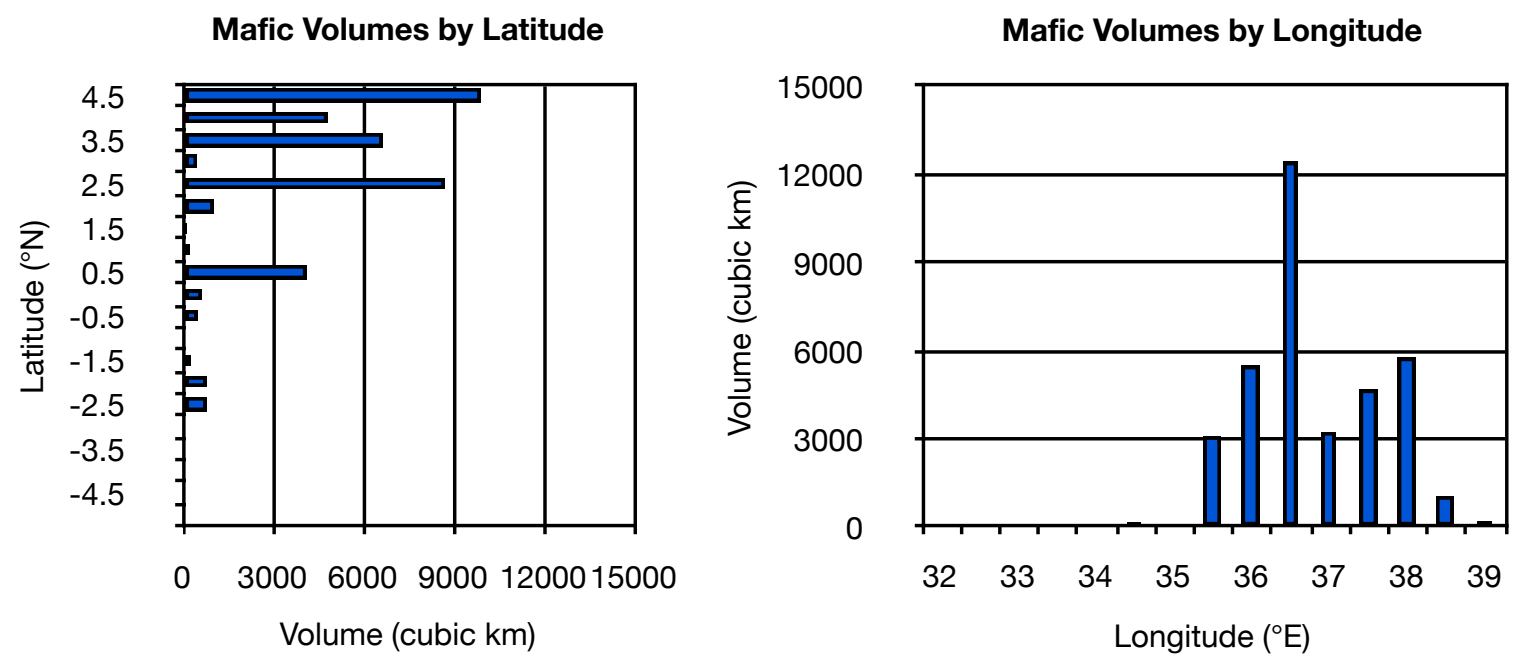

Intermediate Volumes by Latitude

Intermediate Volumes by Longitude
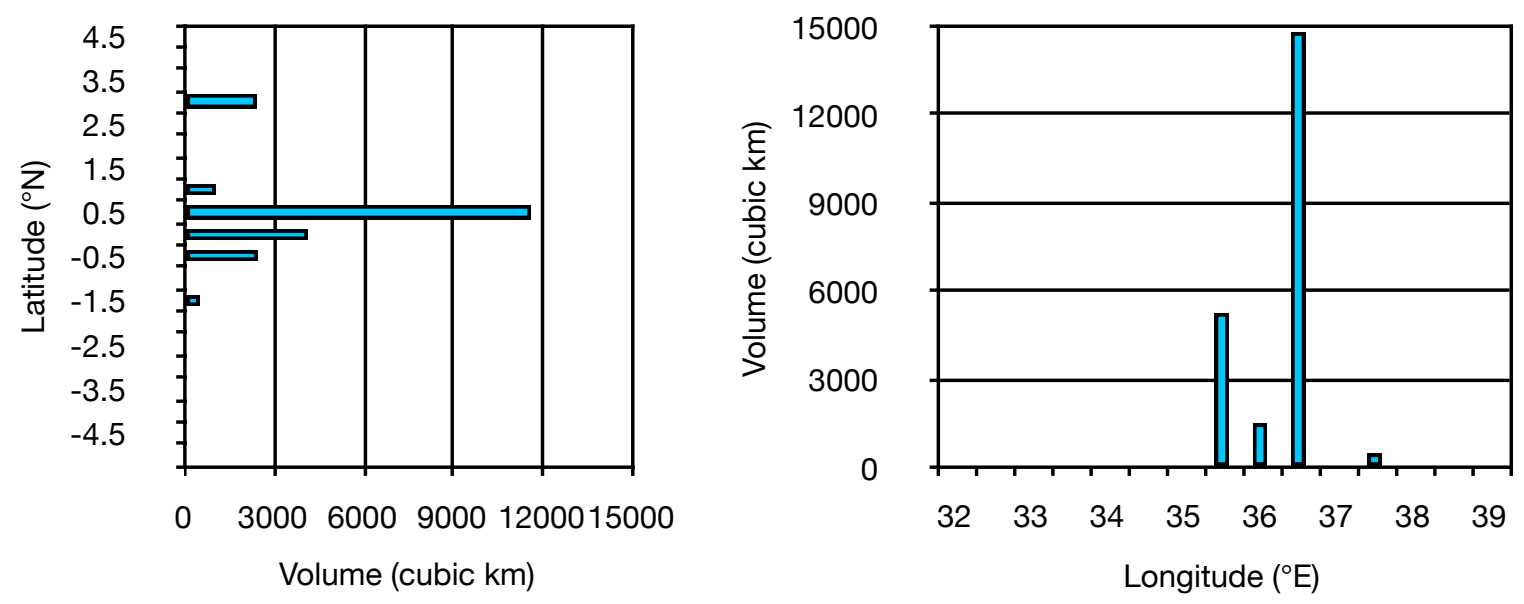

Silicic Volumes by Latitude
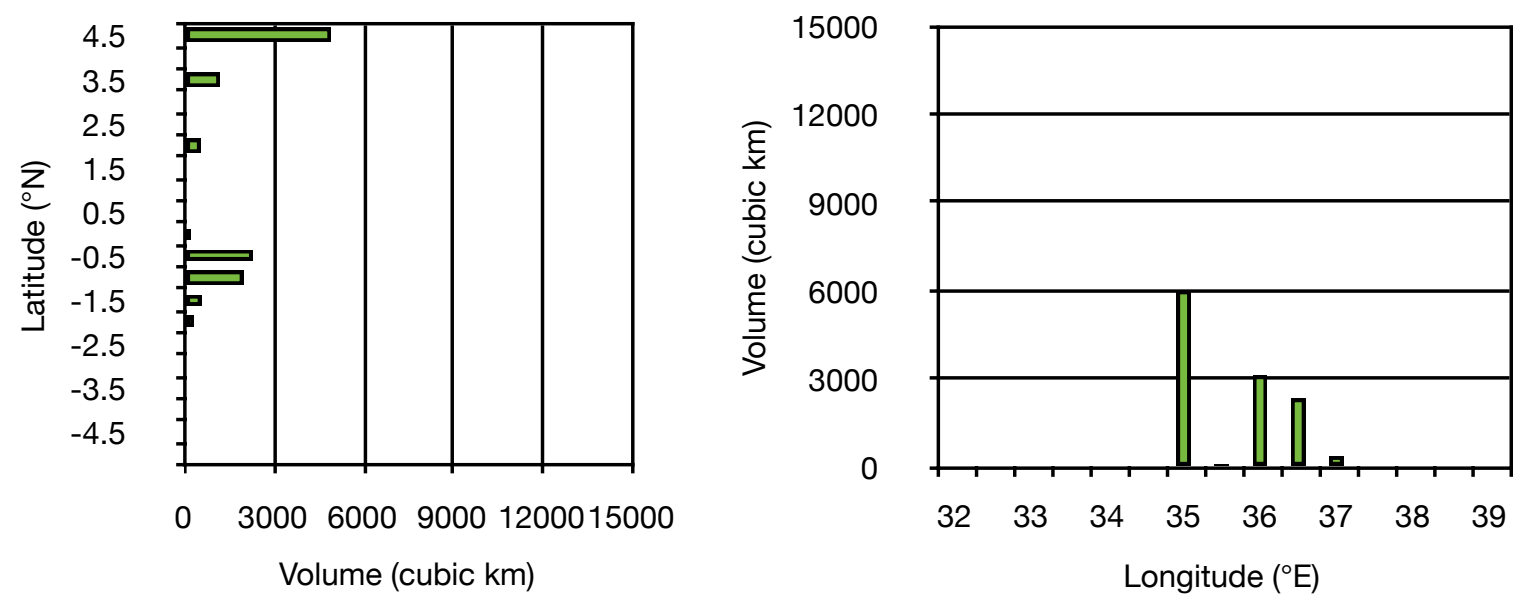

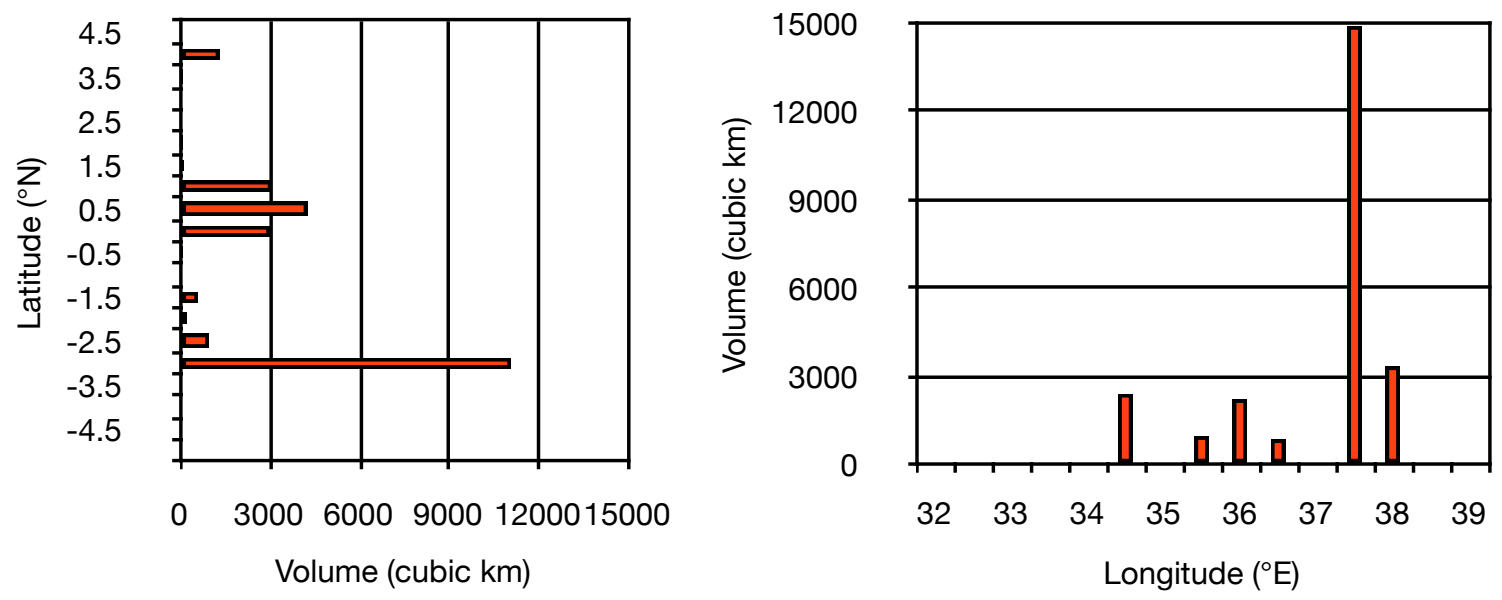

Carbonatite Assoc. Volumes by Latitude

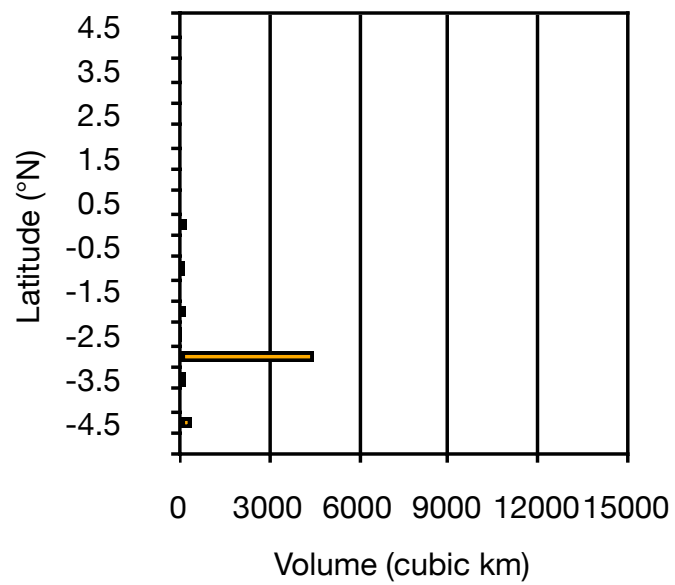

Carbonatite Assoc. Volumes by Longitude

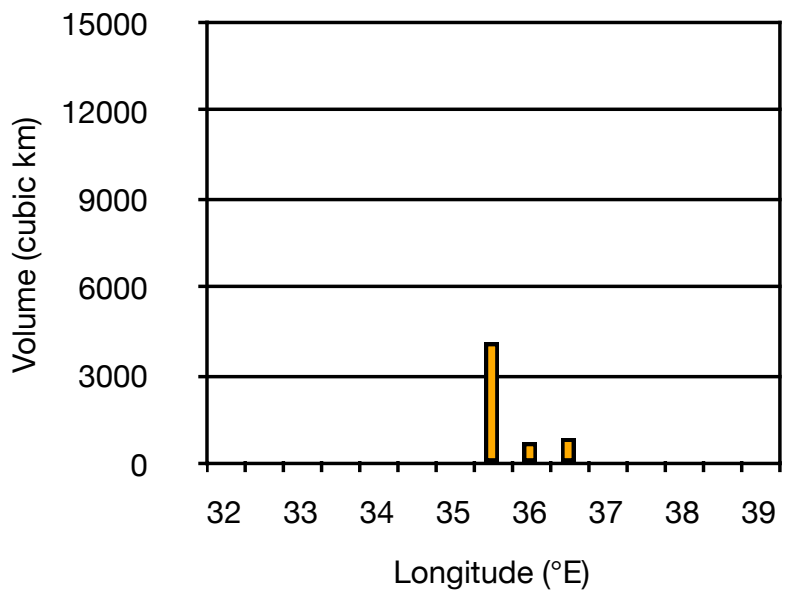

Figure 3.3. (previous and this page): Volumes of different lithologies by Latitude and Longitude. Latitude is displayed on the $y$-axis to represent north-south, and Longitude is displayed on the $x$ axis to represent east-west. Mafic volumes include basalt and nephelinite, Intermediate volumes include phonolite and andesite, and Silicic volumes include trachyte and rhyolite. Mixed volcanic volumes are volcanic cones the produced numerous lithologies, and the Carbonatite Assoc. volumes represent volcanic centers that are known to have produced carbonatite products.

These graphs indicate that mafic products (basalt, nephelinites and melanephelinites) are most common to the north and decrease in prevalence to the south. Mafic eruptives are also seen over a wider longitudinal span than most of the other lithologies. In contrast, the intermediate phonolites are distinctly prevalent around $0.5^{\circ}$ north of the equator and have a relatively narrow longitudinal range. Silicic material (trachyte \& rhyolite) flanks the intermediate 
peak to the north and south, has a similar east-west span but is slightly shifted to the west in comparison. Mixed volcanic centers are widespread in both dimensions, and the very large peak in both graphs corresponds to Kilimanjaro. This very large complex is the highest free standing continental mountain (a distinction that separates it from Mauna Loa which starts at the sea floor), and is "off axis" meaning that it developed a significant distance from the rift valley. This "off axis" positioning explains the very large peak in these graphs farther to the south and east than the other lithologies. Mount Kenya and Nyambeni are also large shield volcanoes that are east of the modern rift valley. In contrast, volcanoes that are associated with carbonatites are only found in the southern section of the rift and have the narrowest observed longitudinal range.

From these plots, it can be seen that mafic eruptives and mixed volcanoes are both widely spread away from the rift valley axis. The intermediate and silicic materials are more tightly constrained to nearer the rift, while carbonatites have a very narrow distribution within the southern extent.

The centroid data can also be plotted directly as either a map (Figure 3.4) or to represent position through time (Figure 3.5). In these figures the centroids are color coded to represent composition of each geologic unit or volcanic assemblage. Symbol sizes are scaled to represent different categories of eruptive volume (see next section for volume methods and discussion), using the following volume ranges in cubic kilometers: 0-1, 1-10, 10-100, 100-1000, 1000-10000, over 10000.

Volcanic assemblages that include carbonatites have again been called out in Figures $\underline{3.4}$ and $\underline{3.5}$ with a unique symbol (a yellow inverted triangle), for the reasons mentioned above. Otherwise, these would be classified as mixed volcanoes. 
There are a few trends visible in Figure 3.4 with regards to spatial distribution of compositions. Carbonatites and trachytes are concentrated south of the equator, with the carbonatites seemingly at the rift edges and the trachytes forming a distinct concentration between the Kenya-Tanzania border and the Nyanza rift $\left(0.25^{\circ} \mathrm{N}\right)$. More of the "off axis" volcanism seems to occur to the east of the rift valley rather than equally distributed on both sides, and this eastward volcanism is dominantly basalts or volcanic centers. The volcanoes preserved to the east of the rift are often quite large, which may be the result of either inherently different "plumbing" than within the rift valley, or due to better preservation. Such buildups of material would be unaffected by the extensive faulting that breaks up the rift floor, and would be less likely to be buried by rift-related fissure eruptions. If the rift axis is taken to roughly coincide with $36.5^{\circ}$ east, the eastern "skew" of basalt and volcanic activity is easily visible in Figure 3.3 as well.

The apparent bi-modal distribution of silicic products over latitude seen in Figure $\underline{3.3}$ can be more clearly seen in Figure 3.4 to be caused by a northern concentration of rhyolite plus the southern concentration of trachytes. These two lithologies are thus relatively distinct with regards to dominant geographic positioning within the rift.

Figure 3.5 shows the same centroid data plotted with latitude (as the main development has been a north to south progression within Kenya) and time axes. The data have been grouped by visual inspection and been designated as Stages I-V. This plot indicates several periods of southwards expansion, stasis, and possible narrowing. Activity is initially confined to a narrow section of the northern Kenya Rift for nearly 10 million years (Stage I). This is followed by southward expansion to just north of the equator (Stage II) and then relatively rapid expansion to near 2 degrees south of the equator (Stage III). Near 10 million years ago the activity associated with the rift may have narrowed to a region centered on the equator (Stage IV), however, this was followed by another 
relatively quick expansion south, in addition to the continuation of eruptions north of 2 degrees (Stage IV).

This patterning indicates that, except for Stage IV, the rift is generally active along its entire length, even as the rift is propagating. In other words, the older sections of the rift are apparently not abandoned. The lack of observed activity to the north and south during Stage IV follows the massive outpouring of phonolite lavas (the plateau phonolites) that cover much of the Kenya Dome. This period between 10 and 6.5 million years ago also coincides with active basin formation within the Western Branch (Table 2.2). It may be possible that stresses related to the development of the Western Branch affected the development and volcanicity of the Eastern Branch within Kenya. The Aswa lineament is a basement structure that has been used to explain the bend in the Kenya Rift at $0.25^{\circ} \mathrm{N}$ (e.g. Chorowicz 2005), and has been noted to align with the termination of the Albertine Rift of the Western Branch (e.g. Kampunzu, Bonhomme, and Kanika 1998; Aanyu 2010) and the large off-axis volcanoes Elgon and Kilimanjaro associated with the Kenya Rift (e.g. Simiyu and Keller 2001). This structural connection between these two rift branches may be a plausible reason why activity on the Western Branch would influence the rift in Kenya.

In terms of compositional changes over time, Stage I is dominated by basalts and rhyolites. Stage II introduces more complexity with the addition of a recognized volcanic center and the first major phonolite eruption. Stage III shows active phonolite production around the equator with continued basalt production north of 2 degrees. The oldest volcanic center with a carbonatite association, and a narrowing of activity marks the start of Stage IV. A distinct proliferation of trachytes and carbonatites south of the equator is noticeable in Stage V. A distinct change in the number and size of observed events also occurs in this most recent stage, with a large number of small events being seen. One aspect to note in particular, is that the "leading edge" of the rift in Tanzania seems to be 
demarcated by central volcanoes, many of which have a carbonatite component, rather than by flood or fissure volcanics as seemed to be the case in Kenya. This may be due to preferential exposure, or perhaps by changing magma generating environments or crustal character.

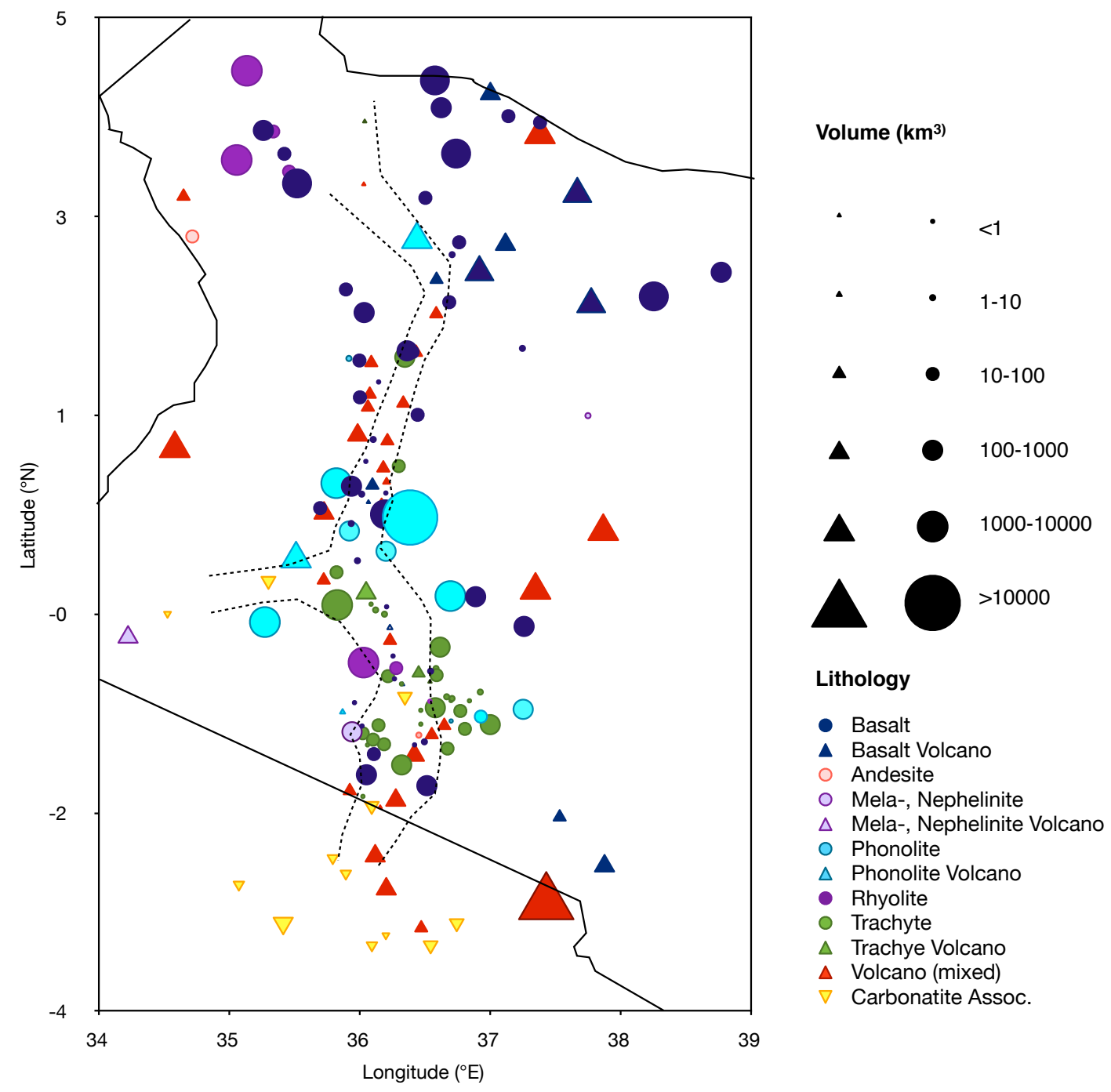

Figure 3.4. Simplified lithology plotted at the centroid for each volcanic units of the Kenya Rift. Dashed lines show the outline of the rift valley from Lake Turkana to the Tanzania Border. Volcanoes that were predominantly a singly composition (e.g. the Chyulu Hills) were plotted as that dominant composition. Symbols have been scaled based on volume of each unit. 


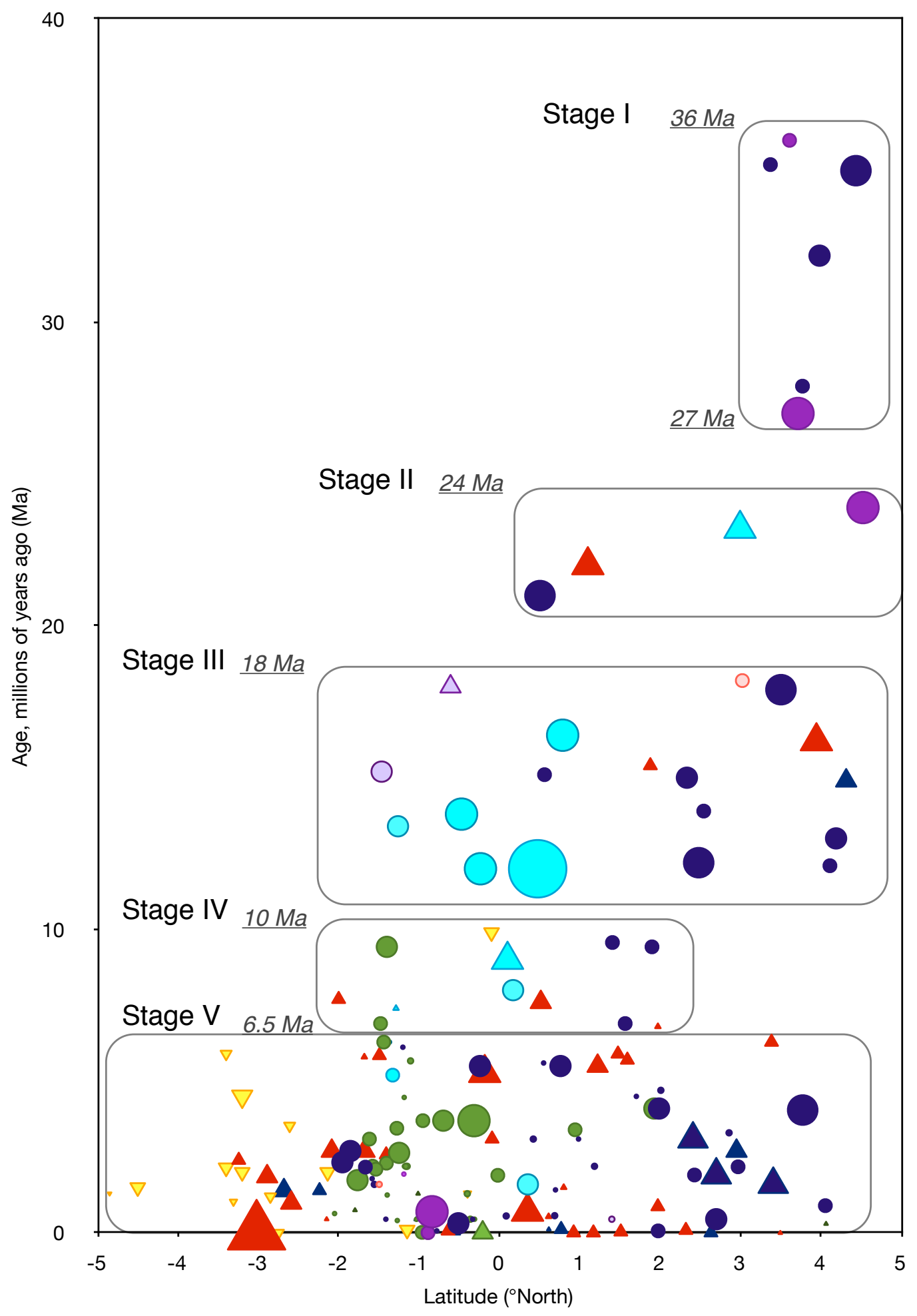

Figure 3.5. Plot of centroid-lithology in a Latitude vs Age dimension. Data groupings are outlined and labeled with Stage numbers to aid in the discussion. Symbols have been scaled to represent erupted volume and are colored by dominant lithology (See Fig 3.4 for legend). 
One thing that should be considered is that, as the Kenya Rift seems to be tracing the Mozambique suture zone (e.g. Chorowicz 2005), and carbonatites seem to have an affiliation with such settings (Burke, Ashwal, and Webb 2003). Carbonatites may have been a "trail blazing" eruptive product that has since been eroded or buried. The concentration of the carbonatite associations near the southern end of the rift may be due to preservation bias; these typically younger volcanoes are readily exposed at the surface and are generally observed in the younger, shallower, rift sections. Given the depths of the northern parts of the rift (Table 2.2), it seems plausible that any pioneering carbonatite products are buried by kilometers of sediments and lavas.

By examining the volume-scaled symbols, it is particularly striking that the frequency of points decreases with increasing age, while the volume per point generally increases. This seems like a good indicator that small-volume flows are not being recognized in the older geologic record due to poor, or lacking, exposure, which may contribute towards a persistent hidden volume problem despite efforts to correct for obscured mapped units.

\subsection{Volume Analysis}

Using the created geologic map, it is possible to extract area information for each formation or unit, and combined with a thickness estimate, volumes can be calculated. For volcanic flows, geometry was estimated to be a simple sheet of even thickness, and volcanic centers were calculated either as cones, similarly to Williams (1972), or isosceles-triangular prisms. Some volcanic centers like the Chyulu Hills, Nyambeni and Hurri Hills have elongated morphologies with a high ridge, rather than a single centralized peak on a roughly circular base. It was determined to be more representative to divide the volcanic centers into two groups based on these differing simple geometries, rather than applying a simple cone morphology to all. 
Thickness data were either obtained from the published literature, or estimated from the available digital elevation models (DEMs). Neither case will give a true representation of the volumes erupted, as the thickness is not likely to be constant over the entire surface area, and estimates from the DEM do not account for subsurface contributions to thickness, nor removal of material due to erosion. It is thus assumed that thicknesses derived from the literature will mostly over-estimate true volume, while estimates from the DEM would under-estimate. Thicknesses used for volume calculations can be seen the attribute table that accompanies the digital shape files.

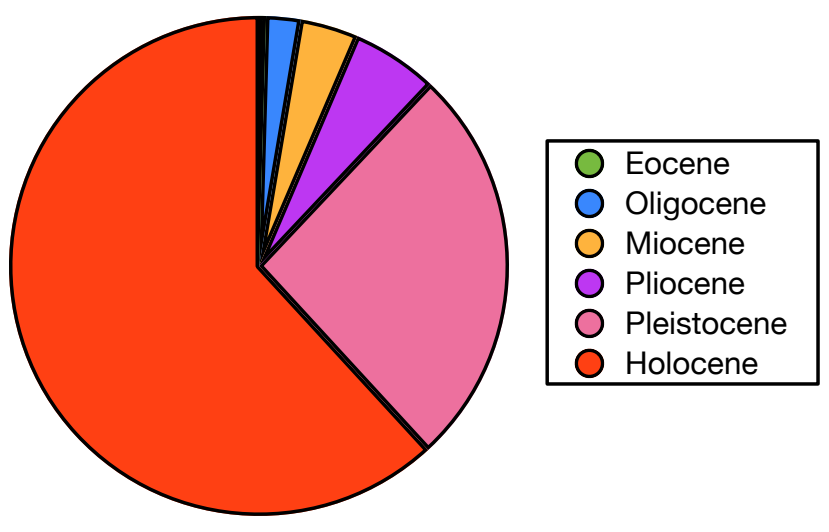

Figure 3.6. Chart showing the relative normalized eruptive rates in $\mathrm{km}^{3} / \mathrm{Ma}$ for different Epochs.

Volumes are calculated using map-based areas of modern surface exposure.
The relative volume erupted during the different geologic Epochs normalized per one million years are shown in Figure 3.6. The data were normalized due to the differing length of time each Epoch spans; without normalizing the data, similar volume plots are dominated by the Oligocene and Miocene, which are also the longest Epochs examined. Un-normalized, the data did not relay any interesting information about eruptive rates, but rather, were mostly indicating that the Oligocene and Miocene were long.

On first inspection, the normalized data in Figure 3.6 seem surprising, as the plot apparently indicates that volcanic activity has been continually increasing through time, with the short Holocene having the greatest normalized volume-rate. This is suspected to be caused by preferential exposure of more recent material. It can easily be seen on the stage-specific geology maps that the rift area is void (Fig. $3.1 c-I)$ until after the Calabrian stage of the Pleistocene. This is the consequence 
of displaying the mapped surface geology by time; many rocks related in lithology and age are found on both the eastern and western rift flanks, and thus logically, exist beneath the recent rift-floor cover. Additionally, the dramatic increase in records of small volume events during the most recent 6.5 million years shown in Figure 3.4 (Stage $\mathrm{V}$ ) also points to a preservation issue regarding the older record.

Better estimates of volume can be obtained by applying the Principle of Lateral Continuity to the mapped units to obtain a maximized volume estimate. Seismic and infrequent well data (discussed below) can then be used as a mapindependent method to evaluate the total volume calculated in this manner.

To adjust for the volume hidden by the rift using the mapped extents, estimated areas were created by correlating related geologic formations across the current rift valley, following Guth (2007). Corrections for rifting related extension were applied to the older formations based on extension amounts in Table 2.2. Accounting for this extension was done by extending the rift-spanning polygons towards the center of the rift valley, but leaving a gap between the two polygons to represent the approximated extension since the time of emplacement. The effect this maximization has on volume estimates can be seen in Figures 3.7 and 3.8. Note that these estimated volumes are used in Figures 3.3-3.5 rather than the volumes calculated directly from the geologic map.

The data in Figure 3.7 are shown as erupted volume per 0.5 or 1 million year time segments. A change in bin-size was chosen due to the decreasing age precision for units older than 7 million years. Eruptive formations that lack specific age dates were assigned to the time division that represented the midpoint of the geologic stage the formation was assigned to. Even without direct age dates, units could generally be assigned to a geologic stage based on stratigraphical relationships. Cumulative volumes since the Eocene are shown in 
Figure 3.8. The additional volume from estimating hidden volumes based on the above description are represented by the red bars and points in Figures 3.7 and 3.8. If utilizing the mapped extents directly, the cumulative erupted volume is calculated at only $50,000 \mathrm{~km}^{3}$, but by estimating original extents of older formations, the maximized cumulative volume is considered closer to 110,000 $\mathrm{km}^{3}$. While area estimates were generally conservative, the effect on cumulative volume was substantial, as evidenced by the difference between the two lines in Figure 3.8 and the resulting total volumes. This estimated value is similar to total volumes obtained by other authors (Baker 1987; Baker, Mohr, and Williams 1972; Williams 1972), and further discussion and comparison is presented in Section 3.3.3 below.

It can be seen in Figure 3.7 that the largest eruptive "event" was likely the eruption of the Miocene phonolites around $11 \mathrm{Ma}$, while the building of volcanic centers like Kilimanjaro, Shompole and Lenderet adds greatly to the early Pleistocene volumes. The aprons of many of these volcanic centers have been buried by more recent eruptions, and many of the more tuffaceous centers have been highly eroded; both factors influence their large contribution towards estimated volume despite being relatively recent. Older events are more likely to have been covered by more recent activity, which is why the proportion of estimated to measured volume generally increases with age. Based on the plotted data, the eruptive activity for the rift is pulsed, with several identified peak periods around 2.5, 11 and 35 million years ago. Secondary peaks are seen at 5 and 18 million years ago. There are very obvious gaps in the record around 21, 25, 29 and 33 million years ago, that last between 2 and 4 million years each. Such gaps may represent missing or obscured data, or may potentially indicate that earlier stages of rift development had longer repose times between periods of volcanic activity. The variable activity shown in Figure 3.7 is in contrast to the steady eruption rate implied by George, Rogers and Kelley (1998) for the Kenya Rift over the last 30 million years. 


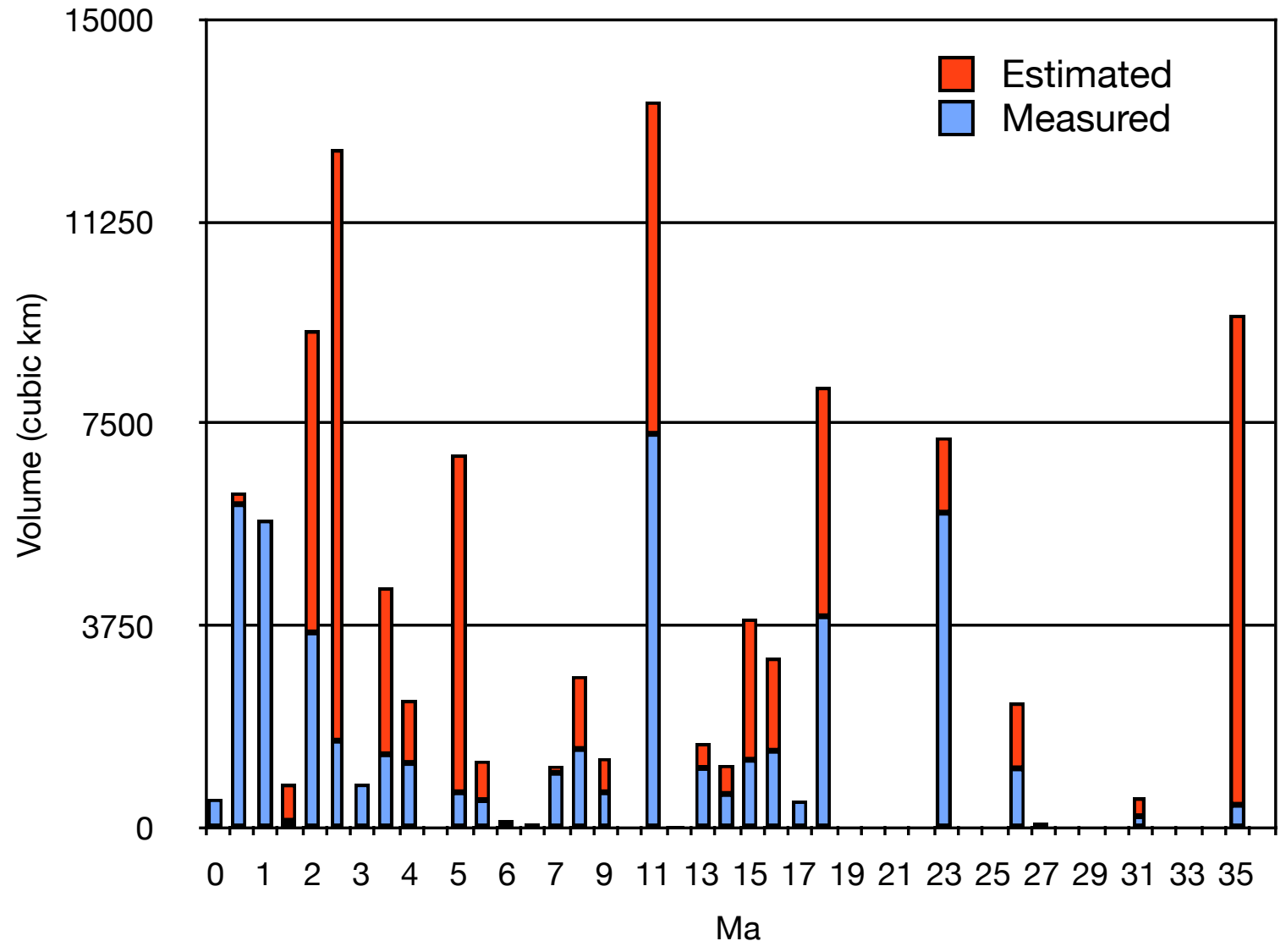

Figure 3.7. Erupted volume over time in the Kenya Rift. Volumes were subdivided for every 0.5 $\mathrm{Ma}$ up to $7 \mathrm{Ma}$, after which volumes are calculated for every $1 \mathrm{Ma}$. Bars with the lower values represent volumes calculated from mapped surface areas. Additional "estimated" volumes represent potential extra volume obscured by more recent material, removed by erosion, or represented by the bulk of a volcanic center.

\section{Cumulative Volume since Eocene}

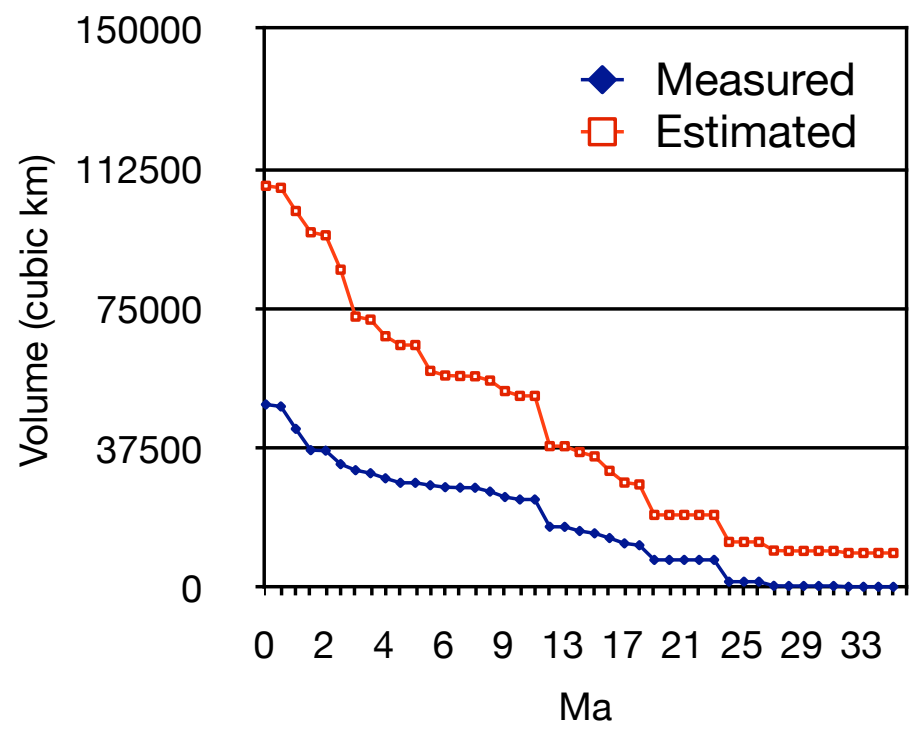

Figure 3.8. Cumulative erupted volume since the late Eocene. The lower line represents volume estimated from measured surface area. The upper series includes estimations to account for burial and erosion of older material. 
The cumulative volume (Figure 3.8) plot can be subdivided into groups by examining the slope (Figure 3.9). "Groups" are used here rather than the "Stages" in Figure 3.5, as the age boundaries are slightly different between the two plots. Using the cumulative curve, the eruptive history can be subdivided into periods of flat (Groups 1 and 4), low (Group 3), medium (Group 2) and high (Group 5) slope. Periods of low slope would be dominated by events that do not appreciably change the cumulative volume. Even though the older events tend to be more volumetric on average, there appears to be too few of the events to drastically change the cumulative volume curve. Group 5, which encompasses the most recent $5.5 \mathrm{Ma}$, contains a large number of small volume events which dramatically affects the plot. While the massive eruptions of the Plateau Phonolites in the mid-Miocene are volumetrically impressive, it seems that the driver of total volume is not the rare large eruption, but rather the accumulation of a massive number of small events. While this could be read as supporting the idea of increasing activity over time as suggested by Figure 3.6, it is more likely that this is a consequence of some sort of preservational or observational bias that skews the older record.

As an alternative to the latitude versus time plot shown in Figure 3.5, the groupings shown in Figure 3.9 can be plotted on a map as a way of showing age progression spatially (Figure 3.10). The symbols represent the Groups shown in Figure 3.9, and no distinction has been made symbolically between volcanic centers and fissure event, in order to highlight the age-based progression.

The overall trends shown in Figures 3.5 and $\underline{3.10}$ are the same. Early activity is relatively constrained to the northern sector of the Kenya Rift, and each successive group extends farther south and east until Group 4. Activity during Groups 3 and 5 shows significant eastward excursions away from the rift valley, but Group 4 only shows activity near the location of the modern rift. Due to the different age divisions between Stages in Figure 3.5 and Groups in Figure 3.9, 
the southern extent for this period of contraction is distinctly different. In this case, Group 4 is narrow longitudinally, but shows southward progression into Tanzania. Both Group and Stage 5 show resumed volcanic expansion to the east, south and north. Again, there is a very clear proliferation of small volume events seen in Group 5 compared to the previous groups.

It is unclear how meaningful these divisions actually are given the discussion on hidden volumes in the next section, however, it is still a convenient way to discuss the observed record by allowing focus on larger-scale trends rather than the noise inherent in considering each event individually.

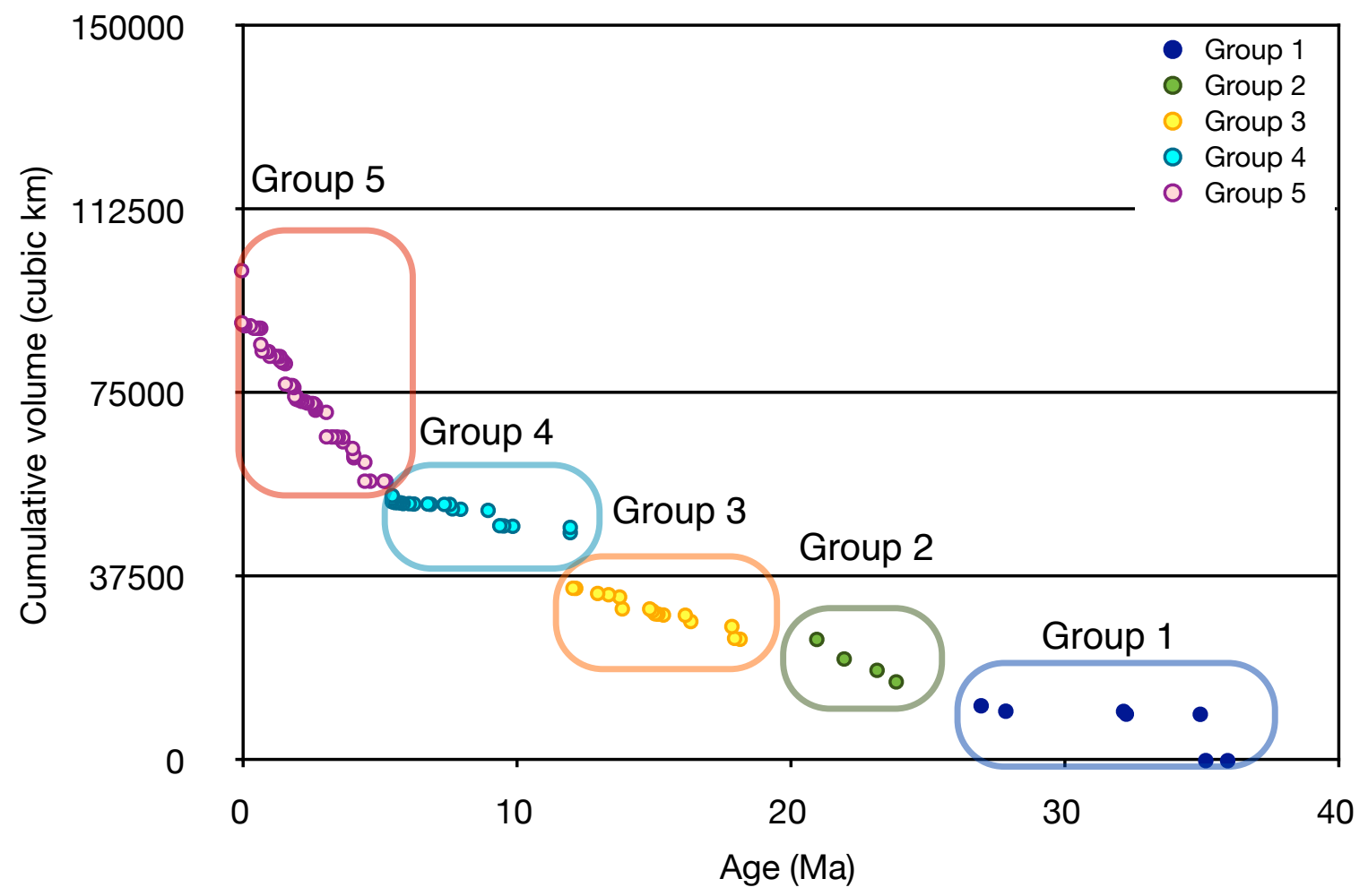

Figure 3.9. Plot showing contribution to cumulative volume over time for each unit's centroid. Groups are based on distinctive slope trends. Note that the time boundaries of the slope defined groups are different than visually distinguished stages in Figure 3.5. 


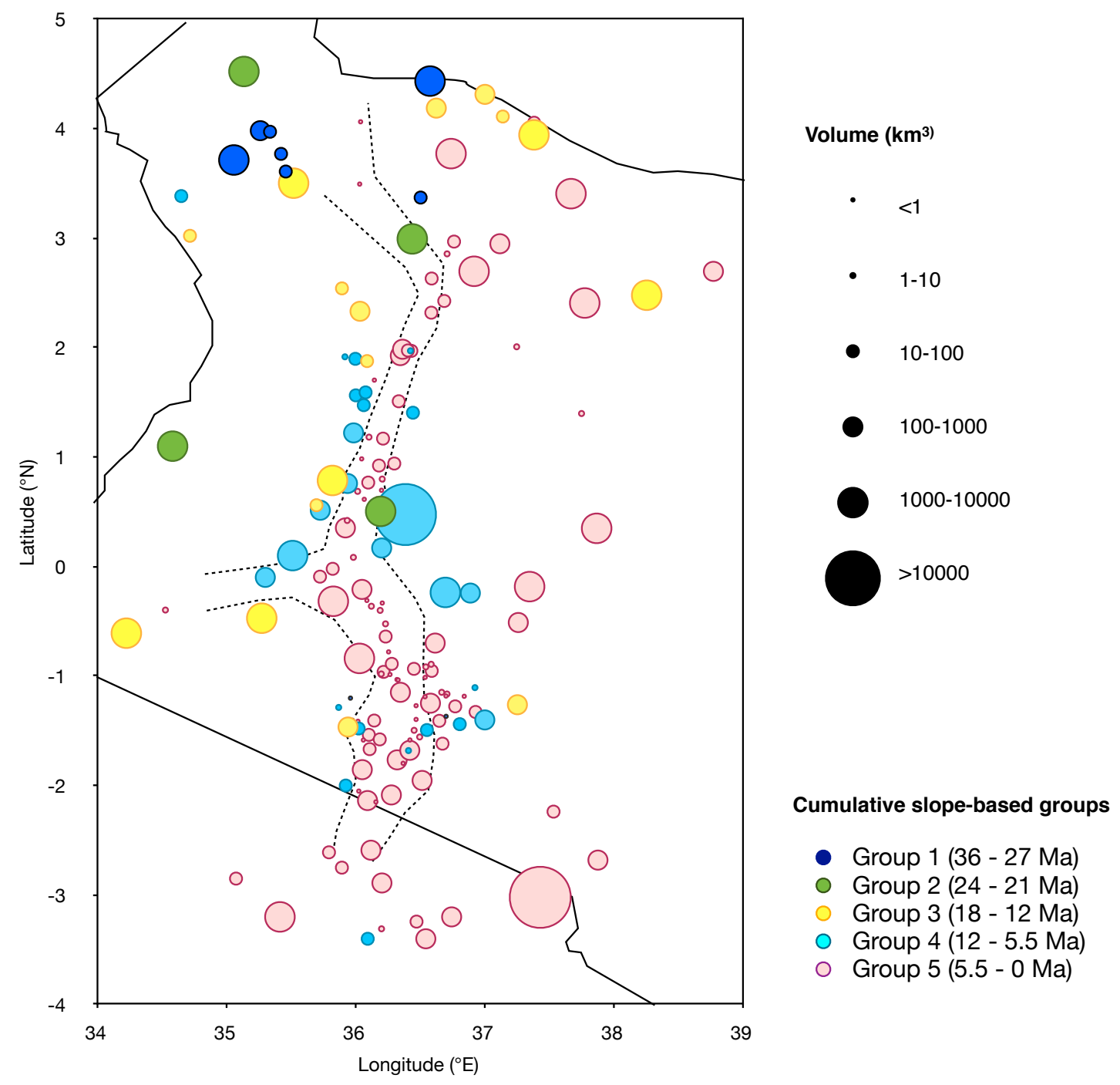

Figure 3.10. Map showing the centroid of each eruptive unit colored by Group, as defined in the previous figure. Symbols have been scaled by eruptive volume.

\subsubsection{Seismically derived thickness estimates}

The previously presented volume calculations and estimates relied on the digitized areas, and a map-independent method of obtaining volume was desired in order to examine the reliability of these methods. In addition to the work present in earlier sections, previously published volume estimates also relied on maps (e.g. Williams 1972). Another way to estimate the rift-related volume is to utilize data from the various large seismic studies of the rift (e.g. the KRISP and 
the EAGLE). While these data are available, for the most part they were not collected at a resolution to distinguish individual volcanic units in the subsurface, and thus cannot be used to constrain unit thicknesses or extents, or to examine volume trends over time. These data can, however, be used to estimate the total thickness of volcanic materials over the crystalline basement in an attempt to further constrain total volume estimates. Future detailed seismic studies, in combination with well data, might allow for better estimates of volume per time by allowing for the correlation of specific seismic horizons with known formations. Computer calculated volumes from 3D seismic models would be a significant improvement, as this would eliminate errors associated with using simplified geometries to model complex basins. At present however, such data are not available for the full length of the rift, however it is still possible to estimate total volume with the data available.

Estimated thicknesses of volcanic material above the metamorphic basement based on seismic data, and the approximate surface area measured from Landsat imagery, are shown in Table 3.1. These thickness and area values were then used to estimate the maximum volume of volcanics within the rift and on the rift flanks, which can be combined to give a total seismic volume estimate. Details regarding the calculations can be found in Appendix $\mathrm{D}$.

Some of the seismic thickness data on the rift flanks is supplemented by borehole data; unlike in the rift valley, the lesser thickness of material on the flanks allows for full penetration of the volcanic layers to the underlying metamorphic rocks. This additional data helps constrain the thickness estimates. For example, Simiyu and Keller (1998) report that a borehole on the Mara Plains encountered 450 meters of lava above the basement near the Oloololo escarpment, and Simiyu and Keller (2001) report that the volcanics near Nairobi reach a thickness of $530 \mathrm{~m}$. 
Volumes for the volcanics within the rift valley were calculated as rectangular bodies, and the thicknesses over the flanks were generally calculated as a triangular wedges. The wedge morphology was used for these estimates as total thickness generally increase towards the rift valley, and thin away from it. One prominent exception is the Yatta Plateau, which runs for an extreme distance $(300 \mathrm{~km})$ away from the rift valley while maintaining a relatively consistent thickness of 12-25 m, likely due to confinement to a paleo-river valley (Wichura et al. 2010). Due to the narrow morphology of the Yatta Plateau, and it's small thickness, this feature was not included in the volume calculations for the flank near Nairobi. The Lokwanamoru High near Lake Turkana was modeled as a flat sheet based on seismic data that suggested no east-west changes in thickness.

Calculations utilizing the seismic data in Table 3.1 indicate a significant cumulative volume that is nearly three times that derived from the map $(310,000$ $\mathrm{km}^{3}$ versus $110,000 \mathrm{~km}^{3}$ ). Additionally, nearly two-thirds of that volume is located in the areas adjacent to the modern rift valley, rather than within it. While the rift basins can be very deep, around 5 kilometers at Naivasha and Suswa, the rift is very narrow compared to the rift flanks. The large volume of material outside the rift valley can be explained by the formation of a pre-rift depression that has been noted by several authors as part of the rift formation sequence (e.g. Baker et al. 1971; King 1978; Clarke et al. 1990). This depression would allow for the significant accumulation of volcanic material observed in the seismic data outside the rift valley. In essence, the rift valley could be conceived as a series of deeper basins superimposed on a shallower pre-rift basin that now comprises the rift's "flanks". The volume contained within that wider, shallower, pre-rift downwarp wins volumetrically over the deeper, but narrow, rift valley. 
Table 3.1. Seismic derived thicknesses of volcanic fill in the rift valley.

\begin{tabular}{|c|c|c|c|c|c|}
\hline & Region & $\begin{array}{l}\text { Rift Region Area } \\
\text { from Landsat }\left(\mathbf{k m}^{2}\right)\end{array}$ & \multicolumn{2}{|c|}{$\begin{array}{c}\text { Seismic } \\
\text { Thickness of } \\
\text { Volcanics }(\mathbf{k m})\end{array}$} & Source \\
\hline \multicolumn{2}{|l|}{ Turkana } & 17200 & \multicolumn{2}{|l|}{1.5} & Morley, Karanja et al. 1999 \\
\hline \multicolumn{2}{|l|}{ Suguta } & 6200 & \multicolumn{2}{|l|}{2} & Dunkley 1993 \\
\hline \multicolumn{2}{|l|}{ Baringo } & 4500 & \multicolumn{2}{|l|}{3} & Dunkley 1993 \\
\hline \multicolumn{2}{|c|}{ Menengai* $^{*}$} & 3600 & \multicolumn{2}{|l|}{2.75} & Simiyu \& Keller 2001 \\
\hline \multicolumn{2}{|c|}{ Naivasha } & 2500 & \multicolumn{2}{|l|}{5} & Simiyu \& Keller 2001 \\
\hline \multicolumn{2}{|l|}{ Suswa } & 2600 & \multicolumn{2}{|l|}{5} & Simiyu \& Keller 2001 \\
\hline \multicolumn{2}{|c|}{ Magadi-Natron* } & 5800 & \multicolumn{2}{|l|}{2.75} & Simiyu \& Keller 1998 \\
\hline \multicolumn{2}{|c|}{ Rift fill volume (km³) } & \multicolumn{4}{|c|}{103050} \\
\hline \multirow{2}{*}{\multicolumn{2}{|c|}{ Flank Region }} & \multirow[t]{2}{*}{$\begin{array}{l}\text { Flank Area from } \\
\text { Landsat }\left(\mathbf{k m}^{2}\right)\end{array}$} & \multicolumn{2}{|c|}{$\begin{array}{l}\text { Fill Thickness } \\
(\mathbf{k m})\end{array}$} & \multirow[t]{2}{*}{ Sources } \\
\hline & & & West & East & \\
\hline \multirow{2}{*}{$\begin{array}{l}\text { West } \\
\text { Turkana } \\
\text { Flank }\end{array}$} & $\begin{array}{l}\text { Lotikipi \& } \\
\text { Gatome basins } \\
\text { Lokwanamoru } \\
\text { High }\end{array}$ & $\begin{array}{l}\text { L: } 9400(80) \\
\text { G: } 12500(65) \\
\text { LH: } 3500(25)\end{array}$ & $\begin{array}{l}\mathrm{L}: 1.5 \\
\mathrm{G}: 4 \\
\mathrm{LH}: 1.5\end{array}$ & $\begin{array}{l}\text { L: } 3.5 \\
\text { G: } 0 \\
\text { LH: } \\
1.5\end{array}$ & Wescott et al. 1999 \\
\hline & $\begin{array}{l}\text { Lokichar \& } \\
\text { Kerio basins }\end{array}$ & $\begin{array}{l}\text { L: } 3000(35) \\
\text { K: } 6800(55)\end{array}$ & 3 & 0 & $\begin{array}{l}\text { Morley, Karanja et al. 1999; } \\
\text { Wescott et al. } 1999\end{array}$ \\
\hline \multicolumn{2}{|c|}{ East Turkana Flank } & $91000(275)$ & 1 & 0 & $\begin{array}{l}\text { Swain et al. } 1986 \text {, } \\
\text { Morley, Bosworth et al. } 1999\end{array}$ \\
\hline \multicolumn{2}{|c|}{ Kinangop Flank } & $42500(200)$ & 3 & 0 & Smith 1994 \\
\hline \multicolumn{2}{|c|}{ Kamasia-Loriu } & $9000(45)$ & 0.7 & 0 & Mugisha et al. 1997 \\
\hline \multicolumn{2}{|c|}{ Uasin Gishu Plateau } & $6500(60)$ & 0 & 1.2 & Mugisha et al. 1997 \\
\hline \multicolumn{2}{|c|}{ Mau Flank } & $14800(75)$ & 0 & 1.5 & Smith 1994 \\
\hline \multicolumn{2}{|c|}{ Nairobi Flank } & $6900(75)$ & $1.25^{\star *}$ & 0.53 & $\begin{array}{l}\text { Saggerson \& Baker } 1965 \\
\text { Simiyu \& Keller } 2001\end{array}$ \\
\hline \multicolumn{2}{|c|}{ Mara Plains Flank } & $8700(75)$ & 1.0 & 0.45 & Simiyu \& Keller 1998 \\
\hline \multicolumn{2}{|c|}{ Rift Flank Volume } & \multicolumn{4}{|c|}{$209,000 \mathrm{~km}^{3}$} \\
\hline \multicolumn{2}{|c|}{$\begin{array}{l}\text { Total Seismic Volume } \\
\text { (Rift Fill + Flank Volume) }\end{array}$} & \multicolumn{4}{|c|}{$310,000 \mathrm{~km}^{3}$} \\
\hline
\end{tabular}

* average of western and eastern depth estimates as basin is asymmetrical

${ }^{* *}$ calculated based on elevation of the sub-Miocene bevel which represents base of volcanics 


\subsubsection{A note on volume estimates; sediments and dense-rock equivalents}

The volumes given in Table 3.1 are considered to be maximum estimates, as the rift fill in seismic density models is often a combination of sediments and volcanics. The overestimation may be less severe than initially suspected however, as much of the sedimentary volume would be derived from the surrounding volcanic terrain. This may, in part, volumetrically balance erosion of volcanic material elsewhere. This assumption is backed by stratigraphic interpretations by Morley, Karanja, et al. (1999) which indicate that the sedimentary sequences overlying the Middle Miocene volcanics west of Lake Turkana are derived primarily from volcanic sources. Sediments underlying the volcanics on the other hand, are arkosic, or contain metamorphic clasts, and are likely derived from the metamorphic basement rocks.

Another additional concern related to calculating volumes are the presence of some very large tuffaceous units that contribute to the calculated, and seismically measured, volumes. Traditionally the volumes of tuffaceous units are computed as a dense-rock equivalent (DRE) in order to account for the decreased density of such rocks. Due to the lack of detailed information for many individual eruptive units, DRE calculations are not feasible at this point. To properly compute a DRE would require information on the density of each tuffaceous unit, which is presently not available. Many of these units have some degree of welding, which is often noted to vary in degree through a unit's thickness, which complicates the matter of accurately determining the DRE. Density measurements made by Simiyu and Keller (2001) on drill cores from the rift show a mean density of 2300 $-2500 \mathrm{~kg} / \mathrm{m}^{3}$, which is in the range of silicic volcanic rocks like rhyolite. In contrast, tephra is more commonly estimated as $1000 \mathrm{~kg} / \mathrm{m}^{3}$ (e.g. Deligne et al. 2010). They did not note any significant thicknesses of very low density as would be expected for a very porous tuff. While DRE calculations for the large pyroclastic and ash-fall units would provide more accurate volume estimates, the 
discrepancy may not be large compared to the volumes shown in Figures 3.7 and 3.8 .

\subsubsection{Volume estimate comparisons}

A number of eruptive volume estimates exist for the Kenya Rift. These estimates, and those derived as part of this study, are shown in Table 3.2 below. The volumes calculated from the digital mapping are in general agreement with other estimates, which were likely calculated in a similar method, but used area measurements from paper maps. The seismically derived volume however is significantly larger than most previous estimates for the Kenya Rift. This either indicates that most of the eruptive volume is hidden beneath more recent volcanics, that there are errors in the seismic thickness estimates, or that the contributions of sediments and tuffs is more significant than expected. Given the great depth of some of the basins associated with the rift however (see Table 2.2), it seems reasonable that a large amount of material may simply be hidden.

Table 3.2. Comparison of erupted volume estimates from different sources for the Kenya Rift

\begin{tabular}{|l|l|}
\hline \multicolumn{1}{|c|}{ Author } & \multicolumn{1}{c|}{ Total estimated eruptive volume } \\
\hline This study & $\begin{array}{l}\text { measured: } 50,000 \mathrm{~km}^{3} \\
\text { estimated max: } 110,000 \mathrm{~km}^{3} \\
\text { Seismic volume: } 310,000 \mathrm{~km}^{3}\end{array}$ \\
\hline Baker, 1987 & $220,000 \mathrm{~km}^{3^{*}}$ \\
\hline Baker, Mohr \& Williams, 1972 & $\sim 113,000 \mathrm{~km}^{3}$ \\
\hline Williams, 1972 & $144,000 \mathrm{~km}^{3}$ \\
\hline
\end{tabular}

* including Northern Tanzania volcanics

\subsubsection{Reconciling seismic and map-derived volume estimates}

Based on a qualitative assessment of Figures 3.5 and 3.10 , there is an apparent change in volume of eruptive over time, where units with volumes over 1000 
cubic kilometers are most likely to be recorded with increasing age. While the data span nearly 36 million years, about $65 \%$ of the plotted centroids represent eruptive activity during the most recent $14 \%$ of that time frame (the last 5 million years).

More quantitatively, Figure 3.11 demonstrates the large distinction between the size-frequency of more recent activity versus the older record. The most recent part of the record shows a very large range in eruptive size, but the small eruptive events drop off quickly with age until around $10 \mathrm{Ma}$. Between 10 and 35 $\mathrm{Ma}$, there are no events that are recognized as being under $10 \mathrm{~km}^{3}$, and for the period between 20 and $25 \mathrm{Ma}$, no events under $1000 \mathrm{~km}^{3}$ are recognized. It is unlikely that all extrusive events were of that size, which points to distinct preservational or observational bias against recognizing the smaller events which dominate the modern activity.

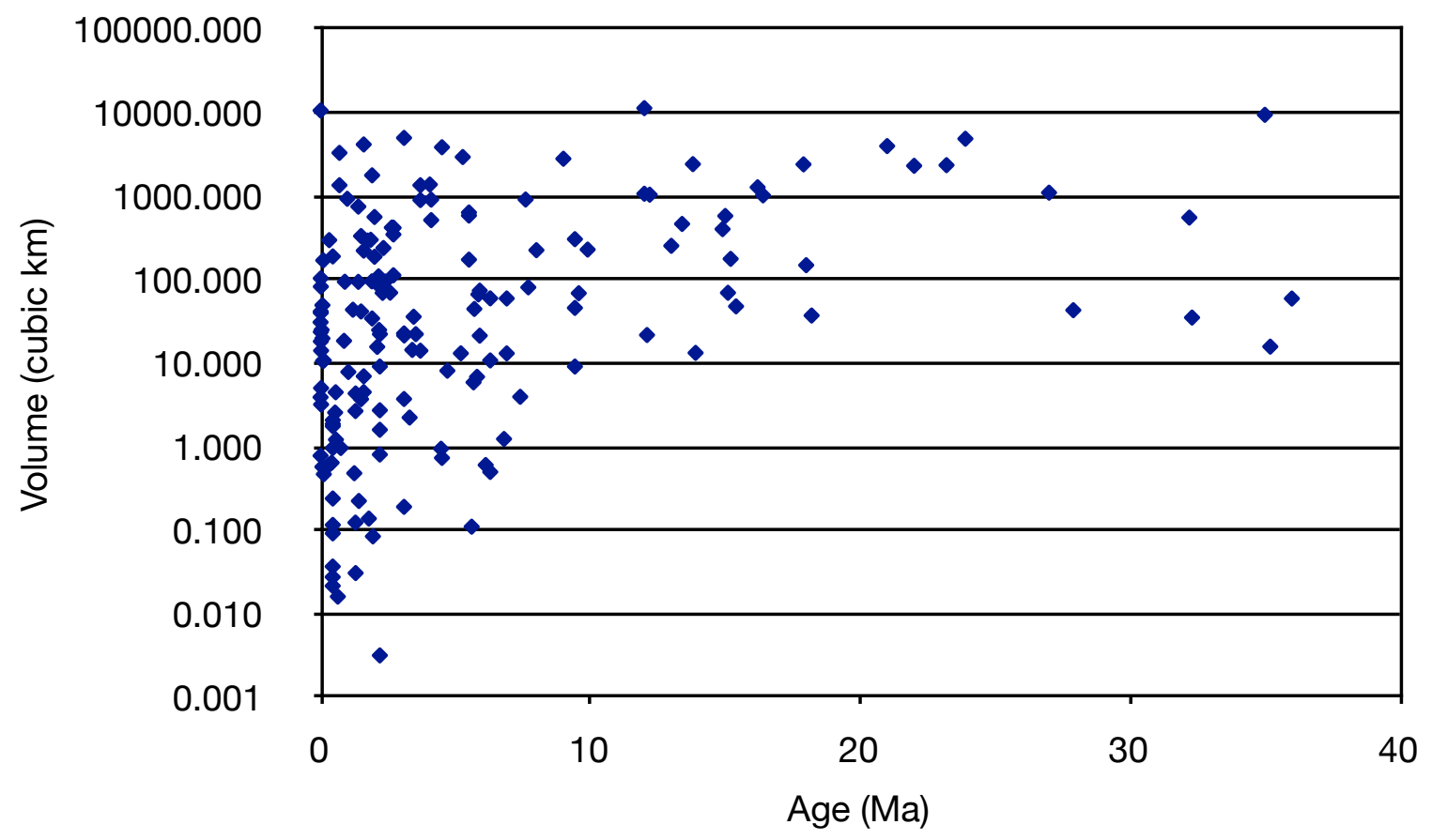

Figure 3.11. Erupted volume of a formation versus age on a semi-log scale demonstrating the decrease in size and number of events with increasing age. 
Given the cumulative volume discrepancy indicated by comparing the map and seismic data, plus the obvious lack of small-volume events shown in Figure 3.11, adjusting the map-based record using modern activity to correct for the "missing" size fraction may allow these estimates to converge. Examining the period over the last five million years, the ratio of volumes erupted by events under $1000 \mathrm{~km}^{3}$ to the volumes erupted by larger events (over $1000 \mathrm{~km}^{3}$ ) is $1: 3$. Considering that the recognition of very large volcanic centers also seems to drop off with age as well, if the large volcanic centers (Kilimanjaro, Nyambeni, Hurri Hills, etc...) are removed from the tally, the contribution of the small eruptions to larger fissure flows becomes 2:1 instead. It may be possible to correct for the perceived bias against small events as age increases if it is assumed is that the small eruptions outnumber the larger eruptions at a ratio consistent with the modern record.

Similarly, the ratio of large volcanic centers to other eruptive products for the last 5 million years is $1.5: 1$. It may be possible that eruptive trends have changed and there simply are factors that lead to the development of these complexes more commonly in the recent record but not the older record. However, there are also factors that decrease the likelihood of recognizing these features as they age. Several large volcanoes observable today have been cut and down dropped by the rifting activity (Aberdare, Ngong Hills, Sambu, Olorgesailie, etc...), and given the depth of some of the basins, it does not seem unreasonable that some older complexes may have been dissected and buried by more recent activity. Additionally, except for the very recent cones, many extinct volcanic centers are highly dissected and eroded despite only being around 2 million years old (e.g. Shompole, Lenderut, Olorgesailie). Gwasi, which is quite old at $18 \mathrm{Ma}$, is barely a topographic high and is only recognizable because it is still exposed at the surface being near Lake Victoria and quite far from the locus of eruptive activity.

Applying the 2:1 ratio to the older large events, based on the volumes erupted prior to 5 million years ago, an additional $115,000 \mathrm{~km}^{3}$ would be expected. 
Combined with the results from the map-based volumes, this excess would bring the total to $225,000 \mathrm{~km}^{3}$. Assuming that the lack of large volcanic centers is indeed a preservation/observation bias, and not reflective of a major change in activity stye, we can apply a similar ratio-based correction by assuming the older activity should model the recent. The erupted volume between 5 and $35 \mathrm{Ma}$ is around $57,000 \mathrm{~km}^{3}$ based on the map-derived estimates. Of that, about 10,500 $\mathrm{km}^{3}$ is recognized to be from large $\left(>2000 \mathrm{~km}^{3}\right)$ volcanic complexes. If we assume that we should expect a similar ratio as observed today, taking into account the volcanos observed, we should expect an extra $60,000 \mathrm{~km}^{3}$.

Modeling the past eruptive history based on the modern record, by way of ratios to products most likely to be preserved, may account for preservation or observation biases. Through such calculations an additional $175,000 \mathrm{~km}^{3}$ from contributions of small events and possible unrecognized volcanic complexes, could be expected for the Kenya Rift. When combined with the volume derived from mapping, a total eruptive volume that is within $10 \%$ of that suggested by the seismic thicknesses is obtained $\left(285,000\right.$ vs $\left.310,000 \mathrm{~km}^{3}\right)$. Collection of new and more detailed seismic data would be important in determining the validity of this ratio-based technique.

Similar biases have also been noted in the historical record, where Deligne et al. (2010) use extreme value statistical methods to examine the likelihood of different sized eruptions being recorded during history. A similar treatment of the data compiled here would be a beneficial avenue to explore.

\subsection{Volcanic pulses and eruptive rate comparisons}

In addition to volumetric estimates for the Kenya Rift, attempts to locate volcanic pulses over time, such as what is shown in Figure 3.7, have also been previously made. In the Northern Kenya Rift, Morley (1999) does this by presenting a plot showing the frequency of age dates versus time. The authors recognize that the 
method is crude, and suggest it is better for showing periods of quiescence. The use of age date frequencies as a proxy for eruptive activity is likely not ideal for the rift. It is, in the opinion of this author, much better to plot eruptive volume over time directly (e.g Figure 3.7), rather than use frequency of age dates. A particular problem with using age dates in this region is that the rift material is not comprehensively dated, with many units poorly constrained or lacking accurate age information totally. At the fall 2012 GeoPRISMS meeting regarding research needs for the East African Rift System, the lack of a good geochronology dataset was brought up repeatedly. While individual outcrops, or sub-basins may be very well dated (usually due to the presence of hominin fossils or artifacts), the coverage is quite poor when the entire rift is considered.

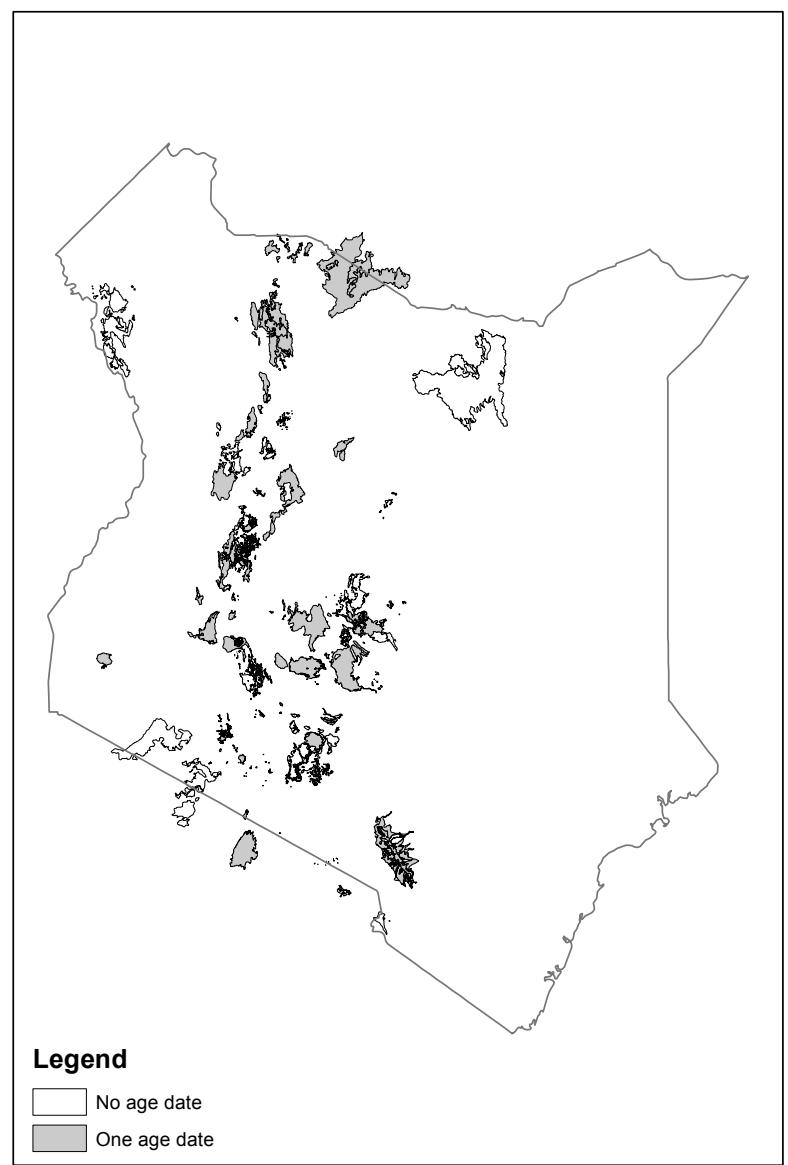

Figure 3.12. Map showing geologic units that lack absolute age information, or are loosely constrained.
To demonstrate this lack of information, a map was created from the digitized data to represent gaps in age dates for the rift related geology (Fig. 3.12). This map shows formations that have either one (considered poorly constrained), or no, associated age dates. Figure 3.12 actually underestimates the problem, as many mapped areas were considered correlative with other units that were age dated, and thus have "inherited" age dates. These situations were not distinguished from units that are actually welldated. As an example of this situation, many of the flows 
associated with the plateau phonolites and trachytes are encompassed by these inherited ages. Given the vast areas covered by these eruptive events, and the individual number of flows within these groups, it is considered likely that the reported ages do not accurately encompass the eruptive duration for these grouped lavas. Another issue not represented in Figure 3.12 is the potential for improving age dates. An example of this is the dating of a phonolite underlying the fossiliferous beds of the Ngorora Formation; K-Ar dating performed in 1985 produced an age of 12.3 $\mathrm{Ma}$ (Hill et al. 1985), but redating the sample using the Ar/Ar step-heating method in 1990 produced an age of $13.24 \mathrm{Ma}$ (discussed in Behrensmeyer, Deino, et al. 2002). Newer age dating techniques could reduce the uncertainty in some ages, and improve the understanding of the timing and duration of certain events.

Keeping in mind the above stated issues with use of age dates, Figure 3.7 can be compared to the data from Morley (1999). There are notable differences in the recognized placement of peaks, as well as the overall shape of the plots. Morley (1999) shows the largest peak at $16-18 \mathrm{Ma}$ and their plot overall could be viewed as representing several periods of increasing activity ramps: 38-24 Ma, 24-10 Ma, and 10-0 Ma. This saw-tooth pattern is not evident in Figure 3.7, however, the periods of supposedly low activity are in general agreement between the two plots, as was postulated by Morley (1999). Overall, the use of age dates as a proxy for volume would likely give a more accurate representation if sampling were either random or very regular. Unfortunately, age dating tends to be very targeted in practice. However, if the seismically derived volume is correct, due to the large ratio of "completely hidden" to exposed volcanic material being near $2: 1$, both methods may miss important periods of volcanic activity, or drastically under represent the activity peaks.

\subsubsection{Eruptive Rates}

From volume and age information, it is possible to estimate eruptive rate, which is one of the more interesting questions relating to volcanically active regions. In 
particular, given the interaction of volcanically derived products and the atmosphere, the question is often whether the eruptions could affect global climates. A large volume erupted over a long time period will have less of an impact on global climate than if the same volume were erupted at a faster rate.

Figure 3.13 attempts to represent eruptive rate for the Kenya Rift, however this figure is fairly crude, as it is essentially the data shown in Figure 3.7 divided by the bin sizes used for that chart. Eruptive rate determinations would benefit greatly from detailed age dating of the most extensive units, as well as an understanding of the "hidden" volcanic volumes indicated in the seismic data (Table 3.1). More comprehensive age dating initiatives could have a profound effect on such estimates, as eruptive rates could be significantly higher if the plateau phonolite group, or Kinangop Tuff, represent short lived eruptive events. As there is very little age control on the subsurface volumes calculated from the seismic data, such data are not included in Figure 3.13, but could obviously have a significant impact.

With regards to large events that have the potential for significantly impacting rate estimates, the Kinangop tuff and Plateau Phonolites are two to consider. The Kinangop Tuffs were likely erupted sometime in the range between 3.4 to $3.7 \mathrm{Ma}$, and represents at least $1,300 \mathrm{~km}^{3}$ of material (not corrected to represent DRE, see earlier section). Erupted as a single event like a Yellowstone Lava Creektype event (1000 km³ DRE, USGS) would represent a significant rate, and may have impacted global climate. The eruption of $1000 \mathrm{~km}^{3}$ of material as a single event would be an 8 on the volcanic explosivity index (VEI) which would, at the very least, dramatically affect nearby landscapes. Baker, Mitchell, and Williams (1988) estimate the minimum volume of the Kinangop Tuffs to be closer to $4000 \mathrm{~km}^{3}$, and estimates for the total volume of ignimbrites erupted by the Kenya Rift during the Pliocene are as high as $10,000 \mathrm{~km}^{3}$ (Smith 1994; Williams 1972). However, the absolute number and size of the individual events the comprise 
these suggested volumes is not presently known. Similarly, the eruption rate for the plateau phonolites could reach those similar to some basaltic large igneous provinces if the phonolites were erupted over 100,000 years. Most of the age dates for these flows are older (from the 1960's-1970's) and have significant uncertainty (200-700ka) based on data from Baker et al. 1971. A comprehensive dating initiative for the flows of the Plateau Phonolite group using new techniques could greatly help in understanding the rate at which flows were erupted.

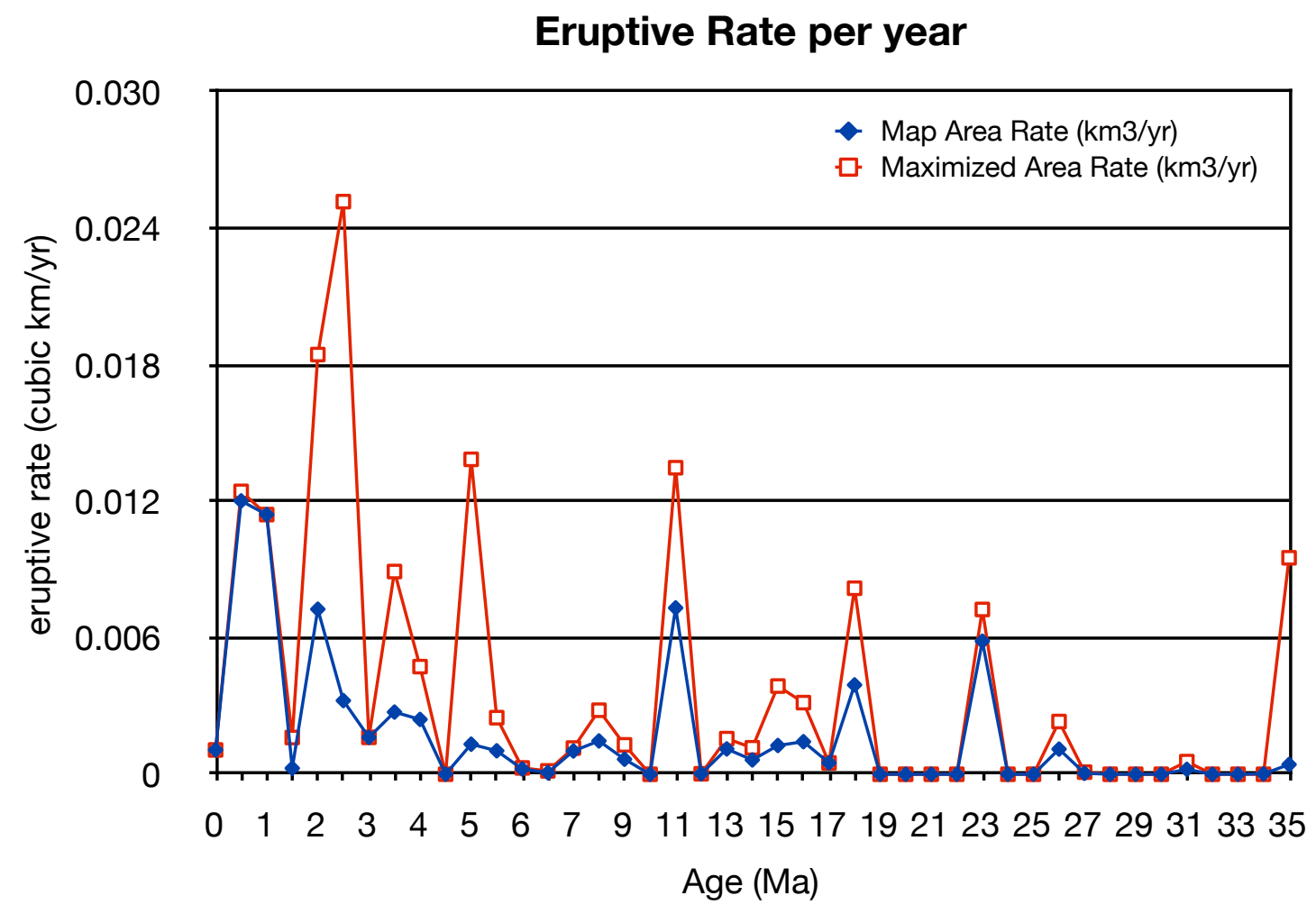

Figure 3.13. Plot showing estimated eruptive rates in cubic kilometers per year over time in millions of years. Blue filled diamonds uses the volume data measured directly from the mapped areas. Red hollow squares use the volume estimates that include subsurface extents for various units.

Rate estimates for East Africa are present by George, Rogers, and Kelley (1998) for the last $50 \mathrm{Ma}$, however, they indicate that Kenya eruptive rates have held steady over the past $25 \mathrm{Ma}$ at $0.015 \mathrm{~km}^{3} / \mathrm{yr}$. While more constrained ages for the largest units would give a better picture than Figures 3.7 and 3.13 , it seems obvious that current evidence does not indicate an eruption steady-state since 
the initiation of rifting. The data presented here, however crude, indicate that the eruptive rate seems to have been highly variable since the start of surface volcanism in the Eocene, with the possibility that short periods of greater eruptive rate are not recognized with the available information.

\subsubsection{Comparisons with other large eruptive events - LIPs and SLIPs}

The eruptive rates shown in Figure 3.13, are quite low compared to recognized rates from the world's large igneous provinces (LIPs). This is due to a relatively small volume (comparatively) erupted over a duration of $35 \mathrm{Ma}$. Volumes and maximum eruptive rates for various LIPs are shown in Table 3.3 below. The "Max eruptive rate" is based on the fastest outpouring given in the cited sources. The average rate over the entire life-span of the active region may be significantly lower than the value given.

While most geologists will be familiar with the basalt-dominated LIPs, Bryan et al. (2002) define a silicic LIP (SLIP) as one that is over $75 \%$ silicic compositions (dacite to rhyolite) and has significant volume contributions from ignimbrites. Two SLIPs recognized by Bryan et al. (2002) related to continental breakup processes are the Whitsunday and Chon Aike volcanic provinces, in Eastern Australia and South America respectively. These are composed of over $80 \%$ intermediatesilicic volcanic products. Unlike mafic LIPs, that often have short emplacement durations, the SLIPs seem to represent much long emplacements on the order of $40 \mathrm{Ma}$.

Bryan et al. (2002) argue that only end members representing the mafic dominated LIPs and silicic dominated SLIPs are observed in the geologic record. These authors suggest that there are no large volcanic provinces with approximately equal distributions of mafic and silicic eruptives. However, they do not seem to consider the Kenyan volcanism, which does not seem to fit these end-member categories. 
Table 3.3. Estimate volume of various continental flood basalts in comparison to the Kenya Rift

\begin{tabular}{|l|c|c|c|l|}
\hline $\begin{array}{c}\text { Continental Flood } \\
\text { Volcanism }\end{array}$ & Age (Ma) & Volume (km³) & $\begin{array}{c}\text { Max. eruptive } \\
\text { rate (km/yr) }\end{array}$ & \multicolumn{1}{|c|}{ Sources } \\
\hline $\begin{array}{l}\text { Mid-Continent Rift } \\
\text { System }\end{array}$ & 1100 & $2,000,000$ & - & Vervoort et al., 2007 \\
\hline Siberian & 250 & $4,000,000$ & 4 & Black et al. 2012 \\
\hline Karoo-Ferrar & $183-184$ & $2,000,000$ & 0.4 & $\begin{array}{l}\text { Heinonen 2010 } \\
\text { Riley \& Knight 2001 }\end{array}$ \\
\hline Deccan & $65-66$ & $2,000,000$ & $0.9+$ & Sen 2011 \\
\hline Ethiopia Flood Basalt & $26-31$ & 250,000 & $0.2-0.3$ & Beccaluva et al. 2009 \\
\hline Columbia River & $0.07-16.5$ & 234,000 & 0.17 & Camp et al. 2003 \\
\hline Rio Grande Rift & $0-40$ & $25,000-100,000+$ & - & $\begin{array}{l}\text { Baldridge et al. } 1991 \\
\text { Keller et al. 1991 }\end{array}$ \\
\hline Ethiopian Rift & $0-35$ & 345,000 & - & $\begin{array}{l}\text { reported in WIlliams } \\
1972\end{array}$ \\
\hline SLIP(?): Kenya Rift & $0-35$ & $110,000-310,000$ & $0.014-0.025$ & this study \\
\hline $\begin{array}{l}\text { SLIP: Whitsunday } \\
\text { Volcanic Province } \\
\text { (Eastern Australia) }\end{array}$ & $100-130$ & $100,000-1,500,000$ & $0.02-0.04^{*}$ & Bryan et al. 2002 \\
\hline $\begin{array}{l}\text { SLIP: Chon Aike } \\
\text { Province (South } \\
\text { America/Antarctica) }\end{array}$ & $153-188$ & 230,000 & 0.013 & Bryan et al. 2002 \\
\hline
\end{tabular}

* total volume was listed as $1.5 \times 10^{6} \mathrm{~km}^{3}$, erupted between $132-95 \mathrm{Ma}$, lower rate has a crude DRE applied (multiplied by 0.6 ), as much of that volume was in sedimentary basins.

The volumetric estimates for the Kenya Rift straddle a revised minimum volume requirement of $250,000 \mathrm{~km}^{3}$ for qualifying as a SLIP (Bryan 2005). In making the case for similarity between the Kenya Rift and this other brand of volcanic province, like the Chon Aike province that is associated with the emplacement of the Karoo and Ferrar LIPs, the Kenya Rift volcanism is related temporally and spatially to the Ethiopian flood basalts, a mafic LIP. Again too, Bryan et al. (2002) note that the two SLIPs listed in Table 3.3 are closely associated with zone of previous subduction and hydrous melting, which is similar to Kenya, where the 
rift follows the ancient subduction zone of the Mozambique Belt. The Kenya volcanism has also spanned approximately $35 \mathrm{Ma}$, which is considered by Bryan et al. (2002) to be a characteristic of SLIPs, in contrast with the geologically short durations of some of the mafic LIPs.

However, unlike the SLIPs, which are defined as having a mafic:silicic ratio of $1: 3$ (Bryan et al. 2002), the Kenya rift has long been recognized as having a near equal ratio, as Williams (1972) calculated a ratio of 1.3:1. Composition results from this study (excluding "mixed" volcanics) place the ratio of mafic to silicic eruptives for the Kenya Rift at a nearly balanced 0.9:1. Looking at the most recent 5 million years, the ratio is slightly more silicic, with a ratio of $0.84: 1$. Even though the large amount of buried rift volcanism indicated in the seismic data is not counted towards this ratio due to unknown composition, it is considered unlikely that hidden volume would skew the composition ratio into either the SLIP or LIP end member categories. The earliest eruptions during the Eocene emplaced both basalts and rhyolites in close proximity during a short time (e.g. the 35 Ma Lokitaung Sequence). Both basalts and more silicic products have continued to be erupted since. Unless there was a drastic change in eruptive character, and all eruptive products of such an episode were buried, it seems defendable to suggest that the hidden volume represents a near equal ratio of mafic to intermediate/silicic material.

Rifting within continental settings is generally recognized to produce volcanic compositions that are alkaline and bimodal (e.g. Bryan et al. 2002; Ayalew et al. 2002). A paper by Corti (2009) on the Main Ethiopian Rift (MER) mentions eruptions of basalts and more silicic products (trachytes, rhyolitic ignimbrites, etc...) after the eruption of the $30 \mathrm{Ma}$ flood basalts. However, no estimates for the relative percentage of mafic:silicic products in the MER overall seem to be available. This ratio has been noted to change though, with an increase in the prevalence of basalt towards the Afar, with fissural basalts being more common 
in the Afar than silicic eruptives. The exact relationships don't seem to be well quantified, with some estimates suggesting $90 \%$ rhyolite for some regions of the MER but others suggesting $60 \%$ basalt for other regions (Abebe et al. 2007).

To compare with a much older continental rift, the Proterozoic Mid-continental Rift System seems to be much more basaltic and voluminous than what is seen in Kenya. Again, this continental rift has a bimodal composition as there are associated rhyolites, which is quite evident by looking at the dominant clasts within the Copper Harbor Conglomerate, which is a basal, alluvial fan rift fill (e.g. Elmore 1983). A rhyolitic ignimbrite that is at least $90 \mathrm{~m}$ thick has been found below what might be a representative of the Copper Harbor Conglomerate seen in the St. Amor well (Ojakangas and Dickas 2002). The overall ratio of mafic to silicic material for the whole rift is not well constrained, however the rift volcanics along the North Shore of Lake Superior have been determined to be around 25\% rhyolite (Vervoort et al. 2007). Assuming there are no "hidden" silicic products at depth or by virtue of being unrecognized (trachytes and phonolites are both visibly dark, but are more silicic than basalt), it appears that the Kenya Rift is significantly more silicic than the Keweenaw rift volcanics. Similarly, the Rio Grande Rift's recent record is noted to be dominantly basaltic with some basaltic andesite and rhyolite (Keller et al. 1991).

Regarding potential impacts on global climate, George, Rogers, and Kelley (1998) argued that the eruptive rates associated with the EARS was too low to have any significant effects. However, the main comparison seemed to be with the very large mafic LIPs. Given the larger volume of intermediate and silicic volcanism present in the Kenya rift, and the presence of voluminous ash and ignimbrite deposits, there is the potential that eruptions may have had enough energy to loft volcanic materials into the upper atmosphere. This could increase the odds of Kenyan volcanic activity affecting the global climate, if even for a short period. Seeing that the eruptive nature of the Kenya rift is quite different 
than a typical LIP, it seems prudent to compare this region against SLIPs instead, and to recognize the implications of eruptions with different silica compositions. More studies on the large ignimbrites especially, would be useful in understanding the explosive history of this region. Melt inclusion studies could also be a benefit in this region by allowing estimates of parental magma volatile contents.

\subsubsection{Volcanic mass flux \& comparisons with other systems}

Instantaneous rates would be important for understanding the potential impact on climate, however total fluxes are easier to derive, as they remove much of the uncertainty associated with lack of age dates or poor information regarding the ignimbrites. Such values also allows for comparisons with other systems, as other than the massive large igneous provinces, maximum fluxes are often unknown. Seismic volume estimates indicate a volumetric flux of $310,000 \mathrm{~km}^{3}$ over 35 million years, or $0.0088 \mathrm{~km} 3 / \mathrm{yr}$, for the Kenya Rift. The eruption rate had previously been estimated at 0.006 km³/yr (Baker 1987; George, Rogers, and Kelley 1998) for Kenya and Northern Tanzania based on total volume reported in Baker (1987).

This volumetric flux can be converted into a mass flux by estimating the density of the different rock groups. Given the argument outlined previously regarding the use of the most recent, well preserved record, the eruptive products are $46 \%$ basaltic and $54 \%$ intermediate to silicic. This is slightly more silicic than if the entire record based on the mapped area is used, and previous estimates for the Kenya Rift suggested mafic percentages of $68 \%$ (reported in Baker 1987) and $57 \%$ (Williams 1972). Results of these calculations can be seen in Table 3.4 below.

The volumetric flux at Kenya is about an order of magnitude less than the maximum rate for Kilauea Volcano, Hawaii which has been estimated at 0.09 
$\mathrm{km}^{3} / y e a r$ during times when an open conduit forms and allows for free access between source and surface (Dvorak and Dzurisin 1993). However, activity was essentially identical to the long term Kenya average at Kilauea between the years 1840 and 1950, where eruptive volume was estimated at $0.009 \mathrm{~km}^{3} / \mathrm{year}$ (Dvorak and Dzurisin 1993).

Table 3.4: Calculations of mass flux for the Kenya Rift.

\begin{tabular}{|l|c|c|c|c|}
\hline \multicolumn{1}{|c|}{ Classification } & $\begin{array}{c}\% \\
\text { eruptives }\end{array}$ & $\begin{array}{c}\text { Density } \\
\left(\mathbf{g} / \mathbf{c m}^{3}\right)\end{array}$ & Mass (kg) & Mass Flux (kg/yr) \\
\hline $\begin{array}{l}\text { Mafic: basalts, } \\
\text { nephelinites, } \\
\text { melanephelinites }\end{array}$ & 46 & 3.0 & $4.26 \times 10^{17}$ & $1.22 \times 10^{10}$ \\
\hline $\begin{array}{l}\text { Silicic: Phonolite, } \\
\text { Trachyte, Rhyolite }+ \\
\text { the mixed volcanics }\end{array}$ & 54 & 2.6 & $4.37 \times 10^{17}$ & $1.25 \times 10^{10}$ \\
\hline Totals & 100 & & $8.63 \times 10^{17}$ & $2.47 \times 10^{10}$ \\
\hline
\end{tabular}

Given that the Hawaiian chain is typically considered a hot spot system, and continental rifting may lead to oceanic ridge formation a comparison to the spreading ridges was also made. The magmatic flux at ocean ridges over the last $80 \mathrm{Ma}$ is has been estimated at $18.1 \mathrm{~km} 3 / \mathrm{yr}$ (Cogné and Humler 2004). Assuming that the density of the erupted basalt is $3.0 \mathrm{~g} / \mathrm{cc}$, the resulting mass flux of $5.43 \mathrm{x}$ $10^{13} \mathrm{~kg} / \mathrm{yr}$. This volume is erupted over a distance that is significantly longer than the Kenya rift, which makes direct comparisons undesirable. To put these different systems on equal footing, so to speak, the mass fluxes were normalized by length. Results can be seen in Table 3.5 below.

Table 3.5: Calculations of normalize mass flux for the Kenya Rift and comparison sites.

\begin{tabular}{|c|c|c|c|}
\hline System & Mass Flux (kg/yr) & Length (km) & $\begin{array}{c}\text { Normalized Mass Flux } \\
(\mathbf{k g} / \mathbf{y r}-\mathrm{km})\end{array}$ \\
\hline Kenya Rift & $2.47 \times 10^{10}$ & 800 & $0.03 \times 10^{9}$ \\
\hline Mid Ocean Ridges & $5.43 \times 10^{13}$ & 60,000 & $0.9 \times 10^{9}$ \\
\hline $\begin{array}{l}\text { Gakkel ridge* (Arctic } \\
\text { Ocean) }\end{array}$ & $1.35 \times 10^{11}$ & 1,800 & $0.075 \times 10^{9}$ \\
\hline
\end{tabular}


* Mass flux for the Gakkel ridge is calculated based on a set of assumptions discussed below.

The normalized rate per year at Kenya is 30 times less than what is seen at the Mid Ocean Ridges taken as a whole. While likely coincidental, this difference in rate is similar to comparing the volumetric rates of the Ethiopian flood basalts and the Kenya volcanics. Both "events" have approximately the same volume (see Table 3.3), however the flood basalts were erupted over only 1 million years while the Kenya volcanics were erupted over 35 million years.

Given that both the Kenya Rift and the oceanic ridges are extensional, whereas the Ethiopian flood basalts pre-date spreading in East Africa, the various spreading rates should also be taken into account in this discussion. The average spreading rate for all the mid-ocean ridges is $\sim 26 \mathrm{~mm} / \mathrm{yr}$ (Cogné and Humler 2004), which is 6.5 times the rate currently seen in Kenya. While that would leave the expectation that the mid-ocean ridges should be more productive than the Kenya Rift, there is still a significant production discrepancy even if the mass flux associated with Kenya were scaled up based on the difference in spreading rate.

There is, however, a wide range of spreading rates exhibited by the oceanic ridges, and the fastest ridges are associated with plates having subducting margins (e.g. the East Pacific Rise). Comparing the Kenya Rift with a ridge spreading at a more similar rate, and associated with a non-subducting plate, would be more ideal. While no ridge is spreading as slowly as what is seen in the modern Kenya Rift, the "ultra-slow" Gakkel ridge in the Arctic Ocean is the closest, as it is spreading at a rate of only $8-13 \mathrm{~mm} / \mathrm{yr}$ (Dick, Lin, and Schouten 2003). No mass fluxes are given for this ridge, but if it is assumed that all erupted volume is translated into extension (this ridge lacks transform faults), the annual volume would be approximately $0.045 \mathrm{~km}^{3} / \mathrm{yr}$. Assuming a wholly basalt composition and a density of $3.0 \mathrm{~g} / \mathrm{cc}$ gives a mass flux of $1.35 \times 10^{11} \mathrm{~kg} / \mathrm{yr}$, and normalized to ridge length provides a value of $7.5 \times 10^{7} \mathrm{~kg} / \mathrm{yr}-\mathrm{km}$. This is only 
about 2.5 times that of the Kenya Rift and is quite similar to the difference in spreading rate between the two systems. The calculation of mass flux for the Gakkel ridge depended on the given spreading rate, however the Kenya estimates were based on the seismically suggested volume, so observed extension did not factor in that rate calculation. The importance of this correlation, if any, is not known at the present time. Recent evidence also indicates that the Gakkel ridge may behave quite differently than faster spreading ridges, as deep sea pyroclastic material found at depths of 4,000 meters suggests a 10-fold higher concentration of carbon dioxide in the basaltic magma (in order to induce fragmentation at such high pressures) than previously observed in mid-ocean ridge basalts (Sohn et al. 2008).

While the Kenya Rift is not too dissimilar from an modern "ultra-slow" spreading ridge in terms of mass-flux, there are no tell-tale signs as to whether a continental rift will successfully proceed to an oceanic ridge. Ziegler and Cloetingh (2004) examined rift evolution for a number of failed and successful rifts, but characteristics of both sets were very similar. Both show a huge range in rifting duration prior to either failure or initiation of spreading, were some rifts fail in only 7.5 Ma, but others rift for $210 \mathrm{Ma}$ before failing (the West Shetland Trough). Alternatively, rifts can proceed to sea-floor spreading in anywhere from 9 to 280 million years after rifting begins. Magmatic and amagmatic rifting examples are also present in both. While plume interactions may enhance magmatic activity of a rift, and serve to thermally weaken the crust, it does not guarantee the successful progression to an oceanic basin. Additionally, in both cases, some rifts experience doming as part of the process, but many do not.

\subsection{Chapter Conclusions: spatial, temporal \& volumetric trends}

Mapped surface areas can be used to estimate eruptive volume, however, seismic data indicates this map-based techniques may underestimate total volume by a significant factor. In this region it is possible to converge on the 
seismically derived volumes by modeling past activity so that it matches the more recent, better exposed, record. The total volume associated with the Kenya rift, its eruptive duration, high content of silicic products, and presence of large ignimbrites, may warrant considering this region as a SLIP in progress. However, with near equal ratios of mafic to silicic products, a mid-member classification may be needed for the SLIP-LIP paradigm. The prevalence of large explosive eruptions in the rift's geologic record may indicate, despite the lower overall eruptive rate compared to a mafic LIP, an enhanced potential to impact climate due to increased injection of ash and aerosols higher into the atmosphere. The Kinangop Tuff may rival the Yellowstone Lava Creek eruption, but at present, the chronologic data is not sufficient to assess the actual scale of the Kinangop eruptions. Importantly, the potential sulfur release of these large eruptive events is unknown, and work by Head et al. (2011) indicates that melt inclusions may significantly underestimate sulfur fluxes in some systems. 


\section{Lake and hominin site distributions from Miocene to present in the Kenya Rift}

The timing of the rifting in East Africa overlaps with the evolution of our own species. This leads to the intriguing question of what, if any, effect did the volcanism have on the distribution of the rift-dwelling human ancestors. The objective of this chapter is to examine the spatial and temporal relationship between the volcanic record of the Kenya Rift and the distribution of hominin sites. This mid-level case study requires the compilation of hominin ${ }^{1}$ data for the rift in order to begin making comparisons against the volcanic data from the previous chapter. As hominin remains are intimately associated with the rift lake basins, lake histories also need to be considered in order to examine the relative impacts of the presence of lacustrine environments versus eruptive events.

The separate, but related, hominin and lacustrine data sets must thus be created to examine the desired question. This chapter is divided into two main sections to facilitate this goal. The first section will deal with the climate and lake evolution of the Kenya Rift. Comparisons between the lake and volcanic data will be discussed independently of the hominin data, which will be introduced in the second main part of this chapter.

\subsection{History of Lake Sedimentation in the Kenya Rift}

For the purposes of comparing lake history records with the rift related volcanism for a mid-level case study, the data need not be very detailed. Attempting to understand the fine-scale patterning of lake level changes, and trying to link those to climate, however, is very difficult. Many aspects of the rift system itself affect lake levels and lake development, externally from climate. The uplift of the East African Plateau, rift related volcanism, and extension driven faulting, are all

\footnotetext{
1 "Hominin" is used here to mean any human ancestor that evolved after the split from the Chimpanzee lineage. See Definitions on page ix for description of Hominin/Hominid term usage.
} 
aspects of the rifting process that influence drainage patterns as well as altering local (possibly even global) climate. The discussion presented below regarding the history of lacustrine deposition in the Kenya Rift is largely presented independently of control mechanism. Due to the complexities of the rift, the patterning of lake distribution presented in this chapter should not be read to represent changing climate. Such determinations require careful, detailed, basinscale studies.

Similarly to the geologic maps for Kenya, many sedimentary histories have been worked out for individual basins, but are scattered amongst numerous journal articles. While not strictly necessary to address the proposed question regarding the potential relationship between hominins and volcanic emplacements, the overall history of the Kenya lakes will be presented. Patterns of lake distribution in the Afar since the Miocene were synthesized and presented by Gasse (1990), and a similar treatment for the Kenya Rift would serve as a useful catalogue of information. Pickford (1994) presents a brief outline of the depositional history of the Kenya Rift from Miocene to present, however newer research allows for more detailed discussion and extends the depositional history to the Oligocene.

To support the lake data, a discussion regarding the controls on climate is provided as a general background, followed by lake data themselves and an outline of the lacustrine history. These data are then presented as plots which allow for comparison with the volcanic data from Chapter 3 , and with the hominin data presented in section 4.2 of this chapter.

\subsubsection{Basics of Climate in the Rift}

While tables 2.1 and 2.2 outline the topographic and structural distinctions between the Western and Eastern branches, there are also important differences in climate and volcanic character between the two branches of the East African Rift System (EARS) that are not encompassed by that data. The Eastern Branch 
is generally recognized to have shallower lake basins with a more active volcanic history, while the Western Branch is occupied by deep lakes and less extensive volcanism. The difference in climate is driven by the topography of the dome that these rift valleys encircle (Fig. 2.2). In particular, moist air from the Atlantic is blocked from the Eastern Branch by the elevated dome, and rains out over the Western Branch. Similarly, much of the moisture from the Indian Monsoons generally rains out over the eastern rift flank rather than within the rift valley (e.g. Brachert et al. 2010; Sepulchre 2006; Pickford 1994). The rainshadow effect occurs on several scales, with the large scale effects being associated with the overall elevation high of the dome, but smaller scale effects are caused by the elevated rift flanks (see Figure 2.2c). This results in much more rain falling on the flanks of the rift valleys than on the rift floor. Around Lake Albert (Northern Western Branch), the rift flank receives $1500 \mathrm{~mm} / \mathrm{yr}$ while the rift floor receives less than $800 \mathrm{~mm} / \mathrm{yr}$ (Brachert et al. 2010). Lake Magadi, on the rift floor of the Eastern Branch, received an average of $475 \mathrm{~mm}$ between the years 2001-2007 (Chimoyi 2009), while Nairobi, situated on the eastern flank, has received an average of $900 \mathrm{~mm} / \mathrm{yr}$ over the past 50 years (Kenya Meteorological Department 2012). The deeper lakes in the Western Branch are likely caused by a combination of increased rainfall relative to the Eastern Branch, plus the fact that more basin space is available for water due to lesser volcanic activity.

Numerous researchers have tried to extract climate information from sedimentary core data and regional lake level patterns. Historically however, not many studies have looked at the relationship between the geological influences and lake histories. As mentioned above in terms of modern rainshadow effects, the largest overall aspect of the rift system that is thought to influence climate, and thus lake levels in this region, is the uplift associated with the rifting. The modern effects of this topography are easily seen in rainfall patterns; however, the total uplift history of East Africa is poorly constrained, with only localized uplift histories available. There is evidence in the Nairobi region derived from the Kapiti 
Phonolites (erupted at $13.5 \mathrm{Ma}$ ), that suggests that significant uplift had already happened by the time of their eruption (Wichura et al. 2010). Further uplift of 1 $\mathrm{km}$ around $3 \mathrm{Ma}$, and another $180 \mathrm{~m}$ during the last $2.65 \mathrm{Ma}$ are indicated by Veldcamp et al. (2007). Understanding the timing of uplift is an important geological question that, unfortunately, cannot be addressed with the available data. It is however, important to point out that the uplifting of East Africa would significantly influence preserved climate records and likely be a main driver of paleolandscape evolution.

To support the concept of a rainshadow effect driving past climate in East Africa, Sepulchre (2006) modeled rainfall in the case where there is no rift (resulting in the elevation of eastern and southern Africa being low, 400m) or if elevation in Ethiopia was only dictated by the eruption of the basaltic trap series (giving an elevation of $2 \mathrm{~km}$, without additional uplift). In both cases, the average rainfall is increased over modern amounts due to enhanced penetration of monsoonal patterns over the continent, and increased convection caused by warmer surface temperatures caused by the lower average elevation. This modeling makes a strong case that the climactic and biologic shifts seen in Africa since the Miocene are significantly influenced by the uplift associated with the East African \& Ethiopian domes. Previously, the aridification seen in the biologic and geologic record has been pinned on cooling of the Indian Ocean and/or northern hemisphere glaciation. Superimposed on the general drying trend caused by regional uplift are many cycles of wetting and drying which have been partly linked to solar and Milankovitch cycles (e.g. Damnati and Taieb 1995; Trauth et al. 2007; Kingston et al. 2007; Maslin and Trauth 2009).

\subsubsection{Lacustrine deposits: volcanic and hominin synergies}

To aid in the discussion of lake histories, Figure 4.1 shows the main basins within Kenya. Note that OI Duvai, while mentioned in the text, is not shown in this figure as that site is located farther to the south within Tanzania. 
The most detailed sedimentary studies within the Eastern and Ethiopian rifts are associated with hominin fossil sites where great effort is invested in determining the paleohabitat during the time of hominin occupation (e.g. White et al. 2009). Lakes in the Western Branch are also relatively well studied, likely due to potential for hydrocarbons (e.g. Andrew Cohen 1990). Since the lake basins in the Eastern Branch are unsuitable for oil and gas formation, except possibly Turkana (Tiercelin et al. 2004), sites lacking fossils are relatively under studied. This spotty data density in space and time hampers wide-spread high resolution comparisons between basins. For example, sites at Olorgesailie (Fig. 4.1, \#13) and Koobi Fora near Lake Turkana (\#1), have been studied intensively as they are associated with lithic artifacts and hominin remains (e.g. Isaac 1978; Behrensmeyer, Potts, et al. 2002; Hillhouse, Cerling, and Brown 1986; Gathogo, Brown, and McDougall 2008). Other major lake basins such as Magadi (\#14), Bogoria (\#7), and Nakuru (\#9), have been studied only cursorily by comparison. Some lacustrine deposits mentioned in the Kenya Geologic Survey reports due to the prevalence of diatomite, making them potential economic deposits, but the age and paleoenvironment of these deposits is unknown (e.g. Matheson 1966). Lake beds (\#12) initially described by Wright (1967) recently received an entire publication devoted to the deposits due to the abundance of fossil vertebrates found there (e.g. Ambrose, Kyule, and Hlusko 2007).

While climate fluctuations can drive lake levels, the rift is heavily influenced by rifting processes and the related volcanism. Such events can dramatically alter a basin's drainage routes and watershed (e.g capturing or diverting streams). Determining the relative significance of volcano-tectonic controls versus climate is still controversial (e.g. Bruhn et al. 2011). Such efforts would be especially hampered by the poor overall volcanic geochronology (e.g. Fig. 3.10) combined with issues associated with sediment age dating. As an example, Peppe et al. (2009) note that an important fossiliferous deposit on Rusinga Island (near Lake Victoria, \#8) has been placed in four different stratigraphical positions by different 
researchers over the years. Rifting produces a number tectonic basins which have been sites of sediment deposition, but the development of large volcanic complexes on sloping land surfaces can also drive the formation of lakes.

Pickford (1994) points out that lakes and swamps tend to form on the uphill side of volcanoes; thus, volcanic activity can drive lake formation by creating hydrologic dams or through the volcano itself creating space for deposition. Examples of associated lakes and volcanoes include Chalbi (Marsabit), Amboseli (Kilimanjaro), and Olorgesailie (Pickford 1994; Bruhn et al. 2011).

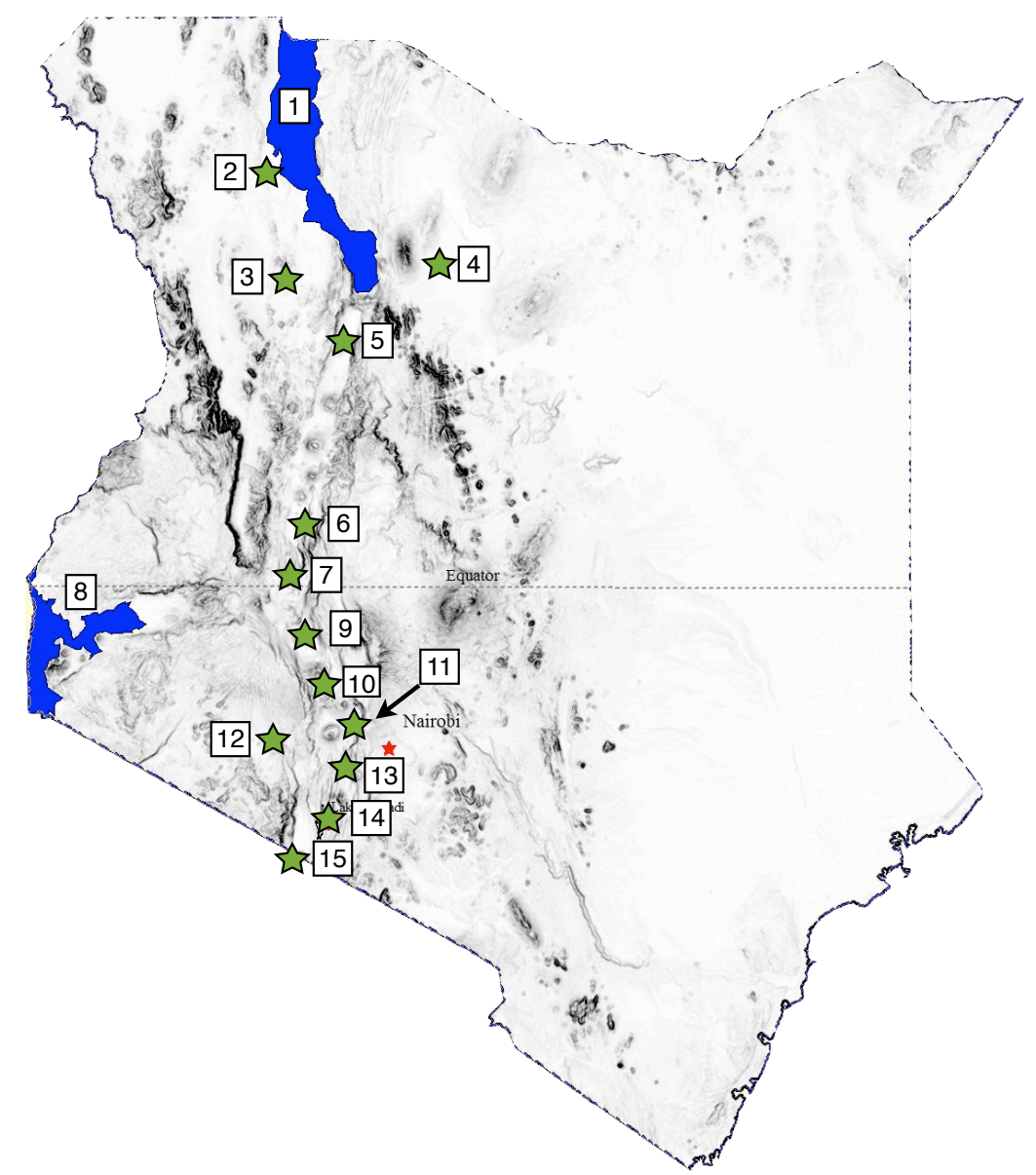

Figure 4.1. Map showing the main lake basins associated with the Kenya Rift. Locations are shown on the digital elevation map of Kenya. Elevation data were derived from the Shuttle Radar Topography Mission (SRTM). Basin names are as follows, names followed by an asterisk $\left({ }^{*}\right)$ are presently dry/do not contain a modern lake: 1 - Turkana; 2 - Lothidok ${ }^{*}$, 3- Lokichar ${ }^{\star}$, 4-Chalbi ${ }^{\star}, 5$ Suguta*, 6-Baringo (sediments of the Tugen Hills are exposed to the west of the modern lake), 7Bogoria, 8-Victoria, 9-Nakuru/Elmenteita, 10-Naivasha, 11-Kedong ${ }^{*}$, 12-Narok Flank*, 13Olorgesailie*, 14-Magadi, 15-Natron. 
Linking climate to lake histories depends on interpretations of past climate conditions, which can also be complicated in a volcanically active system. Volcanism can directly modify lake levels by altering inputs and drainages of a basin, but it can also modify the sedimentary record by creating "mock-aridity" signals in the geologic and biologic record (Harris and van Couvering 1995). Understanding of past climate in this region demands that the volcanic history also be well understood, as lake levels and sediments may not accurately reflect true climate signals. According to Harris and van Couvering (1995), volcanism principally mimics aridity by removing vegetation, burying fertile soil horizons, and displacing animals. The new surfaces dominated by ash can create surficial drought conditions due to the reduced moisture holding capacity of the ash compared to established soils. The authors note that this effect is due to a combination of the high porosity of the fresh ash, lack of organic material and increased thermal conductivity which elevates surface temperatures. Such conditions delay the re-establishment of vegetation and can even result in the formation of "desert" pavements due to resulting wind erosion of loose material. These authors also note that carbonatite or alkaline eruptive materials, such as those associated with the Kenya rift, may further mimic aridity by chemically altering soils and surface waters. In particular, calcretes may be formed "instantaneously" due to the eruption of carbonatite or nephelinite products (Pickford 1994). Thus, rather than indicating long periods of aridity and surface stability, calcrete horizons may be more accurately linked to nearby eruptions. If this is the case, it may be possible to chemically examine calcretes in the rift to identify source, as "instant calcrete" resulting from volcanic ashes may have different chemical signatures than those derived from regular pedogenic processes.

An example of this process is presented by Harris and van Couvering's (1995) case study using the Miocene beds around Kisingiri Volcano, near Lake Victoria. Sediment analysis indicated arid environments, but biologic remains indicated 
humid successional-climax ecosystems. The authors point out that diagenetic and sedimentary lines of evidence for aridity can sometimes be better explained by active volcanism modifying the landscape rather than implicating climate shifts. Conversely, detailed work by Deino et al. (2006) in the Chemeron Formation indicated that cyclic diatomite beds did indicate climate changes rather than tectonic movements within the basin.

From the above discussion, it is easy to conceive that regions lacking abundant fossil remains may simply be considered arid due to the lack of contradicting lines of evidence. In such cases regional comparisons with other basins, as well as with a records of known volcanic activity, would be important to rule out the potential of "mock-aridity".

While unaddressed in the discussion of mock-aridity by Harris and van Couvering's (1995), the volcanic activity may present another interesting problem regarding the use of diatoms as lake level/climate indicators. Changes in diatom assemblages in the sedimentary record are often used to determine depth, salinity and conductivity of lake waters (e.g. Roberts et al. 1993; Verschuren, Laird, and Cumming 2000; Ashley et al. 2004; Bergner and Trauth 2004; Owen et al. 2008). However, local eruptions, rather than changes in water budgets, might also have a large influence over lake chemistry. For example, in a study of a Chilean Lake, Urrutia et al. (2007) found that diatom assemblages changed following tephra eruptions, where Cyclotella af. glomerata replaced Aulacoseira granulata due to increases in available silica. Further studies to determine the relative effect on diatom assemblages resulting from ashy eruptions, particularly involving the alkaline eruption products seen in the rift, might be warranted.

As with determining uplift history, site specific research can work out some of these complex relationships for a single basin at specific times; for example, Bruhn et al. (2011) recognize that the lake cycles seen in the Turkana basin over 
the last 5 million years seems to correlate better with volcanic and faulting episodes rather than with known climate. Similarly, Bergner et al. (2009) argue that tectonic influences on a basin can be significant, even on short time scales $(<100,000$ years) when such events have traditionally considered safely ignored. These authors describe the need for detailed tectonic and volcanic histories, even on 100-year time scales, to adequately understand the forces influencing the basin. Our understanding of past climate in East Africa would be greatly benefitted if such understandings could be extended to all basins for their entire sedimentary history. While it is not within the scope of this work to investigate the above-mentioned issues specifically, it is considered important to draw attention to the unique difficulties of trying to reconstruct climate information from a volcanically active rift.

Despite the patchy nature of studies, and of the lacustrine history in general, the paleolake record within the rift goes back to the Oligocene, with major lacustrine formations and their ages presented in Table 4.1 below. The formations represented in this table are discussed as part of a lake history narrative in the following section, and provide the basis for comparisons with the volcanic and hominin data.

Table 4.1. A list of significant lacustrine deposits within the Kenya rift, including age ranges and pertinent references.

\begin{tabular}{|l|l|l|l|}
\hline \multicolumn{1}{|c|}{ Age $(\mathbf{M a})$} & \multicolumn{1}{|c|}{ Formation/Paleolake } & Modern Lake Basin & \multicolumn{1}{c|}{ Source } \\
\hline $9 \mathrm{ka}$ & Lake Turkana high stand $(457 \mathrm{~m})$ & Turkana & Bruhn et al. 2011 \\
\hline 10.7-12.6 ka & High Magadi Beds & Magadi & Roberts et al. 1993 \\
\hline $11-9.5 \mathrm{ka}$ & Lake Chabli & Chabli playa & Bruhn et al. 2011 \\
\hline $16.5-8.5 \mathrm{ka}$ & $\begin{array}{l}\text { Lake Suguta }(575 \mathrm{~m} \text { strandline; } \\
\text { highest stand at } 9.6 \mathrm{ka})\end{array}$ & Suguta trough & $\begin{array}{l}\text { Dunkley et al. } 1993 \\
\text { Garcin et al. 2009 }\end{array}$ \\
\hline 40-98 ka & Green Beds & Magadi & Behr, 2002 \\
\hline $0.24-0.1$ & Kedong Lake & Kedong & Baker et al., 1988 \\
\hline
\end{tabular}




\begin{tabular}{|c|c|c|c|}
\hline Age (Ma) & Formation/Paleolake & Modern Lake Basin & Source \\
\hline 0.121 & $\begin{array}{l}\text { Lake Suguta (406-460m } \\
\text { strandlines) }\end{array}$ & Suguta trough & $\begin{array}{l}\text { Dunkley et al. } 1993 \\
\text { Garcin et al. } 2009\end{array}$ \\
\hline $0.146-0.133$ & OI Njorowa Gorge & Naivasha & Trauth et al., 2003 \\
\hline 0.2 & Lake Turkana, modern & Turkana & $\begin{array}{l}\text { Brown \& McDougall } 2011 \\
\text { Feibel, } 2011\end{array}$ \\
\hline $0.61-0.235$ & Kapthurian; Tugen Hills & Baringo & Deino \& McBrearty 2002 \\
\hline $0.8-0.3$ & Oloronga Beds & Magadi/Lainyamok & $\begin{array}{l}\text { Potts \& Deino, } 1995 \\
\text { Fairhead et al., } 1972\end{array}$ \\
\hline $0.826-0.509$ & Lake Suguta & Suguta trough & Dunkley et al. 1993 \\
\hline $0.99-0.4$ & Olorgesailie; Members 1-14 & Olorgesalie & $\begin{array}{l}\text { Behrensmeyer, Potts, et al. } \\
2002\end{array}$ \\
\hline $1.1-1.0$ & Peninj Group; lacustrine phase & Natron & $\begin{array}{l}\text { Deino, Domínguez- } \\
\text { Rodrigo, and Luque } 2006\end{array}$ \\
\hline $1.96-0.72$ & Munyu wa Gicheru & Kedong & $\begin{array}{l}\text { Ngecu \& Njue, 1999, } \\
\text { Trauth et al. } 2007\end{array}$ \\
\hline $1.8-1.0$ & Nachukui Lake & Turkana & $\begin{array}{l}\text { Brown et al. } 2001 \\
\text { Feibel, } 2011\end{array}$ \\
\hline $2.06-1.95$ & $\begin{array}{l}\text { Lorenyang Lake, Turkana basin } \\
\text { closed at } 2 \text { Ma by basalts \& } \\
\text { faulting }\end{array}$ & Turkana & $\begin{array}{l}\text { Brown \& McDougall } 2011 \\
\text { Bruhn et al. } 2011\end{array}$ \\
\hline $2.9-2.4$ & $\begin{array}{l}\text { Tulu Bor flood plain deposits with } \\
\text { Waru \& Kokiselei Lakes }\end{array}$ & Turkana & $\begin{array}{l}\text { Brown et al. } 1978 \\
\text { Feibel, } 2011 \\
\text { Caryl-Sue et al. nd }\end{array}$ \\
\hline $\begin{array}{l}3.2-2.35 \\
\text { (deep lake } \\
\text { from } \\
2.66-2.56 \text { ) }\end{array}$ & Chemeron; Tugen Hills & Baringo & $\begin{array}{l}\text { Deino \& Hill, } 2002 \\
\text { Deino et al. } 2006\end{array}$ \\
\hline $3.5-2.9$ & Lake Lokochot & Turkana & $\begin{array}{l}\text { Brown \& McDougall 2011, } \\
\text { Feibel, 2011, } \\
\text { Caryl-Sue et al. nd }\end{array}$ \\
\hline $4.1-3.90$ & Lake Lonyumon & Turkana & $\begin{array}{l}\text { Bruhn et al. } 2011 \\
\text { Haileab et al. 2004, Feibel } \\
2011\end{array}$ \\
\hline 4.7 & Turasha River Valley diatomite & Naivasha & Trauth et al. 2007 \\
\hline $5.3-4.5$ & $\begin{array}{l}\text { Mabaget (Lower Chemeron); } \\
\text { Tugen Hills }\end{array}$ & Baringo & $\begin{array}{l}\text { Pickford et al. 2004, Deino } \\
\text { et al., } 2002\end{array}$ \\
\hline
\end{tabular}




\begin{tabular}{|l|l|l|l|}
\hline \multicolumn{1}{|c|}{ Age (Ma) } & \multicolumn{1}{|c|}{ Formation/Paleolake } & Modern Lake Basin & \multicolumn{1}{c|}{ Source } \\
\hline 6.084 & $\begin{array}{l}\text { Lemudong'o ("first Uaso Ngiro } \\
\text { lake" }\end{array}$ & NA (Narok Flank) & Ambrose et al., 2007 \\
\hline $6.8-6.37$ & $\begin{array}{l}\text { Mpesida \& Lukeino beds; Tugen } \\
\text { Hills }\end{array}$ & Baringo & $\begin{array}{l}\text { Hill et al., 1985 } \\
\text { Kingston et al. 2002 }\end{array}$ \\
\hline $9.64-9.31$ & Namurungule & $\begin{array}{l}\text { Suguta Trough, } \\
\text { Samburu }\end{array}$ & Saneyoshi et al. 2006 \\
\hline $12.7-10.2$ & Ngorora; Tugen Hills & Baringo & $\begin{array}{l}\text { Bishop \& Pickford 1975, } \\
\text { Hill et al., 1985 } \\
\text { Jacobs \& Kabuye 1987 }\end{array}$ \\
\hline 15 & Moboko Formation & & Retallack et al. 2002 \\
\hline $15.8-15.4$ & Muruyur; Tugen Hills & Baringo & Behrensmeyer et al. 2002 \\
\hline $\begin{array}{l}15.5-17 \\
\text { poorly } \\
\text { constrained) }\end{array}$ & Kulu Formation; Rusinga Island & Victoria & Peppe et al. 2009 \\
\hline 16 & Lake Tambach & & Bictoria \\
\hline 17.5 & Locherangan/Lothidok Formation & Turkana - Lothidok & $\begin{array}{l}\text { Brown \& McDougall, 2011 } \\
\text { Leakey et al. 2011 }\end{array}$ \\
\hline 26 & Lokone Shale, age is estimated & Turkana - Lokichar & $\begin{array}{l}\text { Morley, Karanja, et al. 1999 } \\
\text { Leakey et al. 2011 }\end{array}$ \\
\hline 31 & subsurface), age is estimated & Turkana - Lokichar & Morley, Karanja, et al. 1999 \\
\hline
\end{tabular}

There have been many finely detailed studies of individual lakes and formations, and a comprehensive listing of all such studies would be overly lengthy. Such data are often synthesized into more general works, and while data is lost in the process, the generalization is useful for visualizing longer term trends. In order to highlight some of the important previous works, Table 4.2 lists compilation papers that provide lake level syntheses for a number of lakes within the Kenya Rift. These papers utilize a number of specific, focused studies, and would thus also be concentrated sources for locating primary references. In the following section, information gathered from sources in Tables 4.1 and $\underline{4.2}$ are presented graphically, and in narrative, to facilitate discussion of the development and evolution of the lakes associated with the Kenya Rift. 
While the effort to reconstruct past lake histories and landscapes certainly dates back farther than the publications listed in Table 4.2, Pickford (1994) notes significant problems with the early efforts. In particular, early works tended to call all sedimentary deposits "lake" deposits, and reconstructions of lake basins were generally made by connecting areas of exposed sediment. Volumetrically, most of the sediments in the rift are volcaniclastic, and are deposited subaerially; to quote Pickford, 'to treat all these sediments as 'lakebeds', as was often the case in the past, is to miss a great deal of information and to obscure otherwise very interesting and informative depositional histories". Thus, older reconstructions (pre-1950's) should be approached with caution.

Table 4.2. Significant survey publications providing lacustrine histories for wide areas of the Kenya Rift. See references section for full citations.

\begin{tabular}{|l|l|l|}
\hline \multicolumn{1}{|c|}{ Year } & \multicolumn{1}{|c|}{ Authors } & \multicolumn{1}{c|}{ Title } \\
\hline 1972 & Butzer et al. & Radiocarbon dating of East African lake levels \\
\hline 1994 & Pickford & $\begin{array}{l}\text { Patterns of sedimentation and fossil distribution in } \\
\text { the Kenya Rift Valleys }\end{array}$ \\
\hline 2001 & Trauth et al. & $\begin{array}{l}\text { Response of the East African climate to orbital } \\
\text { forcing during the last interglacial (130-117 ka) and } \\
\text { the early last glacial (117-60 ka) }\end{array}$ \\
\hline 2004 & Tiercelin and Lezzar & $\begin{array}{l}\text { A 300 Million Years History of Rift Lakes in Central } \\
\text { and East Africa: An Updated Broad Review }\end{array}$ \\
\hline 2005 & Trauth et al. & Late Cenozoic moisture history of east Africa \\
\hline 2008 & Trauth et al. & $\begin{array}{l}\text { High-and low-latitude forcing of Plio-Pleistocene } \\
\text { East African climate and human evolution }\end{array}$ \\
\hline 2009 & Dawson & $\begin{array}{l}\text { The Gregory Rift Valley and Neogene-Recent } \\
\text { Volcanoes of Northern Tanzania }\end{array}$ \\
\hline 2009 & Maslin and Trauth & $\begin{array}{l}\text { Plio-Pleistocene East African Pulsed Climate } \\
\text { Variability and Its Influence on Early Human } \\
\text { Evolution }\end{array}$ \\
\hline & Bergner et al. & $\begin{array}{l}\text { Tectonic and climatic control on evolution of rift lakes } \\
\text { in the Central Kenya Rift, East Africa }\end{array}$ \\
\hline
\end{tabular}




\subsubsection{Volcanic and Lake Sedimentation trends in the Kenya Rift}

The oldest lacustrine deposit recognized is not exposed at the surface, but was encountered at depth in a well drilled by Shell Oil (see Morley, Karanja, et al. 1999). It is important to note that while the oldest formations shown in Table 4.1 are poorly constrained temporally, evidence indicates the lacustrine record does not significantly post-date the start of rift-related eruptions as would be implied by only examining the exposed sedimentary deposits.

Data from Table 4.1 are plotted in Figure 4.2 to represent the lacustrine history associated with the rift. These data are plotted by time and latitude, with volcanic data from Chapter 3 shown for comparison. Figure 4.3 is the same data plotted by longitude and time. Scaling symbols based lake level was considered, however the many of the recognized lacustrine deposits were derived from lakes of unknown extent. Symbolization in Figures $\underline{4.2}$ and 4.3 instead represents basin affinity, and the figures are intended to show the length of the lacustrine record at different locations in relation to the volcanic trends. The volcanic data are from Figure 3.5 but have been subdued; refer to the previous chapter for the full volcanic plot, associated legend, and discussion of volcanic trends.

Similarly to the volcanic trend, Figure 4.2 shows a southward progression of lake deposits over time. This is unsurprising given that propagation of the rift would dictate the formation of fault-bounded basins. There is an approximate 5 million year gap between volcanic activity and initial lacustrine deposition at different sections of the rift. In general, the earliest rift volcanism in a region is recognized to pre-date the formation of rift faults (e.g. Macdonald 2003), and given the observed relationship between the volcanic and lacustrine record, actual rift graben development may be bracketed by these two events. This suggests that initial lacustrine depositions may be a proxy for faulting in this region. 


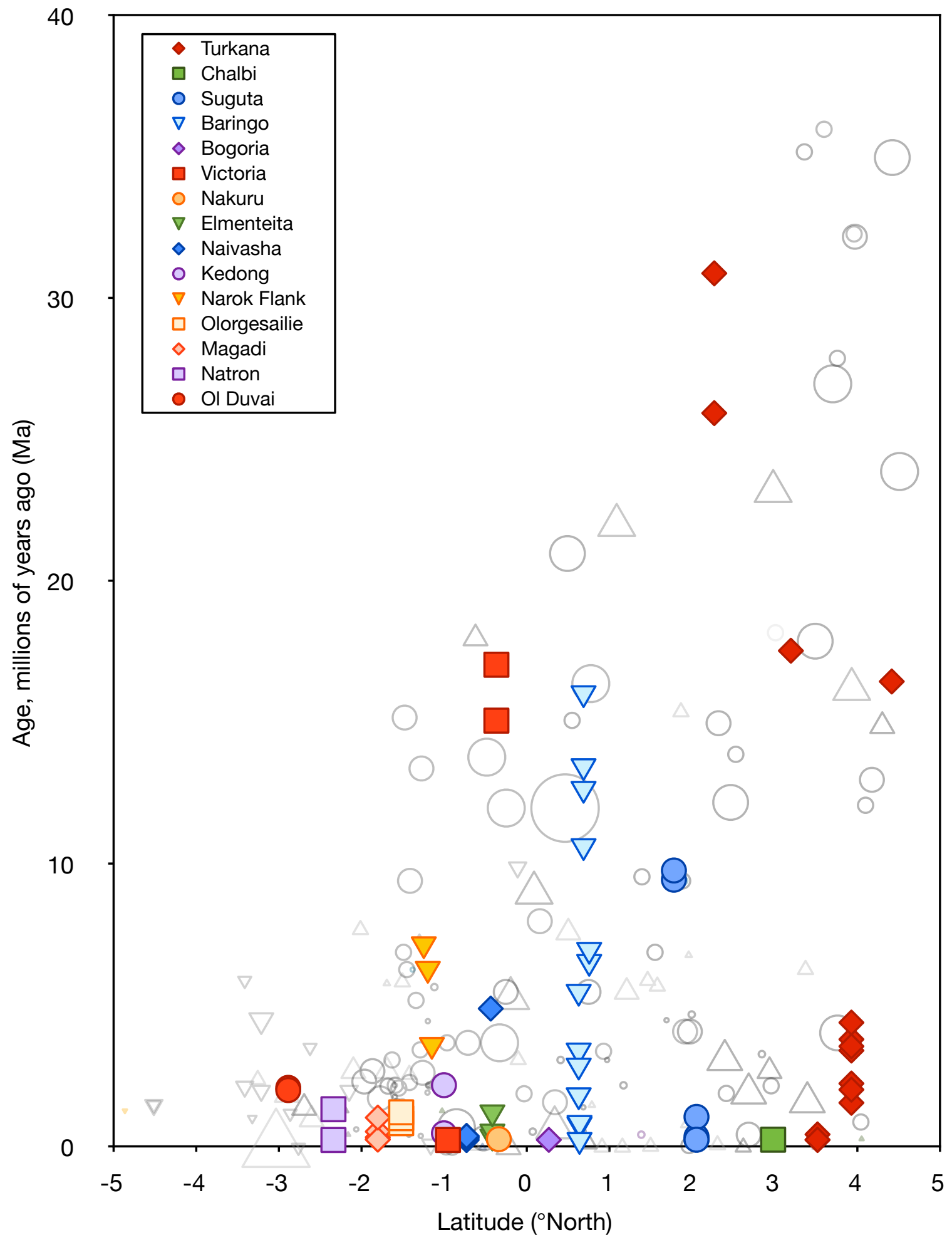

Figure 4.2. Plot showing location of lake deposits, plotted by time and Latitude, colored by associated modern basin. Hollow symbols represent volcanic units shown in Figure 3.5, and are for comparison. 


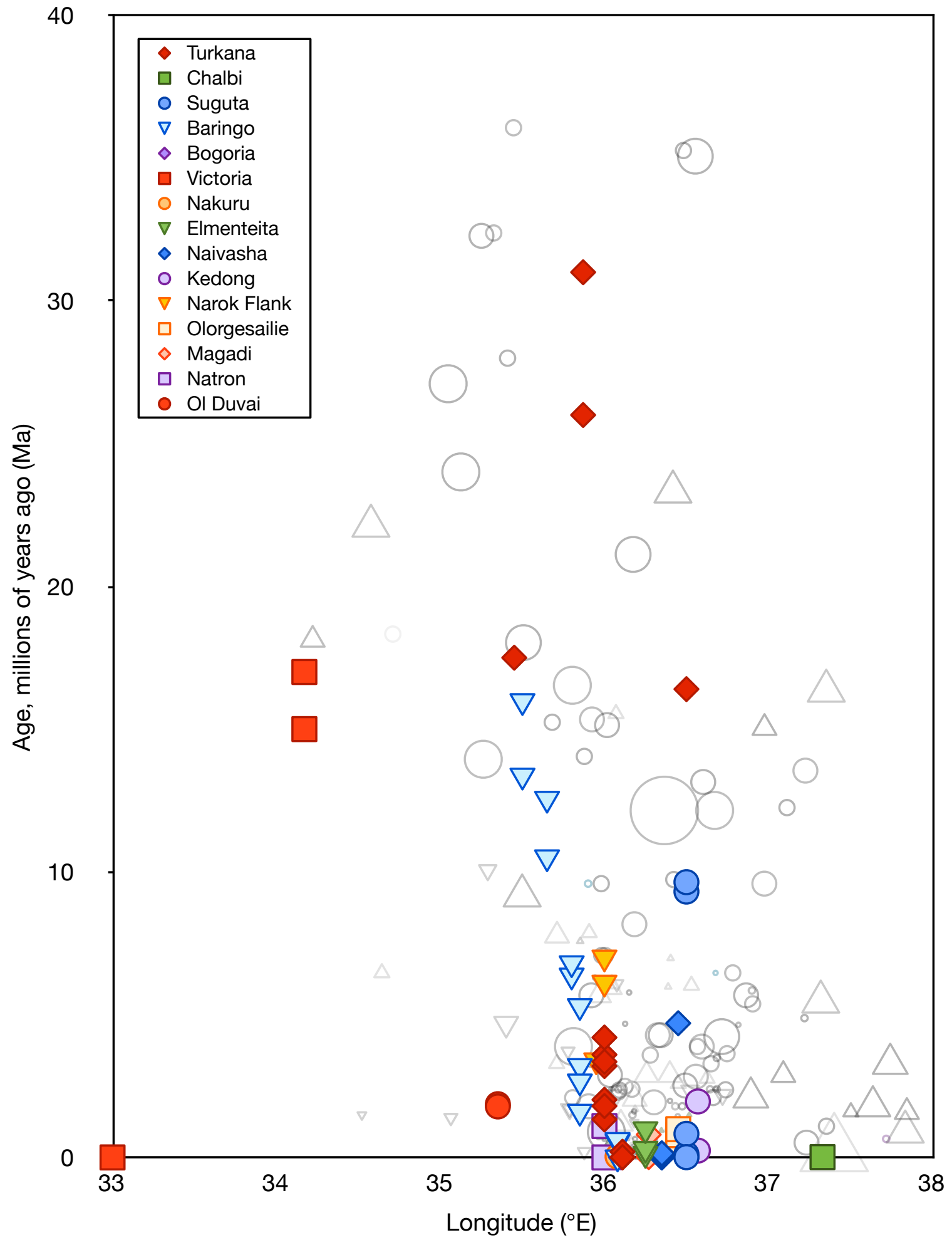

Figure 4.3. Plot showing location of lake deposits, plotted by time and Longitude, colored by associated modern basin. Hollow symbols represent volcanic units shown in Figure 3.5, and are for comparison. 
The same data when plotted as longitude versus (Figure 4.3) indicate an eastward migration of both volcanism and deposition over time. Other than the Lake Victoria and OI Duvai points which are technically not within the Kenya Rift, the lake data show a close correlation with the western boundary of the riftrelated volcanics. This west-boundary association is considered to be due to the general trend where the western boundary faults of the rift develop first, and act as the master faults for the basin (e.g. Baker, Mitchell, and Williams 1988; Simiyu and Keller 2001). This eastward migration has been noted previously, and is especially evident with the Baringo basin, where the Tambach, Ngorora, Lukeino/ Mpesida, Chemeron and Kapthurin deposits are all located successively to the east (Tiercelin 1990). A similar pattern is also seen in the Turkana basin deposits (e.g. Morley 1999; Chorowicz 2005).

A potential cause of the eastward shift over time seen in Figure 4.3 is the large northwest-southeast trending Aswa lineament, which runs between Mounts Elgon and Kilimanjaro, crossing the rift near modern Lake Magadi. This large structural element represents a shear zone formed during the Mozambique orogeny and exerts a significant control on the orientation of the Kenya Rift (e.g. Hetzel and Strecker 1994; Le Turdu et al. 1999; Chorowicz 2005; Le Gall et al. 2007). As the rift propagated southward, this structure may have deflected activity to the southeast. The Aswa shear zone also separates the Eastern and Western rift branches (Kampunzu, Bonhomme, and Kanika 1998), and faulting associated with the Lake Albert graben stops at the intersection with this basement structure (Aanyu 2010). Eastward migration within a single basin's history may represent the widening of the rift valley floor and development of the eastern valley escarpment.

While the oldest lake deposits are found in the southwestern Turkana region (technically the Lokichar basin), the lake record at Turkana is less consistent (or at least, less consistently exposed) than in the Baringo basin. Pickford (1994) 
recognized that certain basins seem prone to repeated lacustrine deposition, and the the Baringo basin was specifically noted. However, this may be a consequence of the great depth of the basin, significant extension and abundant faults. The oldest basin associated with the Kenya Rift, Lake Turkana, is located in a region where the rift valley becomes diffuse, which may inhibit sediment exposure. Lake Baringo, on the other hand, is in a well defined section of the rift, and a series of large boundary faults expose the older lake sediments. Similarly to the issue with volcanic volumes discussed in the previous chapter, a large portion of sedimentary record is likely hidden at depth, and the sedimentary records are likely more extensive than traditionally recognized.

\subsubsection{Lake Deposition History}

A number of authors have created paleolake and landscape reconstructions for various basins within the Kenya Rift. As such images are condensed sources of information, references providing these useful figures are listed in Table 4.3 by basin. Using the data in Table 4.1 along with previous paleo-landscape reconstructions listed in Table 4.3, it is possible to create maps showing the lake distribution in Kenya during different times. Unfortunately, the record degrades significantly with time, such that the extents of the older paleolakes are essentially unknown. It is possible to identify periods of lacustrine deposition, which allows plots like Figures 4.2 and $\underline{4.3}$, but delineation of potential lake boundaries can only be done for the most recent lakes to any degree of confidence. This gap in knowledge is mainly due to exposure of older sequences primarily in fault scarps. Without abundant exposures combined with detailed correlation efforts, identifying the total aerial extent of these older lakes is not possible. The needed correlation efforts are generally only undertaken in regions with hominin sites, and often rely of tephrostratigraphic techniques.

The maps presented in Fig 4.4 (a-d) show major lake configurations during selected time periods over the last 2 million years. While the lake record extends 
at least 30 million years, the available information only allows for reconstructions over a much smaller time frame for the reasons stated above. Despite these issues in diagraming the distribution and extent of the lakes, there is still enough information available in the literature to provide a written description of the general development of lacustrine deposits over time. The following discussion is divided by time, starting with the oldest deposits and working towards the modern situation. Time divisions used for discussion are based on the age boundaries defined by the International Stratigraphy Commission (2010).

Table 4.3. Publications with paleogeographic reconstructions within the Kenya Rift, sorted by modern lake basin.

\begin{tabular}{|l|l|}
\hline \multicolumn{1}{|c|}{ Basin } & \\
\hline Turkana & $\begin{array}{l}\text { Feibel, 2011, } \\
\text { Caryl-Sue et al. nd } \\
\text { Bruhn et al. 2011 } \\
\text { Quinn et al. 2007 } \\
\text { Morley et al. 1992 } \\
\text { Reid \& Frostick, 1986 } \\
\text { Savage \& Williamson, 1978 } \\
\text { Vondra \& Bowen, 1978 }\end{array}$ \\
\hline Suguta & Garcin et al. 2009 \\
\hline Baringo & $\begin{array}{l}\text { Tiercelin, 1990 } \\
\text { Pickford, 1978 }\end{array}$ \\
\hline Nakuru \& & $\begin{array}{l}\text { Bergner et al., 2009 (includes Naivasha basin) } \\
\text { Gowlett \& Crompton, 1994 } \\
\text { Butzer et al. 1972 } \\
\text { Thompson \& Dodson, 1963 }\end{array}$ \\
\hline Naivasha & $\begin{array}{l}\text { Bergner \& Trauth 2004 } \\
\text { Bergner et al. 2003 } \\
\text { Butzer et al. 1972 }\end{array}$ \\
\hline Olduvai & $\begin{array}{l}\text { Owen \& Renaut 1981 (also regional reconstruction from Longonot to Magadi) } \\
\text { Isaac, 1978 }\end{array}$ \\
\hline Olorgesailie & $\begin{array}{l}\text { Hillaire Marcel et al. 1987 } \\
\text { Hillaire Marcel \& Casanova 1987 } \text { Kyser, 2001 }\end{array}$ \\
\hline Magadi-Natron
\end{tabular}




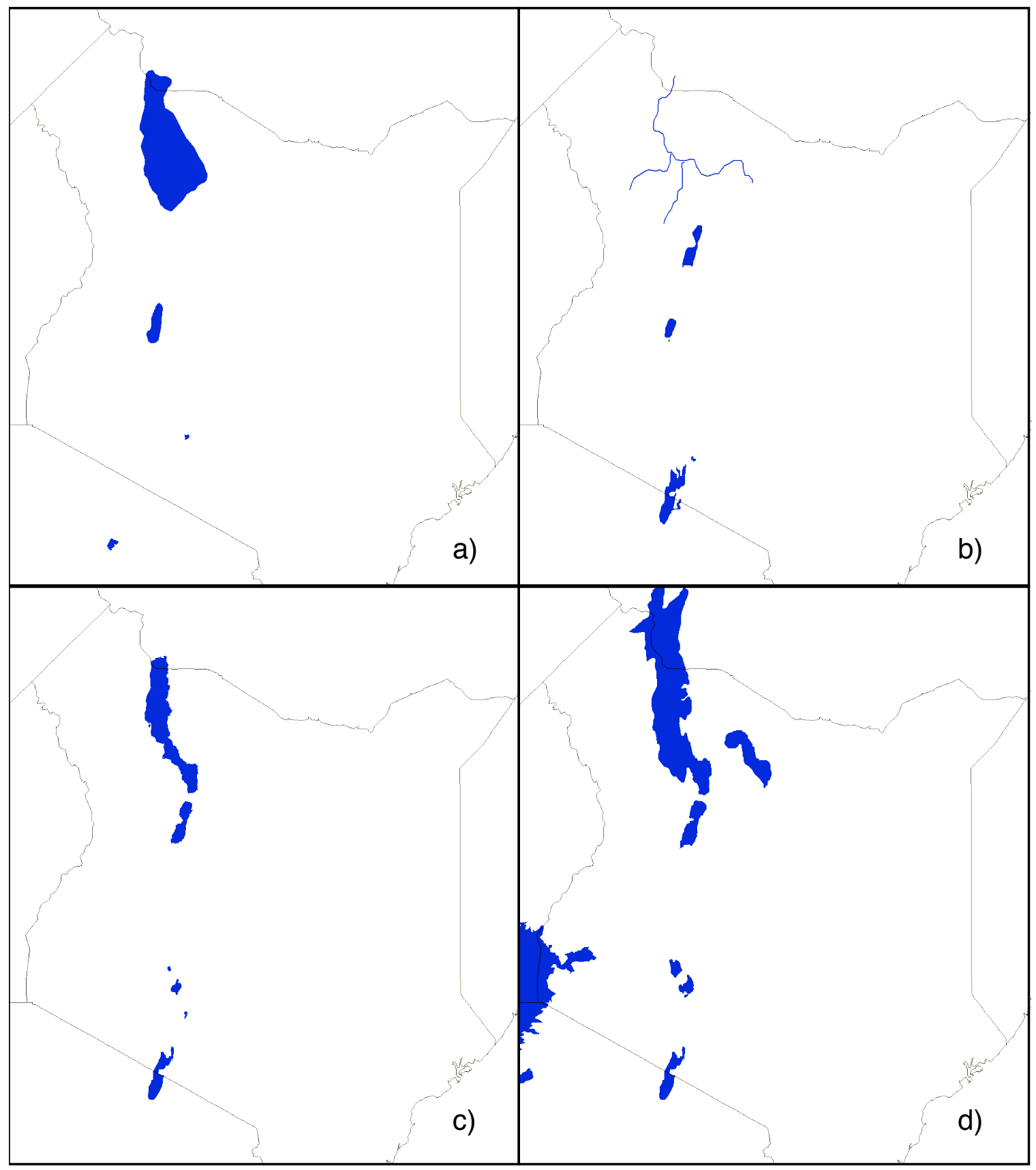

Figure 4.4. Maps showing the general size and distribution of known lakes during different stages from the Pleistocene to the Holocene. See section below for a more detailed description of these time periods. a) the period around $1.7 \mathrm{Ma}$, b) $700 \mathrm{ka}, \mathrm{c}) 100 \mathrm{ka}$, and d) $10 \mathrm{ka}$. 


\section{Oligocene: the earliest rift sediments}

The oldest record of lacustrine deposits likely extends into the Oligocene. As there is very little age control, the assignment of the Loperot shales to the Oligocene is tentative. These sediments were only encountered in core, and the only age constraint is that they are older than the Lokone sediments based on stratigraphic ordering (Morley, Karanja, et al. 1999). The age of the Lokone is estimated to be late Oligocene based on biostratigraphic correlation of the vertebrate fossils to other sites with age constraints (Leakey et al. 2011). Due to

the highly restricted nature of the Lokone sediments spatially (at least in outcrop), not much can be said at this point regarding the size and duration of these two lake stages.

\section{Early Miocene: 15-18 Ma}

Following the general trend observed with the rift volcanism, lacustrine deposition had migrated to near the equator by the early Miocene. Again, our understanding of the distribution of sediments is not sufficient to make paleogeographic reconstructions showing these various lakes. The Tambach sediments are exposed in the Elgeyo escarpment to the west of the modern Lake Baringo, and are capped by the Uasin Gishu and Tiim phonolites (Mugisha et al. 1997). These capping lavas would obscure the spatial distribution of these sediments, which is one of the main reasons the aerial extents of the older lake formations is hard to discern. Similarly, the early Miocene sediments near Lake Victoria are only locally exposed in small outcrops. While there has generally been less volcanism in the Nyanza sub-branch of the rift, sedimentation from the modern Lake Victoria has likely obscured the older sediments.

\section{Mid-Miocene: 9-13 Ma}

There are two main lacustrine deposits representing the mid-Miocene. The Ngorora beds in the Tugen Hills were deposited on top of the Plateau Phonolites 
(specifically the Tiim Phonolite), and are constrained on the western edge of the basin by the Elgeyo escarpment. Numerous vertebrate fossils have been recovered from the Ngorora beds, and plant remains indicate that the environment at the time of deposition was a humid forest (Jacobs and Kabuye 1987). These sediments were later capped by the Ewalel Phonolite (Bishop and Pickford 1975).

Much less is known about the other lake assigned to this period. Wright's "2nd (lower) Uaso Ngiro" lake described in the Narok survey report (Wright 1967) existed on what is now the rift flank west of the Magadi area. No age constraints have yet been placed on this formation other than that they are older than the Lemudong'o Formation from the late Miocene (Ambrose, Nyamai, et al. 2007).

\section{Late Miocene: 6-7 Ma}

The late Miocene is represented by several significant lake deposits, with repeated lacustrine deposition occurring in the Baringo region. These Baringo sediments start with the Mpesida beds, which were deposited between successive eruptions of the Kabarnet Trachyte and occur as lenses of material, whereas the Lukeino beds were deposited above the trachyte (Hill et al. 1985). Being an intra-volcanic sedimentary formation, the Mpesida deposits contain a significant fraction of pyroclastic and tuffaceous material, some of which has been reworked in a lacustrine setting (Kingston et al. 2002). It is noted in Kingston et al. (2002) that the distinction between the Mpesida and Lukeino deposits is not strictly defined, and the lacustrine facies of the Mpesida are essentially identical to descriptions of the Lukeino. While the Lukeino deposits have been well studied on the account of the abundant preserved fauna, the Mpesida sediments are noted to contain (non-hominid) primate fossils, which are notoriously rare, as well as silicified tree remains in the pyroclastic deposits. The exceptionally well preserved trees suggest the presence of a "wet lowland forest" with trees over $50 \mathrm{~m}$ in height during this time (Kingston et al. 2002). 
During a similar time frame, about $200 \mathrm{~km}$ to the south of the deposition centers of the Tugen Hills, the Lemudong'o beds were being deposited. While no hominid remains have been found, a wealth of vertebrate fossils have been recognized and allowed for environmental reconstructions in this region (Ambrose et al. 2003; Ambrose, Nyamai, et al. 2007). These beds were initially described as the "1st (upper) Uaso Ngiro" lake by Wright (1967), and are mainly exposed along the Enkorika fault within the Lemudong'o gorge. The sediments in this formation represent two periods of lacustrine deposition, separated by a period dominated by fluvial and subaerial deposition, including the formation of paleosols. As in the Tugen Hills, a large component of the sediments are volcanically derived, and interbedded ashes have allowed these deposits to be age dated (Ambrose, Nyamai, et al. 2007). The preserved fauna in this formation are used to suggest a gallery forest associated with a slow moving river feeding the lake, as well as a surrounding grassy woodland (Ambrose, Bell, et al. 2007). In contrast to the Lukeino formation to the north, the Lemudong'o lake may have been less permanent, and situated in a region that was more conducive to grasses.

As of the Kirtlandia publication in 2007 devoted to the Lemudong'o beds (e.g. Ambrose, Nyamai, et al. 2007), there was not enough information to confidently demarcate the basin boundaries. It was similarly noted by Ambrose et al. (2007) that the boundaries of the other lakes described by Wright (1967) are also poorly constrained.

The Mabaget Formation (also referred to as the Lower Chemeron) represents yet another lacustrine phase in the Baringo region. Similarly to the Mpesida/Lukeino beds, this formation has yielded fossil evidence indicating the presence of tropical forests at the time of deposition. Remains of water chevrotain (a small, fanged dear) and peafowl suggest that the Mabaget Formation was deposited near a forest with abundant water (Pickford, Senut, and Mourer-Chauvire 2004). 
This formation is separated from the Lukeino formation by the Kapaina basalts and Tabarin ignimbrite (Deino et al. 2002).

\section{Pliocene: 3-4 Ma}

The most recent of the three lakes described by by Wright (1967) is separated from the Lemudong'o lake sediments by a trachyte ash and lava flow. These younger lake beds have been named the Seyabei Lake, but the underlying trachytes have not yet been dated, and thus the only age constraint is that these beds are younger than the Lemudong'o sediments (Ambrose, Nyamai, et al. 2007).

Unlike the Tugen Hills/ Baringo region of the rift which shows an extensive set of lake records, this period marks the first time since the Oligocene that the Lake Turkana region starts showing lacustrine deposition again. While there was significant deposition in the Turkana basin during the Miocene, the resulting Nawata formation represented deposition by a major river system, with no associated evidence for significant lacustrine settings (Feibel 2011). During the Pliocene however, lacustrine deposition was resumed by the presence of several named lake phases (Lonyumon and Lokochot).

\section{Late Pliocene - Early Pleistocene: 1.7-3 Ma}

Much of the Chemeron Formation in the Tugen Hills predates the start of the Pleistocene, however, the lowest sections traditionally included in this formation that date back to the Miocene have been sectioned off as the Mabaget Formation by some authors, (e.g. Pickford, Senut and Mourer-Chauviré 2004). Part of the formation from 2.7-2.5 Ma consists of a cyclic deposition of alternating 3-7 meter thick lacustrine diatomite beds and fluvial sediments. The cyclic nature has been tied precessional driven changes to the African monsoon, as the interpreted span between diatomite beds is $23.2 \mathrm{ka}$ (Deino et al. 2006). So while the earlier formations in this region (Mabaget, Lukeino and Mpesdia) indicate relatively 
stable humid conditions (Pickford, Senut, and Mourer-Chauvire 2004), the period between 2.7-2.5 Ma recorded in the Chemeron Formation indicates marked wetdry oscillations (Deino et al. 2006).

A significant part of this period in the Turkana Basin is represented by the Tulu Bor floodplain, indicating that fluvial processes again dominated after the deposition of the Lokochot sediments in the Pliocene. While the Tulu Bor deposition did include two minor lacustrine phases, and the next significant lake phases in this basin were the Lorenyang and Nachukui (Feibel 2011).

Farther to the south, the Munyu wa Gichiru diatomite beds were deposited in the Kedong basin, north of Olorgesailie. These deposits are $29 \mathrm{~m}$ thick, and have been dated based on interbedded tuffs and intruded rhyolites (Trauth et al. 2007). Diatom remains within the deposits examined by Trauth et al. (2007) indicate the rapid formation of a deep lake around $1.7 \mathrm{Ma}$ followed by increased evidence for shallowing upwards in the section.

\section{Discussion of Pliocene - Pleistocene Climate}

Overall, this time period is one of important environmental changes in East Africa. During the Miocene, evidence from the lacustrine deposits near Baringo indicated the presence of humid forests, however this is not the case at the present time. It is notable that evidence from Mount Kenya indicates that the equatorial region experienced significant uplift around $3 \mathrm{Ma}$ (Veldkamp et al. 2007), which may have enhanced the region's sensitivity to moisture patterns (e.g. Maslin and Trauth 2009).

Similarly, Brachert et al. (2010) present data regarding the monsoonal intensity over the Western Rift Branch for the past $7 \mathrm{Ma}$ based on stable isotope analysis of hippopotamid teeth. Plants utilize several metabolic pathways, which can influence stable carbon ratios in the geologic/biologic record. Most plants utilize 
the "C3" pathway, however, other floral groups including the grass family (Poaceae) utilize the "C4" pathway. By examining carbon isotope ratios, the relative abundance of these different plant groups can be inferred. Isotope results from Brachert et al. (2010) suggest that hippopotamids had a diet consisting of exclusively C3 plants (herbaceous/woody) between 7.5-4.0 Ma, and exclusively C4 (grasses/sedges) from 2.5 Ma to near present. The only mixed diet was recorded in a sub-recent tooth from Lake Edward. Pollen analysis support the dominance of $\mathrm{C} 3$ vegetation prior to $2.5 \mathrm{Ma}$, with a switch to arid steppe and savannah (grass dominated) environments between 2-3 Ma.

While changes in monsoonal patterns are linked to lake levels in the Pliocene and Holocene, not all changes in lake levels are sufficiently explained by only invoking changes in monsoonal intensities. Maximum aridity is recorded in the stable isotope record of the Albertine Rift between 1.5-2.3 Ma, however, there is no matching increase in dust transport into the Atlantic during this time (Brachert et al. 2010). Instead, these changes are linked to changing rain shadow effects and the reorganization of drainage patterns caused by rift shoulder uplift.

\section{Middle Pleistocene: 0.5-1.5 Ma}

During the Middle Pleistocene more consistent deposition is seen in the southern parts of the Kenya rift. Unlike earlier deposits, which are now found on the flanks of the rift (e.g. Lemudong'o), these more recent deposits are fully contained within the rift valley. In the Natron basin, the oldest lacustrine deposits are part of the Peninj Group, and have been determined to be around 1.1 Ma (AI Deino, Domínguez-Rodrigo, and Luque 2006). Note that ages for this formation provided in Dominguez-Rodrigo et al. (2001) were later determined by Deino et al. (2006) to be an overestimation by about $0.5 \mathrm{Ma}$.

Around the same time as the lacustrine expansion at Natron, the lake that deposited the Olorgesailie Formation sediments was present to the north (e.g. 
Owen et al. 2008; Behrensmeyer, Potts, et al. 2002). This lake was highly variable, and the deposits record shifting lacustrine, fluvial, and exposed conditions over the course of a few hundred thousand years. Due to the slope of the rift floor, water likely drained out of this lake and into the Magadi basin, as Isaac (1978) notes the presence of a water-worn gorge between the Koora and Magadi grabens to the south. The modern OI Keju Nyiro river that flows out of the Olorgesailie basin towards the south can be seen to disappear in the Koora Graben, but in more humid periods the flow may have used that water-worn path as a path into the Magadi basin. The Olorgesailie beds are notable for a significant accumulation of stone hand axes within the succession, as well as a more recently discovered hominin skull (Potts et al. 2004).

The sediments of the Natron basin are significantly older than those of the Magadi basin to the north. Lakes Magadi and Natron are currently separated only because of the modern low lake levels and evaporative climate, but during more humid climates water flooded both basins to form a single lake (e.g. Eugster and Nissenbaum 1980; Hillaire Marcel, Casanova, and Taieb 1987). The oldest sediments in the Magadi basin are the Oloronga sediments, which are nearly 300 ka younger than the Peninj Group lacustrine phase. Lake deposits correlative with the Peninj Group may be present in the Magadi basin, however extensive resurfacing of the Magadi basin by flood trachytes (1.4 to $0.7 \mathrm{Ma}$ ) may have buried any such sediments. The trachytes appear to become less frequent towards Lake Natron, which may explain the differential age of the oldest exposed sediments between these two basins.

The Oloronga beds also have associated with hominin activity, with both artifacts and a teeth having been found (Shipman, Potts, and Pickford 1983). The main fossiliferous section at the Lainyamok site within the Oloronga Formation has been interpreted as a debris flow into a lake (Potts, Shipman, and Ingall 1988). Evidence from the sediments at Lainyamok suggest periods fluctuating lake 
levels, where lacustrine silts with fish remains are succeeded by sediments with preserved mudcracks. The deposition of these sediments is estimated at 390-362 ka (Potts and Deino 1995). Similarly aged artifacts (340-220 ka) are also noted from Olorgesailie by Behrensmyer et al. (2009).

Deposition also was occurring farther to the north, where the Kapthurin sediments of the Baringo Basin overlie the of the Chemeron Formation, which had been tilted and faulted (Tryon and McBrearty 2006). These sediments also provided the first fossil chimpanzee, indicating that the Pan and Homo genera were coexisting in East African around 543 ka (McBrearty and Jablonski 2005). Deposition was likely by a braided stream system and a lake, where the relative positions of these environments changed over time. Evidence suggests that the habitat around the Baringo region at this time was a woodland near a lake that alternated between fresh and alkaline states as lake level fluctuated (McBrearty and Jablonski 2005).

\section{Late Pleistocene: 100-200 ka}

Sedimentary evidence indicates that large lakes existed during this time in most of the lake basins, from Lake Magadi to Lake Turkana. One particularly interesting case is that of the hypothetical "Lake Kedong" which is suggested to have existed against the southeast flank of Suswa, a large shield volcano in the rift valley between Lakes Naivasha and Magadi. Evidence for a massive flood due to the draining of this lake was first mentioned by Baker and Mitchell (1976). The suggested deposits from this flood are easily distinguished in satellite imagery, and can be traced for about $17 \mathrm{~km}$ north of the Ngong-Magadi road. The plain to the north of these deposits, which also include the older Munyu wa Gicheru diatomite, currently supports no perennial body of water. The presence, and then subsequent breaching, of a volcanic dam is considered a likely scenario for both forming a lake, and creating the observed deposits. The lake would have likely received water from the highlands to the east, as well as outflow from 
Naivasha. Based on modern digital elevation models, and the presence of possible volcanic dams, it is estimated the this lake may have had a water depth of around $40 \mathrm{~m}$.

\section{Holocene: the last $10 \mathrm{ka}$}

Around $10 \mathrm{ka}$, the lakes in the Kenya Rift were again at very high levels. This early Holocene humid period is widely recognized, as it has left very distinctive strandlines in many of the modern basins. Several lake basins were interconnected during this time, such as Magadi-Natron and Elmenteita-Nakuru. Other regions, now dry, had significant lakes during this time such as the Suguta trough and the Chalbi desert (see Tables 4.1 and $\underline{4.2}$ for pertinent references).

Based on analysis of lakes in Northern Africa during the Quaternary, the Early to Mid Holocene was wetter than today, with conditions becoming increasingly arid after 5 ka (e.g. Damnati 2000). Damnati suggests that increased moisture around 10,000 years ago is attributed to increased solar radiation during the summer which enhanced the monsoons. Monsoonal intensity began to weaken around 7 ka followed by another period of wetness/monsoonal strengthening around $6 \mathrm{ka}$.

While it is tempting to link these changes solely to Milankovitch cycles, Broecker et al. (1998) use oxygen isotopes to argue that these changes in climate were abrupt, and can be linked to North Atlantic events. They thus argue for climate regime "flipping" where the climate quickly transitions between different modes, rather than there being smooth transition between wet and dry periods.

\section{Holocene: Present lacustrine settings}

The present climate of the area surrounding the Kenya Rift varies dramatically, from rainforest near Lake Victoria to arid bushland surrounding Lakes Turkana and Magadi. Within the main rift valley itself, elevation rises and falls as the 
valley crosses the smaller Kenyan Dome (Figure 2.2). The rift floor sits at an elevation of $\mathbf{3 6 0}$ meters at Turkana, rises to 1900 meters at Lake Naivasha, and then decreases to 600 meters at Magadi. This change in topography influences the surface temperatures and available moisture along the floor of the rift. As previously noted, the rift shoulders create a rainshadow within the rift valley, and as a consequence, the shoulders tend to receive more rain than the rift floor. Rain patterns in Kenya are bimodal and driven by the monsoonal patterns, where most of the rainfall over the rift occurs between the months March and June (peaking in May), with a secondary rainy season during October and November.

Due to the discrepancy of rainfall between the rift shoulders and floor, many of the lakes within the rift valley are ultimately fed by rivers sourced in the highlands of the rift shoulders. Without this fluvial input into the rift valley, many of the lakes would likely be playas like Chabli, as the many sections of the rift valley floor have higher evaporation rates than annual precipitation. Lake Baringo, which is one of the few fresh water lakes in the Kenya rift valley, loses $1650-2300 \mathrm{~mm} / \mathrm{yr}$ due to evaporation, but only receives $450-900 \mathrm{~mm} / \mathrm{yr}$ of precipitation (Odada, Onyando, and Obudho 2006). Lakes Magadi and Natron only have standing water in some regions year round due to the presence of hot springs. Even then, the input from the springs is not enough to keep the center of these lakes flooded year-round, and their surfaces are only submerged during the rainy season.

Examining the lakes and surrounding environments today gives a good indication of the complicated nature of rift lakes. Under the same overall climate, individual lake basins are strongly controlled by the relative altitudes of flanks and rift floor. Some lakes are deep and fresh, while others are seasonal alkaline pans. Even without active volcanism altering drainages within the Kenya Rift today, the lake systems are varied and complex. Despite this, looking at more general patterns in the presence of lakes over time suggests trends agreeable with the known volcanic trends, and a possibility of utilizing lakes as a faulting proxy. 


\subsection{Hominin developments in reference to rift and lake basin development}

The previous section detailed the lacustrine history as it is related to the rift, but the geology and physical evolution of the East African Rift is also intimately tied to the development of our own species. In particular, new research is being published that focuses on examining the relationship between tectonically influenced landscapes and hominin sites (e.g. Bailey, Reynolds, and King 2011; Reynolds, Bailey, and King 2011; Marshall 2010). While there are many subtle influences between rifting, environments, and local climate, volcanic activity is expected to produce dramatic consequences on the local landscape which should exert some control on the distribution of species in the landscape. The aim of this section is thus, to begin addressing the question of how the rift related volcanic activity may have impacted the distribution of hominins within the rift.

The topic of hominin research is considered to be outside the realm of knowledge of the expected reader. As such, the first section of this discussion is presented as a general background, written by a geologist for geoscientists who are not familiar with the study of our biologic ancestors.

\subsubsection{Background to hominin research}

Terminology regarding the evolution of Homo sapiens can be confusing.

Provided below are brief definitions of some common terms used when talking about the human family line.

Hominid: all of the Great Apes (Hominins, Gorillas, Chimpanzees \& Orangutans).

Hominin: replaces the original use of the term Hominid. A hominin is an organism we consider to be a human or a human ancestor (direct or indirect). So, for example, all Australopithecines and Ardipithecines are considered hominins.

Human: all members of the genus Homo. 
Adding to the confusion for those not accustomed to the field, many fossils are assigned genus and species designations when discovered, but have since been reclassified several times. Some designations are suggested, used for a brief time, and then discarded. When examining references on this topic as a nonspecialist, it is important to keep in mind that the current validity of provided designations may be uncertain. Wood and Leakey (2011) provide a synthesis paper discussing the state of knowledge for hominins found within the OmoTurkana basin, which also highlights many of the nomenclatural difficulties.

Unlike the comparative clarity of the geologic classification schemes, there is wide disagreement about how broad species classifications should be. Tattersall and Schwartz (2009) provide a good description of some of the confusion regarding the designation of the genus Homo. While some authors list evidence for the genus Homo as early as $2.4 \mathrm{Ma}$, the oldest definitive evidence for a specimen of our genus according to Tattersall and Schwartz (2009) are the fossilized remains known as 'Turkana Boy' (1.6 Ma).

Finding the fossilized hominin remains allows for an understanding of the physical changes that occurred in our lineage over time, as well as the spatial and temporal distribution of species. However, fossilization is a relatively rare event, especially for terrestrial organisms like hominins. One distinct advantage of studying our own lineage is that hominins have been fashioning stone tools for at least 2.5 million years (Semaw et al. 1997), which greatly improves the chances of hominin habitation being recorded in the geologic record. These tools provide important clues to understanding hominin evolution, as they are more abundant than hominin fossils themselves, and they can offer insights on mental and cultural developments.

However, similarly to the difficulties in scientifically naming hominin fossil remains, an extra level of confusion for the non-archeologist is the use of several 
naming schemes to classify tool artifacts. A widely used older scheme utilizes place-derived names to indicate tools of a particular form, while a somewhat newer scheme refers to the main forms as representing different Modes (1-5). The confusion lies in that both schemes (in addition to several others) are still in use. Below is a description of the different Modes and their equivalent placebased name from Clark (1977).

Mode 1; Oldowan/ Early Stone Age; core flake or pebble tool industry with no symmetric patterns. First evidence in Ethiopia at $2.6 \mathrm{Ma}$, widespread by $1.5 \mathrm{Ma}$ and is considered a common, or generic tool style. Emphasis is on the edge of the tool, with little evidence of reworking or extensive flaking. This generally produced an irregular working edge.

Mode 2; Acheulian/ Early Stone Age; Hand axes \& symmetrical artifacts, first appear at 1.4 Ma. Base stone was worked to produce an edge around most of the stone's perimeter to produce a hand held tool.

Mode 3: Levallois/Middle Stone Age; Prepared core and flake; aim seems to be to produce finished flakes, so the base stone is prepared in such a way that flakes can be struck off in a finished state.

Mode 4: Later Stone Age; Punch-struck blades and some longer chisel-like tools were produced. Tools seemed to be produced in such a manner that new edges could be easily formed when the edge dulled. These tools were often used to cut and shape antler, ivory and bone materials. This mode is definitely associated with complex culture and was only used by modern humans.

Mode 5: Later Stone Age; Formation of microliths, which were small blades less than an inch long, which were then formed into composite tools. For example, several microliths could be fastened to a pole to form a barbed harpoon.

It used to be widely thought that the individual stone techniques represented distinct cultures, or groups of humans, but with the increasing availability of age dates for archaeological sites it has been determined that this is not the case. 
Mode 1 tools, while being the earliest and simplest tools found, are also found through many time periods, and are associated with many different types of hominins. This complicates the picture, as an artifact of a particular style cannot be used to date a deposit, nor can it directly indicate the type of hominin that created the tool (except in the broadest sense). For example, Isaac (1978) reports that Levallois artifacts (Mode 3 ) were found in the alluvial fan deposits surrounding Olorgesailie, but it is not possible to say with any certainty that the Levallois technique represents a distinct time period. Such tool sites are not included in the compiled data because they cannot be worked into a temporal framework without additional information.

To further elaborate on the issues of linking tool styles with ages, what is known as the "Acheulean technique" was named for a French suburb where tools of that style were first described. Similar tools are commonly found in Africa, but the African varieties are three times older than the European ones (Isaac 1978). Additionally, in studying the progression of tool technologies in the Kapthurin Formation near Lake Baringo, Tryon and McBrearty (2006) note that the tool technologies do not suddenly appear and completely replace older ones. The Mode 3 techniques may have been derived from Mode 2, but both sets are found together over significant time spans.

While the mode classification scheme is used here to facilitate discussion, an important argument to consider is presented by Delagnes \& Roche (2005). These authors argue against labeling all lithic sites using the standard nomenclatures, as they suggest that using generalized large classes to describe tools can imply technical stasis, while the actual diversity within and among sites can be quite large. 


\subsubsection{Hominin trends in the Rift}

Data for hominin site occurrences (remains or tools) were compiled from the literature, and can be found in Appendix $\mathrm{E}$ along with associated references. Figure 4.5 shows the distribution of these sites by age and latitude. Due to the issues mentioned above regarding the determination of genus and species for hominin remains, the data were simplified to make the figures in this chapter. Fossil remains were classified as hominid, hominin, and human, using the definitions presented above. While there may be debate in if a specimen is Homo habilis or ergaster, the assignment to the genus Homo is generally consistent. Many sites contain only evidence of hominin occupation by way of stone tool deposits, and such sites were plotted by Mode.

The earliest hominid fossils observed in the Kenya Rift are found in the equatorial region, but not in the northern or southern sections of this rift. This may be due to some combination of inappropriate habitat, lack of sediment exposure in certain basins (e.g. Turkana basin) or lack of appropriately aged sediments (southern rift). The first recognized hominin within the rift is also found in this equatorial region, however, around 4 million years ago activity seems to suddenly diverge away from the equatorial region. Subsequent occupation appears to be strongly concentrated in the northern and southern rift sections during the last 4 million years. However, the time of this divergence is also around the same time that we see a switch from hominids to hominins. This pattern may be explainable by environmental parameters, as the the hominid and hominin groups may prefer different habitats. Hominin and human activity then appears to migrate northwards back towards the equator from the southern rift sector. It should be noted that similar migratory trends may have also occurred from the north, but may be obscured due to the lack of suitable depositional environments that could record such a migration between Lakes Turkana and Baringo. 


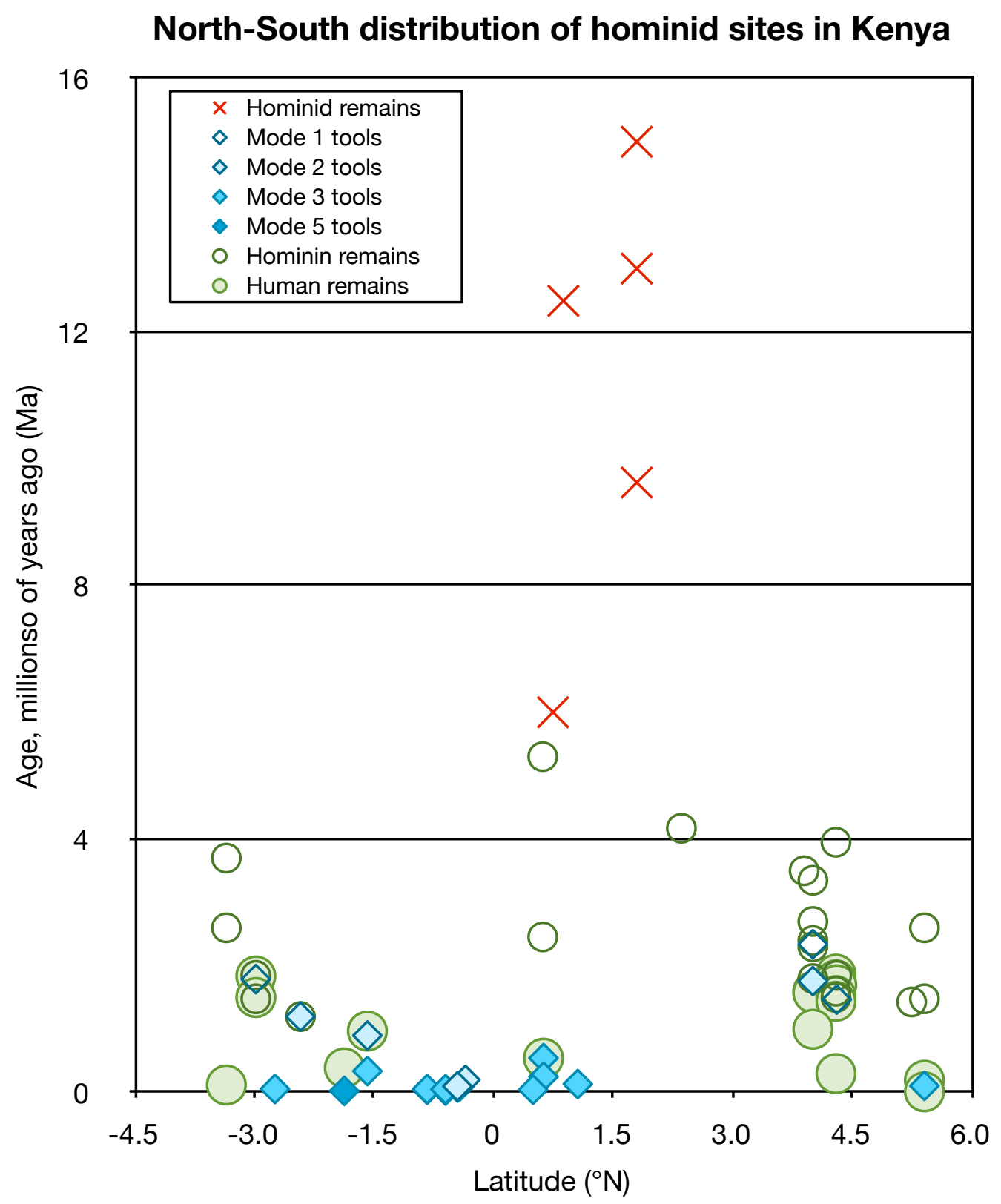

Figure 4.5. Plot showing the distribution of hominid fossil localities within the Kenya Rift by latitude and time.

The compilation of this dataset allows for the main question posed at the beginning of this chapter to be addressed, as the hominid data shown in Figure 4.5 can be plotted against the the geologic data (Fig. 3.5) and lacustrine data (Fig. 4.2). This allows for an initial investigation of the spatial and temporal relationships between these data sets. In both the hominid-geology (Fig. 4.6a) 
and hominid-lacustrine (Fig. 4.6b) plots, the non-hominid data has been subdued to increase readability of the plots. Refer back to the original geologic and lacustrine plots for the associated legends.

As the hominid data only go back to $16 \mathrm{Ma}$, the geologic and lacustrine data sets have been truncated. There is some ambiguity in Figure 4.6a, as latitude nonuniquely identifies sites; in particular OI Duvai seemingly overlaps with Kilimanjaro, when these sites are well separated. The data in Figure 4.6a are presented as longitude versus age in Figure 4.7 to help address that issue.

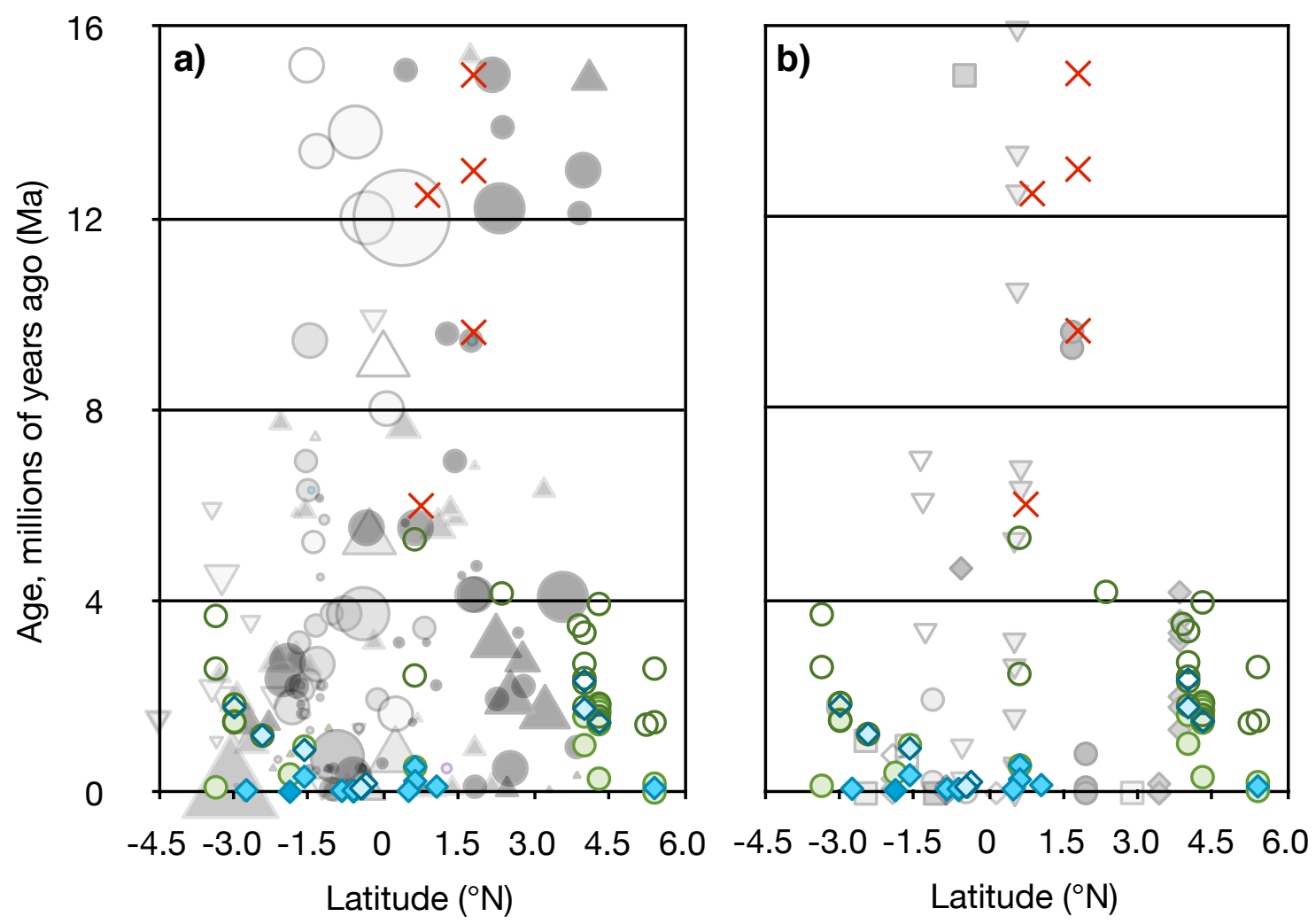

Figure 4.6. Plots comparing hominid site distribution with volcanic data and lacustrine deposits. a) hominid sites for the Kenya rift with geologic data in grey, see Figure 3.5 for associated geologic legend. b) same hominid site data with lake data in grey, see Figure 4.2 for associated legend. 
Due to the truncation of the data older than 16 million years, the oldest lake deposits, which are in the Turkana region, are not shown in Figure 4.6b. Despite Turkana having the longest sedimentation history, there are no exposed lacustrine deposits in the Turkana basin that are the same age as the hominidbearing sediments of Baringo. While the history of sedimentation in the Baringo basin is relatively consistent, hominin activity appears to be concentrated to the northern and southern sections of the rift during the most recent $4 \mathrm{Ma}$. While not assessed here, there could be habitat issues that make the central/equatorial Kenya rift a non-desirable site for hominins at this time.

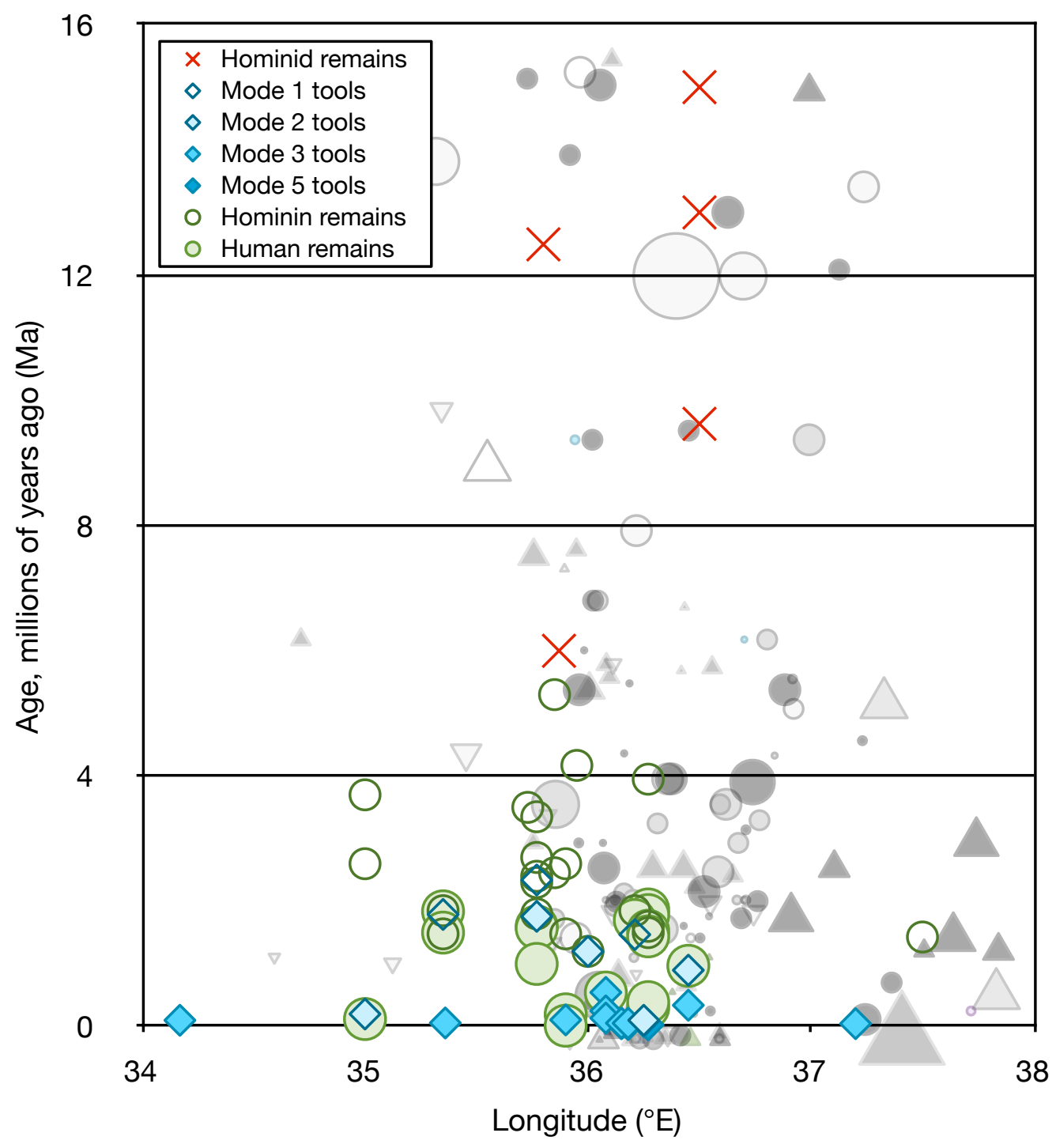

Figure 4.7. Hominid sites in the Kenya rift, plotted with volcanic activity in grey. Data are plotted as longitude versus age. Please see Figure 3.5 for geologic legend. 
Examining Figures 4.6a and 4.7 suggests another possibility for the lack of hominins in the central Kenya Rift. Hominins are seemingly abundant in the Turkana region, and the far southern extent of the rift, which are both regions outside the zones of abundant volcanism. Especially dense regions of volcanic activity at $1.5^{\circ}$ south and $3.0^{\circ}$ north may have played a role in the positioning of the hominins during this time. The Turkana region, which shows evidence of being well occupied since $4 \mathrm{Ma}$, has been comparatively quite during this time period. The hominin concentration in the southern rift appears to skirt the edge of a region of dense volcanic activity, and may indicate that populations moved northward, towards the equator, as the volcanic activity lessened. In essence, Figure 4.6 suggests that volcanic avoidance may have played a role in the distribution of hominins in the landscape during this period.

In some cases, this observed correlation may be a preservation bias, where volcanic activity buries hominin-containing sediments which are not subsequently exposed. For the Baringo basin however, there appears to be a sparse hominin record during the last $4 \mathrm{Ma}$, despite available lacustrine deposits.

To limit the data considered here, fossiliferous sites lacking hominid remains were not catalogued. A number of such sites exist within the rift however, and trends based on other animal populations could prove insightful. Utilizing a larger range of fossil data may help distinguish between general non-preferred habitat versus active avoidance; in theory other large, mobile animals would also be driven away by volcanic activity. Inclusion of such non-hominid fossiliferous sites would also increase the number of available data points to compare against the lake and volcanic data.

Another future step would be to combine this data with paleoenvironment maps based on preserved plant and animal remains. Basell (2008) plots middle stone age (Mode 3) sites on paleovegetation maps, but only for last $20 \mathrm{ka}$, however, no significant trends were seen over that time period. Extending such maps to cover 
the full range of available hominin data could uncover larger-scale patterns. Detailed analyses of sediments at Olduvai indicated shifting patterns of land use over the course of 50 ka related to wet and dry periods, but that required a high resolution study (Ashley, Tactikos, and Owen 2009). Spotting trends on a larger scale may require looking at a time span significantly longer than $20 \mathrm{ka}$. Such efforts would be helpful in determining if hominin distributions seen after 4 million years were driven by volcanic modulation of those regions.

\subsection{Conclusions: rift-related lacustrine \& hominin trends}

In examining the spatial and temporal trends of the known hominid sites, there is an obvious correlation with the sedimentary record until around 4 million years ago. Despite a continued lacustrine record in the Baringo region, the hominin sites cluster around the northern and southern edges of the Kenya-Tanzania rift, and only more recently do hominin sites appear again near the equator. Detailed studies of the Baringo basin may help elucidate why hominins seemingly avoided the Baringo region from $4-0.5 \mathrm{Ma}$. This may simply be due to the difference in preferred habitat between the hominid and hominin groups, as the sediments in the Tugen Hills suggest recurring periods of humid tropical forest. However, the correlations between the hominin, lacustrine, and volcanic data presented here, suggest hominins may have been driven from, and later kept away from, the equatorial region by volcanic activity. Further study on mobile animal groups may also help answer the question between habitat preference and active avoidance.

Lacustrine trends mimic the volcanic progression, but with a temporal delay of a few million years. Both the lake deposits and volcanics show a south and eastward migration over time. We should expect lakes to develop as the rift propagates and creates fault-bounded basins. The delay between these two data sets may represent the expected gap in time between initial volcanism and faulting (Baker et al. 1977). As such, initial lacustrine deposition in an area may 
serve as a proxy for fault initiation. Volcano-tectonic forces were initially discounted when earlier authors tried to explain the pattern of sedimentation within the rift (see Pickford 1994 for a discussion). However, from the data presented here, it is evident that a complex interplay of differing factors exert enormous control on the resulting rift sedimentary trends, and likely, on the distribution of species as well.

\subsubsection{Open questions and future research needs:}

There are a number of large questions that still need to be addressed regarding these topics. The following paragraphs offer a brief descriptions of the question or need (presented in order of increasing complexity), and how such efforts would help the science community's understanding of the East African Rift.

Studies of rift calcretes to test if it is possible to recognize the volcanically derived "instantaneous" varieties from the normal pedogenic varieties. If such discrimination is possible, it would allow for a more robust aridity record for the rift.

Better environment interpretations could be used to create detailed paleolandscape reconstructions such as those created by Feibel and Schwindinger for National Geographic (Caryl-Sue et al.) or by Blakey and Ranney (2008) for the Colorado Plateau. Such maps would be a useful expansion of the work presented here, due to the great ability of maps to visually synthesize large amounts of data.

Further examination of the potential role volcanism has on hominin distributions could be attempted by expanding analysis to include other large mammals and environmental trends. Are the correlations seen here due to environment? Are other animals affected? It is thought that if the Baringo region was missing other large mammals, that could strengthen 
the idea of hominin displacement due to volcanism. Assuming both large mammals and hominins are missing, two possibilities are currently considered: either an inhospitable environment at Baringo directly precluded large mammal groups, or volcanic barriers prevented migration of these groups back into the Baringo region, even if the environment would normally be considered attractive. If the environment were hospitable, but large mammals were absent, it might be expected that various birds or small mammals might be present, as those groups would likely have an easier time moving across barriers that act against larger animals.

Adoption of a standard log format (such as Log ASCII standard, las, used for oil/gas wells) for sedimentary records in the rift would be useful for sharing and disseminating data. The Oxford Lake-Level Database (OLLDB) provides text files in a standard format, but these only cover the late Quaternary and reflect lake level status rather than stratigraphy. The benefit of using LAS would be that for any given location/outcrop/core, the stratigraphy can be noted in addition to any number of data columns. Due to the oil and gas industry, there are already a number of programs available that automatically read and graphically display LAS files.

What is the uplift history during the period that hominins were evolving in the rift? Uplift of East Africa likely had a large impact on local climates, but has also been considered quite important with respect to global climate modeling. Uplift histories have been worked out for a few locations during a few time periods, however the full sequence of uplift for east African is not well constrained. One potential source of information may be the Congo Basin, as Moucha and Forte's (2011) simulation suggests that the Congo Basin may have been subsiding during the same time as the East African uplift due to mantle drawdown. It may be possible that this 
adjacent basin preserves a sedimentary record indicating the uplift history. The coastal region of Kenya may also preserved important sediments relating to uplift, however, due to tensions with Somalia and illicit pirate activity, studies in that area are currently considered unsafe.

How do the tropics respond to climate change? What happened in the tropics during the most recent glacial cycles? Current evidence indicates that during the last glacial period, the tropics were drier than today while the temperate-zone deserts were wetter (Broecker et al. 1998; Broecker and Liu 2001; Bessems et al. 2008). Links between lake sediments within the rift have already been tied to the El-Niño Southern Oscillation (ENSO) events (Damnati and Taieb 1995) and possible Milankovitch cycles (Trauth, Deino, and Strecker 2001; Trauth et al. 2003; Deino:2006ul, Trauth et al. 2007; Ashley, Tactikos, and Owen 2009). The isolation of the local volcano-tectonic events on lake levels from the regional climate signal should allow for a more robust comparison with global climate changes, and potentially strengthen the argument for these proposed links. A more accurate uplift history would also allow for better climate modeling to examine relations between the tropics and northern latitudes.

There is also a need for more data. The need for better geochronological information related to the rift volcanics has been mentioned numerous times in this work and at a recent meeting of scientists working on the East African Rift. However, there is also the need for more sedimentary data related to the lakes associated with the rift. A large scale drilling program has been suggested for several of these rift lakes to acquire a continuous sediment record that spans the period of time that hominins were occupying the rift (Andrew Cohen et al. 2009; Hamilton et al. 2010). A recent report by Hamilton et al. (2010), specifically lists the need for improvements to be made to our understanding of the climate in East 
Africa in order to understand human evolution. A good general understanding of climate patterns exists for these regions, but not on the time scales that would be important to small hominin populations. A 10-20 year research initiative was suggested, involving a drilling program covering both modern lake basins (Victoria, Turkana, Magadi) and paleolake deposits (Tugen Hills, Olorgesailie). Unfortunately a related project (Behrensmeyer et al. 2009) focusing specifically on Lake Magadi and the Olorgesailie deposits has not yet been funded (T. Lowenstein, pers. comm.). At the fall 2012 GeoPRISMS workshop on the East African Rift, it was mentioned that funding was secured to drill several important hominin sites in Ethiopia and Kenya. In this project, cores will be drilled during 2013-2014 in the Northern Awash, Chew Bahir, West Turkana, Tugen Hills, and Lake Magadi basins (A. Cohen, pers. comm.). The need for more data is thus widely recognized by the larger scientific community, and hopefully these additional coring efforts will better constrain basin evolution histories and climate trends.

Ideally the cores collected from the above-mentioned efforts will help in the separation of volcano-tectonic events and true climate signals. Even in a relatively short core from Lake Magadi $(10 \mathrm{~m})$, it was suggested that changes in hematite and goethite concentrations represented stream capture during a high stand in the early Holocene (Williamson et al. 1993). Similar analyses over longer cores could provide important clues regarding basin inputs, which may help distinguish periods of drainage rearrangement versus climate changes.

It quite likely that the lake records suffer from the same problem as the hidden volcanic volumes. The proposed scientific drilling programs are generally geared towards collecting sediments above the shallowest underlying volcanics. Very deep wells would provide important information 
on the volcanic stratigraphy and interbedded sediments, however, unless somehow leveraged in conjunction with geothermal exploration, such wells would likely be prohibitively expensive. Detailed seismic would likely be the most cost-effective method of assessing the sub-volcanic sedimentary record. In particular, 3D seismic techniques can sometimes provide enough resolution to identify buried stream channels, which could be very helpful in landscape reconstructions. Quantitative seismic geomorphology studies such as that by Wood (2007) can be conducted due to the amazing subsurface details acquired by 3D seismic surveys. These studies would likely be most successful for the recent sedimentary record above the volcanics, however some success in imaging sediments under basalts has been achieved by utilizing lower frequencies (e.g. Fainstein et al. 2012). Most such studies in the literature are done in coastal waters using ship-borne instruments, so it is unclear if similar results would be if obtained in a continental setting. A number of reflection seismic lines were run in the Turkana region (e.g. Morley, Karanja, et al. 1999) and the sub-volcanic data seems reasonably well imaged, however the thickness of the volcanics is less than 500m in the Lokichar basin. Imaging under the Plateau Phonolite group may be more of a technical challenge.

There are obviously many topics of research that could use more attention and detailed study with regards to understanding the East African Rift dynamic with climate and biology. The complex relationship between volcano-tectonic events and the sedimentary record means that improving the understanding of the timing and distribution of volcanic eruptions would allow for better interpretation of the sedimentary record and how that translates into climate and environment reconstructions. 


\section{Discussion \& Conclusions}

While easily accessible, map-based volume estimates are affected by biases against the recognition of small volcanic events, and seem to result in significant under reporting of total volume. While estimated volume derived from the presented digital map is similar to previous estimates by Baker (1987), Baker, Mohr \& Williams (1972), and Williams (1972), it is significantly less than the $310,000 \mathrm{~km}^{3}$ indicated by the seismic data.

Seismic data also indicate that much of the erupted volume is outside of the modern rift valley. This likely represents accumulation of material in a pre-rift depression, which is commonly discussed as an early stage in rift development for this region (e.g. Baker et al. 1971; King 1978). Thus, while outside of the modern rift valley, these eruptive units may still be within a larger rift-related depression which may be more of a circular feature, in contrast to the linear nature of the rift valley. In geophysical surveys, the rift valley is strongly delineated (Simiyu and Keller 2001), similar to what is seen for the buried Proterozoic Midcontinent Rift in North America (e.g. Ojakangas, Morey, and Green 2001). While it is expected that the significant amount of volcanic material flanking the Kenya Rift should be visible in gravity data, in theory, data presented by Simiyu and Keller (2001) is quite complex and this does not seem to be the case. The gravity data is largely driven by the depth of the basement, and the presence of intrusions, meaning some volcanic centers are gravity highs, but others are gravity lows due to dominance of pyroclastic material and lack of significant crustal intrusions. The faulting, changing depth to basement, and differential intrusive material makes the gravity data heterogenous which may help "hide" material outside the rift that would be visible in seismic data. It seems likely that most continental rift systems would be similarly complex, and excess material outside the rift axis may be hidden by this complexity when using certain geophysical techniques. The Midcontinent Rift under the Michigan basin is 
common imaged using gravity, and if additional material filled a pre-rift downwarp, the excess material outside the axial rift graben may have helped enhance crustal subsidence after the thermal anomaly potentially responsible for the rifting was removed and/or when the crust was later stressed by the formation of the Appalachians (Howell and van der Pluijm 1990).

Examining temporal trends in eruptive volumes (Figure 3.11) for the Kenya Rift clearly indicates a lack of observable small sized events in the older record, where some periods only show eruptive events over $1000 \mathrm{~km}^{3}$. This gap in the record may be the largest reason why there is such a large discrepancy between the map-based and seismic-based volume estimates. While small, these events are especially numerous during the last 5 million years, and their significant effect on cumulative volume is clearly shown in Figure 3.9. The bias against the recognition of small events can be corrected for by assuming the modern record accurately represents typical rift activity. A good convergence of the map-derived estimate and seismic estimate is then achieved by modeling past activity to resemble the modern eruptive size distributions. This technique is a simple, yet novel use of the available data. Future application of extreme value theory, such as that employed by Deligne et al. (2010) for examining gaps in the historical volcanic record, could be useful.

Overall, total volume derived from mapped areas should be treated as a minimum value, unless the study area is very young and the mapped units are known to sit directly on basement rocks. The results of this study suggest that volume versus time plots can indicate if there are biases in preservation within a system, and the data may allow for the correction of such biases. These corrections rely on an assumption that processes associated with rift related volcanism have remained relatively consistent through time. However, as noted by Deligne et al. (Deligne, Coles, and Sparks 2010), some very large events may operate in fundamentally different ways than more common, smaller, events, 
which can make the extreme events hard to model. Due to the nature of the biases observed in the Kenya Rift, it appears that the extreme events are the most likely to be noticed, while it is the frequent small eruptions that are missing from the record. This may indicate that the method used here to correct biases in the older record may be more robust than if the bias had been in the other direction, and involved trying to reconstruct extreme events from common events.

Additionally, the technique of utilizing age date frequencies as a proxy for eruptive activity is considered undesirable due to incomplete dating of rift material. Such a technique may work in a well dated system, but comparing the age-date based record presented by Morley (1999) with the map-based volume trends presented in Figure 3.7 shows distinct differences in pattern and periods of perceived maximum activity. However, as suggested by Morley (1999), the age-date based technique may be good for recognizing lulls in activity, as those periods match reasonably well between the two sets of records.

Examining overall trends in volcanic activity, there is a southward migration of the rift-related volcanism over time, which has previously been recognized (e.g. Macdonald et al. 2001; Macdonald 2003). However, analysis of the centroid positions of each formation indicates that this southern propagation did not progress at a constant rate. Instead, there are several periods of expansion followed by stasis, where volcanism is active but does not seem to be migrating. A brief period of activity contraction between 6.5 and 10 million years ago coincides with active basin formation in the Western Branch. Basement structures such as the Aswa shear zone physically link the two rift branches in the subsurface, and seem to exert control over the rift structure, as a prominent bend in the rift occurs when it crosses this structure (e.g. Kampunzu, Bonhomme, and Kanika 1998; Chorowicz 2005; Aanyu 2010). This allows for a suggested causal relationship between the concurrent propagation and extension 
in the Western Rift and the equatorial concentration of activity in Kenya observed in the data presented here.

No simple compositional trends are observed when examining changes in bulk lithology through time in the Kenya Rift. Erupted lithology switches between mafic and silicic dominated, with some periods having near equal output. Intermediate products (e.g. phonolites) only dominate during the mid-Miocene, which was when the plateau phonolite series was erupted across much of the Kenya Dome (e.g. Macdonald 2003). Positional trends indicate that basalts and rhyolites are more common in the northern part of the rift, while trachytes are predominantly located south of the equator. As the rift's age decreases to the south, this pattern may be age (extent of rifting) related. Another important connection is that Turkana is a site of previous Mesozoic rifting, and it may be easier for mafic melts to reach the surface. Baker et al. (1977) note that the high density of parental melts may generally prohibit their eruption, especially if connections with deeper sources are cut off. In such cases, those melt would fractionate and large eruptions of lower density lavas like phonolites and trachytes would occur rather instead of basalts. The unique "double rifted" structure at Turkana, in terms of the Kenya Rift, may be one reason for this eruptive zonation of prevalent basalt in the north, and more silicic material to the south.

Carbonatites seem to have a very narrow range, and are preferentially found in the youngest, southern parts of the rift. Older examples of carbonatite products are found in the Nyanza branch, which runs between the main Kenya Rift and Lake Victoria. These older volcanic centers are still exposed due to the relatively low volcanic activity associated with the Nyanza rift branch. Given that there are old examples, the carbonatites may be a "trail blazing" product that is erupted during initial stages of rift development. Their confinement to the youngest parts of the modern rift may be a consequence of preferential exposure, in that they are present at depth under most of the rift length, but have not yet been buried 
where the rift is young. Given that the equatorial phonolites have been replaced by trachytes, it is hinted that there may be lithologic progression with the simplest explanation being the amount of extension. If carbonatites are trailblazing, phonolites may come next, pre-dating the formation of large boundary faults on the rift. As extension continues, conditions may change such that trachytes replace phonolites in regions where the rift is well defined. Perhaps the end result is exemplified by the region around Lake Turkana where basalts can easily reach the surface, and fractionation produces rhyolites rather than trachytes and phonolites. It is however important to note that these would only be large-scale trends, while modern smale-scale eruptions can be highly heterogenous, with a single cone erupting trachyte, phonolite, and basalt.

Volcanic activity is prevalent to the east of the modern rift valley, and these extrusive products are dominantly comprised of basalt or mixed volcanic centers. In contrast, the phonolites, trachytes, and carbonatites are more closely associated with the narrow region defined by the rift valley. While the flood phonolites cover a large portion of the Kenya Dome as noted above, the centroid for these massive eruptions is closely associated with the location of the modern rift.

Based on volumes and age durations laid out by Bryan et al. (2002) and Bryan (2005), the Kenya Rift mostly qualifies as a Silicic Large Igneous Province (SLIP). Unlike the basalt-dominated Large Igneous Provinces (LIPs), SLIPs are generally emplaced over a long period of time (40 Ma), and are dominated by silicious eruptive material and ignimbrites. However, Bryan et al. (2002) indicate that there are no intermediate examples of a volcanic province that has near equal proportions of mafic and silicic material. Compositional data for the Kenya Rift indicates that it is such an example. Williams (1972) calculated a near equivalent mafic:silica ratio, with basalts being slightly dominant, however, the volumes calculated in this work indicate silicious products are slightly dominant. 
In either case, the Kenya Rift extrusives are very definitely an example of a midmember between the composition of SLIPs and LIPs, while the eruptive behavior is more "SLIP-like". While continental rifts are typically recognized as being bimodal in their eruption compositions (e.g. Bryan et al. 2002; Ayalew et al. 2002), they generally fall into the SLIP or LIP end members. For example, the Proterozoic Midcontintent Rift System (MRS) is about 75\% basalt and 25\% rhyolite based on studies on the north shore of Lake Superior (Vervoort et al. 2007), and the SLIPs mentioned by Bryan et al. (2002) are over $75 \%$ silicic composition. The early volcanic history at the Rio Grande Rift, is complicated due to superimposed volcanics from both the Great Basin and rift system, but the more recent record ascribed to the rift is dominantly basaltic with some basaltic andesite and rhyolite (Keller et al. 1991).

Instantaneous, or maximum, eruptive rates are currently not possible due to the lack of age dates on certain important formations that are known to be quite voluminous and/or explosive. Overall fluxes from the rift since initiation are more robust as they bypass the need for well dated individual units. Calculated mass fluxes of material from the Kenya Rift are $12.5 \mathrm{Tg} / \mathrm{yr}$ of silicic and intermediate composition plus $12.2 \mathrm{Tg} / \mathrm{yr}$ of mafic composition. To compare with other rifts or divergent boundaries, it is considered important to also correct for length of the system. The length-normalized total mass flux for the Kenya Rift is $0.03 \mathrm{Tg} / \mathrm{yr}$ $\mathrm{km}$, which is similar to that of a modern "ultra-slow" spreading ridge. However, despite this similarity to an active divergent margin, data presented by Ziegler and Cloetingh (2004) suggests that there are no concrete identifying characteristics that indicate the potential success or failure of a rift.

Comparisons of the volcanic and lacustrine trends show similar patterns, which makes sense as both are ultimately controlled by the development and propagation of the rift. Thus, the southward and eastward trends seen in the volcanic data are mimicked by the lacustrine deposits, but with a delay of a few 
million years. If the volcanism is a proxy for rift migration in general, initial lacustrine deposition may be a proxy for actual rift faulting, potentially caused by the earlier removal of magma and gravity collapse of the overlying crust (Baker et al. 1977) . Earliest lacustrine deposition generally post-dates initial volcanism in a region by about 5 million years. As volcanism is generally thought to pre-date the formation of rift faults (e.g. Macdonald 2003), it is hypothesized here that actual rift graben development occurs during the window between these two events. Baker and Mitchell (1976) note that volcanism, at least in the relatively modern southern rift, generally ceased during periods of major rift faulting, thus the initial lacustrine deposition in a region may be closely tied to these earliest fault motions, filling the new depression during the following hiatus in volcanic activity.

Examining overall patterns of rift system development, an interesting correlation can be drawn between the East African Rift System (EARS) and the Midcontinent Rift System (MRS) of North America. The MRS is only known to have two branches, one that runs from Kansas to the Upper Peninsula of Michigan, and the second through the Lower Peninsula of Michigan (e.g. Ojakangas and Dickas 2002). While the Lake Nipigon region is sometimes considered a third arm of the MRS, the dominance of sills rather than dikes indicates the region was nonextensional during volcanic emplacement, and associated faults are suggested to be due to thermal subsidence rather than extension (Hart and MacDonald 2007).

Except for exposures around Lake Superior, the two recognized rift arms are only seen via geophysical methods as they are deeply buried by more recent sediments. This 2-arm scenario is not typical of the "textbook" examples of rifting, which generally start with the formation of a triple junction, followed by spreading and abandonment of one arm. New age data from the Main Ethiopian Rift (MER) however, indicates that the East African Rift System started with only 2 arms; the Red Sea and Gulf of Aden, which began developing around $30 \mathrm{Ma}$. The MER started near Lake Turkana, nearly $1000 \mathrm{~km}$ to the south, then propagated 
northward to create the triple junction at $11 \mathrm{Ma}$ (Wolfenden et al. 2004). That we see only two arms in the MRS may be typical of rifts despite the common textbook renderings. One possibility is that a third arm related to the MRS may have developed to the north, as there are several prominent suture zones (e.g. the Abitibi greenstone belt) that could have provided weak zones for a rift to propagate along. Given that the Main Ethiopian Rift started nearly $1000 \mathrm{~km}$ away from the modern triple junction, if the MRS did have a similar evolution, any evidence may be under the Paleozoic sediments of the Hudson Bay basin.

Alternatively, it may be possible that a third arm will not develop without a preexisting weak spot to propagate from. It is intriguing that the MER migrated north from the Lake Turkana region, which is also the location where the EARS crosses the Mesozoic Anza graben, which was a rift zone associated with the separation of Madagascar (Delvaux 1991; Greene, Richards, and Johnson 1991). Similarly, recent data suggests that the earliest activity of the Western Branch is in the Rukwa Rift basin (Roberts et al. 2012) and is of similar age (25 $\mathrm{Ma}$ ) to the earliest expression of the MER (Wolfenden et al. 2004). The Rukwa basin is also located near the intersection of the EARS and an older rift, in this case the Luangwa Rift, which was originally a Karoo basin associated with the breakup of Pangea (e.g. Delvaux 1991; Catuneanu et al. 2005). These preweakend zones may allow for the development of one of the rift arms at a distance, and it is unclear what the resulting rift geometry would be without these weak points.

While the MRS allows for a comparison with an ancient rift valley in terms of volcanic volume, composition, and rift geometry, it does not allow for the study of how such a geologic event influences biologic communities. At $1.1 \mathrm{Ga}$, the MRS formed during a period where the only obvious fossil remains are those of stromatolites, which would have been passive inhabitants of a flooded rift valley. The EARS on the other hand provides crucial exposures of fossil-laden 
sediments that may allow for the interaction between biologic communities and volcanically and tectonically active landscapes to be investigated. Preliminary investigations conducted here suggests that human ancestors may have actively avoided parts of the rift that were highly eruptive, despite the presence of lakes. While there may be an aspect of volcanic avoidance, it has been recently recognized that there is a close association between hominins and tectonically active regions. Tectonic landscapes may have provided continual water supplies, physical protection, and enhanced local biodiversity, all of which may have made such regions attractive to human ancestors (Bailey, Reynolds, and King 2011; Reynolds, Bailey, and King 2011). At the same time, environmental fragmentation and volcanic activity may have led to high rates of mammal turn-over, and distinct patterns of isolation and dispersion, within the rift (Reynolds 2007), which may have implications for the number of hominin species associated with this structure.

Rift attraction, yet volcanic avoidance, could be further tested by more closely examining trends in other animal populations during this timespan. Less mobile, or habitat limited, animals may show different trends over time than more flexible animals that can easily migrate to other regions. Testing volcanic avoidance would also require paleoenvironment reconstructions to make sure trends are not simply habitat preference.

\subsection{Conclusions}

Comparisons of map-based and seismic volume estimates indicates significant biases inherent in using mapped surface geology for calculations of volume. Such preservational or observational biases can be recognized by changes in eruptive size frequencies, and if modern baseline activity can be identified the biases can be corrected for. Activity in the Kenya Rift is slightly more silicic than mafic, however activity is surprisingly balanced unlike other rift systems noted in the literature, SLIPs or LIPs. While the Kenya Rift has many characteristics of 
what has been defined for a SLIP, the near equal ratio of mafic and silicic products warrants either a new mid-member classification between SLIPS and LIPs, or a revised definition of what qualifies as a SLIP. However, due to the dominance of basalts in the Turkana region, Kenya may be an odd example due to influences of earlier rifting on erupted composition. If the Mesozoic rifting is the cause of the spatial distribution of basalts seen in the Kenya Rift, the output from this "twice rifted" region may have compositionally moved the Kenya Rift out of the normally defined SLIP composition window. In other words, the Kenya Rift may have been a perfectly normal SLIP by the definition of Bryan et al. (2002) if the area had not experienced Mesozoic rifting.

Mass fluxes normalized to rift length for the Kenya Rift are similar to that for a modern, "ultra-slow" mid-ocean ridge, though conclusions cannot be made regarding the eventual success or failure of the rift. Comparisons of different rifts made by other authors have found nothing intrinsic to a rift itself that could characteristically determine its eventual fate.

Examination of spatial trends in the rift is enhanced by simplifying the complex geometries of the mapped formations to a single centroid per formation. Trends are then easily observed by plotting centroids by time and either latitudinal or longitudinal position. Volcanism and lacustrine deposition both show migration to the south and east over time, with lacustrine deposition lagging the initial volcanism by a few million years. Initiation of lacustrine deposition is a potential proxy for rift faulting, and the set of initial volcanism and deposition could bracket first major fault movements. The volcanic expansion to the south progresses at an inconsistent rate, and activated sections of the rift generally remain active. The only observed period of volcanic contraction is correlated with pronounced activity in the Western Branch. Large scale basement features that physically connect the two rift branches may allow for a more direct coupling between these two rifts. 
Comparisons of volcanic activity and hominin sites indicates a gap in habitation near the equator which may be related to active rift volcanism. While hominin activity was abundant in the northern and southern sections of the Kenya Rift, very few remains are found in the central rift sector after 4 million years ago. This is despite the earliest hominid remains of the Kenya Rift being found in the equatorial sediments. While the change in distribution may be related to different habitat preferences between hominids and hominins, abundant volcanism around the equator during the last 4 Ma may have created physical and environmental barriers for larger species. While recent research suggests that hominins were particularly attracted to tectonically active landscapes, volcanic activity associated with the Kenya Rift may have driven populations out of some areas, and resulted in population fragmentation. 


\section{References}

Aanyu, K. 2010. "Influence of Pre-Existing Fabrics on Fault Kinematics and Rift Geometry of Interacting Segments: Analogue Models Based on the Albertine Rift (Uganda), Western Branch- ...." Journal of African Earth Sciences.

Abebe, B, V Acocella, T Korme, and D Ayalew. 2007. "Quaternary Faulting and Volcanism in the Main Ethiopian Rift." Journal of African Earth Sciences 48 (2-3) (June): 115-124. doi:10.1016/j.jafrearsci. 2006.10.005.

Albaric, J, J Deverchère, C Petit, J Perrot, and Bernard Le Gall. 2009. "Crustal Rheology and Depth Distribution of Earthquakes: Insights From the Central and Southern East African Rift System." Tectonophysics 468 (1-4): 28-41.

Alley, Sharon L. The Late Quaternary South Atlantic; a Nannoplankton Study. The Late Quaternary South Atlantic; a Nannoplankton Study. Salt Lake City, UT: University of Utah.

Ambrose, Stanley, Christopher Bell, Raymond Bernor, J-R Boisserie, CM Darwent, David DeGusta, Alan Deino, et al. 2007. "The Paleoecology and Paleogeographic Context of Lemudong'O Locality 1, a Late Miocene Terrestrial Fossil Site in Southern Kenya." Kirtlandia 56: 38-52.

Ambrose, Stanley, CM Nyamai, EM Mathu, and MAJ Williams. 2007. "Geology, Geochemistry, and Stratigraphy of the Lemudong'O Formation, Kenya Rift Valley." Kirtlandia 56: 53-64.

Ambrose, Stanley, LJ Hlusko, D Kyule, AL Deino, and M Williams. 2003. "Lemudong'o: a New 6 Ma Paleontological Site Near Narok, Kenya Rift Valley." Journal of Human Evolution 44 (6): 737-742.

Ambrose, Stanley, MD Kyule, and Leslea Hlusko. 2007. "History of

Paleontological Research in the Narok District of Kenya." Kirtlandia 56: 1-37.

Ananthaswamy, Anil. 2012. "Plume Power: Deep Engines of Earthquakes and Volcanoes." New Scientist (2878) (August 21): 38-41. http:// www.newscientist.com/article/mg21528781.600-plume-powerdeep-engines-of-earthquakes-and-volcanoes.html.

Anderson, Don L. 2005. "Scoring Hotspots: the Plume and Plate Paradigms." In Plates, Plumes, and Paradigms, ed. Gillian R. Foulger, James $\mathrm{H}$. Natland, Dean C. Presnall, and Don L Anderson, 31-54. Boulder, CO: Geological Society of America.

Anderson, Don L, and James H. Natland. 2005. "A Brief History of the Plume Hypothesis and Its Competitors: Concept and Controversy." In Plates, Plumes, and Paradigms, ed. Gillian R. Foulger, James $\mathrm{H}$. Natland, Dean C. Presnall, and Don L Anderson, 119-145. Boulder, CO: Geological Society of America. 
Anon. 2012. "Nairobi Rainfall." Kenya Meteorological Department. http:// www.meteo.go.ke/customer/climat/rain.html.

Argus, Donald F, Richard G Gordon, and Charles DeMets. 2011. "Geologically Current Motion of 56 Plates Relative to the No-Net-Rotation Reference Frame." Geochemistry Geophysics Geosystems 12 (Q11001) (November 5): 13. doi:10.1029/2011GC003751. http:// geoscience.wisc.edu/ chuck/MORVEL/index.html.

Ashley, Gail M, J Maitima Mworia, AM Muasya, Richard Bernhart Owen, SG Driese, VC Hover, Robin W Renaut, MF Goman, S Mathai, and SH Blatt. 2004. "Sedimentation and Recent History of a Freshwater Wetland in a Semi-Arid Environment: Loboi Swamp, Kenya, East Africa." Sedimentology 51 (6): 1301-1321.

Ashley, Gail M, Joanne C Tactikos, and Richard Bernhart Owen. 2009. "Hominin Use of Springs and Wetlands: Paleoclimate and Archaeological Records From Olduvai Gorge ( 1.79-1.74 Ma)." Palaeogeography Palaeoclimatology Palaeoecology 272 (1-2) (January 2): 1-16. doi: 10.1016/j.palaeo.2008.10.016.

Ayalew, D, P Barbey, B Marty, L Reisberg, G Yirgu, and R Pik. 2002. "Source, Genesis, and Timing of Giant Ignimbrite Deposits Associated with Ethiopian Continental Flood Basalts." Geochimica Et Cosmochimica Acta 66 (8): 1429-1448.

Bailey, D Ken, and Alan R Woolley. 2005. "Repeated, Synchronous Magmatism Within Africa: Timing, Magnetic Reversals, and Global Tectonics." In Plates, Plumes, and Paradigms, ed. Gillian R. Foulger, James H. Natland, Dean C. Presnall, and Don L Anderson, 388:365-377. Boulder, CO: Geological Society of America.

Bailey, Geoffrey N, Sally C Reynolds, and Geoffrey C P King. 2011. "Landscapes of Human Evolution: Models and Methods of Tectonic Geomorphology and the Reconstruction of Hominin Landscapes." Journal of Human Evolution 60 (3) (March 1): 257-280. doi: 10.1016/j.jhevol.2010.01.004.

Baker, Brian. 1954. Geology of the Southern Machakos District, Degree Sheet 52, S.W. Quadrant. Vol. 27. Nairobi: Kenya Geological Survey.

Baker, Brian. 1958. "Geology of the Lake Magadi Area." Kenya Geologic Survey 42: 1-85.

Baker, Brian. 1963. "Geology of the Area South of Magadi." Kenya Geologic Survey 61: 1-33.

Baker, Brian. 1967. "Geology of the Mount Kenya Area." Kenya Geologic Survey 79: 1-90.

Baker, Brian. 1975. "Geology and Geochemistry of the Ol Doinyo Nyokie Trachyte Ignimbrite Vent Complex, South Kenya Rift Valley." Bulletin Volcanologique 39 (3): 420-440.

Baker, Brian. 1987. "Outline of the Petrology of the Kenya Rift Alkaline Province." Geological Society London Special Publications 30 (1): 293. 
Baker, Brian, and John Graham Mitchell. 1976. "Volcanic Stratigraphy and Geochronology of the Kedong-Olorgesailie Area and the Evolution of the South Kenya Rift Valley." Journal of the Geological Society 132 (5): 467-484.

Baker, Brian, LAJ Williams, JA Miller, and FJ Fitch. 1971. "Sequence and Geochronology of the Kenya Rift Volcanics ." Tectonophysics 11: 191-215.

Baker, Brian, and J. Wohlenberg. 1971. "Structure and Evolution of the Kenya Rift Valley.." Nature 229 (5286) (February 19): 538-542.

Baker, Brian, P Mohr, and L Williams. 1972. "Geology of the Eastern Rift System of Africa." Special Paper - Geological Society of America 136.

Baker, Brian, G Goles, W Leeman, and M Lindstrom. 1977. "Geochemistry and Petrogenesis of a Basalt-Benmoreite-Trachyte Suite From the Southern Part of the Gregory Rift, Kenya." Contributions to Mineralogy and Petrology 64 (3): 303-332.

Baker, Brian, John Graham Mitchell, and L A J Williams. 1988. "Stratigraphy, Geochronology and Volcano-Tectonic Evolution of the KedongNaivasha-Kinangop Region, Gregory Rift Valley, Kenya." Journal of the Geological Society 145 (1): 107-116.

Baldridge, WS, FV Perry, DT Vaniman, LD Nealey, BD Leavy, AW Laughlin, P Kyle, Y Bartov, G Steinitz, and ES Gladney. 1991. "Middle to Late Cenozoic Magmatism of the Southeastern Colorado Plateau and Central Rio Grande Rift(New Mexico and Arizona, U. S. a.): a Model for Continental Rifting." Tectonophysics 197 (2-4): 327-354.

Basell, Laura S. 2008. "Middle Stone Age (MSA) Site Distributions in Eastern Africa and Their Relationship to Quaternary Environmental Change, Refugia and the Evolution of Homo Sapiens." Quaternary Science Reviews 27 (27-28) (December 1): 2484-2498. doi:10.1016/ j.quascirev.2008.09.010.

Bastow, I D, Derek Keir, and Eve Daly. 2011. "The Ethiopia Afar Geoscientific Lithospheric Experiment (EAGLE): Probing the Transition From Continental Rifting to Incipient Seafloor Spreading." In Volcanism and Evolution of the African Lithosphere, ed. L Beccaluva, G Bianchini, and Marjorie Wilson, 51-76. Geological Society of America.

Bauernhofer, AH, CA Hauzenberger, E Wallbrecher, G Hoinkes, S Muhongo, and EM Mathu. 2008. "Pan-African Deformation in Se Kenya and Ne Tanzania: Geotectonic Implications for the Development of the North-Central Mozambique Belt." African Journal of Science and Technology 9 (1) (June 4): 50-71.

Bear, L M, and Geological Survey of Kenya. 1955. Geology of the Taveta Area : Explanation of Degree Sheets 64 N.E. and 64 S.E. (with Coloured Geological Maps). Vol. 32. Nairobi: Kenya Geological Survey. 
Beccaluva, L, G Bianchini, C Natali, and F Siena. 2009. "Continental Flood Basalts and Mantle Plumes: a Case Study of the Northern Ethiopian Plateau." Journal of Petrology.

Behr, HJ. 2002. "Magadiite and Magadi Chert: a Critical Analysis of the Silica Sediments in the Lake Magadi Basin, Kenya." SEPM Special Publication: Sedimentation in Continental Rifts 73: 257-273.

Behrensmeyer, Anna, Alan Deino, Andrew Hill, John Kingston, and JJ Saunders. 2002. "Geology and Geochronology of the Middle Miocene Kipsaramon Site Complex, Muruyur Beds, Tugen Hills, Kenya." Journal of Human Evolution 42 (1-2): 11-38.

Behrensmeyer, Anna, Richard Potts, Alan Deino, and Peter Ditchfield. 2002. "Olorgesailie, Kenya: a Million Years in the Life of a Rift Basin." SEPM Special Publication: Sedimentation in Continental Rifts 73: 97-106.

Behrensmeyer, Anna, T K Lowenstein, R B Owen, R Potts, and Robin W Renaut. 2009. "A Proposal to Drill the Olorgesailie and Magadi Basins, Southern Kenya Rift.." Unpublished Proposal (March 1): 1-11.

Bergner, A G N, M R Strecker, M H Trauth, A Deino, F Gasse, P Blisniuk, and M Dühnforth. 2009. "Tectonic and Climatic Control on Evolution of Rift Lakes in the Central Kenya Rift, East Africa." Quaternary Science Reviews 28 (25-26) (December 1): 2804-2816. doi:10.1016/ j.quascirev.2009.07.008.

Bergner, Andreas, and MH Trauth. 2004. "Comparison of the Hydrological and Hydrochemical Evolution of Lake Naivasha (Kenya) During Three Highstands Between 175 and 60 Kyr BP." Palaeogeography Palaeoclimatology Palaeoecology 215 (1-2): 17-36.

Bergner, Andreas, MH Trauth, and B Bookhagen. 2003. "Paleoprecipitation Estimates for the Lake Naivasha Basin (Kenya) During the Last 175 Ky Using a Lake-Balance Model." Global and Planetary Change 36 (1-2): 117-136.

Bessems, Ilse, D Verschuren, JM Russell, J Hus, F D van der Meer, and Brian Cumming. 2008. "Palaeolimnological Evidence for Widespread Late 18th Century Drought Across Equatorial East Africa."

Palaeogeography Palaeoclimatology Palaeoecology 259 (2-3): 107-120.

Birt, CS, PKH Maguire, MA Khan, H Thybo, G Randy Keller, and JP Patel. 1997. "The Influence of Pre-Existing Structures on the Evolution of the Southern Kenya Rift Valley-Evidence From Seismic and Gravity Studies." Tectonophysics 278 (1-4): 211-242.

Bishop, WW, and Martin Pickford. 1975. "Geology, Fauna and Palaeoenvironments of the Ngorora Formation, Kenya Rift Valley." Nature 254 (5497): 185-192. doi:10.1038/254185a0.

Bishop, William, Andrew Hill, and Martin Pickford. 1978. "Chesowanja: a Revised Geological Interpretation.” In Geological Background to Fossil Man, 
ed. Walter W. Bishop, 309-327. Edinburgh: Scottish Academic Press.

Black, Benjamin A, Linda T Elkins-Tanton, Michael C Rowe, and Ingrid Ukstins Peate. 2012. "Magnitude and Consequences of Volatile Release From the Siberian Traps." Earth and Planetary Science Letters 317-318 (February 1): 363-373. doi:10.1016/j.epsl.2011.12.001.

Blakey, Ronald, and Wayne Ranney. 2008. Ancient Landscapes of the Colorado

Plateau. Grand Canyon Association.

Blome, Margaret Whiting, Andrew S Cohen, Christian A Tryon, Alison S Brooks, and Joellen Russell. 2012. "The Environmental Context for the Origins of Modern Human Diversity: a Synthesis of Regional Variability in African Climate 150,000-30,000 Years Ago." Journal of Human Evolution 62 (5) (May 1): 563-592.

Brachert, Thomas Christian, Gerhard B Brügmann, Dieter F Mertz, Ottmar Kullmer, Friedemann Schrenk, Dorrit E Jacob, Immaculate Ssemmanda, and Heinrich Taubald. 2010. "Stable Isotope Variation in Tooth Enamel From Neogene Hippopotamids: Monitor of Meso and Global Climate and Rift Dynamics on the Albertine Rift, Uganda." International Journal of Earth Sciences 99 (7) (October 4): 1663-1675. doi:10.1007/s00531-010-0518-1.

Broecker, Wallace, and Tanzhuo Liu. 2001. "Rock Varnish: Recorder of Desert Wetness?." GSA Today 11 (8): 4-10.

Broecker, Wallace, D Peteet, I Hajdas, J Lin, and E Clark. 1998. "Antiphasing Between Rainfall in Africa'S Rift Valley and North America'S Great Basin." Quaternary Research 50 (1): 12-20.

Brotzu, P, L Morbidelli, M. Nicoletti, EM Piccirillo, and G Traversa. 1984. "Miocene to Quaternary Volcanism in Eastern Kenya: Sequence and Geochronology." Tectonophysics 101 (1): 75-86.

Brown, Barbara, Francis Brown, and A Walker. 2001. "New Hominids From the Lake Turkana Basin, Kenya." Journal of Human Evolution 41 (1): 29-44.

Brown, Francis H, and IAN McDougall. 2011. "Geochronology of the Turkana Depression of Northern Kenya and Southern Ethiopia." Evolutionary Anthropology: Issues, News, and Reviews 20 (6) (December 14): 217-227. doi:10.1002/evan.20318.

Brown, Francis H, F Clark Howell, and G. G. Eck. 1978. "Observations on Problems of Correlation of Late Cenezoic Hominid-Bearing Formations in the North Lake Turkana Basin." In Geological Background to Fossil Man, ed. Walter W. Bishop, 473-498. Edinburgh: Scottish Academic Press.

Bruhn, Ronald L, Francis H Brown, Patrick N Gathogo, and Bereket Haileab. 2011. "Pliocene Volcano-Tectonics and Paleogeography of the Turkana Basin, Kenya and Ethiopia." Journal of African Earth Sciences 59 (2-3) (February 1): 295-312. doi:10.1016/j.jafrearsci. 2010.12.002. 
Bryan, Scott E. 2005. "Silicic Large Igneous Provinces." MantlePlumes. http:// www.mantleplumes.org/SLIPs.html.

Bryan, Scott E., Teal R. Riley, Dougal Jerram, Christopher J. Stephens, and PT Leat. 2002. "Silicic Volcanism: an Undervalued Component of Large Igneous Provinces and Volcanic Rifted Margins." Geological Society of America Special Paper 362: 99-120.

Buchanan, M J. 2010. "Stratigraphic and Structural Geology of Area 117, Koobi Fora Region, Northern Kenya." University of Utah Unpublished Thesis. May: 152.

Burke, K, LD Ashwal, and SJ Webb. 2003. "New Way to Map Old Sutures Using Deformed Alkaline Rocks and Carbonatites." Geology 31 (5): 391.

Burke, Kevin. 2011. "Plate Tectonics, the Wilson Cycle, and Mantle Plumes: Geodynamics From the Top." Annual Review of Earth and Planetary Sciences 39 (1) (May 30): 1-29. doi:10.1146/annurevearth-040809-152521.

Butzer, KW, GL Isaac, JL Richardson, and C Washbourn-Kamau. 1972. "Radiocarbon Dating of East African Lake Levels." Science 175 (4026): 1069.

Camp, Victor E., Martin E. Ross, and William E. Hanson. 2003. "Genesis of Flood Basalts and Basin and Range Volcanic Rocks From Steens Mountain to the Malheur River Gorge, Oregon." Geological Society of America Bulletin 115: 105-128.

Caryl-Sue, Sean P. O'Connor, Mary Schons, Craig S Feibel, and Patricia Schwindinger. "Paleogeography of Lake Turkana." National Geographic Education. Scientists Study Rocks and Sediments to Reconstruct the Past. http://education.nationalgeographic.com/ education/media/paleogeography-lake-turkana/.

Catuneanu, O, H Wopfner, PG Eriksson, B Cairncross, BS Rubidge, RMH Smith, and Phillip Hancox. 2005. "The Karoo Basins of South-Central Africa." Journal of African Earth Sciences 43 (1-3): 211-253.

Chakrabarti, Ramananda, Asish R Basu, Alba P Santo, Dario Tedesco, and Orlando Vaselli. 2009. "Isotopic and Geochemical Evidence for a Heterogeneous Mantle Plume Origin of the Virunga Volcanics, Western Rift, East African Rift System." Chemical Geology 259 (3-4) (February 25): 273-289. doi:10.1016/j.chemgeo.2008.11.010.

Chang, Sung-Joon, and Suzan Van der Lee. 2011. "Mantle Plumes and Associated Flow Beneath Arabia and East Africa." Earth and Planetary Science Letters 302 (3-4) (February 1): 448-454. doi: 10.1016/j.epsl.2010.12.050.

Chapman, Gregory, and Maureen Brook. 1978. "Chronostratigraphy of the Baringo Basin, Kenya." In Geological Background to Fossil Man, ed. Walter W. Bishop, 6:207-223. Edinburgh: Scottish Academic Press. 
Charsley, T. 1987a. Geology of the Laisamis Area. Vol. 106. Degree Sheet 28 with Coloured 1:250 000 Geological Map and Results of Geochemical Exploration. Kenya Geological Survey.

Charsley, T. 1987b. Geology of the North Horr Area. Vol. 110. Degree Sheet 12 with Coloured 1:250,000 Geological Map. Kenya Geological Survey.

Chimoyi, Lucy Andere. 2009. A Critical Review of Current Water Use in Magadi

Township, Kenya with Recommendations for Long Term

Sustainable Management Practices. Johannesburg. http://

wiredspace.wits.ac.za/bitstream/handle/10539/7707/Lucy \%20Research\%20Report.pdf?sequence=2.

Chorowicz, J. 2005. "The East African Rift System." Journal of African Earth

Sciences 43 (1-3): 379-410.

Chu, Dezhi, and Richard G Gordon. 1998. "Current Plate Motions Across the Red

Sea." Geophysical Journal International 135 (2): 313-328. doi:

10.1046/j.1365-246X.1998.00658.x.

Clark, Grahame. 1977. World Prehistory in New Perspective. 3rd ed. Cambridge University Press.

Clarke, M C D, D G Woodhall, D Allen, and G Darling. 1990. "Geological, Volcanological and Hydrogeological Controls on the Occurrence of Geothermal Activity in the Area Surrounding Lake Naivasha, Kenya ": 1-141.

Clément, JP, M Caroff, C Hémond, Jean-Jacques Tiercelin, C Bollinger, H Guillou, and J Cotten. 2003. "Pleistocene Magmatism in a Lithospheric Transition Area: Petrogenesis of Alkaline and Peralkaline Lavas From the Baringo-Bogoria Basin, Central Kenya Rift." Canadian Journal of Earth Sciences 40 (9): 1239-1257.

Cogné, Jean-Pascal, and Eric Humler. 2004. "Temporal Variation of Oceanic Spreading and Crustal Production Rates During the Last 180 My." Earth and Planetary Science Letters 227 (3-4) (November 15): 427-439.

Cohen, Andrew. 1990. "Tectono-Stratigraphic Model for Sedimentation in Lake Tanganyika, Africa." AAPG Special Volumes M 50 (Lacustrine Basin Exploration: Case Studies and Modern Analogs): 137-150.

Cohen, Andrew, J R Arrowsmith, Anna Behrensmeyer, CJ Campisano, Craig Feibel, S Fisseha, R W Johnson, ZK Bedaso, CA Lockwood, and E Mbua. 2009. "Understanding Paleoclimate and Human Evolution Through the Hominin Sites and Paleolakes Drilling Project." Scientific Drilling (8): 60-65.

Cohen, AS, MJ Soreghan, and CA Scholz. 1993. "Estimating the Age of Formation of Lakes: an Example From Lake Tanganyika, East African Rift System." Geology 21 (6): 511.

Corti, Giacomo. 2009. "Continental Rift Evolution: From Rift Initiation to Incipient Break-Up in the Main Ethiopian Rift, East Africa." Earth Science 
Reviews 96 (1-2) (September 1): 1-53. doi:10.1016/j.earscirev. 2009.06.005.

Crossley, R. 1979. "The Cenozoic Stratigraphy and Structure of the Western Part of the Rift Valley in Southern Kenya." Journal of the Geological Society 136 (4): 393-405.

Crossley, R, and RM Knight. 1981. "Volcanism in the Western Part of the Rift Valley in Southern Kenya." Bulletin of Volcanology 44 (2): 117-128. Damnati, Brahim. 2000. "Holocene Lake Records in the Northern Hemisphere of Africa." Journal of African Earth Sciences 31 (2): 253-262.

Damnati, Brahim, and M Taieb. 1995. "Solar and ENSO Signatures in Laminated Deposits From Lake Magadi (Kenya) During the Pleistocene/ Holocene Transition." Journal of African Earth Sciences 21 (3): 373-382.

Davies, G. 1998. "A Channelled Plume Under Africa." Nature 395: 743-744.

Dawson, JB. 2008. "The Gregory Rift Valley and Neogene-Recent Volcanoes of

Northern Tanzania." Geological Society Memoir 33: 1-112.

Deino, AL, and Andrew Hill. 2002. "40Ar/39Ar Dating of Chemeron Formation Strata Encompassing the Site of Hominid KNM-BC 1, Tugen Hills, Kenya." Journal of Human Evolution 42 (1-2): 141-151.

Deino, AL, John Kingston, JM Glen, RK Edgar, and Andrew Hill. 2006.

"Precessional Forcing of Lacustrine Sedimentation in the Late Cenozoic Chemeron Basin, Central Kenya Rift, and Calibration of the Gauss/Matuyama Boundary." Earth and Planetary Science Letters 247 (1-2): 41-60.

Deino, AL, Manuel Domínguez-Rodrigo, and L Luque. 2006. "40Ar/39Ar Dating of the Pleistocene Peninj Group, Lake Natron, Tanzania.” AGU Fall Meeting Abstracts: 1771.

Deino, Alan, L Tauxe, M Monaghan, and Andrew Hill. 2002. "40Ar/39Ar

Geochronology and Paleomagnetic Stratigraphy of the Lukeino and Lower Chemeron Formations at Tabarin and Kapcheberek, Tugen Hills, Kenya." Journal of Human Evolution 42 (1-2): 117-140.

Delagnes, A, and H Roche. 2005. "Late Pliocene Hominid Knapping Skills: the Case of Lokalalei 2C, West Turkana, Kenya." Journal of Human Evolution 48 (5): 435-472.

Deligne, N I, S G Coles, and R S J Sparks. 2010. "Recurrence Rates of Large Explosive Volcanic Eruptions." Journal of Geophysical Research 115 (B6) (June 8). doi:10.1029/2009JB006554.

Delvaux, D. 1991. "The Karoo to Recent Rifting in the Western Branch of the East African Rift System: a Bibliographic Synthesis." Rapport Annuel 1989-1990: 63-83.

DeMets, Charles, Richard G Gordon, and Donald F Argus. 2010. "Geologically Current Plate Motions." Geophysical Journal International 181 (1) (April): 1-80. doi:10.1111/j.1365-246X.2009.04491.x. 
Dick, Henry J B, Jian Lin, and Hans Schouten. 2003. "An Ultraslow-Spreading Class of Ocean Ridge.." Nature 426 (6965) (November 27): 405412. doi:10.1038/nature02128.

Dodson, R G. 1953. Geology of the South-East Machakos Area, Degree Sheet 52, S. E. Quadrant. Vol. 25. Nairobi: Kenya Geological Survey.

Dodson, R G. 1971. Geology of the Area South of Lodwar : Degree Sheet 18, N.E. Quarter, with Coloured Geological Map. Vol. 87. Nairobi: Kenya Geological Survey.

Dodson, R G. 1991. Geology of the Barchuma-Kom Area. Vol. 93. Nairobi: Kenya Geological Survey.

Dodson, R G, and F J Matheson. 1991. Geology of the Area North-East of Marsabit. Vol. 94. Nairobi: Kenya Geological Survey.

Dominguez-Rodrigo, M, J Serrallonga, J. Juan-Tresserras, L Alcala, and L Luque. 2001. "Woodworking Activities by Early Humans: a Plant Residue Analysis on Acheulian Stone Tools From Peninj (Tanzania)." Journal of Human Evolution 40 (4) (April 1): 289-299. doi:10.1006/jhev. 2000.0466.

Dundas, D. L., and G.W. Awadalla. 1999. "Quarter Degree Sheet 16 \& 27 Loliondo." Geological Survey of Tanzania. Dodoma.

Dunkley, P N, M Smith, D J Allen, and W G Darling. 1993. The Geothermal Activity and Geology of the Northern Sector of the Kenya Rift Valley. British Geological Survey. Vol. 93.

Dvorak, John J., and Daniel Dzurisin. 1993. "Variations in Magma Supply Rate at Kilauea Volcano, Hawaii." Journal of Geophysical Research 98 (B12): 22255-22268. doi:10.1029/93JB02765.

Ebinger, CJ. 1989. "Geometric and Kinematic Development of Border Faults and Accommodation Zones, Kivu-Rusizi Rift, Africa." Tectonics 8 (1): 117-133.

Ebinger, Cynthia J. 2005. "Ebinger: the Bullerwell Lecture: Continental Break-Up: the East African Perspective." Astronomy and Geophysics 46 (2): $16-21$.

Ebinger, Cynthia J, and NH Sleep. 1998. "Cenozoic Magmatism Throughout East Africa Resulting From Impact of a Single Plume." Nature 395 (6704): 788-791.

Elmore, R Douglas. 1983. "Precambrian Non-Marine Stromatolites in Alluvial Fan Deposits, the Copper Harbor Conglomerate, Upper Michigan." Sedimentology 30: 829-842.

Eugster, H, and A Nissenbaum. 1980. Lake Magadi, Kenya, and Its Precursors. Hypersaline Brines and Evaporites.

Fainstein, Roberto, Rajesh Kalra, G. K. Prasad, S. Chandrashekhar, and C. Visweswara Rao. 2012. "Modern Sub-Basalt Seismic Imaging Deepwater Realm Offshore Southwest India." In, 1-7. http:// www.slb.com/ /media/Files/technical papers/misc/spgp241.pdf.

Fairburn, W A. 1963. "Geology of the North Machakos-Thika Area." Kenya Geologic Survey 59: 1-48. 
Fairburn, W A. 1966. Geology of the Fort Hall Area : Degree Sheet 44, S.W. Quarter (with Coloured Geological Map). Vol. 73. Nairobi: Kenya Geological Survey.

Fairhead, JD, John Graham Mitchell, and L A J Williams. 1972. "New K/Ar Determinations on Rift Volcanics of S. Kenya and Their Bearing on Age of Rift Faulting." Nature 238 (83): 66-69.

Feibel, Craig S. 2011. "A Geological History of the Turkana Basin." Evolutionary Anthropology: Issues, News, and Reviews 20 (6) (December 14): 206-216. doi:10.1002/evan.20331.

Findlater, Ian C. 1978. "Isochronous Surfaces Within the Plio-Pleistocene Sediments East of Lake Turkana." In Geological Background to Fossil Man, ed. Walter W. Bishop, 415-420. Edinburgh: Scottish Academic Press.

Foulger, Gillian R. 2007. "The 'Plate' Model for the Genesis of Melting Anomalies." In Plates, Plumes, and Planetary Processes, ed. Gillian R. Foulger and Donna M. Jurdy, 430:1-25. Boulder, CO: Geological Society of America.

Foulger, Gillian R., and Donna M. Jurdy, eds. 2007. Plates, Plumes, and Planetary Processes. Vol. 430. Special Paper. Boulder, CO: Geological Society of America.

Foulger, Gillian R., James H. Natland, Dean C. Presnall, and Don L Anderson, eds. 2005. Plates, Plumes, and Paradigms. Special Paper. Boulder, CO: Geological Society of America.

Franklin, Bryan M. 2009. Analysis and Performance of a UPC Implementation of a Parallel Longest Common Subsequence Algorithm. Michigan Technological University.

Frostick, LE. 1997. "The East African Rift Basins." African Basins 3: 187-209. Furman, T. 2006. "Tertiary Mafic Lavas of Turkana, Kenya: Constraints on East African Plume Structure and the Occurrence of High- Volcanism in Africa." Journal of Petrology 47 (6) (March 7): 1221-1244. doi: 10.1093/petrology/egl009.

Furman, T. 2007. "Geochemistry of East African Rift Basalts: an Overview." Journal of African Earth Sciences 48 (May 18): 147-160. doi: 10.1016/j.jafrearsci.2006.06.009.

Furman, T, JG Bryce, J Karson, and A lotti. 2004. "East African Rift System (EARS) Plume Structure: Insights From Quaternary Mafic Lavas of Turkana, Kenya." Journal of Petrology 45 (5): 1069.

Furman, T, JG Bryce, T. Rooney, B. Hanan, G Yirgu, and D Ayalew. 2006. "Heads and Tails: 30 Million Years of the Afar Plume." In The Afar Volcanic Province Within the East African Rift System, ed. G Yirgu, CJ Ebinger, and PKH Maguire, 259:97-121. Geological Society of London, Special Publications.

Garcin, Yannick, Annett Junginger, Daniel Melnick, Daniel O Olago, Manfred R Strecker, and Martin H Trauth. 2009. "Late Pleistocene-Holocene Rise and Collapse of Lake Suguta, Northern Kenya Rift." 
Quaternary Science Reviews 28 (9-10) (May 1): 911-925. doi: 10.1016/j.quascirev.2008.12.006.

Garnero, Edward J, Thorne Lay, and Allen McNamara. 2007. "Implications of Lower-Mantle Structural Heterogeneity for the Existence and Nature of Whole-Mantle Plumes." In Plates, Plumes, and Planetary Processes, ed. Gillian R. Foulger and Donna M. Jurdy, 430:79-101. Boulder, CO: Geological Society of America.

Gasse, F. 1990. "Tectonic and Climatic Controls on Lake Distribution and Environments in Afar From Miocene to Present." AAPG Special Volumes M 50 (Lacustrine Basin Exploration: Case Studies and Modern Analogs): 19-41.

Gathogo, Patrick N, Francis H Brown, and IAN McDougall. 2008. "Stratigraphy of the Koobi Fora Formation (Pliocene and Pleistocene) in the Loiyangalani Region of Northern Kenya." Journal of African Earth Sciences 51 (5) (August): 277-297. doi:10.1016/j.jafrearsci. 2008.01.010.

George, Rhiannon, Nick Rogers, and Simon Kelley. 1998. "Earliest Magmatism in Ethiopia: Evidence for Two Mantle Plumes in One Flood Basalt Province." Geology 26 (10) (October 1): 923-926. doi: 10.1130/0091-7613(1998)026<0923:EMIEEF>2.3.CO;2.

Gowlett, JAJ, and RH Crompton. 1994. "Kariandusi: Acheulean Morphology and the Question of Allometry." African Archaeological Review 12 (1): 342.

Greene, LC, DR Richards, and RA Johnson. 1991. "Crustal Structure and Tectonic Evolution of the Anza Rift, Northern Kenya." Tectonophysics 197 (2-4): 203-211.

Grommé, CS, TA Reilly, AE Mussett, and RL Hay. 1970. "Palaeomagnetism and Potassium-Argon Ages of Volcanic Rocks of Ngorongoro Caldera, Tanzania." Geophysical Journal International 22: 101-115.

Guest, N J. 1953. "The Geology and Petrology of the Engaruka-OIDonyo L'engaiLake Natron Area of Northern Tanganyika Territory." Unpublished Dissertation Univ. of Sheffield [U.K.]: 1-224.

Guest, N J, and R Pickering. 1966. "Kibangaini." Tanzania Mineral Resources Division. Dodoma: Ministry of Industries, Mineral Resources and Power.

Guest, N J, R Pickering, and Tanzania Mineral Resources Division. 1966. "Gelai \& Ketumbeine." Mineral Resources Division, Tanzania. Dodoma: Ministry of Industries, Mineral Resources and Power.

Gurnis, M., J.X. Mitrovica, J Ritsema, and H.J. Van Heijst. 2000. "Constraining Mantle Density Structure Using Geological Evidence of Surface Uplift Rates: the Case of the African Superplume." Geochemistry Geophysics Geosystems 1 (7): 1999GC000035.

Guth, Alexandria L. 2007. Evolution of the Southern Kenya Rift From Miocene to Present with a Focus on the Magadi Area. Houghton, MI: Michigan Technological University. 
Guth, Lawrence R. 1991. Kinematic Analysis of the Deformational Structures of Eastern Isla De Margarita, Venezuela. Houston, TX: Rice University.

Hackman, B. D., J. Ridgway, and C. C. Rundle. 1988. Geology of the BaringoLaikipia Area : Degree Sheet 35 with Coloured 1:250,000 Geological Map and Results of Geochemical Exploration. Vol. 104. Nairobi: Kenya Geological Survey.

Hackman, B. D., T Charsley, J. Kagasi, R Key, W. S. Siambi, and A. F. Wilkinson. 1989. Geology of the Isiolo Area : Degree Sheet 36, with Coloured 1:250,000 Geological Map and Results of Geochemical Exploration. Vol. 103. Nairobi: Kenya Geological Survey.

Haileab, Bereket, Francis Brown, IAN McDougall, and PN GATHOGO. 2004. "Gombe Group Basalts and Initiation of Pliocene Deposition in the Turkana Depression, Northern Kenya and Southern Ethiopia." Geological Magazine 141 (01): 41-53.

Hamilton, Robert M, B Asfaw, Gail M Ashley, Thure E Cerling, Andrew Cohen, P B deMenocal, Andrew Hill, et al. 2010. Understanding Climate's Influence on Human Evolution. National Academies Press. Washington, D.C.: The National Academies Press.

Harris, Judith, and John van Couvering. 1995. "Mock Aridity and the

Paleoecology of Volcanically Influenced Ecosystems." Geology 23

(7) (July): 593. doi:

10.1130/0091-7613(1995)023<0593:MAATPO>2.3.CO;2.

Hart, Thomas Robert, and Carole Anne MacDonald. 2007. "Proterozoic and Archean Geology of the Nipigon Embayment: Implications for Emplacement of the Mesoproterozoic Nipigon Diabase Sills and Mafic to Ultramafic Intrusions." Canadian Journal of Earth Sciences 44 (8): 1021-1040. doi:10.1139/E07-026.

Haug, G.H., and M R Strecker. 1995. "Volcano-Tectonic Evolution of the Chyulu Hills and Implications for the Regional Stress Field in Kenya." Geology 23 (2): 165-168.

Hay, RL, and TK Kyser. 2001. "Chemical Sedimentology and Paleoenvironmental History of Lake Olduvai, a Pliocene Lake in Northern Tanzania." Geological Society of America Bulletin 113 (12): 1505.

Heinonen, Jussi S, Richard W Carlson, and Arto V Luttinen. 2010. "Isotopic (Sr, $\mathrm{Nd}, \mathrm{Pb}$, and $\mathrm{Os}$ ) Composition of Highly Magnesian Dikes of Vestfjella, Western Dronning Maud Land, Antarctica: a Key to the Origins of the Jurassic Karoo Large Igneous Province?." Chemical Geology 277 (3-4) (October 20): 227-244. doi:10.1016/j.chemgeo. 2010.08.004.

Hetzel, R, and M R Strecker. 1994. "Late Mozambique Belt Structures in Western Kenya and Their Influence on the Evolution of the Cenozoic Kenya Rift." Journal of Structural Geology 16 (2): 189-202. 
Hill, Andrew, RE Drake, L Tauxe, and M Monaghan. 1985. "Neogene Palaeontology and Geochronology of the Baringo Basin, Kenya." Journal of Human Evolution 14 (8): 759-773.

Hillaire Marcel, C, and Joel Casanova. 1987. "Isotopic Hydrology and Paleohydrology of the Magadi (Kenya) - Natron (Tanzania) Basin During the Late Quaternary." Palaeogeography Palaeoclimatology Palaeoecology 58: 155-181.

Hillaire Marcel, C, Joel Casanova, and M Taieb. 1987. Isotopic Age and Lacustrine Environments During Late Quaternary in theTanzanian Rift (Lake Natron). Climate; History, Periodicity, and Predictability.

Hillhouse, JW, Thure Cerling, and Francis Brown. 1986. "Magnetostratigraphy of the Koobi Fora Formation, Lake Turkana, Kenya." Journal of Geophysical Research 91: 11581-11595.

Howell, Paul D., and Ben A van der Pluijm. 1990. "Early History of the Michigan Basin: Subsidence and Appalachian Tectonics.” Geology 18 (1) (December): 1195. doi: 10.1130/0091-7613(1990)018<1195:EHOTMB>2.3.CO;2. Huerta, Audrey D, Andrew A Nyblade, and Angela M Reusch. 2009. "Mantle Transition Zone Structure Beneath Kenya and Tanzania: More Evidence for a Deep-Seated Thermal Upwelling in the Mantle." Geophysical Journal International 177 (3) (June): 1249-1255. doi: 10.1111/j.1365-246X.2009.04092.x.

Isaac, Glynn. 1978. "The Olorgesailie Formation; Stratigraphy, Tectonics and the Palaeogeographic Context of the Middle Pleistocene Archaeological Sites." In Geological Background to Fossil Man, ed. Walter W. Bishop, 173-206. Edinburgh: Scottish Academic Press.

Jacobs, BF, and C Kabuye. 1987. "A Middle Miocene (12. 2 My Old) Forest in the East African Rift Valley, Kenya." Journal of Human Evolution 16 (2): 147-155.

Jennings, D. J. 1971. Geology of the Molo Area: Degree Sheet 42, N.E. Quarter. Vol. 86. Nairobi: Kenya Geological Survey.

Johnson, RW. 1969. "Volcanic Geology of Mount Suswa, Kenya." Philosophical

Transactions for the Royal Society of London. Series a, Mathematical and Physical Sciences: 383-412.

Jones, WB, and SJ Lippard. 1979. "New Age Determinations and the Geology of the Kenya Rift-Kavirondo Rift Junction, W Kenya." Journal of the Geological Society 136 (6): 693-704.

Joubert, P. 1957. Geology of the Namanga-Bissel Area. Vol. 39. Explanation of Degree Sheet 58 N.E. and S.E. Kenya Geological Survey.

Joubert, Pieter. 1966. Geology of the Loperot Area. Vol. 74. Degree Sheet 18,

S.E. Quarter. Nairobi: Kenya Geological Survey.

Kampunzu, AB, and P Mohr. 1991. "Magmatic Evolution and Petrogenesis in the East African Rift System." In, 85-136.

Kampunzu, AB, MG Bonhomme, and M Kanika. 1998. "Geochronology of Volcanic Rocks and Evolution of the Cenozoic Western Branch of 
the East African Rift System." Journal of African Earth Sciences 26 (3): 441-461.

Keller, G Randy, MA Khan, P Morgan, RF Wendlandt, WS Baldridge, KH Olsen, C Prodehl, and LW Braile. 1991. "A Comparative Study of the Rio Grande and Kenya Rifts." Tectonophysics 197 (2-4): 355-371.

Keranen, K, and SL Klemperer. 2008. "Discontinuous and Diachronous Evolution of the Main Ethiopian Rift: Implications for Development of Continental Rifts." Earth and Planetary Science Letters 265 (1-2): 96-111.

Key, R. 1987. Geology of the Marsabit Area. Vol. 108. Degree Sheet 20 with Coloured 1:250,000 Geological Map and Results of Geochemical Exploration. Kenya Geological Survey.

Key, R, and R Watkins. 1988. Geology of the Sabarei Area. Vol. 111. Degree Sheets 3 and 4 with Coloured 1:250,000 Geological Map and Results of Geochemical Exploration. Kenya Geological Survey.

Key, R. M., and J. Ridgway. 1987. Geology of the Maralal Area : Degree Sheet 27 with Coloured 1:250 000 Geological Map and Results of Geochemical Exploration. Vol. 105. Nairobi: Kenya Geological Survey.

Khan, M, J Mechie, C Birt, G Byrne, S Gaciri, B Jacob, G Keller, et al. 1999. "The Lithospheric Structure of the Kenya Rift as Revealed by WideAngle Seismic Measurements": 257-269.

Kieffer, Bruno, Nicholas Arndt, Henriette Lapierre, Florence Bastien, Delphine Bosch, Arnaud Pecher, Gezahegn Yirgu, et al. 2004. "Flood and Shield Basalts From Ethiopia: Magmas From the African Superswell." Journal of Petrology 45 (4) (April 1): 793-834. doi: 10.1093/petrology/egg112.

King, Basil. 1978. "Structural and Volcanic Evolution of the Gregory Rift Valley." In Geological Background to Fossil Man, ed. Walter W. Bishop, 2954. Edinburgh: Scottish Academic Press.

Kingston, John, Alan Deino, RK Edgar, and Andrew Hill. 2007. "Astronomically Forced Climate Change in the Kenyan Rift Valley 2.7 E2. $55 \mathrm{Ma}$ : Implications for the Evolution of Early Hominin Ecosystems." Journal of Human Evolution 20 (1e17): 1 e17.

Kingston, John, B Fine Jacobs, Andrew Hill, and Alan Deino. 2002. "Stratigraphy, Age and Environments of the Late Miocene Mpesida Beds, Tugen Hills, Kenya." Journal of Human Evolution 42 (1-2): 95-116.

Laerdal, T, and MR Talbot. 2002. "Basin Neotectonics of Lakes Edward and George, East African Rift." Palaeogeography Palaeoclimatology Palaeoecology 187 (3-4): 213-232.

Lay, Thorne, and Edward J Garnero. 2011. "Deep Mantle Seismic Modeling and Imaging." Annual Review of Earth and Planetary Sciences 39 (1) (May 30): 91-123. doi:10.1146/annurev-earth-040610-133354.

Le Gall, Bernard, P Nonnotte, J Rolet, M Benoit, H Guillou, M MousseauNonnotte, J Albaric, and J Deverchère. 2007. "Rift Propagation at 
Craton Margin. Distribution of Faulting and Volcanism in the North Tanzanian Divergence (East Africa) During Neogene Times." Tectonophysics.

Le Turdu, C, Jean-Jacques Tiercelin, J Richert, J Rolet, J Xavier, R Renaut, K Lezzar, C Coussement, and C Morley. 1999. "Influence of Preexisting Oblique Discontinuities on the Geometry and Evolution of Extensional Fault Patterns; Evidence From the Kenya Rift Using SPOT Imagery." In Geoscience of Rift Systems - Evolution of East Africa, ed. C. K. Morley, 173-191. American Association of Petroleum Geologists.

Leakey, Meave, Ari Grossman, Mercedes Gutiérrez, and John G Fleagle. 2011. "Faunal Change in the Turkana Basin During the Late Oligocene and Miocene." Evolutionary Anthropology: Issues, News, and Reviews 20 (6) (December 14): 238-253. doi:10.1002/evan.20338.

Leat, P. T. 1983. The Structural and Geochemical Evolution of Menengai Caldera Volcano, Kenya Rift Valley. University of Lancaster.

Macdonald, R. 2003. "Magmatism of the Kenya Rift Valley: a Review." Earth and Environmental Science Transactions of the Royal Society of Edinburgh 93 (3): 239-253.

Macdonald, R, N W Rogers, J G Fitton, S Black, and M Smith. 2001. "PlumeLithosphere Interactions in the Generation of the Basalts of the Kenya Rift, East Africa." Journal of Petrology 42 (5): 877-900.

Marshall, AS, R Macdonald, N W Rogers, J G Fitton, A G Tindle, K Nejbert, and R W Hinton. 2009. "Fractionation of Peralkaline Silicic Magmas: the Greater Olkaria Volcanic Complex, Kenya Rift Valley." Journal of Petrology 50 (2) (February 1): 323-359. doi:10.1093/petrology/ egp001.

Marshall, Michael. 2010. "Evolution by Shake, Rattle and Roll." New Scientist 2786 (Nov 13): 8-9.

Maslin, MA, and MH Trauth. 2009. "Plio-Pleistocene East African Pulsed Climate Variability and Its Influence on Early Human Evolution." The First Humans: Origin and Early Evolution of the Genus Homo: 151.

Mason, P., and A. B. Gibson. 1957. Geology of the Kalossia-Tiati Area. Degree Sheet 26, N.E. and S.E. Quarters (with Two Coloured Geological Maps). Vol. 41. Nairobi: Kenya Geological Survey.

Matheson, F J. 1966. "Geology of the Kajiado Area." Kenya Geologic Survey 70: $1-57$.

Matyska, Ctirad, and David A. Yuen. 2007. "Lower-Mantle Material Properties and Convection Models of Multiscale Plumes." In Plates, Plumes, and Planetary Processes, ed. Gillian R. Foulger and Donna M. Jurdy, 137-163. Boulder, CO: Geological Society of America.

McBrearty, S, and NG Jablonski. 2005. "First Fossil Chimpanzee." Nature 437: 105-108.

McCall, G J H. 1967. "Geology of the Nakuru-Thomson's Falls-Lake Hannington Area." Kenya Geologic Survey 78: 1-143. 
McClusky, S., R. Reilinger, S. Mahmoud, D. Ben Sari, and A. Tealeb. 2003. "GPS Constraints on Africa (Nubia) and Arabia Plate Motions."

Geophysical Journal International 155 (September 12): 126-138.

McDougall, IAN, and Francis Brown. 2009. "Timing of Volcanism and Evolution of the Northern Kenya Rift." Geological Magazine 146 (1): 34-47.

McDougall, IAN, and Ronald T. Watkins. 2006. "Geochronology of the Nabwal Hills: a Record of Earliest Magmatism in the Northern Kenyan Rift Valley." Geological Magazine 143 (01): 25-39.

McHone, J Gregory, Don L Anderson, Erin K Beutel, and Yuri A Fialko. 2005. "Giant Dikes, Rifts, Flood Basalts, and Plate Tectonics: a Contention of Mantle Models." In Plates, Plumes, and Paradigms, ed. Gillian R. Foulger, James H. Natland, Dean C. Presnall, and Don L Anderson, 388:401-420. Boulder, CO: Geological Society of America.

Mechie, J, G Randy Keller, C Prodehl, MA Khan, and SJ Gaciri. 1997. "A Model for the Structure, Composition and Evolution of the Kenya Rift." Tectonophysics 278 (1-4): 95-119.

Mechie, J, G Randy Keller, C Prodehl, SJ Gaciri, LW Braile, WD Mooney, D Gajewski, and KJ Sandmeier. 1994. "Crustal Structure Beneath the Kenya Rift From Axial Profile Data." Tectonophysics 236 (1-4): 179200.

Merle, Olivier. 2011. "A Simple Continental Rift Classification." Tectonophysics 513 (1-4) (December 5): 88-95. doi:10.1016/j.tecto.2011.10.004.

Morley, C. K. 1999. "Basin Evolution Trends in East Africa." In Geoscience of Rift Systems - Evolution of East Africa, ed. C. K. Morley, 131-150. American Association of Petroleum Geologists.

Morley, C. K., F M Karanja, W. A. Wescott, D. M. Stone, R. M. Harper, S. T. Wigger, and R. A. Day. 1999. "Geology and Geophysics of the Western Turkana Basins, Kenya." In Geoscience of Rift Systems Evolution of East Africa, ed. C. K. Morley, 19-54. American Association of Petroleum Geologists.

Morley, C. K., W Bosworth, R. A. Day, R. Lauck, R. Bosher, D. M. Stone, S. T. Wigger, W. A. Wescott, D. Haun, and N. Bassett. 1999. "Geology and Geophysics of the Anza Graben." In Geoscience of Rift Systems - Evolution of East Africa, ed. C. K. Morley, 67-90. American Association of Petroleum Geologists.

Morley, C. K., W. A. Wescott, D. M. Stone, R. M. Harper, S. T. Wigger, and F M Karanja. 1992. "Tectonic Evolution of the Northern Kenyan Rift." Journal of the Geological Society 149: 333-348.

Morley, C. K., W. A. Wescott, R. M. Harper, and S. M. Cunningam. 1999. "Geology and Geophysics of the Rukwa Rift." In Geoscience of Rift Systems - Evolution of East Africa, ed. C. K. Morley, 91-110. American Association of Petroleum Geologists. 
Moucha, Robert, and Alessandro M Forte. 2011. "Changes in African Topography Driven by Mantle Convection." Nature Publishing Group 4 (10) (August 28): 707-712. doi:10.1038/ngeo1235.

Moucha, Robert, Alessandro M Forte, David B Rowley, Jerry X Mitrovica, Nathan A Simmons, and Stephen P Grand. 2008. "Mantle Convection and the Recent Evolution of the Colorado Plateau and the Rio Grande Rift Valley." Geology 36 (6): 439. doi:10.1130/G24577A.1.

Mugisha, F, Cynthia J Ebinger, M R Strecker, and D Pope. 1997. "Two-Stage Rifting in the Kenya Rift: Implications for Half-Graben Models." Tectonophysics 278 (1-4): 63-81.

Ngecu, WM, and J Njue. 1999. "Lithostratigraphy and Distribution of Pleistocene Sediments of the Munyu Wa Gicheru Formation in South Kenya Rift Valley ." Journal of African Earth Sciences 29 (2): 411-421.

Nolet, Guust, Richard Allen, and Dapeng Zhao. 2007. "Mantle Plume Tomography." Chemical Geology 241 (3-4) (July): 248-263. doi: 10.1016/j.chemgeo.2007.01.022.

Nyamai, CM, EM Mathu, N OPIYO-AKECH, and E Wallbrecher. 2003. "A Reappraaisal of the Geology, Geochemistry, Structures and Tectonics of the Mozambique Belt in Kenya, East of the Rift System." Ajst 4 (2).

Nyamweru, C K. 1986. "Quaternary Environments of the Chalbi Basin, Kenya; Sedimentary and Geomorphological Evidence." In Sedimentation in the African Rifts, ed. LE Frostick, Robin W Renaut, I Reid, and Jean-Jacques Tiercelin, 25:297-310. Oxford: The Geological Society.

Nyblade, A A. 2011. "The Upper-Mantle Low-Velocity Anomaly Beneath Ethiopia, Kenya, and Tanzania: Constraints on the Origin of the African Superswell in Eastern Africa and Plate Versus Plume Models of Mantle Dynamics." In Volcanism and Evolution of the African Lithosphere, ed. L Beccaluva, G Bianchini, and Marjorie Wilson, 478:37-50. Geological Society of America.

Nyblade, A A, and S.W. Robinson. 1994. "The African Superswell." Geophysical Research Letters 21 (9): 765-768.

Nyblade, AA, and RA Brazier. 2002. "Precambrian Lithospheric Controls on the Development of the East African Rift System." Geology 30 (8): 755.

Nyblade, AA, TJ Owens, H Gurrola, J Ritsema, and CA Langston. 2000. "Seismic Evidence for a Deep Upper Mantle Thermal Anomaly Beneath East Africa." Geology 28 (7): 599.

Ochieng, J. O., Kenya Mines and Geological Dept, and British Geological Survey. 1988. Geology of the Loiyangalani Area. Vol. 107. Degree Sheet 19 with Coloured 1:250 000 Geological Map. Nairobi: Kenya Geological Survey.

Odada, EO, Japheth Onyando, and Peninah A Obudho. 2006. "Lake Baringo: Experience and Lessons Learned Brief." Lake Basin Management Initiative: $31-43$. 
Ojakangas, RW, and AB Dickas. 2002. "The 1.1-Ga Midcontinent Rift System, Central North America: Sedimentology of Two Deep Boreholes, Lake Superior Region." Sedimentary Geology 147 (1-2): 13-36.

Ojakangas, RW, GB Morey, and JC Green. 2001. "The Mesoproterozoic Midcontinent Rift System, Lake Superior Region, USA." Sedimentary Geology 141: 421-442.

Omenda, PA. 1998. "The Geology and Structural Controls of the Olkaria Geothermal System, Kenya." Geothermics 27 (1): 55-74.

Omenge, J. M., R. E. Okelo, and E. P. Wright. 1992. Geology of the ChyuluOloitokitok Area. Vol. 112. Nairobi: Kenya Geological Survey.

Opdyke, Neil D, Dennis V Kent, Kainian Huang, David A Foster, and J P Patel. 2010. "Equatorial Paleomagnetic Time-Averaged Field Results From 0-5 Ma Lavas From Kenya and the Latitudinal Variation of Angular Dispersion." Geochemistry Geophysics Geosystems 11 (5) (May 21): Q05005. doi:10.1029/2009GC002863.

Owen, Richard Bernhart, and Robin W Renaut. 1981. "Palaeoenvironments and Sedimentology of the Middle Pleistocene Olorgesailie Formation, Southern Kenya Rift Valley." Palaeoecology of Africa and the Surrounding Islands 13: 147-174.

Owen, Richard Bernhart, Richard Potts, Anna Behrensmeyer, and Peter Ditchfield. 2008. "Diatomaceous Sediments and Environmental Change in the Pleistocene Olorgesailie Formation, Southern Kenya Rift Valley." Palaeogeography Palaeoclimatology Palaeoecology 269 (1-1) (April 11): 17-37. doi:doi:10.1016/j.palaeo.2008.06.021.

Patel, JP, and PKS Raja. 1979. "Paleomagnetic Results From the Narosura and Magadi Volcanics of Kenya." Physics of the Earth and Planetary Interiors 19 (3): P7-P14.

Peppe, Daniel J, Kieran P McNulty, Susanne M Cote, William E H HarcourtSmith, Holly M Dunsworth, and John A Van Couvering. 2009. "Stratigraphic Interpretation of the Kulu Formation (Early Miocene, Rusinga Island, Kenya) and Its Implications for Primate Evolution." Journal of Human Evolution 56 (5) (May 1): 447-461. doi:10.1016/ j.jhevol.2009.02.006.

Pickford, M, and Peter Andrews. 1981. "The Tinderet Miocence Sequence in Kenya." Journal of Human Evolution 10 (1): 11-33.

Pickford, M, B Senut, and C Mourer-Chauvire. 2004. "Early Pliocene Tragulidae and Peafowls in the Rift Valley, Kenya: Evidence for Rainforest in East Africa." Comptes Rendus Palevol 3 (3): 179-189.

Pickford, Martin. 1978a. "Geology, Palaeoenvironments and Vertebrate Faunas of the Mid-Miocene Ngorora Formation, Kenya." In Geological Background to Fossil Man, ed. Walter W. Bishop, 237-262. Edinburgh: Scottish Academic Press.

Pickford, Martin. 1978b. "Stratigraphy and Mammalian Palaeontology of the LateMiocene Lukeino Formation, Kenya." In Geological Background to 
Fossil Man, ed. Walter W. Bishop, 263-278. Edinburgh: Scottish Academic Press.

Pickford, Martin. 1994. "Patterns of Sedimentation and Fossil Distribution in the Kenya Rift Valleys." Journal of African Earth Sciences 18 (1): 5160.

Pik, R, B Marty, and DR Hilton. 2006. "How Many Mantle Plumes in Africa? the Geochemical Point of View." Chemical Geology 226 (3-4): 100-114.

Pik, Raphaël. 2011. "Geodynamics: East Africa on the Rise." Nature Publishing Group 4 (10) (October 1): 660-661. doi:10.1038/ngeo1274.

Pik, Raphaël, Bernard Marty, Jean Carignan, Gezahegn Yirgu, and Teklewold Ayalew. 2008. "Timing of East African Rift Development in Southern Ethiopia: Implication for Mantle Plume Activity and Evolution of Topography." Geology 36 (2): 167-170. doi:10.1130/G24233A.1.

Potts, Richard, and AL Deino. 1995. "Mid-Pleistocene Change in Large Mammal Faunas of East Africa." Quaternary Research 43 (1): 106-113.

Potts, Richard, P Shipman, and E Ingall. 1988. "Taphonomy, Paleoecology, and Hominids of Lainyamok, Kenya." Journal of Human Evolution 17 (6): 597-614.

Prodehl, C, JRR Ritter, J Mechie, G Randy Keller, MA Khan, B Jacob, K Fuchs, IO Nyambok, JD Obel, and D Riaroh. 1997. "The KRISP 94 Lithospheric Investigation of Southern Kenya-the Experiments and Their Main Results." Tectonophysics 278 (1-4): 121-147.

Quinn, RL, CJ Lepre, JD Wright, and Craig Feibel. 2007. "Paleogeographic Variations of Pedogenic Carbonate $\delta 13 \mathrm{C}$ Values From Koobi Fora, Kenya: Implications for Floral Compositions of Plio-Pleistocene Hominin Environments." Journal of Human Evolution 53 (5): 560573.

Randel, R P, and R W Johnson. 1991. "Geology of the Suswa Area." Kenya Geologic Survey 97: 1-52.

Reid, I, and LE Frostick. 1986. "Slope Processes, Sediment Derivation and Landform Evolution in a Rift Valley Basin, Northern Kenya." In Sedimentation in the African Rifts, ed. LE Frostick, Robin W Renaut, I Reid, and Jean-Jacques Tiercelin, 99-111. Oxford: The Geological Society.

Retallack, G, Jonathan G Wynn, Brenda R. Benefit, and Monte L. McCrossin. 2002. "Paleosols and Paleoenvironments of the Middle Miocene, Maboko Formation, Kenya." Journal of Human Evolution 42 (6) (June 1): 659-703. doi:10.1006/jhev.2002.0553.

Reynolds, Sally C, Geoff N Bailey, and Geoffrey C P King. 2011. "Landscapes and Their Relation to Hominin Habitats: Case Studies From Australopithecus Sites in Eastern and Southern Africa." Journal of Human Evolution 60 (3) (March 1): 281-298. doi:10.1016/j.jhevol. 2010.10.001.

Reynolds, SC. 2007. "Mammalian Body Size Changes and Plio-Pleistocene Environmental Shifts: Implications for Understanding Hominin 
Evolution in Eastern and Southern Africa." Journal of Human Evolution 53 (5): 528-548.

Riley, Teal R., and Kim B. Knight. 2001. "Review: Age of Pre-Break-Up Gondwana Magmatism." Antarctic Science 13 (2): 99-110.

Rix, P. 1967. Geology of the Kinna Area; Degree Sheet 37, SW Quarter, with Coloured Geological Map. Vol. 81. Nairobi: Kenya Geological Survey.

Roberts, E M, N J Stevens, P M O'Connor, P H G M Dirks, M D Gottfried, W C Clyde, R A Armstrong, A I S Kemp, and S Hemming. 2012. "Initiation of the Western Branch of the East African Rift Coeval with the Eastern Branch." Nature Publishing Group 5 (4) (March 25): 289-294. doi:10.1038/ngeo1432.

Roberts, N, M Taieb, P Barker, B Damnati, M Icole, and D Williamson. 1993.

"Timing of the Younger Dryas Event in East Africa From Lake-Level Changes." Nature 366: 146-148.

Roller, S, J Hornung, M Hinderer, and I Ssemmanda. 2010. "Middle Miocene to Pleistocene Sedimentary Record of Rift Evolution in the Southern Albert Rift (Uganda)." International Journal of Earth Sciences 99 (7) (October 6): 1643-1661. doi:10.1007/s00531-010-0560-z.

Saggerson, E P. 1952. Geology of the Kisumu District. Vol. 21. Degree Sheet 41, N.E. Quadrant. Nairobi: Kenya Geological Survey.

Saggerson, E P. 1963. Geology of the Simba-Kibwezi Area : Degree Sheet 59, N.E. Quarter (with Coloured Geological Map). Vol. 58. Nairobi: Geology of the Simba-Kibwezi.

Saggerson, E P. 1966. Geology of the Loita Hills Area; Degree Sheets 50, S.E. Quarter and 57, N.E. Quarter. Vol. 71. Nairobi: Kenya Geological Survey.

Saggerson, E.P. 1991. Geology of the Nairobi Area. Vol. 98. Degree Sheet 51, N.E. Quarter. Nairobi: Kenya Geological Survey.

Saggerson, E P, and Brian Baker. 1965. "Post-Jurassic Erosion-Surfaces in Eastern Kenya and Their Deformation in Relation to Rift Structure." Quarterly Journal of Geological Society 121: 51-72.

Sanders, L D. 1963. Geology of the Voi-South Yatta Area; Degree Sheets 65, N.E. Quarter 60, S.E. Quarter, and Parts of the S.W., N.W., and N.E. Quarter of Degree Sheet 60 (with Two Coloured Maps). Vol. 54. Nairobi: Kenya Geological Survey.

Sanders, L D. 1963. Geology of the Eldoret Area; Degree Sheet 34, N.W. Quarter. Vol. 64. Nairobi: Kenya Geological Survey.

Saneyoshi, M, K Nakayama, T Sakai, Y SAWADA, and H Ishida. 2006. "Half Graben Filling Processes in the Early Phase of Continental Rifting: the Miocene Namurungule Formation of the Kenya Rift." Sedimentary Geology 186 (1-2): 111-131.

Sarbas, B. 2008. "The GEOROC Database as Part of a Growing Geoinformatics Network." Ed. S. R. Brady, A. K. Sinha, and L. C. Gundersen. U.S. Geological Survey Scientific Investigations Report 5172. 
Geoinformatics 2008-Data to Knowledge, Proceedings: 42-43. http://georoc.mpch-mainz.gwdg.de/georoc/Start.asp.

Savage, Robert J. G., and Peter G. Williamson. 1978. "The Early History of the Turkana Depression." In Geological Background to Fossil Man, ed. Walter W. Bishop, 375-394. Edinburgh: Scottish Academic Press.

Searle, Derek Lawrence. 1954. Geology of the Sultan Hamud Area; Explanation of Degree Sheet 59 N.W. Vol. 29. Nairobi: Kenya Geological Survey.

Semaw, S, P R Renne, JWK Harris, Craig Feibel, Raymond Bernor, N Fesseha, and K Mowbray. 1997. "2.5-Million-Year-Old Stone Tools From Gona, Ethiopia." Nature 385 (23 January): 333-336.

Sen, Gautam. 2001. "Generation of Deccan Trap Magmas." Proc. Indian Acad. Sci. (Earth Planet Sci.) 110 (4) (December): 409-431.

Sepulchre, P. 2006. "Tectonic Uplift and Eastern Africa Aridification." Science 313 (5792) (September 8): 1419-1423. doi:10.1126/science.1129158.

Shackleton, Robert M., and Geological Survey of Kenya. 1945. Geology of the Nyeri Area (with Coloured Geological Map). Vol. 12. Nairobi: Kenya Geological Survey.

Shipman, Pat, Richard Potts, and Martin Pickford. 1983. "Lainyamok, a New Middle Pleistocene Hominid Site." Nature (London) 306 (5941): 365-368.

Simiyu, SM, and G Randy Keller. 1998. "Upper Crustal Structure in the Vicinity of Lake Magadi in the Kenya Rift Valley Region." Journal of African Earth Sciences 27 (3): 359-371.

Simiyu, SM, and G Randy Keller. 2001. "An Integrated Geophysical Analysis of the Upper Crust of the Southern Kenya Rift." Geophysical Journal International 147 (3): 543-561.

Skilling, IP. 1988. The Geological Evolution of Suswa Volcano, Kenya. University of Lancaster. Unpublished Dissertation.

Sleep, N. 2007. "Origins of the Plume Hypothesis and Some of Its Implications." In Plates, Plumes, and Planetary Processes, ed. Gillian R. Foulger and Donna M. Jurdy, 430:29-45. Boulder, CO: Geological Society of America.

Smith, M. 1994. "Stratigraphic and Structural Constraints on Mechanisms of Active Rifting in the Gregory Rift, Kenya." Tectonophysics 236: 322.

Sohn, Robert A, Claire Willis, Susan Humphris, Timothy M Shank, Hanumant Singh, Henrietta N Edmonds, Clayton Kunz, et al. 2008. "Explosive Volcanism on the Ultraslow-Spreading Gakkel Ridge, Arctic Ocean." Nature 453 (7199) (June 26): 1236-1238. doi:10.1038/ nature07075.

Stamps, D S, L M Flesch, and E Calais. 2010. "Lithospheric Buoyancy Forces in Africa From a Thin Sheet Approach." International Journal of Earth Sciences 99 (7) (March 24): 1525-1533. doi:10.1007/ s00531-010-0533-2. 
Stamps, D Sarah, Eric Calais, Elifuraha Saria, Chris Hartnady, Jean-Mathieu Nocquet, Cynthia J Ebinger, and Rui M Fernandes. 2008. "A Kinematic Model for the East African Rift." Geophysical Research Letters 35 (5) (March 7). doi:10.1029/2007GL032781.

Stern, R.J. 1994. "Arc-Assembly and Continental Collision in the Neoproterozoic African Orogen: Implications for the Consolidation of Gondwanaland." Annual Review of Earth and Planetary Sciences 22: 319-351.

Sun, Daoyuan, Don Helmberger, and Michael Gurnis. 2010. "A Narrow, MidMantle Plume Below Southern Africa." Geophysical Research Letters 37 (9) (May 4). doi:10.1029/2009GL042339.

Tattersall, lan, and Jeffrey H Schwartz. 2009. "Evolution of the Genus Homo." Annual Review of Earth and Planetary Sciences 37 (1) (May): 6792. doi:10.1146/annurev.earth.031208.100202.

Tauxe, L, M Monaghan, RE Drake, GH Curtis, and H Staudigel. 1985. "Paleomagnetism of Miocene East African Rift Sediments and the Calibration of the Geomagnetic Reversal Time Scale." Journal of Geophysical Research-Solid Earth 90 (B6): 4639-4646.

Thompson, A O. 1964. Geology of the Kijabe Area; Degree Sheet 43, S.E. Quarter (with Coloured Geological Map). Vol. 67. Nairobi: Kenya Geological Survey.

Thompson, A O, and R G Dodson. 1963. "Geology of the Naivasha Area." Kenya Geologic Survey 55: 1-88.

Thybo, H, P K H Maguire, C Birt, and E. Perchuc. 2000. "Seismic Reflectivity and Magmatic Underplating Beneath the Kenya Rift." Geophysical Research Letters 27 (17) (September): 2745-2748.

Tiercelin, Jean-Jacques. 1990. "Rift-Basin Sedimentation: Responses to Climate, Tectonism and Volcanism. Examples of the East African Rift." Journal of African Earth Sciences 10: 283-305.

Tiercelin, Jean-Jacques, and K Lezzar. 2004. "A 300 Million Years History of Rift Lakes in Central and East Africa: an Updated Broad Review." In The East African Great Lakes: Limnology, Palaeolimnology and Biodiversity, ed. Eric O Odada and Daniel O Olago, 3-60. Springer.

Tiercelin, Jean-Jacques, Andrew Cohen, Michael J Soreghan, and KE Lezzar. 1994. "Pleistocene-Modern Deposits of the Lake Tanganyika Rift Basin, East Africa: a Modern Analog for Lacustrine Source Rocks and Reservoirs." SEPM Special Publication: 37-59.

Tiercelin, Jean-Jacques, JL Potdevin, CK Morley, MR Talbot, H Bellon, A Rio, Bernard Le Gall, and W Vétel. 2004. "Hydrocarbon Potential of the Meso-Cenozoic Turkana Depression, Northern Kenya. I.

Reservoirs: Depositional Environments, Diagenetic Characteristics, and Source Rock-Reservoir Relationships." Marine and Petroleum Geology 21 (1): 41-62. 
Trauth, MH, AL Deino, and M R Strecker. 2001. "Response of the East African Climate to Orbital Forcing During the Last Interglacial (130-117 Ka) and the Early Last Glacial (117-60 Ka)." Geology 29 (6): 499.

Trauth, MH, Alan Deino, Andreas Bergner, and M R Strecker. 2003. "East African Climate Change and Orbital Forcing During the Last 175 Kyr BP." Earth and Planetary Science Letters 206 (3-4): 297-313.

Trauth, MH, MA Maslin, Alan Deino, and M R Strecker. 2005. "Late Cenozoic Moisture History of East Africa." Science 309 (5743): 2051.

Trauth, MH, MA Maslin, Alan Deino, M R Strecker, Andreas Bergner, and M Dühnforth. 2007. "High-and Low-Latitude Forcing of PlioPleistocene East African Climate and Human Evolution." Journal of Human Evolution 53 (5): 475-486.

Tryon, CA, and S McBrearty. 2006. "Tephrostratigraphy of the Bedded Tuff Member (Kapthurin Formation, Kenya) and the Nature of Archaeological Change in the Later Middle Pleistocene." Quaternary Research 65 (3): 492-507.

United States Geological Survey. 2005. "Selection of Colors and Patterns for Geologic Maps of the U.S. Geological Survey." Pubsusgsgov. http:// pubs.usgs.gov/tm/2005/11B01/05tm11b01.html.

Urrutia, Roberto, Alberto Araneda, Fabiola Cruces, Laura Torres, Luis Chirinos, Hans C Treutler, Nathalie Fagel, et al. 2007. "Changes in Diatom, Pollen, and Chironomid Assemblages in Response to a Recent Volcanic Event in Lake Galletué (Chilean Andes)." Limnologica Ecology and Management of Inland Waters 37 (1) (February): 4962. doi:10.1016/j.limno.2006.09.003.

Veldkamp, A, E Buis, J R Wijbrans, D O Olago, E H Boshoven, M Marée, and R $M$ van den Berg van Saparoea. 2007. "Late Cenozoic Fluvial Dynamics of the River Tana, Kenya, an Uplift Dominated Record." Quaternary Science Reviews 26 (22-24) (November): 2897-2912. doi:10.1016/j.quascirev.2007.06.033.

Veldkamp, A, J M Schoorl, J R Wijbrans, and L Claessens. 2012. "Mount Kenya Volcanic Activity and the Late Cenozoic Landscape Reorganisation in the Upper Tana Fluvial System." Geomorphology 145-146 (C) (April 1): 19-31. doi:10.1016/j.geomorph.2011.10.026.

Verniers, J. 1997. "Detailed Stratigraphy of the Neogene Sediments at Tinde and Other Localities in the Central Manonga Basin." In Neogene Paleontology of the Manonga Valley, Tanzania : a Window Into the Evolutionary History of East Africa, 14:33-66. New York: Plenum Press.

Verschuren, D, KR Laird, and Brian Cumming. 2000. "Rainfall and Drought in Equatorial East Africa During the Past 1,100 Years." Nature 403 (6768): 410-414.

Vervoort, Jeff D, Karl Wirth, Bryan Kennedy, Travis Sandland, and Karen S Harpp. 2007. "The Magmatic Evolution of the Midcontinent Rift: New Geochronologic and Geochemical Evidence From Felsic 
Magmatism." Precambrian Research 157 (1-4) (August 1): 235268. doi:10.1016/j.precamres.2007.02.019.

Vogt, Peter R. 1975. "Changes in Geomagntic Reversal Frequency at Times of Tectonics Change: Evidence for Coupling Between Core and Upper Mantle Processes." Earth and Planetary Science Letters 25: 313321.

Vondra, Carl F., and Bruce E. Bowen. 1978. "Stratigraphy, Sedimentary Facies and Paleoenvironments, East Lake Turkana, Kenya." In Geological Background to Fossil Man, ed. Walter W. Bishop, 395-414. Edinburgh: Scottish Academic Press.

Walker, Kristoffer T, Götz Bokelmann, Simon Klemperer, and A Nyblade. 2005. "Shear Wave Splitting Around Hotspots: Evidence for UpwellingRelated Mantle Flow?." In Plates, Plumes, and Paradigms, ed. Gillian R. Foulger, James H. Natland, Dean C. Presnall, and Don L Anderson, 388:171-192. Boulder, CO: Geological Society of America.

Walsh, J. 1963. Geology of the Ikutha Area : Degree Sheet 60, N.W. Quarter (with Coloured Geological Map). Vol. 56. Nairobi: Kenya Geological Survey.

Walsh, J. 1969. "Geology of the Eldama Ravine-Kabarnet Area." Kenya Geologic Survey 83. Degree Sheet 34 S.E. Quarter: 48.

Walsh, J. 1972. Geology of the Moyale Area. Vol. 89. Degree Sheet 14. Nairobi: Kenya Geological Survey.

Walsh, J, and R G Dodson. 1969. Geology of Northern Turkana. Vol. 82. Degree Sheets 1, 2, 9, and 10. Nairobi: Geological Survey of Kenya.

Watkins, Ronald T. 1986. "Volcano-Tectonic Control on Sedimentatio in the Koobi Fora Sedimentary Basin, Lake Turkana." In Sedimentation in the African Rifts, ed. LE Frostick, Robin W Renaut, I Reid, and JeanJacques Tiercelin, 85-95. Oxford: The Geological Society.

Wescott, W. A., S. T. Wigger, D. M. Stone, and C. K. Morley. 1999. "Geology and Geophysics of the Lotikipi Plain." In Geoscience of Rift Systems Evolution of East Africa, ed. C. K. Morley, 55-65. American Association of Petroleum Geologists.

Wescott, WA, CK Morley, and F M Karanja. 1996. Tectonic Controls on the Development of Rift-Basin Lakes and Their Sedimentary Character: Examples From the East African Rift System. Limnology, Climatology and Paleoclimatology of the East African Lakes. CRC Press.

White, T D, B Asfaw, Yonas Beyene, Yohannes Haile-Selassie, C O Lovejoy, G Suwa, and G Woldegabriel. 2009. "Ardipithecus Ramidus and the Paleobiology of Early Hominids." Science 326 (5949) (October 2): 64-64, 75-86. doi:10.1126/science.1175802.

Wichura, H, R Bousquet, R Oberhansli, M R Strecker, and M H Trauth. 2010. "Evidence for Middle Miocene Uplift of the East African Plateau." Geology 38 (6) (June 1): 543-546. doi:10.1130/G31022.1. 
Wilkinson, A. F. 1988. Geology of the Allia Bay Area. Vol. 109. Degree Sheet 11, with Coloured 1:250 000 Geological Map. Nairobi: Kenya Geological Survey.

Wilkinson, Peter, and Charles Downie. 1965. Explanatory Notes on the Geological Map of Kilimanjaro (Covering Quarter Degree Sheets 42, 56 and 57). Explanatory Notes on the Geological Map of Kilimanjaro (Covering Quarter Degree Sheets 42, 56 and 57). Explanatory Notes on the Geological Map of Kilimanjaro (Covering Quarter Degree Sheets 42, 56 and 57). Dar es Salaam: Tanzania Geological Survey Division.

Williams, LAJ. 1966. Geology of the Chanler's Falls Area : Degree Sheet 37, N.W. Quarter. Vol. 75. Nairobi: Kenya Geological Survey.

Williams, LAJ. 1972. Geology of the Amboseli Area. Vol. 90. Nairobi: Kenya Geological Survey.

Williams, LAJ. 1972. "The Kenya Rift Volcanics; a Note on Volumes and Chemical Composition." East African Rifts Tectonophysics 15 (1-2): 83-96.

Williams, LAJ. 1978. "Character of Quaternary Volcanism in the Gregory Rift Valley." In Geological Background to Fossil Man, ed. Walter W. Bishop, 55-69. Edinburgh: Scottish Academic Press.

Williams, LAJ. 1991. Geology of the Mau Area. Vol. 96. Nairobi: Kenya Geological Survey.

Williams, L A J, and G. R. Chapman. 1986. "Relationships Between Major Structures, Salic Vocanism and Sedimentation in the Kenya Rift From the Equator Northwards to Lake Turkana." In Sedimentation in the African Rifts, ed. LE Frostick, Robin W Renaut, I Reid, and Jean-Jacques Tiercelin, 59-74. Oxford: The Geological Society.

Williams, L A J, and F J Matheson. 1991. Geology of the Buna Area. Vol. 95. Nairobi: Kenya Geological Survey.

Williams, L, and P Truckle. 1980. "Volcanic Sequences in the Kenya Rift." Atti Dei Convegni Lincei, Accademia Nazionale Dei Lincei 47: 123-132.

Williamson, Peter G., and Robert J. G. Savage. 1986. "Early Rift Sedimentation in the Turkana Basin, Northern Kenya." In Sedimentation in the African Rifts, ed. LE Frostick, Robin W Renaut, I Reid, and JeanJacques Tiercelin, 267-283. Oxford: The Geological Society.

Williamson, D, M Taieb, Brahim Damnati, M Icole, and N Thouveny. 1993. "Equatorial Extension of the Younger Dryas Event: Rock Magnetic Evidence From Lake Magadi(Kenya)." Global and Planetary Change 7 (1-3): 235-242.

Wohlenberg, J, and N Bhatt. 1972. "Report on Airmagnetic Surveys of Two Areas in the Kenya Rift Valley." East African Rifts Tectonophysics 15 (1-2): 143-149. 
Wolfenden, E, Cynthia J Ebinger, G Yirgu, AL Deino, and Dereje Ayalew. 2004. "Evolution of the Northern Main Ethiopian Rift: Birth of a Triple Junction." Earth and Planetary Science Letters 224 (1-2): 213-228.

Wong, How-Kin, and R P Von Herzen. 1974. "A Geophysical Study of Lake Kivu, East Africa." Geophysical Journal of the Royal Astronomical Society 37: 371-389.

Wood, Bernard, and Meave Leakey. 2011. "The Omo-Turkana Basin Fossil Hominins and Their Contribution to Our Understanding of Human Evolution in Africa." Evolutionary Anthropology: Issues, News, and Reviews 20 (6) (December 14): 264-292. doi:10.1002/evan.20335.

Wood, L J. 2007. "Quantitative Seismic Geomorphology of Pliocene and Miocene Fluvial Systems in the Northern Gulf of Mexico, U.S.a.." Journal of Sedimentary Research 77 (9) (September 1): 713-730. doi: 10.2110/jsr.2007.068.

Woolley, Alan R. 2001. The Alkaline Rocks and Carbonatites of the World. Vol. 3. Part 3: Africa. Bath, UK: The Geological Society.

Wright, J. B. 1967. Geology of the Narok Area; Degree Sheet 50, NE Quarter. Vol. 80. Nairobi: Kenya Geological Survey.

Ziegler, Peter A, and Sierd Cloetingh. 2004. "Dynamic Processes Controlling Evolution of Rifted Basins." Earth Science Reviews 64 (1-2) (January): 1-50. doi:10.1016/S0012-8252(03)00041-2. 


\section{Appendix A}

Description of the attribute table columns found in Kenya-volcanics.dbf. Note that due to the limitations of the shapefile format, column headings were limited to ten (10) characters, which is why some are abbreviated.

Table A.1. Headings and descriptions of fields in the attribute table for for the Kenya-volcanics shapefile.

\begin{tabular}{|c|c|}
\hline Heading & Description \\
\hline \multicolumn{2}{|l|}{ GM_Layer } \\
\hline Perimeter & generated by Global Mapper \\
\hline Symbol & Symbology used in this study to distinguish lithologic units \\
\hline Original_S & Original unit symbology from source maps \\
\hline Eon & \multirow{5}{*}{$\begin{array}{l}\text { Used to specify the relative geologic age of the unit. } \\
\text { Naming is based on the } 2010 \text { International Commission of Stratigraphy time } \\
\text { divisions. }\end{array}$} \\
\hline Era & \\
\hline Period & \\
\hline Epoch & \\
\hline Stage & \\
\hline Age_Min & youngest given age for unit in literature \\
\hline Age_Max & oldest given age for unit in literature \\
\hline Age_Units & $\begin{array}{l}\text { Describes the units used for Age_Min or Age_Max. Different age scales were } \\
\text { used to enhance readability of the data. } \\
\text { A.D.: standard calendar year representation, used for very recent units } \\
\text { ka: Kilo-annum, thousands of years } \\
\text { Ma: Mega-annum, millions of years }\end{array}$ \\
\hline Age_Type & $\begin{array}{l}\text { Designates the method used to determine the absolute age assigned for Age_Min } \\
\text { or Age_Max if know. } \\
\text { est: estimated, often based on stratigraphic relationships } \\
\text { C-14: radiocarbon isotope dating } \\
\text { K-Ar: Potassium-Argon radioisotope method } \\
\text { Ar-Ar: Argon-Argon method } \\
\text { U/Th: Uranium-Thorium ratio }\end{array}$ \\
\hline Sources & $\begin{array}{l}\text { References used for age, lithology or original map sources. References are given } \\
\text { as Author-year. Full references can be found in Appendix B. }\end{array}$ \\
\hline Lithology & rock type/description of the mapped unit \\
\hline Notes & pertinent notes regarding mapped unit \\
\hline
\end{tabular}




\begin{tabular}{|l|l|}
\hline \multicolumn{1}{|c|}{ Heading } & \multicolumn{1}{c|}{ Description } \\
\hline Subname & $\begin{array}{l}\text { Same as "Symbol" in most cases. Used to create grouping hierarchies, where } \\
\text { related units shared the same GM_Type but were distinguished using Subname. }\end{array}$ \\
\hline Map & $\begin{array}{l}\text { original name of Kenya/Tanzania Geological Survey map that covers location the } \\
\text { unit is mapped in. Note that unit may not appear on the original map named here. } \\
\text { See "Sources" for full list of references. }\end{array}$ \\
\hline Unit_Above & unit stratigraphically above mapped unit \\
\hline Unit_Below & unit stratigraphically below mapped unit \\
\hline Polarity & magnetic polarity, if known \\
\hline m_thick & thickness of unit given in literature \\
\hline est_thick & estimated thickness from SRTM DEM \\
\hline GM_Type & \\
\hline Layer & \\
\hline Name & generated by Global Mapper \\
\hline Enclosed_A & generated by Global Mapper \\
\hline Island_Are &
\end{tabular}

file type descriptions:

DBF $^{\star}$ : database file that contains shapefile attribute information in dBase IV format.

PRJ: Projection format as plain text. Optional file to accompany shapefile data.

SHP*: Esri shapefile that contains the vector feaures.

SHX*: Esri shapefile index, file contains the position index of the vector features.

* These files are all required for using the shapefile 


\section{Appendix B}

Full reference list to accompany the digital shape file.

Ambrose, Stanley, CM Nyamai, EM Mathu, and MAJ Williams. 2007. "Geology, Geochemistry, and Stratigraphy of the Lemudong'O Formation, Kenya Rift Valley." Kirtlandia 56: 53-64.

Baker, Brian. 1958. "Geology of the Lake Magadi Area." Kenya Geologic Survey 42: 1-85.

Baker, Brian. 1963. "Geology of the Area South of Magadi." Kenya Geologic Survey 61: 1-33.

Baker, Brian. 1965. An Outline of the Geology of the Kenya Rift Valley. Report on the Geology and Geophysics of the East African Rift System.

Baker, Brian. 1967. "Geology of the Mount Kenya Area." Kenya Geologic Survey 79: 1-90.

Baker, Brian. 1975. "Geology and Geochemistry of the OI Doinyo Nyokie Trachyte Ignimbrite Vent Complex, South Kenya Rift Valley." Bulletin Volcanologique 39 (3): 420-440.

Baker, Brian, and John Graham Mitchell. 1976. "Volcanic Stratigraphy and Geochronology of the Kedong-Olorgesailie Area and the Evolution of the South Kenya Rift Valley." Journal of the Geological Society 132 (5): 467-484.

Baker, Brian, G Goles, W Leeman, and M Lindstrom. 1977. "Geochemistry and Petrogenesis of a Basalt-Benmoreite-Trachyte Suite From the Southern Part of the Gregory Rift, Kenya." Contributions to Mineralogy and Petrology 64 (3): 303-332.

Baker, Brian, John Graham Mitchell, and L A J Williams. 1988. "Stratigraphy, Geochronology and Volcano-Tectonic Evolution of the Kedong-Naivasha-Kinangop Region, Gregory Rift Valley, Kenya." Journal of the Geological Society 145 (1): 107-116.

Baker, Brian, LAJ Williams, JA Miller, and FJ Fitch. 1971. "Sequence and Geochronology of the Kenya Rift Volcanics ." Tectonophysics 11: 191-215.

Behrensmeyer, Anna, Alan Deino, Andrew Hill, John Kingston, and JJ Saunders. 2002. "Geology and Geochronology of the Middle Miocene Kipsaramon Site Complex, Muruyur Beds, Tugen Hills, Kenya." Journal of Human Evolution 42 (1-2): 11-38.

Brotzu, P, L Morbidelli, M. Nicoletti, EM Piccirillo, and G Traversa. 1984. "Miocene to Quaternary Volcanism in Eastern Kenya: Sequence and Geochronology." Tectonophysics 101 (1): 75-86.

Brown, Francis H, and IAN McDougall. 2011. "Geochronology of the Turkana Depression of Northern Kenya and Southern Ethiopia." Evolutionary Anthropology: Issues, News, and Reviews 20 (6) (December 14): 217-227. doi:10.1002/evan.20318.

Bruhn, Ronald L, Francis H Brown, Patrick N Gathogo, and Bereket Haileab. 2011. "Pliocene Volcano-Tectonics and Paleogeography of the Turkana Basin, Kenya and Ethiopia." Journal of African Earth Sciences 59 (2-3) (February 1): 295-312. doi: 10.1016/j.jafrearsci.2010.12.002.

Buchanan, M J. 2010. "Stratigraphic and Structural Geology of Area 117, Koobi Fora Region, Northern Kenya." Unpublished Thesis May: 152.

Chapman, Gregory, and Maureen Brook. 1978. "Chronostratigraphy of the Baringo Basin, Kenya." In Geological Background to Fossil Man, ed. Walter W. Bishop, 6:207223. Edinburgh: Scottish Academic Press.

Charsley, T. 1987a. Geology of the Laisamis Area. Report ;; 106; Variation: Report (Kenya. Mines and Geological Dept.) ;; No. 106. Vol. 106. Degree Sheet 28 with Coloured 1:250 000 Geological Map and Results of Geochemical Exploration. Kenya Geological Survey.

Charsley, T. 1987b. Geology of the North Horr Area. Vol. 110. Degree Sheet 12 with Coloured 1:250,000 Geological Map. Kenya Geological Survey. 
Clarke, M C D, D G Woodhall, D Allen, and G Darling. 1990. "Geological, Volcanological and Hydrogeological Controls on the Occurrence of Geothermal Activity in the Area Surrounding Lake Naivasha, Kenya ": 1-141.

Crossley, R. 1979. "The Cenozoic Stratigraphy and Structure of the Western Part of the Rift Valley in Southern Kenya." Journal of the Geological Society 136 (4): 393-405.

Crossley, R, and RM Knight. 1981. "Volcanism in the Western Part of the Rift Valley in Southern Kenya." Bulletin of Volcanology 44 (2): 117-128.

Deino, Alan, and S McBrearty. 2002. "40Ar/39Ar Dating of the Kapthurin Formation, Baringo, Kenya." Journal of Human Evolution 42 (1-2): 185-210.

Deino, Alan, L Tauxe, M Monaghan, and Andrew Hill. 2002. "40Ar/39Ar Geochronology and Paleomagnetic Stratigraphy of the Lukeino and Lower Chemeron Formations at Tabarin and Kapcheberek, Tugen Hills, Kenya." Journal of Human Evolution 42 (1-2): 117-140.

Dodson, R G. 1991. Geology of the Barchuma-Kom Area. Vol. 93. Nairobi: Kenya Geological Survey.

Dodson, R G, and F J Matheson. 1991. Geology of the Area North-East of Marsabit. Vol. 94. Nairobi: Kenya Geological Survey.

Drake, RE, JA Van Couvering, Martin Pickford, GH Curtis, and JA Harris. 1988. "New Chronology for the Early Miocene Mammalian Faunas of Kisingiri, Western Kenya." Journal of the Geological Society 145 (3): 479.

Dunkley, P N, M Smith, D J Allen, and W G Darling. 1993. The Geothermal Activity and Geology of the Northern Sector of the Kenya Rift Valley. British Geological Survey. Vol. 93.

Ebinger, C, T Yemane, D Harding, S Tesfaye, S Kelley, and D Rex. 2000. "Rift Deflection, Migration, and Propagation; Linkage of the Ethiopian and Eastern Rifts, Africa." Geological Society of America Bulletin 112 (2): 163-176.

Evans, A. L., J. D. Fairhead, and John Graham Mitchell. 1971. "Potassium--Argon Ages From the Volcanic Province of Northern Tanzania." Nature Physical Science 229 (1) (January): 19-20. doi:10.1038/physci229019a0.

Fairburn, W A. 1963. "Geology of the North Machakos-Thika Area." Kenya Geologic Survey 59: $1-48$.

Fairburn, W A, and F J Matheson. 1970. Geology of the Loiya-Lorugumu Area. Degree Sheets 17, N.E. Quarter and 18, N.W. Quarter. Nairobi: Kenya Geological Survey.

Fairhead, JD, John Graham Mitchell, and L A J Williams. 1972. "New K/Ar Determinations on Rift Volcanics of S. Kenya and Their Bearing on Age of Rift Faulting." Nature 238 (83): 66-69.

Gathogo, Patrick N, Francis H Brown, and IAN McDougall. 2008. "Stratigraphy of the Koobi Fora Formation (Pliocene and Pleistocene) in the Loiyangalani Region of Northern Kenya." Journal of African Earth Sciences 51 (5) (August): 277-297. doi:10.1016/ j.jafrearsci.2008.01.010.

Gibson, A. B. 1954. Geology of the Broderick Falls Area. Vol. 26. Degree Sheet 33, N.E. Quadrant. Nairobi: Kenya Geological Survey.

Guest, N J, R Pickering, and Tanzania Mineral Resources Division. 1966. "Gelai \& Ketumbeine." Mineral Resources Division, Tanzania. Dodoma: Ministry of Industries, Mineral Resources and Power.

Hackman, B. D., J. Ridgway, and C. C. Rundle. 1988. Geology of the Baringo-Laikipia Area : Degree Sheet 35 with Coloured 1:250,000 Geological Map and Results of Geochemical Exploration. Vol. 104. Nairobi: Kenya Geological Survey.

Haileab, Bereket, Francis Brown, IAN McDougall, and PN GATHOGO. 2004. "Gombe Group Basalts and Initiation of Pliocene Deposition in the Turkana Depression, Northern Kenya and Southern Ethiopia." Geological Magazine 141 (01): 41-53.

Haug, G.H., and M R Strecker. 1995. "Volcano-Tectonic Evolution of the Chyulu Hills and Implications for the Regional Stress Field in Kenya." Geology 23 (2): 165-168. 
Head, Elisabet M, Alison M Shaw, Paul J Wallace, Kenneth WW Sims, and Simon A Carn. 2011. "Insight Into Volatile Behavior at Nyamuragira Volcano (DR Congo, Africa) Through Olivine-Hosted Melt Inclusions." G3: Geochemistry, Geophysics, Geosystems 12 (10).

Jager, Tj. 1982. Soils of the Serengeti Woodlands, Tanzania. Center Agricultural Pub \& Document.

James, T. C. 1957. "Occurrences of Helium-Bearing Gases in Musoma and North Mara Districts, Lake Provinces ." In Records (Annual Report Part II) of the Geological Survey of Tanganyika, 66-72. Geological Survey of Tanganyika.

Jones, WB, and SJ Lippard. 1979. "New Age Determinations and the Geology of the Kenya RiftKavirondo Rift Junction, W Kenya." Journal of the Geological Society 136 (6): 693-704.

Joubert, Pieter. 1966. Geology of the Loperot Area. Vol. 74. Degree Sheet 18, S.E. Quarter. Nairobi: Kenya Geological Survey.

Key, R. 1987. Geology of the Marsabit Area. Vol. 108. Degree Sheet 20 with Coloured 1:250,000 Geological Map and Results of Geochemical Exploration. Kenya Geological Survey.

Key, R, and R Watkins. 1988. Geology of the Sabarei Area. Vol. 111. Degree Sheets 3 and 4 with Coloured 1:250,000 Geological Map and Results of Geochemical Exploration. Kenya Geological Survey.

Lagat, John. 2004. Geology, Hydrothermal Alteration and Fluid Inclusion Studies of Olkaria Domes Geothermal Field, Kenya. Reykjavík: United Nations University.

Le Gall, Bernard, P Nonnotte, J Rolet, M Benoit, H Guillou, M Mousseau-Nonnotte, J Albaric, and $J$ Deverchère. 2008. "Rift Propagation at Craton Margin. Distribution of Faulting and Volcanism in the North Tanzanian Divergence (East Africa) During Neogene Times." Tectonophysics 448 (1-4): 1-19.

Leat, P. T. 1983. The Structural and Geochemical Evolution of Menengai Caldera Volcano, Kenya Rift Valley. University of Lancaster.

Leat, PT. 1991. "Volcanological Development of the Nakuru Area of the Kenya Rift Valley." Journal of African Earth Sciences 13 (3-4): 483-498.

Macdonald, R, and B Scaillet. 2006. "The Central Kenya Peralkaline Province: Insights Into the Evolution of Peralkaline Salic Magmas." Lithos 91 (1-4): 59-73.

Macdonald, R, H E Belkin, J G Fitton, N W Rogers, K Nejbert, A G Tindle, and A S Marshall. 2008. "The Roles of Fractional Crystallization, Magma Mixing, Crystal Mush Remobilization and Volatile-Melt Interactions in the Genesis of a Young BasaltPeralkaline Rhyolite Suite, the Greater Olkaria Volcanic Complex, Kenya Rift Valley." Journal of Petrology 49 (8) (July 7): 1515-1547. doi:10.1093/petrology/ egn036.

Macdonald, R, N W Rogers, J G Fitton, S Black, and M Smith. 2001. "Plume-Lithosphere Interactions in the Generation of the Basalts of the Kenya Rift, East Africa." Journal of Petrology 42 (5): 877-900.

Mahaney, W C, Rene Barendregt, M Villeneuve, J Dostal, T. S. Hamilton, and M. W. Milner. 2011. "Late Neogene Volcanics and Interbedded Palaeosols Near Mount Kenya." Geological Society London Special Publications 357: 301-318.

Marshall, A S, R Macdonald, N W Rogers, J G Fitton, A G Tindle, K Nejbert, and R W Hinton. 2009. "Fractionation of Peralkaline Silicic Magmas: the Greater Olkaria Volcanic Complex, Kenya Rift Valley." Journal of Petrology 50 (2) (February 1): 323-359. doi:10.1093/petrology/egp001.

Matheson, F J. 1966. "Geology of the Kajiado Area." Kenya Geologic Survey 70: 1-57.

McCall, G J H. 1958. Geology of the Gwasi Area. Degree Sheet 41, South-West Quarter and Part of North-West Quarter (with Coloured Maps). Vol. 45. Nairobi: Kenya Geological Survey. 
McCall, G J H. 1967. "Geology of the Nakuru-Thomson's Falls-Lake Hannington Area." Kenya Geologic Survey 78: 1-143.

McDougall, IAN, and Francis Brown. 2009. "Timing of Volcanism and Evolution of the Northern Kenya Rift." Geological Magazine 146 (1): 34-47.

McDougall, IAN, and Ronald T. Watkins. 2006. "Geochronology of the Nabwal Hills: a Record of Earliest Magmatism in the Northern Kenyan Rift Valley." Geological Magazine 143 (01): 25-39.

Mugisha, F, Cynthia J Ebinger, M R Strecker, and D Pope. 1997. "Two-Stage Rifting in the Kenya Rift: Implications for Half-Graben Models.” Tectonophysics 278 (1-4): 63-81.

Nonnotte, P, H Guillou, Bernard Le Gall, M Benoit, J Cotten, and S Scaillet. 2008. "New K-Ar Age Determinations of Kilimanjaro Volcano in the North Tanzanian Diverging Rift, East Africa." Journal of Volcanology and Geothermal Research 173 (1-2): 99112.

Ochieng, J. O., Kenya Mines and Geological Dept, and British Geological Survey. 1988. Geology of the Loiyangalani Area. Vol. 107. Degree Sheet 19 with Coloured 1:250 000 Geological Map. Nairobi: Kenya Geological Survey.

Omenge, J. M., R. E. Okelo, and E. P. Wright. 1992. Geology of the Chyulu-Oloitokitok Area. Vol. 112. Nairobi: Kenya Geological Survey.

Opdyke, Neil D, Dennis V Kent, Kainian Huang, David A Foster, and J P Patel. 2010. "Equatorial Paleomagnetic Time-Averaged Field Results From 0-5 Ma Lavas From Kenya and the Latitudinal Variation of Angular Dispersion." Geochemistry Geophysics Geosystems 11 (5) (May 21): Q05005. doi:10.1029/2009GC002863.

Randel, R P, and R W Johnson. 1991. "Geology of the Suswa Area." Kenya Geologic Survey 97: $1-52$.

Reilly, TA, PKS Raja, AE Mussett, and A Brock. 1976. "The Palaeomagnetism of Late Cenozoic Volcanic Rocks From Kenya and Tanzania." Geophysical Journal International 45: 483-494.

Retallack, G, Jonathan G Wynn, Brenda R. Benefit, and Monte L. McCrossin. 2002. "Paleosols and Paleoenvironments of the Middle Miocene, Maboko Formation, Kenya." Journal of Human Evolution 42 (6) (June 1): 659-703. doi:10.1006/jhev. 2002.0553.

Rix, P. 1967. Geology of the Kinna Area; Degree Sheet 37, SW Quarter, with Coloured Geological Map. Vol. 81. Nairobi: Kenya Geological Survey.

Rogers, N W, PJ Evans, S Blake, SC Scott, and CJ Hawkesworth. 2004. "Rates and Timescales of Fractional Crystallization From 238U-230Th-226Ra Disequilibria in Trachyte Lavas From Longonot Volcano, Kenya." Journal of Petrology 45 (9): 1747-1776.

Saggerson, E. 1991. Geology of the Nairobi Area. Vol. 98. Degree Sheet 51, N.E. Quarter. Nairobi: Kenya Geological Survey.

Saggerson, E P. 1952. Geology of the Kisumu District. Vol. 21. Degree Sheet 41, N.E. Quadrant. Nairobi: Kenya Geological Survey.

Sanders, L D. 1963. "Geology of the Voi-South Yatta Area." Kenya Geologic Survey 54. Degree Sheets 65, N.E. Quarter, 60, S.E. Quarter, and Parts of the S.W., N.W., and N.E. Quarter of Degree Sheet 60: 48.

Sanders, L D. 1965. "Geology of the Contact Between the Nyanza Shield and the Mozambique Belt in Western Kenya (a Revised Geology of the Broderick Falls Area, Degree Sheet 33, N.E. Quarter)." Geological Survey of Kenya Bulletin 7: 45.

Saneyoshi, M, K Nakayama, T Sakai, Y SAWADA, and H Ishida. 2006. "Half Graben Filling Processes in the Early Phase of Continental Rifting: the Miocene Namurungule Formation of the Kenya Rift." Sedimentary Geology 186 (1-2): 111-131.

Scott, SC, and IP Skilling. 1999. "The Role of Tephrachronology in Recognizing Synchronous Caldera-Forming Events at the Quaternary Volcanoes Longonot and Suswa, South Kenya Rift." Geological Society London Special Publications 161 (1): 47. 
Simiyu, SM, and G Randy Keller. 2001. "An Integrated Geophysical Analysis of the Upper Crust of the Southern Kenya Rift." Geophysical Journal International 147 (3): 543-561.

Skilling, IP. 1988. The Geological Evolution of Suswa Volcano, Kenya. Unpublished Dissertation.

Smith, M. 1994. "Stratigraphic and Structural Constraints on Mechanisms of Active Rifting in the Gregory Rift, Kenya." Tectonophysics 236: 3-22.

Veldkamp, A, J M Schoorl, J R Wijbrans, and L Claessens. 2012. "Mount Kenya Volcanic Activity and the Late Cenozoic Landscape Reorganisation in the Upper Tana Fluvial System." Geomorphology 145-146 (C) (April 1): 19-31. doi:10.1016/j.geomorph. 2011.10.026.

Vétel, William, Bernard Le Gall, and John J Walsh. 2005. "Geometry and Growth of an Inner Rift Fault Pattern: the Kino Sogo Fault Belt, Turkana Rift (North Kenya)." Journal of Structural Geology 27 (12) (January): 2204-2222. doi:10.1016/j.jsg.2005.07.003.

Walsh, J. 1969. "Geology of the Eldama Ravine-Kabarnet Area." Kenya Geologic Survey 83. Degree Sheet 34 S.E. Quarter: 48.

Wilkinson, A. F. 1988. Geology of the Allia Bay Area. Vol. 109. Degree Sheet 11, with Coloured 1:250 000 Geological Map. Nairobi: Kenya Geological Survey.

Wilkinson, P, J Mitchell, P Cattermole, and C Downie. 1986. "Volcanic Chronology of the MeruKillimanjaro Region, Northern Tanzania." Journal of the Geological Society of London 143 (4): 601-605.

Wilkinson, Peter, and Charles Downie. 1965. Explanatory Notes on the Geological Map of Kilimanjaro (Covering Quarter Degree Sheets 42, 56 and 57). Explanatory Notes on the Geological Map of Kilimanjaro (Covering Quarter Degree Sheets 42, 56 and 57). Explanatory Notes on the Geological Map of Kilimanjaro (Covering Quarter Degree Sheets 42, 56 and 57). Dar es Salaam: Tanzania Geological Survey Division.

Williams, Laurence. 1978. "Character of Quaternary Volcanism in the Gregory Rift Valley." In Geological Background to Fossil Man, ed. Walter W. Bishop, 55-69. Edinburgh: Scottish Academic Press.

Williams, Laurence Albert Joseph. 1964. Geology of the Mara River-Sianna Area. Vol. 64. Degree Sheet 50, N.W. and S.W. Quarters (with Two Coloured Geological Maps). Nairobi: Kenya Geological Survey.

Woolley, Alan R. 2001. "Kenya." In The Alkaline Rocks and Carbonatites of the World, 100-142. Bath, UK: The Geological Society.

Wright, J. B. 1967. Geology of the Narok Area; Degree Sheet 50, NE Quarter. Vol. 80. Nairobi: Kenya Geological Survey. 


\section{Appendix C}

See CD for full-page versions of paleo-geologic maps.

File paths, names and sizes are listed below.

Path:

$<$ Guth_2013>/PaleoMaps.zip

the ZIP file is a compressed folder (PaleoMaps) containing the following files:

Table C.1. List of file name, size, and type, of maps showing paleogeography provided on accompanying CD.

\begin{tabular}{|l|l|l|}
\hline \multicolumn{1}{|c|}{ File Name } & \multicolumn{1}{c|}{ File Size } & \multicolumn{1}{c|}{ File Type } \\
\hline 01Eocene & $359 \mathrm{kB}$ & PDF \\
\hline 02Oligocene & $148 \mathrm{kB}$ & PDF \\
\hline 03MioLower & $234 \mathrm{kB}$ & PDF \\
\hline 04MioMiddle & $390 \mathrm{kB}$ & PDF \\
\hline 05MioUpper & $435 \mathrm{kB}$ & PDF \\
\hline 06Zanclean & $483 \mathrm{kB}$ & PDF \\
\hline 07Piacenzian & $659 \mathrm{kB}$ & PDF \\
\hline 08Gelasian & $761 \mathrm{kB}$ & PDF \\
\hline 09Calabrian & $929 \mathrm{kB}$ & PDF \\
\hline 10lonian & $1.2 \mathrm{MB}$ & PDF \\
\hline 11Upper & $1.3 \mathrm{MB}$ & PDF \\
\hline 12Holocene & $1.3 \mathrm{MB}$ & PDF \\
\hline
\end{tabular}

PDF: Portable Document Format developed by Adobe. 


\section{Appendix D}

Calculations used for seismically derived flank volumes. The volume of the Lokwanamoru High region was calculated as a rectangular prism. The other sections regions were calculated as the sum of a right triangular prism above a rectangular prism.

a: Max Fill

b: Max-Min fill

c: Min Fill

d. (Flank) Length

Volume $=\left(\left(b^{*} e\right) / 2\right)^{\star} d+\left(c^{*} e^{*} d\right)$ or: $((a+c) / 2)^{\star} e^{\star} d$

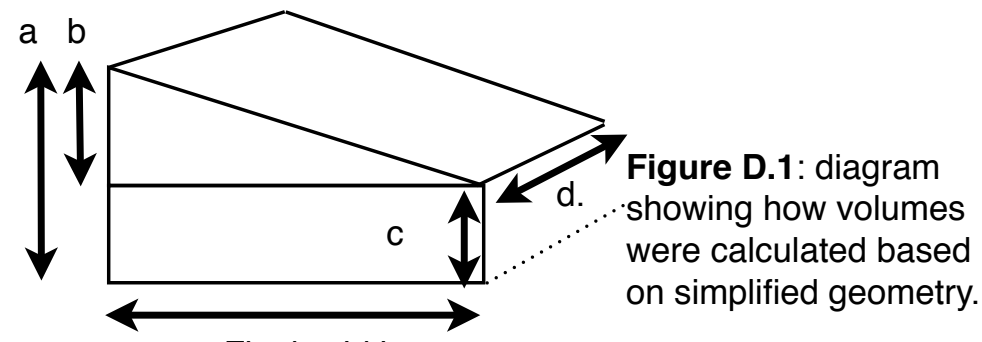

e. Flank width

Table D.1. Values used to calculate seismic-based volumes for subsections of the Kenya Rift.

\begin{tabular}{|c|c|c|c|c|c|c|c|}
\hline Basin & $\begin{array}{c}\text { Flank Area } \\
\left(\mathbf{k m}^{2}\right)\end{array}$ & $\begin{array}{c}\text { Flank } \\
\text { width }(\mathbf{k m})\end{array}$ & $\begin{array}{l}\text { Length (km, } \\
\text { calculated) }\end{array}$ & $\begin{array}{l}\text { Max fill } \\
(\mathbf{k m})\end{array}$ & $\begin{array}{l}\text { Min Fill } \\
\text { (km) }\end{array}$ & $\begin{array}{l}\text { x-section } \\
\text { area }\left(\mathbf{k m}^{2}\right)\end{array}$ & $\begin{array}{c}\text { Volume } \\
\left(\mathbf{k m}^{3}\right)\end{array}$ \\
\hline Lotikipi & 9,400 & 80 & 118 & 3.5 & 1.5 & 200 & 23500 \\
\hline Gatome & 12,500 & 65 & 192 & 4 & 0 & 130 & 25000 \\
\hline $\begin{array}{c}\text { Lokwanamoru } \\
\text { High }\end{array}$ & 3,500 & 25 & 140 & 1.5 & 1.5 & 37.5 & 5250 \\
\hline Lokichar & 3,000 & 35 & 86 & 3 & 0 & 52.5 & 4500 \\
\hline Kerio & 6,800 & 55 & 124 & 3 & 0 & 82.5 & 10200 \\
\hline $\begin{array}{l}\text { East Turkana } \\
\text { Flank }\end{array}$ & 91,000 & 275 & 331 & 1 & 0 & 137.5 & 45500 \\
\hline $\begin{array}{l}\text { Kinangop } \\
\text { Flank }\end{array}$ & 42,500 & 200 & 213 & 3 & 0 & 300 & 63750 \\
\hline $\begin{array}{c}\text { Kamasia- } \\
\text { Loriu }\end{array}$ & 9,000 & 45 & 200 & 0.7 & 0 & 15.75 & 3,150 \\
\hline $\begin{array}{l}\text { Uasin Gishu } \\
\text { Plateau }\end{array}$ & 6500 & 60 & 108 & 1.2 & 0 & 36 & 3900 \\
\hline Mau Flank & 14,800 & 75 & 197 & 1.5 & 0 & 56.25 & 11100 \\
\hline Nairobi Flank & 6,900 & 75 & 92 & 1.25 & 0.53 & 66.75 & 6,14 \\
\hline $\begin{array}{l}\text { Mara Plains } \\
\text { Flank }\end{array}$ & 9400 & 75 & 125 & 1 & 0.45 & 54.375 & 6,815 \\
\hline Kavirondo Rift & 7100 & 45 & 158 & 0.1 & 0 & 2.25 & 35 \\
\hline Total: & & & & \multicolumn{2}{|c|}{$\begin{array}{l}\text { values for the } \\
\text { Kavirondo rift are } \\
\text { estimates from the } \\
\text { mapping thicknesses - } \\
\text { no seismic control was } \\
\text { found }\end{array}$} & & 20916 \\
\hline
\end{tabular}




\section{Appendix E}

Hominin data used to create plots in Chapter 4. Data are sorted by biologic remain type, then by age (descending). Full references can be found following the table.

"Bio" types are as follows:

$$
\begin{aligned}
& 1=\text { hominid remains } \\
& 2=\text { hominin tools }
\end{aligned}
$$

\section{1: Mode 1; Olduwan}

\section{2: Mode 2; Acheulian}

\section{3: Mode 3; Middle Stone Age \& Levallois}

2.4: Later Stone Age (no sites represent this technology here)

2.5: Later Stone Age; microliths

$3=$ hominin remains

$4=$ human remains (representatives of the genus Homo)

\begin{tabular}{|c|c|c|c|c|c|c|c|}
\hline${ }^{\circ} \mathbf{E}$ & ${ }^{\circ} \mathbf{N}$ & $\begin{array}{l}\text { Age } \\
\text { (Ma) }\end{array}$ & Bio & Basin & Formation & Notes & Sources \\
\hline 36.5 & 1.8 & 15 & 1 & $\begin{array}{l}\text { Suguta trough } \\
\text { (Samburu Hills) }\end{array}$ & Aika Aiteputh & $\begin{array}{l}\text { Nacholapithecus } \\
\text { kerioi }\end{array}$ & Saneyoshi et al. 2006 \\
\hline 36.5 & 1.8 & 13 & 1 & $\begin{array}{l}\text { Suguta trough } \\
\text { (Samburu Hills) }\end{array}$ & Aika Aiteputh & Kenyapithecus & Nakajima \& Torii, 1987 \\
\hline 35.8 & 0.88 & 12.49 & 1 & Baringo & Ngorora & Proconsul? & $\begin{array}{l}\text { Jacobs \& Kabuye, } \\
\text { 1987, Hill et al. } 2002\end{array}$ \\
\hline 36.5 & 1.8 & 9.624 & 1 & $\begin{array}{l}\text { Suguta trough } \\
\text { (Samburu Hills) }\end{array}$ & Namurungule & $\begin{array}{l}\text { Samburupithecus } \\
\text { kiptalami }\end{array}$ & $\begin{array}{l}\text { Chujo et al. 2002, } \\
\text { Saneyoshi et al. } 2006\end{array}$ \\
\hline 35.87 & 0.75 & 6 & 1 & Baringo & Lukeino & Orrorin tugenensis & Senut et al. 2001 \\
\hline 35.77 & 4.01 & 2.34 & 2.1 & Turkana & Lokalalei & Oldowan Tools & $\begin{array}{l}\text { Delagnes \& Roche, } \\
2005\end{array}$ \\
\hline 35.35 & -2.98 & 1.79 & 2.1 & OI Duvai & $\begin{array}{l}\text { lowermost Bed } \\
\text { II }\end{array}$ & Oldowan Tools & Ashley et al. 2009 \\
\hline 36.21 & 4.31 & 1.468 & 2.1 & Turkana & Koobi Fora & $\begin{array}{l}\text { Oldowan Tools } \\
\text { (early stone age) }\end{array}$ & Stern, 2005 \\
\hline 35.77 & 4.01 & 1.76 & 2.2 & Turkana & $\begin{array}{l}\text { Nachukui } \\
\text { Formation }\end{array}$ & $\begin{array}{l}\text { Acheulian \& } \\
\text { Oldowan Tools, }\end{array}$ & Lepre et al. 2011 \\
\hline 36 & -2.42 & 1.2 & 2.2 & Natron & $\begin{array}{l}\text { Peninj, upper } \\
\text { Humbu } \\
\text { Formation }\end{array}$ & $\begin{array}{l}\text { Acheulian \& } \\
\text { Olduwan, age from } \\
\text { Dominguez- } \\
\text { Rodrigo } 2001 \text { was } \\
\text { significantly revised } \\
\text { by Deino et al. } \\
2006\end{array}$ & $\begin{array}{l}\text { Isaac \& Curtis 1974, } \\
\text { Dominguez-Rodrigo } \\
2001 \text {, Deino et al. } \\
2006\end{array}$ \\
\hline 36.45 & -1.58 & 0.9 & 2.2 & Olorgesailie & Member 7 & Acheulean Tools & Potts et al. 1999 \\
\hline 35.00 & -0.35 & 0.2 & 2.2 & Nyanza Rift & Simbi & Sangoan Tools & McBrearty, 1992 \\
\hline 36.25 & -0.45 & 0.1 & 2.2 & Elmenteita & $\begin{array}{l}\text { Kariandusi } \\
\text { fluvial seds }\end{array}$ & $\begin{array}{l}\text { Acheulian Tools, } \\
\text { age very tentative, } \\
\text { must be younger } \\
\text { than } 122 \text { ka based } \\
\text { on underlying dated } \\
\text { tuff }\end{array}$ & Bergner et al. 2009 \\
\hline
\end{tabular}

Table E.1. Locations, ages, and notes regarding hominid-bearing deposits in the Kenya Rift. 


\begin{tabular}{|c|c|c|c|c|c|c|c|}
\hline${ }^{\circ} \mathbf{E}$ & ${ }^{\circ} \mathbf{N}$ & $\begin{array}{l}\text { Age } \\
\text { (Ma) }\end{array}$ & Bio & Basin & Formation & Notes & Sources \\
\hline 36.08 & 0.63 & 0.545 & 2.3 & Baringo & Kapthurin & MSA tools (mode 3 ) & $\begin{array}{l}\text { Johnson and } \\
\text { Mcbrearty, } 2010\end{array}$ \\
\hline 36.45 & -1.58 & 0.340 & 2.3 & Olorgesailie & Olorgesailie & MSA tools (mode 3 ) & $\begin{array}{l}\text { Behrensmyer et al. } \\
2009\end{array}$ \\
\hline 36.08 & 0.63 & 0.25 & 2.3 & Baringo & Kapthurin & MSA tools (mode 3 ) & $\begin{array}{l}\text { Tryon \& McBrearty, } \\
2006\end{array}$ \\
\hline 36.08 & 1.06 & 0.135 & 2.3 & $\begin{array}{l}\text { South of Silali } \\
\text { Volcano }\end{array}$ & Kapedo Tuff & MSA tools (mode 3 ) & $\begin{array}{l}\text { Tryon, C.A., Roach, } \\
\text { N.T., Logan, M.A.V. } \\
2008\end{array}$ \\
\hline 35.90 & 5.41 & 0.106 & 2.3 & Omo Kibish & $\begin{array}{l}\text { Bird Nest Site } \\
\text { (BNS) }\end{array}$ & MSA tools (mode 3 ) & $\begin{array}{l}\text { Shea, } 2008 \text {, Brown et } \\
\text { al. } 2012\end{array}$ \\
\hline 34.17 & -0.42 & 0.1 & 2.3 & Rusinga Island & Wasiriya Beds & $\begin{array}{l}\text { MSA tools (mode } \\
\text { 3), age very } \\
\text { tentative, based on } \\
\text { possible correlation } \\
\text { with Longonot/ } \\
\text { Suswa }\end{array}$ & Tryon et al. 2010 \\
\hline 36.25 & -0.45 & 0.08 & 2.3 & Elmenteita & $\begin{array}{l}\text { Kariandusi } \\
\text { fluvial seds }\end{array}$ & $\begin{array}{l}\text { MSA tools (mode } \\
3 \text { ), age very } \\
\text { tentative }\end{array}$ & Bergner et al. 2009 \\
\hline 35.36 & -2.74 & 0.057 & 2.3 & Natron & $\begin{array}{l}\text { Nasera Rock } \\
\text { Shelter }\end{array}$ & MSA tools (mode 3 ) & Blome et al. 2012 \\
\hline 36.15 & -0.83 & 0.055 & 2.3 & $\begin{array}{l}\text { Mau } \\
\text { Escarpment }\end{array}$ & $\begin{array}{l}\text { Enkapune Ya } \\
\text { Muto }\end{array}$ & MSA tools (mode 3 ) & $\begin{array}{l}\text { Blome et al. } 2012, \\
\text { Ambrose } 1998\end{array}$ \\
\hline 36.18 & -0.6 & 0.053 & 2.3 & Eburru & Prospect Farm & MSA tools (mode 3 ) & Willoughby, 2007 \\
\hline 37.2 & 0.5 & 0.046 & 2.3 & Mukogodo Hills & $\begin{array}{l}\text { Shurmai } \\
\text { Rockshelter }\end{array}$ & MSA tools (mode 3 ) & Blome et al. 2012 \\
\hline 36.15 & -0.83 & 0.045 & 2.5 & $\begin{array}{l}\text { Mau } \\
\text { Escarpment }\end{array}$ & $\begin{array}{l}\text { Enkapune Ya } \\
\text { Muto }\end{array}$ & LSA Tools (Mode 5) & $\begin{array}{l}\text { Blome et al. } 2012 \text {, } \\
\text { Ambrose } 1998\end{array}$ \\
\hline 36.18 & -0.6 & 0.032 & 2.5 & Eburru & Prospect Farm & LSA Tools (Mode 5) & Willoughby, 2007 \\
\hline 36.27 & -1.87 & 0.027 & 2.5 & Magadi & $\begin{array}{l}\text { High Magadi } \\
\text { Beds, Olkena } \\
\text { \& Oloololo }\end{array}$ & LSA Tools (Mode 5) & $\begin{array}{l}\text { Barthelm et al., } 2003 \\
\& 2009\end{array}$ \\
\hline 35.85 & 0.62 & 5.3 & 3 & Baringo & $\begin{array}{l}\text { Mabaget } \\
\text { (Lower } \\
\text { Chemeron) }\end{array}$ & $\begin{array}{l}\text { Australopithecus } \\
\text { praegens or } \\
\text { Ardipithecus } \\
\text { ramidus }\end{array}$ & $\begin{array}{l}\text { Pickford, Senut, and } \\
\text { Mourer-Chauvire, } \\
2004\end{array}$ \\
\hline 35.95 & 2.36 & 4.17 & 3 & Turkana & Kanapoi & $\begin{array}{l}\text { Australopithecus } \\
\text { anamensis }\end{array}$ & Leakey et al. 1998 \\
\hline 36.27 & 4.3 & 3.95 & 3 & Turkana & $\begin{array}{l}\text { Koobi Fora, } \\
\text { Lokochot } \\
\text { Member }\end{array}$ & $\begin{array}{l}\text { Australopithecus } \\
\text { anamensis }\end{array}$ & Wood \& Leakey, 2011 \\
\hline 35 & -3.35 & 3.7 & 3 & Laetoli & & bipedal footprints & White et al., 2009 \\
\hline 35.73 & 3.9 & 3.5 & 3 & Turkana & $\begin{array}{l}\text { Lomekwi } \\
\text { Member }\end{array}$ & Kenyanthropus & Leakey et al. 2001 \\
\hline 35.77 & 4.01 & 3.35 & 3 & Turkana & $\begin{array}{l}\text { Lomekwi } \\
\text { Member }\end{array}$ & $\begin{array}{l}\text { Australopithecus } \\
\text { afarensis }\end{array}$ & Brown et al. 2001 \\
\hline 35.77 & 4.01 & 2.7 & 3 & Turkana & $\begin{array}{l}\text { Lomekwi } \\
\text { Member }\end{array}$ & $\begin{array}{l}\text { Australopithecus } \\
\text { sp. indet. }\end{array}$ & Brown et al. 2001 \\
\hline 35.90 & 5.41 & 2.6 & 3 & Omo & & $\begin{array}{l}\text { Paranthropus } \\
\text { boisei/aethiopicus }\end{array}$ & $\begin{array}{l}\text { Wood \& Constantino, } \\
2007\end{array}$ \\
\hline 35 & -3.35 & 2.6 & 3 & Laetoli & Ndolanya Beds & $\begin{array}{l}\text { Paranthropus } \\
\text { boisei }\end{array}$ & $\begin{array}{l}\text { Wood \& Constantino, } \\
2007\end{array}$ \\
\hline 35.85 & 0.62 & 2.456 & 3 & Baringo & Chemeron & Homo? & $\begin{array}{l}\text { Deino \& Hill, 2002, } \\
\text { Tattersall \& Swartz }\end{array}$ \\
\hline 35.77 & 4.01 & 2.4 & 3 & Turkana & $\begin{array}{l}\text { Nachukui } \\
\text { Formation }\end{array}$ & $\begin{array}{l}\text { Paranthropus } \\
\text { boisei }\end{array}$ & $\begin{array}{l}\text { Wood \& Constantino, } \\
2007\end{array}$ \\
\hline
\end{tabular}




\begin{tabular}{|c|c|c|c|c|c|c|c|}
\hline${ }^{\circ} \mathbf{E}$ & ${ }^{\circ} \mathbf{N}$ & $\begin{array}{l}\text { Age } \\
\text { (Ma) }\end{array}$ & Bio & Basin & Formation & Notes & Sources \\
\hline 35.77 & 4.01 & 2.3 & 3 & Turkana & $\begin{array}{l}\text { Nachukui } \\
\text { Formation }\end{array}$ & $\begin{array}{l}\text { Homo? designation } \\
\text { debated by } \\
\text { Pickering et al., } \\
\text { sample is plotted } \\
\text { as hominin }\end{array}$ & $\begin{array}{l}\text { Prat et al. 2005, } \\
\text { Pickering et al. } 2011\end{array}$ \\
\hline 36.21 & 4.31 & 1.85 & 3 & Turkana & KBS Member & $\begin{array}{l}\text { Australopithecus } \\
\text { boisei }\end{array}$ & Brown et al. 2001 \\
\hline 35.35 & -2.98 & 1.85 & 3 & Ol Duvai & & $\begin{array}{l}\text { Paranthropus } \\
\text { boisei }\end{array}$ & $\begin{array}{l}\text { Wood \& Constantino, } \\
2007\end{array}$ \\
\hline 35.77 & 4.01 & 1.8 & 3 & Turkana & Natoo Member & $\begin{array}{l}\text { Australopithecus } \\
\text { boisei }\end{array}$ & Brown et al. 2001 \\
\hline 36.27 & 4.3 & 1.6 & 3 & Turkana & Koobi Fora & $\begin{array}{l}\text { Paranthropus } \\
\text { boisei }\end{array}$ & $\begin{array}{l}\text { Wood \& Constantino, } \\
2007\end{array}$ \\
\hline 36.27 & 4.3 & 1.5 & 3 & Turkana & Koobi Fora & $\begin{array}{l}\text { Paranthropus } \\
\text { boisei }\end{array}$ & $\begin{array}{l}\text { Wood \& Constantino, } \\
2007\end{array}$ \\
\hline 35.90 & 5.41 & 1.48 & 3 & Omo & & $\begin{array}{l}\text { Paranthropus } \\
\text { boisei }\end{array}$ & $\begin{array}{l}\text { Wood \& Constantino, } \\
2007\end{array}$ \\
\hline 35.35 & -2.98 & 1.48 & 3 & Ol Duvai & & $\begin{array}{l}\text { Paranthropus } \\
\text { boisei }\end{array}$ & $\begin{array}{l}\text { Wood \& Constantino, } \\
2007\end{array}$ \\
\hline 37.5 & 5.25 & 1.43 & 3 & Konso & & $\begin{array}{l}\text { Paranthropus } \\
\text { boisei }\end{array}$ & $\begin{array}{l}\text { Wood \& Constantino, } \\
2007\end{array}$ \\
\hline 36 & -2.42 & 1.2 & 3 & Natron & Peninj & $\begin{array}{l}\text { Paranthropus } \\
\text { boisei, ages from } \\
\text { Deino et al. } 2006\end{array}$ & $\begin{array}{l}\text { Wood \& Constantino, } \\
\text { 2007, Deino et al. } \\
2006\end{array}$ \\
\hline 36.27 & 4.3 & 1.87 & 4 & Turkana & $\begin{array}{l}\text { Upper Burgi } \\
\text { member }\end{array}$ & $\begin{array}{l}\text { Homo ergaster? } \\
\text { occipital bone }\end{array}$ & Wood \& Leakey, 2011 \\
\hline 35.35 & -2.98 & 1.84 & 4 & Ol Duvai & Bed I & $\begin{array}{l}\text { Homo habilis found } \\
\text { in fluviolacustrine } \\
\text { deposit with } \\
\text { Oldowan artifacts }\end{array}$ & Clarke 2012 \\
\hline 36.27 & 4.3 & 1.78 & 4 & Turkana & Koobi Fora & Homo erectus & Pickering et al. 2011 \\
\hline 36.21 & 4.31 & 1.7 & 4 & Turkana & KBS Member & Homo sp. & Brown et al. 2001 \\
\hline $\begin{array}{l}35.77 \\
35.77\end{array}$ & 4.01 & $\begin{array}{r}1.6 \\
157\end{array}$ & 4 & Turkana & Nariokotome & $\begin{array}{l}\text { "Turkana Boy" } \\
\text { Homo ergaster }\end{array}$ & $\begin{array}{l}\text { Tattersall, T. \& } \\
\text { Schwartz, J.H. } 2009 .\end{array}$ \\
\hline 36.27 & 4.3 & 1.53 & 4 & Turkana & $\begin{array}{l}\text { Koobi Fora/ } \\
\text { Okote member }\end{array}$ & $\begin{array}{l}\text { Homo erectus } \\
\text { Homo ergaster } \\
\text { footprints }\end{array}$ & $\begin{array}{l}\text { Brown et al. } 2001 \\
\text { Bennett et al., } 2009\end{array}$ \\
\hline 35.35 & -2.98 & 1.5 & 4 & Ol Duvai & & Homo erectus? & Schwartz, 2004 \\
\hline 36.27 & 4.3 & 1.44 & 4 & Turkana & Koobi Fora & Homo habilis & Wood \& Leakey, 2011 \\
\hline 35.77 & 4.01 & 1.0 & 4 & Turkana & $\begin{array}{l}\text { Nachukui } \\
\text { Formation }\end{array}$ & Homo erectus & Brown et al. 2001 \\
\hline 36.45 & -1.58 & 0.97 & 4 & Olorgesailie & Olorgesailie & $\begin{array}{l}\text { H. erectus? \& } \\
\text { Acheulean stone } \\
\text { tools }\end{array}$ & $\begin{array}{l}\text { Potts et al. 2004, } \\
\text { Schwartz, } 2004\end{array}$ \\
\hline 36.27 & 4.3 & 0.3 & 4 & Turkana & $\begin{array}{l}\text { uppermost } \\
\text { Koobi Fora }\end{array}$ & $\begin{array}{l}\text { Homo } \\
\text { rhodesiensis, not } \\
\text { well dated }\end{array}$ & Wood \& Leakey, 2011 \\
\hline 36.08 & 0.63 & 0.543 & 4 & Baringo & Kapthurin & $\begin{array}{l}\text { Homo erectus, } \\
\text { Homo } \\
\text { rhodesiensis, Pan }\end{array}$ & $\begin{array}{l}\text { McBrearty and } \\
\text { Jablonski, } 2005\end{array}$ \\
\hline 36.27 & -1.87 & 0.390 & 4 & Magadi & Lainyamok & $\begin{array}{l}\text { Acheulian Tools, } \\
\text { teeth }\end{array}$ & $\begin{array}{l}\text { Shipman et al. } 1983 \text {, } \\
\text { Potts et al. } 1988 \text {, Potts } \\
\text { \& Deino } 1995\end{array}$ \\
\hline 35.90 & 5.41 & 0.195 & 4 & Omo Kibish & Member I & $\begin{array}{l}\text { H. sapiens, "Omo I } \\
\text { \& II" }\end{array}$ & Brown \& Fuller, 2008 \\
\hline 35 & -3.35 & 0.120 & 4 & Laetoli & & Homo sapiens & $\begin{array}{l}\text { Tattersall, T. \& } \\
\text { Schwartz, J.H. } 2009 .\end{array}$ \\
\hline 35.90 & 5.41 & 0.013 & 4 & Omo Kibish & JHS & H. sapiens & Brown \& Fuller, 2008 \\
\hline
\end{tabular}




\section{Hominid Table References:}

Ambrose, Stanley. 1998. "Chronology of the Later Stone Age and Food Production in East Africa." Journal of Archaeological Science 25 (4) (April 1): 377-392. doi:10.1006/jasc. 1997.0277.

Ashley, Gail M, Joanne C Tactikos, and Richard Bernhart Owen. 2009. "Hominin Use of Springs and Wetlands: Paleoclimate and Archaeological Records From Olduvai Gorge ( 1.79-1.74 Ma)." Palaeogeography Palaeoclimatology Palaeoecology 272 (1-2) (January 2): 1-16. doi:10.1016/j.palaeo.2008.10.016.

Barthelme, J, K Hunt, Lazarus Ngari, W ole Kipintoi, Raphael Kweyu, and S Murimi. 2009. "Renewed Survey and Excavations in the Lake Magadi Basin, Southern Kenya." Nyame Akuma 71 (June): 54-62.

Barthelme, J, S Murimi, Lazarua Ngari, and R DELONG. 2003. "Recent Archaeological Research in the Lake Magadi Basin, Southern Kenya." Nyame Akuma 60 (December): 813.

Behrensmeyer, Anna, T K Lowenstein, R B Owen, R Potts, and Robin W Renaut. 2009. "A Proposal to Drill the Olorgesailie and Magadi Basins, Southern Kenya Rift.." Unpublished Proposal (March 1): 1-11.

Bennett, M R, J W K Harris, B G Richmond, D R Braun, E Mbua, P Kiura, D Olago, et al. 2009. "Early Hominin Foot Morphology Based on 1.5-Million-Year-Old Footprints From lleret, Kenya." Science 323 (5918) (February 27): 1197-1201. doi:10.1126/ science. 1168132.

Bergner, A G N, M R Strecker, M H Trauth, A Deino, F Gasse, P Blisniuk, and M Dühnforth. 2009. "Tectonic and Climatic Control on Evolution of Rift Lakes in the Central Kenya Rift, East Africa." Quaternary Science Reviews 28 (25-26) (December 1): 28042816. doi:10.1016/j.quascirev.2009.07.008.

Blome, Margaret Whiting, Andrew S Cohen, Christian A Tryon, Alison S Brooks, and Joellen Russell. 2012. "The Environmental Context for the Origins of Modern Human Diversity: a Synthesis of Regional Variability in African Climate 150,000-30,000 Years Ago." Journal of Human Evolution 62 (5) (May 1): 563-592. doi:10.1016/ j.jhevol.2012.01.011.

Brown, Barbara, Francis Brown, and A Walker. 2001. "New Hominids From the Lake Turkana Basin, Kenya." Journal of Human Evolution 41 (1): 29-44.

Brown, Francis H, and Chad R Fuller. 2008. "Stratigraphy and Tephra of the Kibish Formation, Southwestern Ethiopia." Journal of Human Evolution 55 (3) (September): 366403. doi:10.1016/j.jhevol.2008.05.009.

Brown, Francis H, IAN McDougall, and John G Fleagle. 2012. "Correlation of the KHS Tuff of the Kibish Formation to Volcanic Ash Layers at Other Sites, and the Age of Early Homo Sapiens (Omo I and Omo II)." Journal of Human Evolution 63 (4) (October 1): 577-585. doi:10.1016/j.jhevol.2012.05.014.

Chujo, T, M Hyodo, M Saneyoshi, C Kashine, and Y SAWADA. 2002. "A Preliminary Report on Paleomagnetic Study of Hominoid Fossil Bearing Formation in Samburu Hills, Northern Kenya." In.

Clarke, R J. 2012. "A Homo Habilis Maxilla and Other Newly-Discovered Hominid Fossils From Olduvai Gorge, Tanzania." Journal of Human Evolution 63 (2) (August 1): 418428. doi:10.1016/j.jhevol.2011.11.007.

Deino, AL, and Andrew Hill. 2002. "40Ar/39Ar Dating of Chemeron Formation Strata Encompassing the Site of Hominid KNM-BC 1, Tugen Hills, Kenya." Journal of Human Evolution 42 (1-2): 141-151.

Deino, AL, John Kingston, JM Glen, RK Edgar, and Andrew Hill. 2006. "Precessional Forcing of Lacustrine Sedimentation in the Late Cenozoic Chemeron Basin, Central Kenya 
Rift, and Calibration of the Gauss/Matuyama Boundary." Earth and Planetary Science Letters 247 (1-2): 41-60.

Deino, AL, Manuel Domínguez-Rodrigo, and L Luque. 2006. "40Ar/39Ar Dating of the Pleistocene Peninj Group, Lake Natron, Tanzania." AGU Fall Meeting Abstracts: 1771.

Delagnes, A, and H Roche. 2005. "Late Pliocene Hominid Knapping Skills: the Case of Lokalalei 2C, West Turkana, Kenya." Journal of Human Evolution 48 (5): 435-472.

Dominguez-Rodrigo, M, J Serrallonga, J. Juan-Tresserras, L Alcala, and L Luque. 2001. "Woodworking Activities by Early Humans: a Plant Residue Analysis on Acheulian Stone Tools From Peninj (Tanzania)." Journal of Human Evolution 40 (4) (April 1): 289-299. doi:10.1006/jhev.2000.0466.

Hill, Andrew, Meave Leakey, John D Kingston, and Steve Ward. 2002. "New Cercopithecoids and a Hominoid From 12.5Ma in the Tugen Hills Succession, Kenya." Journal of Human Evolution 42 (1-2) (January): 75-93. doi:10.1006/jhev.2001.0518.

Isaacs, Glynn LI., and GH Curtis. 1974. "Age of Early Acheulian Industries From the Peninj Group, Tanzania." Nature 249 (5) (June): 624-627. doi:10.1038/249624a0.

Jacobs, BF, and C Kabuye. 1987. "A Middle Miocene (12. 2 My Old) Forest in the East African Rift Valley, Kenya." Journal of Human Evolution 16 (2): 147-155.

Johnson, Cara Roure, and Sally Mcbrearty. 2010. "500,000 Year Old Blades From the Kapthurin Formation, Kenya." Journal of Human Evolution 58 (2): 193-200. doi:10.1016/ j.jhevol.2009.10.001.

Leakey, M G MG, F F Spoor, F H FH Brown, P N PN Gathogo, C C Kiarie, L N LN Leakey, and I I McDougall. 2001. "New Hominin Genus From Eastern Africa Shows Diverse Middle Pliocene Lineages.." Nature 410 (6827) (March 22): 433-440. doi: 10.1038/35068500.

Leakey, MG, Craig Feibel, IAN McDougall, C Ward, and A Walker. 1998. "New Specimens and Confirmation of an Early Age for Australopithecus Anamensis." Nature 393 (6680): 62-66.

Lepre, Christopher J, Hélène Roche, Dennis V Kent, Sonia Harmand, Rhonda L Quinn, JeanPhilippe Brugal, Pierre-Jean Texier, Arnaud Lenoble, and Craig S Feibel. 2011. "An Earlier Origin for the Acheulian." Nature 477 (7362) (August 31): 82-85. doi: 10.1038 /nature10372.

McBrearty, S, and NG Jablonski. 2005. "First Fossil Chimpanzee." Nature 437: 105-108.

Mcbrearty, Sally. 1992. "Sangoan Technology and Habitat at Simbi." Nyame Akuma 38 (December): 34-40.

Nakajima, T, and M Torii. 1987. "Paleomagnetism of Miocene Rocks in the Western Area of Baragoi, Northern Kenya." African Study Monographs, Supplementary Issue 5: 47-58.

Pickering, R, P H G M Dirks, Z Jinnah, D J de Ruiter, S E Churchill, A I R Herries, J D Woodhead, J C Hellstrom, and L R Berger. 2011. "Australopithecus Sediba at 1.977 Ma and Implications for the Origins of the Genus Homo." Science 333 (6048) (September 8): 1421-1423. doi:10.1126/science.1203697.

Pickford, M, B Senut, and C Mourer-Chauvire. 2004. "Early Pliocene Tragulidae and Peafowls in the Rift Valley, Kenya: Evidence for Rainforest in East Africa." Comptes Rendus Palevol3 (3): 179-189.

Potts, Richard, and AL Deino. 1995. "Mid-Pleistocene Change in Large Mammal Faunas of East Africa." Quaternary Research 43 (1): 106-113.

Potts, Richard, Anna Behrensmeyer, AL Deino, Peter Ditchfield, and J Clark. 2004. "Small MidPleistocene Hominin Associated with East African Acheulean Technology." Science 305 (5680): 75-78.

Potts, Richard, Anna Behrensmeyer, and Peter Ditchfield. 1999. "Paleolandscape Variation and Early Pleistocene Hominid Activities: Members 1 and 7, Olorgesailie Formation, Kenya." Journal of Human Evolution 37 (5): 747-788. 
Potts, Richard, P Shipman, and E Ingall. 1988. "Taphonomy, Paleoecology, and Hominids of Lainyamok, Kenya." Journal of Human Evolution 17 (6): 597-614.

Prat, Sandrine, Jean-Philip Brugal, Jean-Jacques Tiercelin, Jean-Alix Barrat, Marcel Bohn, Anne Delagnes, Sonia Harmand, et al. 2005. "First Occurrence of Early Homo in the Nachukui Formation (West Turkana, Kenya) at 2.3-2.4Myr." Journal of Human Evolution 49 (2) (August): 230-240. doi:10.1016/j.jhevol.2005.03.009.

Saneyoshi, M, K Nakayama, T Sakai, Y SAWADA, and H Ishida. 2006. "Half Graben Filling Processes in the Early Phase of Continental Rifting: the Miocene Namurungule Formation of the Kenya Rift." Sedimentary Geology 186 (1-2): 111-131.

Schwartz, Jeffrey H. 2004. "Getting to Know Homo Erectus." Science 305 (5680): 53-54.

Senut, B, Martin Pickford, Dominique Gommery, Pierre Mein, Kiptalam Cheboi, and Yves Coppens. 2001. "First Hominid From the Miocene (Lukeino Formation, Kenya)." Comptes Rendus De I'Académie Des Sciences - Series IIA - Earth and Planetary Science 332 (January): 137-144. doi:10.1016/S1251-8050(01)01529-4.

Shea, John J. 2008. "The Middle Stone Age Archaeology of the Lower Omo Valley Kibish Formation: Excavations, Lithic Assemblages, and Inferred Patterns of Early Homo Sapiens Behavior." Journal of Human Evolution 55 (3) (September): 448485. doi:10.1016/j.jhevol.2008.05.014.

Shipman, Pat, Richard Potts, and Martin Pickford. 1983. "Lainyamok, a New Middle Pleistocene Hominid Site." Nature (London) 306 (5941): 365-368.

Stern, Nicola. 2005. "Early Hominin Activity Traces at FxJj43, a One and a Half Million-Year-Old Site in the Koobi Fora Formation in Northern Kenya." Nyame Akuma 64 (December): 41-49.

Tattersall, lan, and Jeffrey H Schwartz. 2009. "Evolution of the Genus Homo." Annual Review of Earth and Planetary Sciences 37 (1) (May): 67-92. doi:10.1146/annurev.earth. 031208.100202.

Tryon, CA, and S McBrearty. 2006. "Tephrostratigraphy of the Bedded Tuff Member (Kapthurin Formation, Kenya) and the Nature of Archaeological Change in the Later Middle Pleistocene." Quaternary Research 65 (3): 492-507.

Tryon, CA, NT Roach, and MAV Logan. 2008. "The Middle Stone Age of the Northern Kenyan Rift: Age and Context of New Archaeological Sites From the Kapedo Tuffs." Journal of Human Evolution 55 (4): 652-664.

Tryon, Christian A, J Tyler Faith, Daniel J Peppe, David L Fox, Kieran P McNulty, Kirsten Jenkins, Holly Dunsworth, and Will Harcourt-Smith. 2010. "The Pleistocene Archaeology and Environments of the Wasiriya Beds, Rusinga Island, Kenya." Journal of Human Evolution 59 (6) (December 1): 657-671. doi:10.1016/j.jhevol. 2010.07.020.

White, T D, B Asfaw, Yonas Beyene, Yohannes Haile-Selassie, C O Lovejoy, G Suwa, and G Woldegabriel. 2009. "Ardipithecus Ramidus and the Paleobiology of Early Hominids." Science 326 (5949) (October 2): 64-64, 75-86. doi:10.1126/science. 1175802.

Willoughby, Pamela. 2007. The Evolution of Modern Humans in Africa : a Comprehensive Guide. AltaMira Press.

Wood, Bernard, and Meave Leakey. 2011. "The Omo-Turkana Basin Fossil Hominins and Their Contribution to Our Understanding of Human Evolution in Africa." Evolutionary Anthropology: Issues, News, and Reviews 20 (6) (December 14): 264-292. doi: 10.1002/evan.20335.

Wood, Bernard, and Paul Constantino. 2007. "Paranthropus Boisei: Fifty Years of Evidence and Analysis." American Journal of Physical Anthropology 134 (S45): 106-132. doi: 10.1002/ajpa.20732. 